\title{
Representation of Immigrants in New Zealand Print Media: A Critical Discourse Analysis
}

\author{
Neda Salahshour
}

A thesis submitted to Victoria University of Wellington in fulfilment of the requirements for the degree of Doctor of Philosophy

Victoria University of Wellington

Te Whare Wānanga o te Ūpoko o te Ika a Māui

2017 



\section{Abstract \\ Representation of Immigrants in New Zealand Print Media: A Critical Discourse Analysis}

New Zealand is often perceived as one of the most diverse countries in terms of its population, with "more ethnicities in New Zealand than there are countries in the world" (Statistics New Zealand, 2013). According to the 2013 census, 39\% of people who live in Auckland, New Zealand's most immigrant-populated city, were born overseas. In such a setting, the issue of social harmony becomes important. Media institutions hold power and therefore their representations play a significant role in how immigrants are perceived and whether they are embraced and welcomed or resisted. It is for this reason that media discourse deserves attention.

Research in this area in the context of New Zealand has been limited and furthermore has leaned towards content analysis or a purely qualitative analysis of a specific diaspora. Addressing these issues, my research aims to gain a better understanding of how immigrants are discursively constructed in the New Zealand Herald newspaper during the years 2007 and 2008. Given that the Global Financial Crisis began to make its presence felt in 2008, this study also sought to investigate expected discrepancies in the representation of immigrants during economically challenging times.

Grounded within a critical approach, this study adopts methodic triangulation; that is, the data is analysed using two complementary analytical frameworks, namely that of corpus-assisted discourse analysis (Baker, KhosraviNik, Krzyzanowski, McEnery, \& Wodak, 2008) and the Discourse-Historical Approach (Reisigl \& Wodak, 2009). Using these two frameworks, I use statistical information as entry points into the data and explore significant collocations which contribute to the construction of dominant representations. This analysis is followed by an in-depth analysis of systematically sampled news articles with the aim of identifying the 
various discursive and argumentation strategies commonly employed in print media.

The findings from both analyses point to a rather ambivalent representation of immigrants. On the one hand, immigrants are constructed as being qualified and playing an important role in filling skill shortages in New Zealand. This positive construction depicts immigrants as an economic resource which ought to be capitalized. In addition, liquid metaphors, previously argued to dehumanize immigrants and construct them as uncontrollable (KhosraviNik, 2009) are surprisingly used in my data to construct the immigration of large numbers of immigrants to New Zealand as essential. On the other hand, immigrants are also constructed as threateningly Other or passive victims. Therefore, immigrants are not only constructed as beneficial to New Zealand society but are also represented as being problematic.

This study identifies a unique representation of immigrants in the New Zealand Herald which could perhaps be explained by the unique socio-political and geographical context of the country. The triangulation and methodic rigour of this study also ensure that the findings are generalizable to the whole dataset and contribute to current understandings of immigrant representation and approaches to the study of discourse and representation. 


\section{Acknowledgements}

First and foremost, my deepest gratitude goes to my supervisors Dr. Derek Wallace and Professor Janet Holmes who have over the past four years of my doctoral studies guided, advised, critiqued, and inspired me. Without their unceasing support, I would not have been able to come so far on this incredibly bumpy journey. I will be forever grateful for your invaluable help and support.

I would also like to express my deepest appreciation to my family members, who have acted as a sounding board and listened carefully to, and at times challenged my perspectives. In particular, my husband has supported me relentlessly throughout this journey and words cannot express how grateful I am for the sacrifices you have made on my behalf. My father and mother have both been great mentors for me too. My father has always challenged me to question taken-for-granted assumptions and hence has encouraged me to be the critical thinker I am today.

Numerous scholars, colleagues, and friends have also provided advice and help through this journey. In particular, I would like to thank Dr. Majid KhosraviNik, Dr. Costas Gabrielatos, Dr. Anthony Lawrence, and others who are members on social media groups dedicated to providing help and support for postgraduate students and scholars.

Finally, I would like to thank Victoria University of Wellington for not only providing an excellent environment for academic endeavors to take place but also for providing me the necessary funding, the Victoria Doctoral Scholarship, to conduct this research. 


\section{Contents}

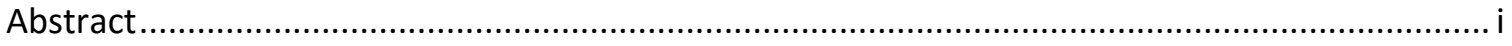

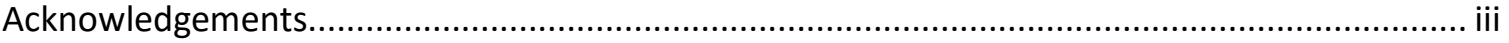

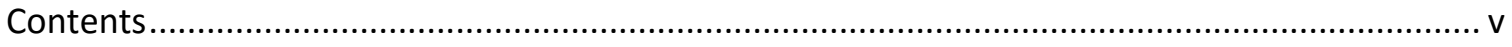

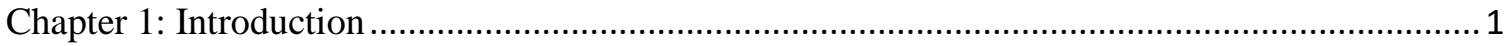

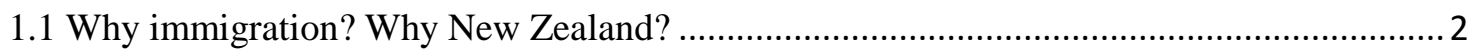

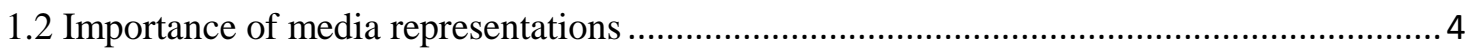

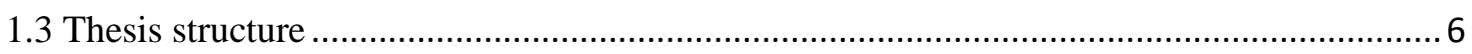

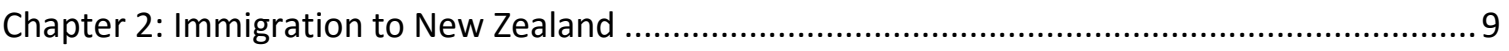

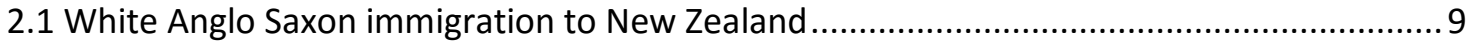

2.2 Non-Anglo Saxon immigration to New Zealand............................................................. 11

2.3 Late twentieth century immigration policies................................................................... 13

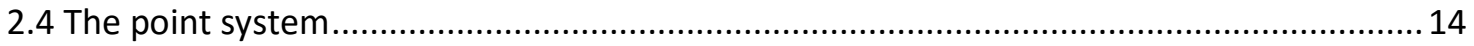

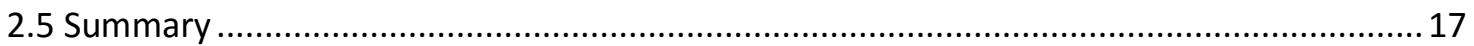

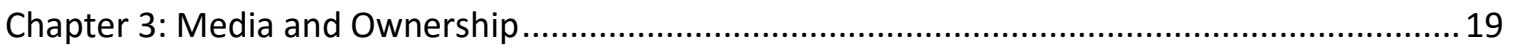

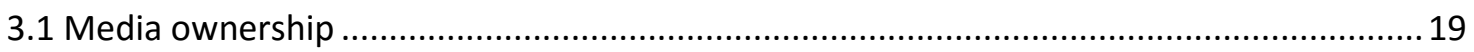

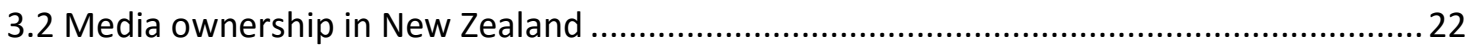

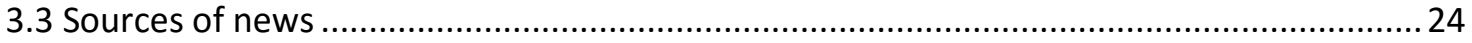

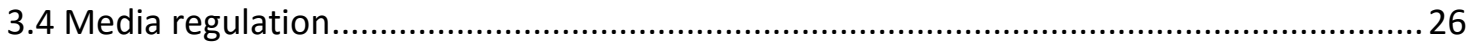

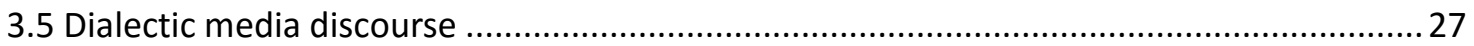

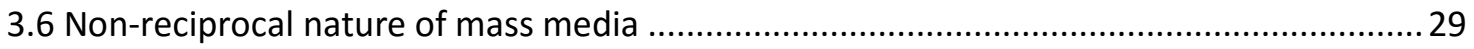

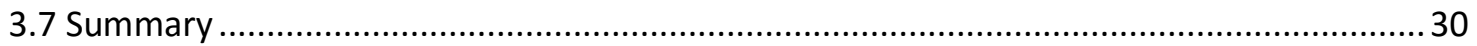

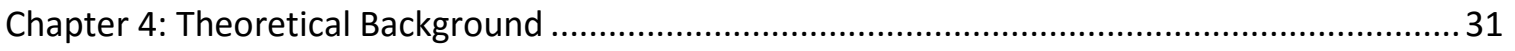

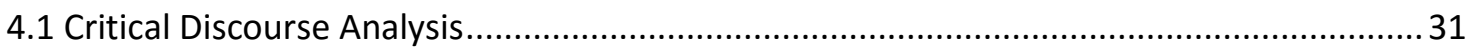

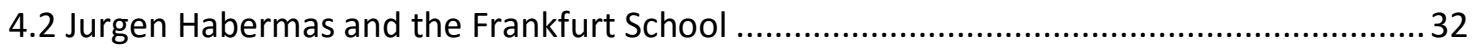

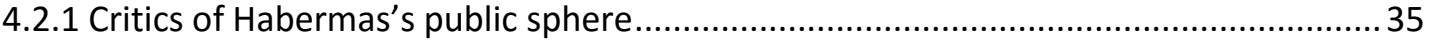

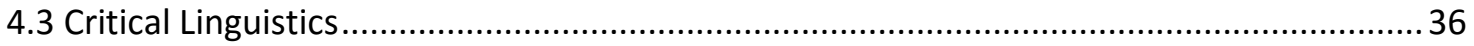

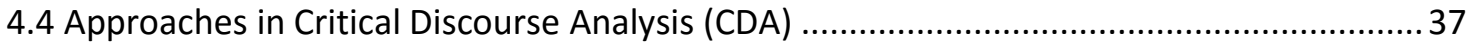

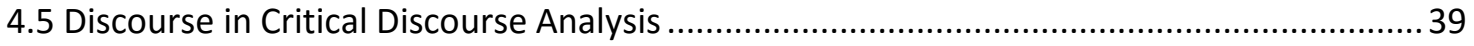

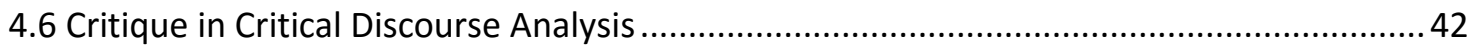




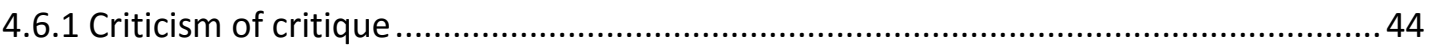

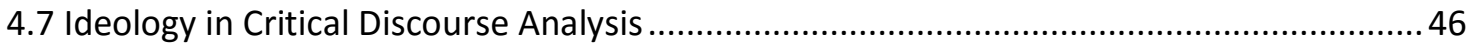

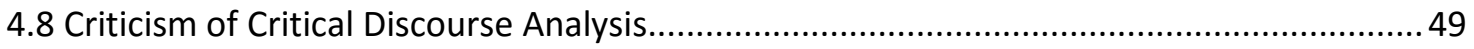

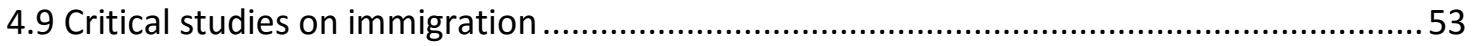

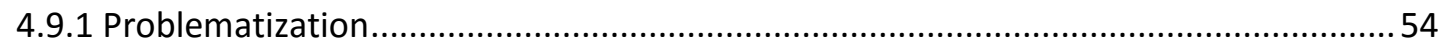

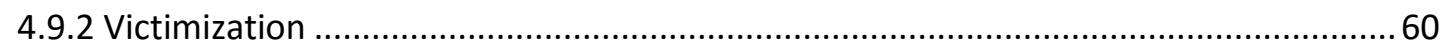

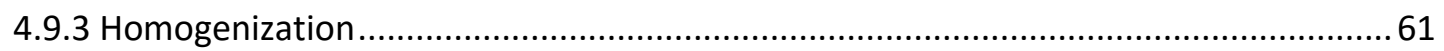

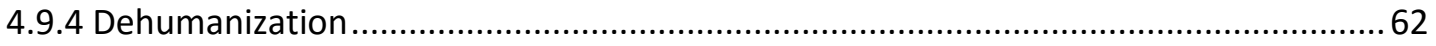

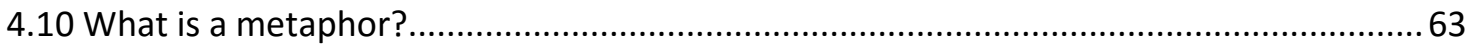

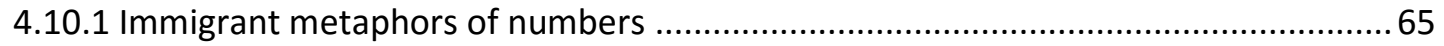

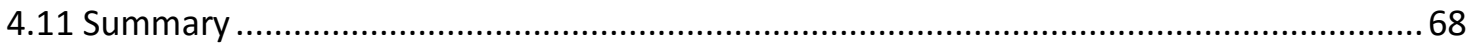

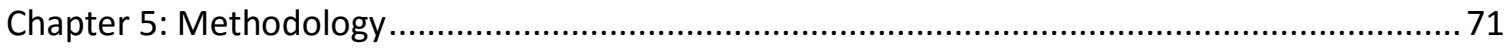

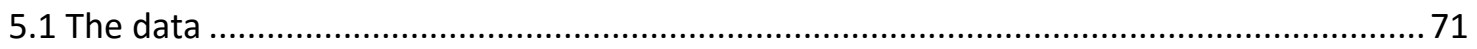

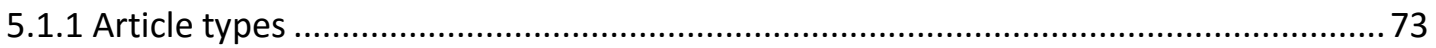

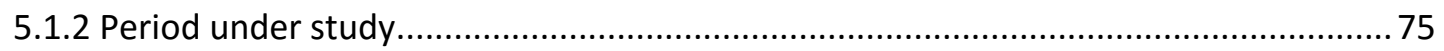

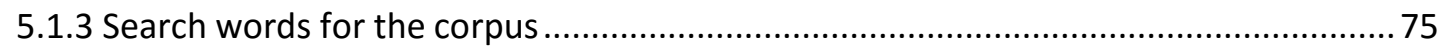

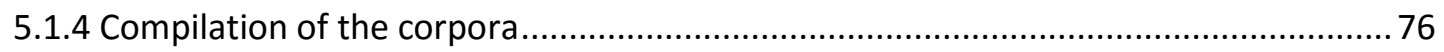

5.2 Corpus-Assisted Discourse Analysis (Collocation analysis) ............................................. 77

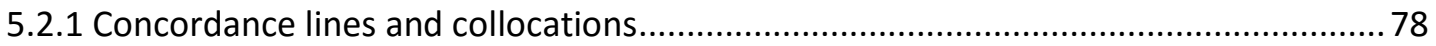

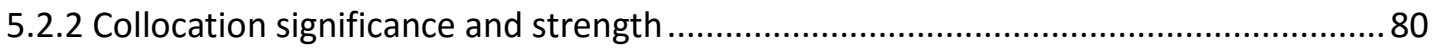

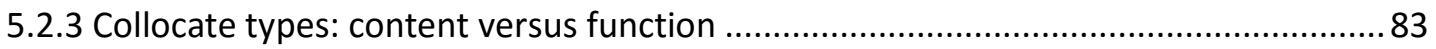

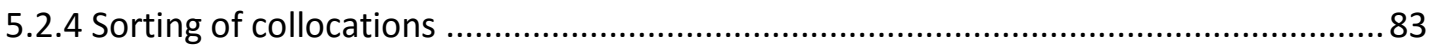

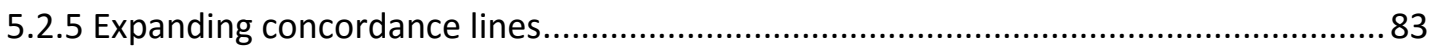

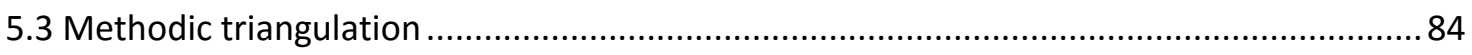

5.4 Limitations of Corpus Linguistics \& Critical Discourse Analysis ........................................ 85

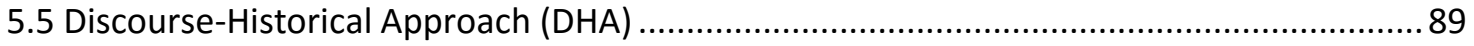

5.5.1 Context in Discourse-Historical Approach (DHA) ...................................................... 91

5.5.2 Tools for Discourse-Historical Approach (DHA) ........................................................ 91

5.6 Data sampling for qualitative Critical Discourse Analysis ................................................. 95

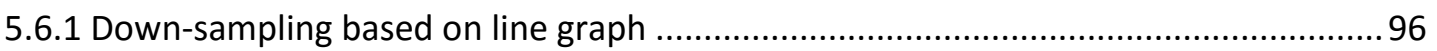

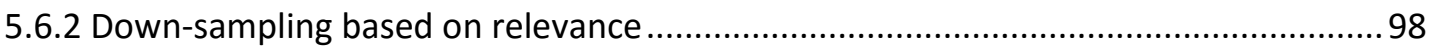

5.6.3 Down-sampling based on topic analysis .................................................................99 


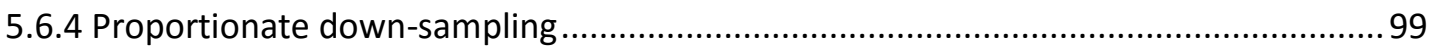

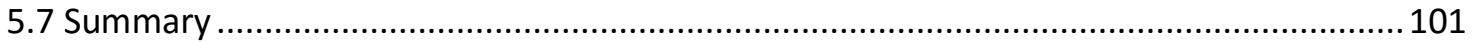

Chapter 6: Corpus Assisted Discourse Analysis (A Collocation Analysis) ....................................103

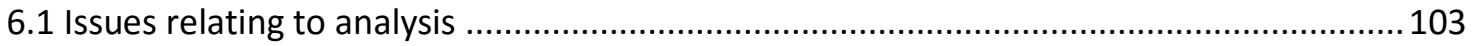

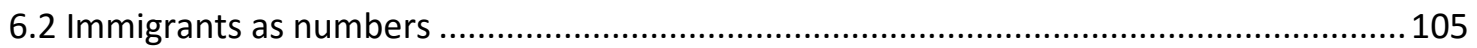

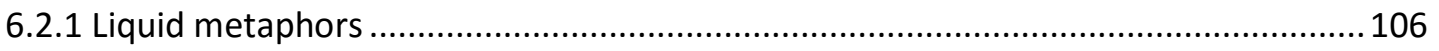

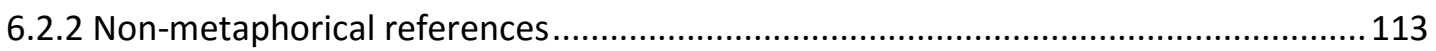

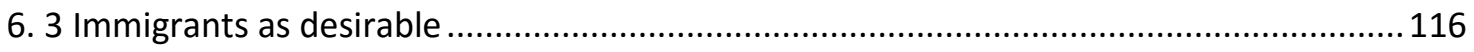

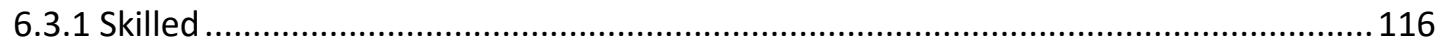

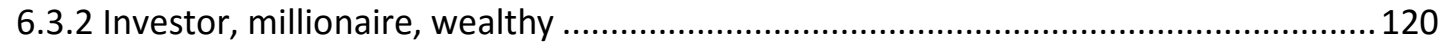

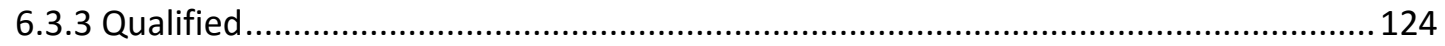

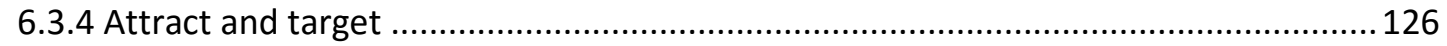

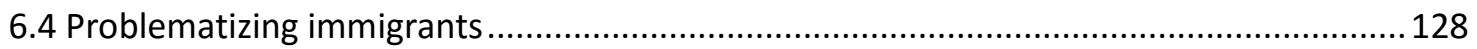

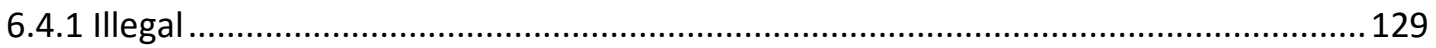

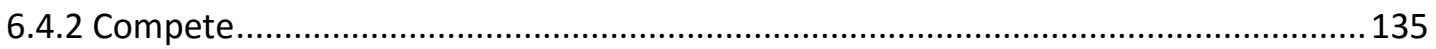

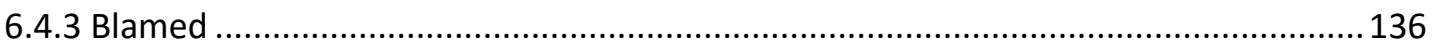

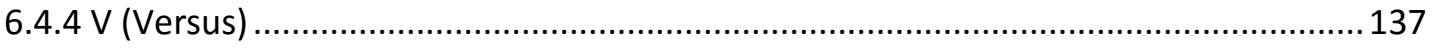

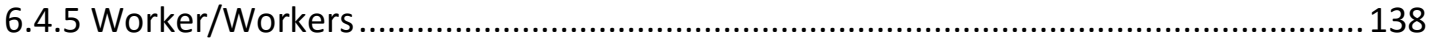

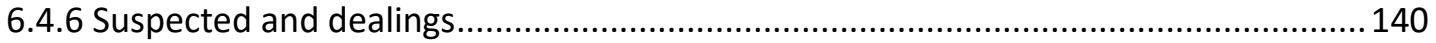

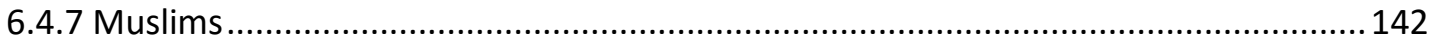

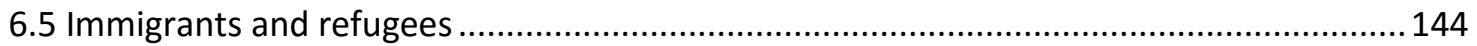

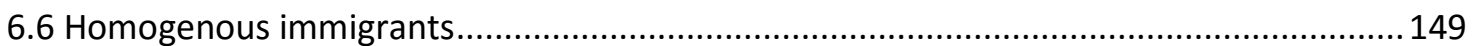

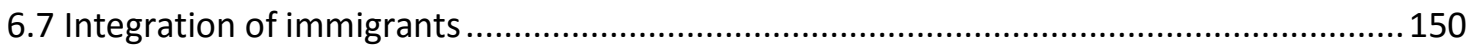

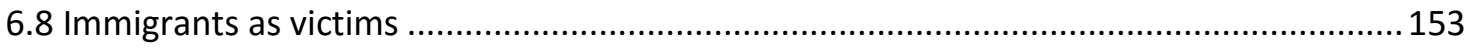

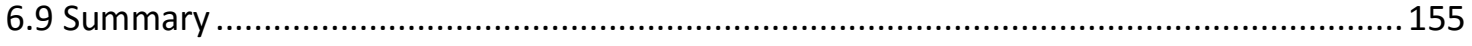

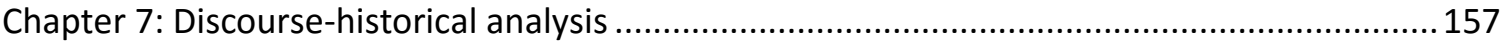

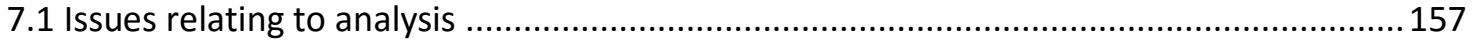

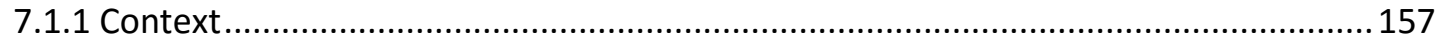

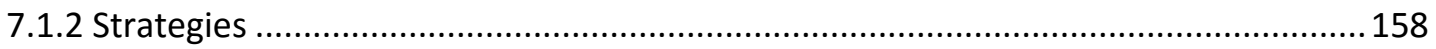

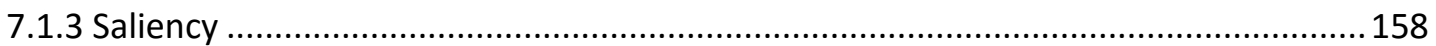

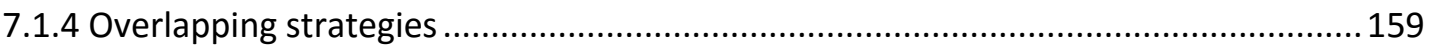

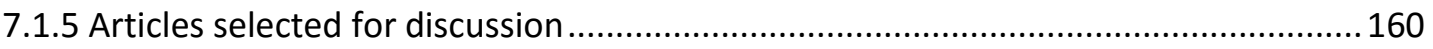


7.2 Textual Analysis 1: news reports entitled 'Peters wants immigration cuts to protect jobs' under the theme of 'Immigration and election'

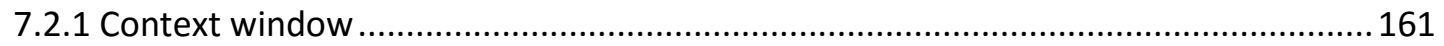

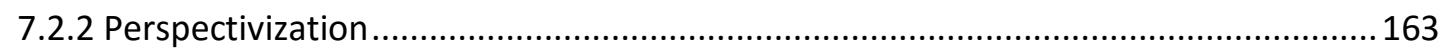

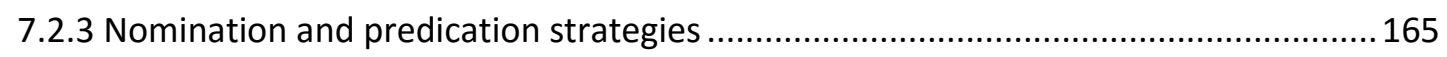

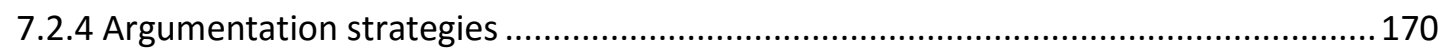

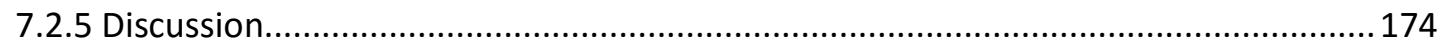

7.3 Textual Analysis 2: An opinion piece entitled 'Peters blind to inconvenient truth' under the

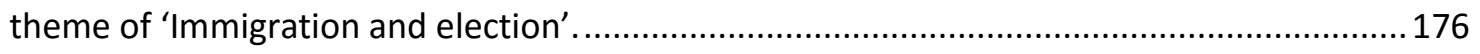

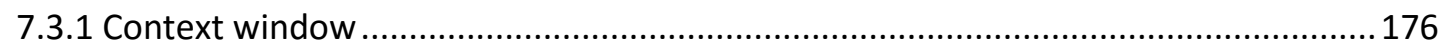

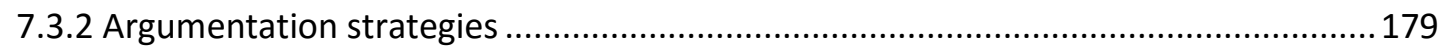

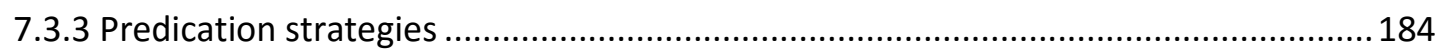

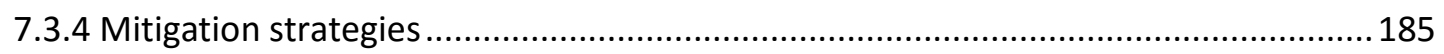

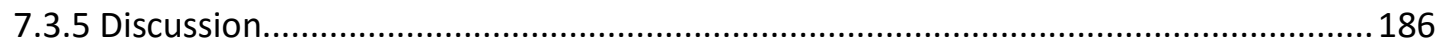

7.4 Textual Analysis 3: News report entitled 'Schemes aim to make use of rich migrant

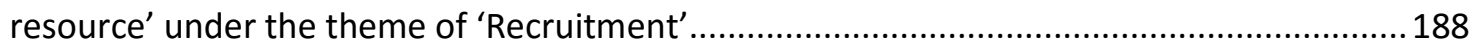

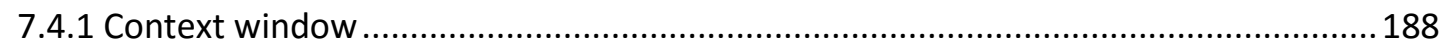

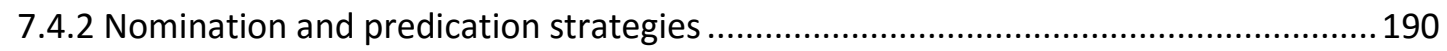

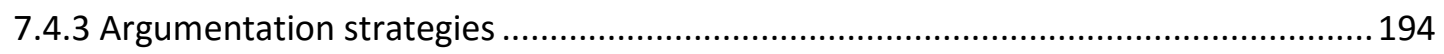

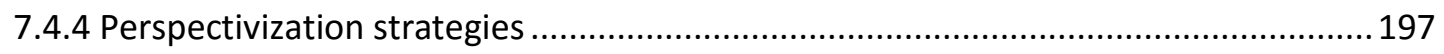

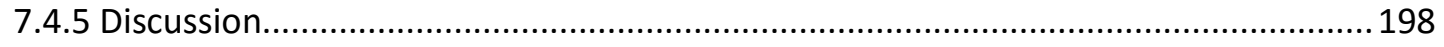

7.5 Textual Analysis 4: News report entitled 'Record numbers leaving for Australia' under the

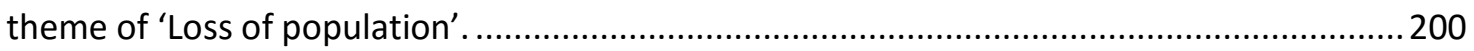

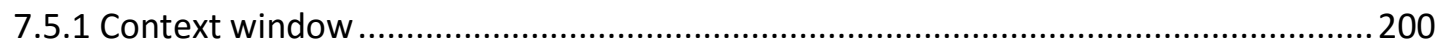

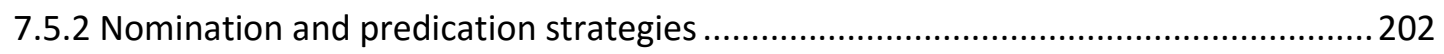

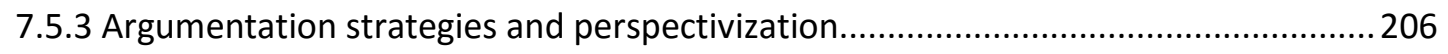

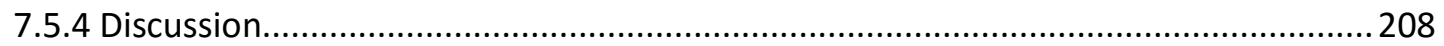

7.6 Textual Analysis 5: News report entitled 'Illegal immigrants may have exploited lax ID

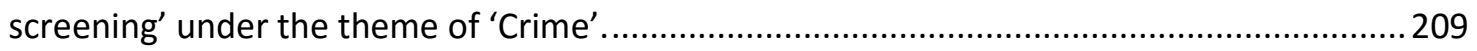

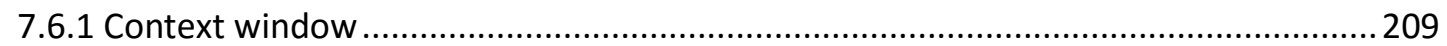

7.6.2 Nomination, predication and mitigation strategies................................................ 211

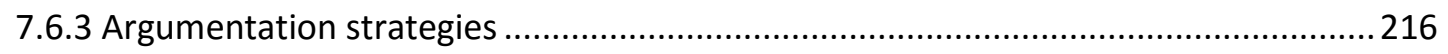

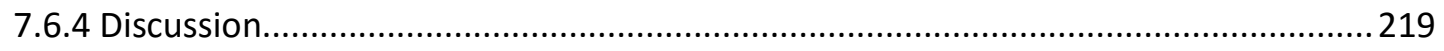

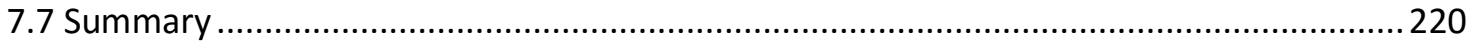




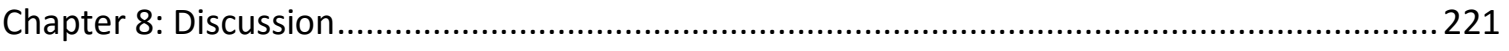

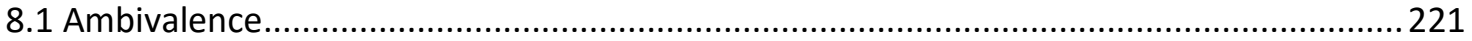

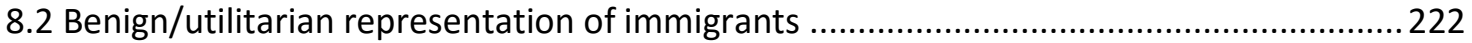

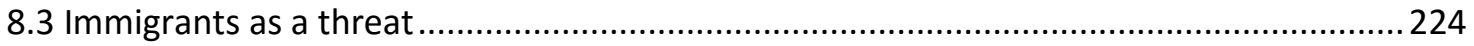

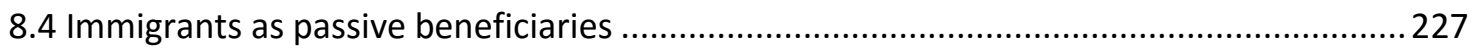

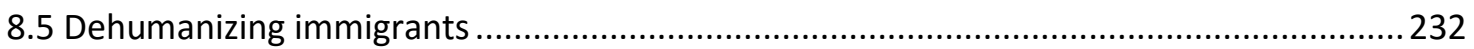

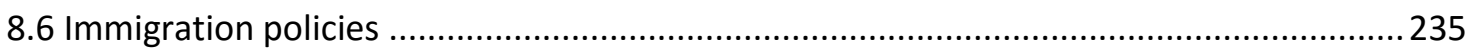

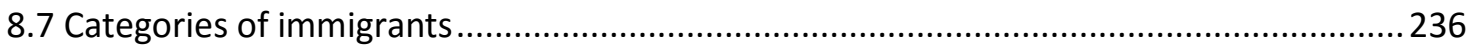

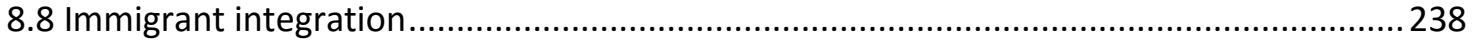

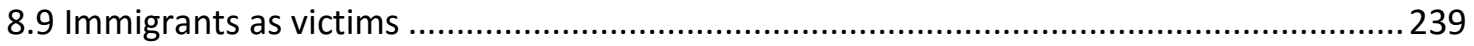

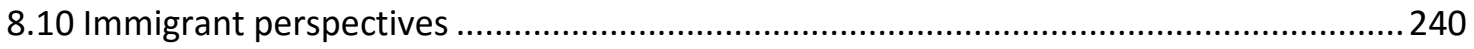

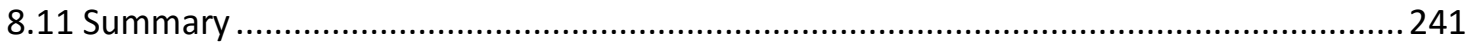

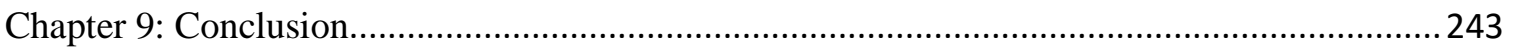

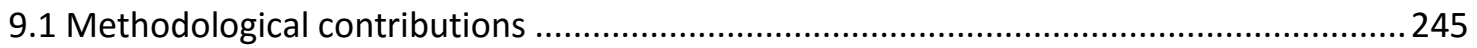

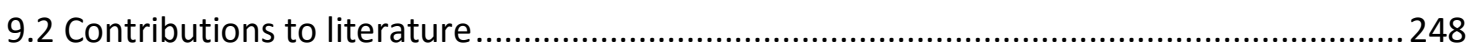

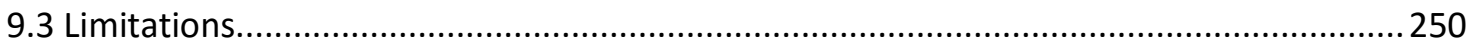

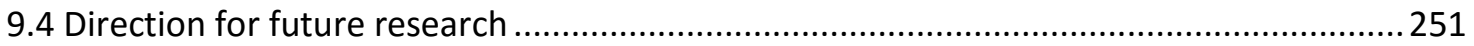

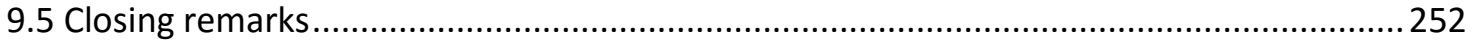

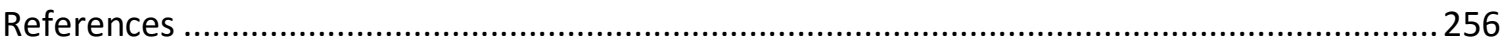

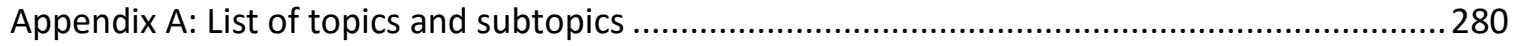

Appendix B: List of significant collocations, MI, and LL scores ..............................................284

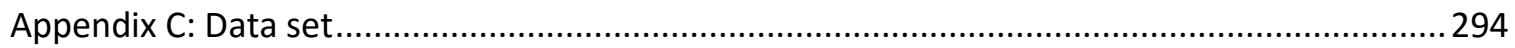




\begin{tabular}{|l|l|}
\hline \multicolumn{2}{|c|}{ List of Figures } \\
\hline Figure 4.1 CDA approaches and their theoretical backgrounds & 39 \\
\hline Figure 4.2 The Yellow Peril & 59 \\
\hline Figure 5.1 List of most common topoi & 94 \\
\hline Figure 5.2 Illustration of the various stages of downsizing & 96 \\
\hline Figure 5.3 Search word frequency line graph & 97 \\
\hline
\end{tabular}

\begin{tabular}{|c|c|}
\hline \multicolumn{2}{|l|}{ List of Tables } \\
\hline Table 5.1 New Zealand Herald Readership Figures & 72 \\
\hline Table 5.2 Number of words in each corpus & 77 \\
\hline Table 5.3 A selection of discursive strategies & 93 \\
\hline Table 5.4 Proportionate sampling of data based on topic analysis & 100 \\
\hline Table 6.1 Collocates relating to immigrants as numbers & 105 \\
\hline Table 6.2 Collocates referring to immigrants as desirable & 117 \\
\hline Table 6.3 Collocates referring to immigrants as problematic & 129 \\
\hline Table 6.4 Collocates referring to immigrants as refugees & 144 \\
\hline
\end{tabular}




\begin{tabular}{|l|l|}
\hline Table 6.5 Collocates referring to immigrants as a homogenous group & 149 \\
\hline Table 6.6 Collocates referring to the integration of immigrants & 151 \\
\hline Table 6.7 Collocates referring to immigrants as victims & 153 \\
\hline $\begin{array}{l}\text { Table 7.1 Information regarding articles selected for analysis in Chapter } 7 \\
\text { frequencies }\end{array}$ & 160 \\
\hline $\begin{array}{l}\text { Table 8.2 Collocates which represent immigrants as undesirable and their } \\
\text { frequencies }\end{array}$ & 226 \\
\hline
\end{tabular}


"For like all modes of communication, television, radio, and newspapers observe certain rules and conventions to get things across intelligibly, and it is these, often more than the reality being conveyed, that shape the material delivered by the media."

(Said, 1997, pp. 48-49)

\section{Chapter 1: Introduction}

The power of media representations and the influence they exert on the lives of individuals became clear to me at a very young age. I was born in Iran (often referred to as the least understood country) but in 1991 my family moved to the United Kingdom in pursuit of higher and better education. Having lived for nine years in the county of Essex, and attended a co-educational state school in the small town of Wivenhoe, I, in many ways, considered myself a typical British kid. Despite being aware of my family lineages to Iran, and frequent questions as to the roots of my darker hair and skin, I often tactfully avoided revealing my origins to anyone. For one thing, reports in the media were not positive and my previous attempts were encountered unfavourably with some instances ending with a look on the face of the recipient as if to say: "where the hell is that?" and others responding even less favourably by referring to it as a war-stricken country.

Having tactfully forced my Iranian identity out of the picture, I was happily developing into adolescence when my parents decided that "enough is enough, it's time we went back home". Dumbfounded at this sudden decision, I entered my first stage of shock which was underpinned by the idea of having to say goodbye to everything and everybody that made up my version of reality. This was followed by a period of desperate plea. Yet my attempt to change my parents' course of action was in vain. They had made up their minds. This is when the second stage of shock hit me, that is, when I realized where it was I was actually going to: Iran. Despite my only real memory of Iran being one where my grandfather's photo was hung on a wall, I, ironically (considering that I was an Iranian myself) was inundated with many unpromising images of what I thought life in Iran would be like: a 
life abundant in primitiveness, backwardness, and restrictions where I would be obliged to wear a piece of cloth over my head!

These puzzling thoughts and images prevailed for the final month of my life in the UK until the time came for us to catch that flight to the dreaded land. However the real revelation came when I arrived in Iran only to realize that it was much different than how I expected it to be. As days, weeks, and months went by, I entered my third stage of shock. This period was characterized by a lot of why questions and a lot of comparisons between my previous home, the UK, and my newly thrown upon me home, Iran. With so many of the stereotypical images being proven wrong, I could not help but ask myself: "Why did I, a 14 year old young adult, perceive Iran, my country of birth so negatively?" and "Where did these images come from?" Considering that my parents take pride in being Iranian, they could not have influenced me adversely. Nor did I or my family have contact with other Iranians in the predominantly British town of Wivenhoe. In fact, as I later realized, it was precisely this lack of contact which allowed this contempt to breed. The only possible source was the media. Had I actually visited Iran and met other Iranians, I would not have so easily been swayed by the narrow and limited representations of Iran that I was offered through the media.

Later I became a university student and became acquainted with the sterling literature of Edward Said. His work nurtured a critical outlook towards media representations that so strongly underpins this study and helped me rethink and question constructions of reality which are thrown at us. Here, 15 years on, I have become a critical discourse analyst and it is through this critical lens that I hope to shed light on media representations of immigration in the New Zealand print media.

\subsection{Why immigration? Why New Zealand?}

Immigration is defined as "the act of moving across international boundaries from a country of origin (or country of emigration) to take up residence in a country of destination

(or country of immigration)"(Samers, 2010, pp. 9-10). According to UNESCO, the term 
migrant can be understood as "any person who lives temporarily or permanently in a country where he or she was not born and has acquired some significant social ties to this country" (United Nations Educational, Scientific, and Cultural Organization, n.d). However, there are subtle differences in respect of who is considered a 'migrant' or 'immigrant'. These terms (i.e. 'immigrant' and 'migrant') appear frequently within this study and hence require clarification from the outset. The term 'migrant' is generally accepted as a more encompassing term which includes migrants who leave as well as those enter a country (i.e. emigrant and immigrant). The term 'immigrant', on the other hand, is more specific and pertains to people who enter a country. As the main focus of this study is to gain understanding on how people who intend on entering or have already entered New Zealand are represented, i.e. immigrants, and for consistency purposes, I have adopted the term 'immigrant' in this thesis. The exception to this is when discussing specific terms used within quotes or data presented.

But why is immigration in the context of New Zealand important? We are living in an increasingly multicultural and global environment brought about by migration. New Zealand is no exception. According to Singham (2006) "New Zealand is one of the highest migrant receiving countries in the world" (p. 33) and along with many other countries is regarded as an "immigration society" by the OECD (Keeley, 2009, p. 30). Since 2010, it is one of the leading countries in relation to the number of immigrants received. Statistics from the New Zealand government show that in 2006, 37 percent of Auckland's population was born overseas. The 2013 census shows a two percent increase in this number. This increasing diversity in populations brings many colours to the country and yet also some challenges. Diversity in New Zealand has not always been embraced. It has been resisted and/or rejected and presents challenges on multiple levels. Recent attitudinal surveys conducted in New Zealand, for example, show a preference for immigrants from the United Kingdom, Ireland, South Africa and Europe, with many participants in the study stating that they believe that there are too many immigrants in New Zealand from non-traditional source countries like China and the Pacific Islands (Johnston, Trilin, Gendall, \& Spoonley, 2010). Since "media representations of racial/ethnic population growth help shape how individuals perceive the racial and ethnic composition of their community and, in turn, how 
they perceive the composition of the nation" (McConnell, 2011, p. 179), it follows that if social harmony is to develop among the myriad of ethnic groups residing here, it is useful to find out how immigrants are commonly represented by media institutions.

\subsection{Importance of media representations}

The main reason for the selection of a critical analytical framework for this study is because this research considers the various media as institutions which hold significant social power. Media, as social institutions, not only present various aspects of culture, politics and society (Bell, 1998, p. 64) but these characteristics also shape society in doing so. Bell (1998) points to this nature of media discourse when he states:

Media 'discourse' is important both for what it reveals about society and because it also itself contributes to the character of society. Linguistic research on the media has always emphasized this last concern, focusing where issues of ideology and power are closest to the surface. (p. 65)

In other words, discourse is both "socially constitutive as well as socially conditioned" (Fairclough \& Wodak, 1997, p. 258) which means that it both shapes society and is shaped by it. Hence, the discussion of the importance of media representations is inseparable from an understanding of the characteristics of media discourse itself. The power of media discourse gains further resonance as the media has a significantly larger reach. In other words, media discourse, unlike everyday spoken discourse, has the capability to reach a large proportion of the population.

A critical approach to the study of discourse such as the Discourse-Historical Approach (DHA) and corpus-assisted discourse analysis (the two analytical frameworks adopted in this thesis) provide an optimum framework for the analysis of media discourse. Critical approaches also maintain that the discourse of the media is important since the media, as formalized institutions, are more accessible by some members of society than others (Van 
Dijk, 1996). Scholars of these approaches define social power as "control exercised by one group or organization (or its members) over the actions and/or the minds of (the members of) another group", and deem social power "illegitimate" as it limits "the freedom of action of others", influences "their knowledge, attitudes or ideologies", and serves the interests of those in power resulting in "social inequality" (Van Dijk, 1996, p. 84). Furthermore, since "power relations are discursive" (Fairclough \& Wodak, 2010, p. 102), we need to unravel the discursive strategies used in media discourse if we want to understand the power inequalities constructed within them. Hence, it can be argued that critical approaches to discourse "pursue emancipatory objectives" (Wodak \& Meyer, 2009a, p. 27) and aim to foreground social inequalities as captured/presented in discourse.

It is in this spirit that I embark on the representation of immigrants in media discourse using a critical lens. Linking the implications of media discourse discussed above to the context of immigration in New Zealand, it is important to note that in-depth research into the discursive construction of immigrant representation in New Zealand print media has been minimal when compared with literature in Europe and the United States. Therefore, with the ultimate aim of gaining an in-depth understanding of how immigrants are represented within New Zealand media, this thesis, aims to answer the following research question:

- How are immigrants represented in the New Zealand Herald during 2007$2008 ?$

And in particular, this study aims to provide answers to the following more specific research questions which are partially shaped by the analytical frameworks adopted:

- What collocations do the search words, 'migrant (s)', 'immigrant (s)', and 'Asians' have in the New Zealand Herald?

- How are immigrants referred to, described, and how often are they given voice in the New Zealand Herald? 
- What argumentation strategies are used to argue for/against immigrants in the New Zealand Herald?

And finally, a more methodologically oriented research question:

- How do the findings from the corpus analysis contribute to the findings from a traditional approach to Critical Discourse Analysis such as DHA?

\subsection{Thesis structure}

The introductory chapter of this thesis is followed by two background chapters which provide the contextual historical background on immigration and media ownership in the context of New Zealand in order to describe the broader socio-political context of the study as encouraged in Critical Discourse Analysis (CDA).

Chapter 4 provides a review of the theoretical and philosophical background of the study. It provides a theme-based review of relevant literature on the representation of immigrants in the news media. This chapter also defines key theoretical concepts across approaches and within the school of thought of CDA. It provides a brief introduction to the main approaches to CDA. However, it refrains from discussing the DHA approach as it is more fittingly introduced at length in Chapter 5. The decision to discuss the DHA approach in Chapter 5 rather than Chapter 4 is based on the fact that DHA is one of the main analytical frameworks of this study and offers tools for analysis of the data. Other contents of Chapter 5 include a discussion of the procedure as well as the benefits of using both a corpusassisted approach to discourse and a more qualitatively oriented approach such as the DHA (Reisigl \& Wodak, 2009). In addition, the data for this study and discussions surrounding the choice of data as well as the period chosen are outlined here. Finally, crucial discussion surrounding the data collection and data sampling are also elaborated. 
In Chapter 6, the results of the analysis of the data using corpus tools are addressed and the main thematic representations of immigrants based on significant collocational patterns are outlined.

Chapter 7 discusses the results using a more in-depth Critical Discourse Analysis approach. Drawing on the DHA, this chapter provides a comprehensive analysis of five newspaper articles to illustrate the various discursive strategies used in the construction of immigrant representation. The chapter is followed by Chapter 8 which brings together the findings from the collocation analysis and the discourse-historical analysis and compares these findings with the broader qualitative data set. The final chapter serves as a conclusion chapter and presents the contributions and limitations of the study as well as suggestions for much needed future research. 
"This country is not what the agents represented it to be; they are sending out thousands into a country where there is no work. Every step you take you sink up to the waist in mud or sand. There are no bridges, so you have to swim across the river...If you know anyone that is coming out here warn them of what they will have to go through."'Immigrant experience in Arnold, 1981)

\section{Chapter 2: Immigration to New Zealand}

This chapter provides a historical review of European and other non-Māori ${ }^{1}$ immigration in the context of New Zealand. While initially sketching Anglo Saxon immigration to New Zealand, it also discusses the first non-Anglo Saxon immigrants who came to the isolated islands of New Zealand in later years. This chapter also provides a review of the everchanging immigration policies and the various socio-political factors which have influenced and shaped immigration in the context of New Zealand.

\subsection{White Anglo Saxon immigration to New Zealand}

Despite controversy over the exact time when people referred to as Māori arrived, many scholars believe that Māori discovered the islands and migrated from Eastern Polynesia over a thousand years ago.

Centuries later, Abel Tasman, the Dutch explorer, was the first European to discover the islands now called New Zealand or Aotearoa (the original name in Te Reo Māori). However, it was in the mid 17th century that Captain James Cook made his first mapping of the islands as part of the British empire's plan to expand its colonization (Palmer et al., 2014, p. 435). Despite the Europeans discovering the existence of these far flung islands in 1769 (Wilson, 2015), it took some time for new settlers to migrate to New Zealand due to its remote location. The first arrivals sailed across the Tasman in pursuit of tradable

\footnotetext{
${ }^{1}$ Māori refers to the aboriginal inhabitants of New Zealand.
} 
goods. They were mainly sealers, and whalers in search of goods, or missionaries hoping to convert the local indigenous people to Christianity (Phillips, 2013a).

It was not until 1840 that more systematic mass immigration to New Zealand took place. The main reason for the shift in British immigrant numbers was because of the signing of the Treaty of Waitangi in which apparently "Maori ceded sovereignty" (O'Sullivan, 2008, p. 319; a discussion of the controversies surrounding The Treaty of Waitangi is outside the scope of this study; see O'Sullivan for three dominating discourses on the Treaty). This supposedly gave the British the rights of legal citizenship to the islands and led to a partnership which consisted of the sharing of sovereignty among the Māori chiefs and the British Crown. It was not long after that the New Zealand Company was established (Phillips, 2013b). The New Zealand Company was a commercial company, "carefully planned and well financed. At its core was an assembly of merchants, ship-owners, financiers and politicians" (Moon, 2013, p. 24). The company aimed at promoting life in the newly acquired islands to the British Anglo Saxons. Various incentives in the form of land and free travel were offered to the British in order to encourage them to emigrate to these remote islands and to actualize the British ambition of colonization. Booklets and pamphlets which depicted New Zealand as a country with a benign climate and social conditions were also distributed in the British cities with the hope that they would attract skilled laborers (mechanics and agricultural laborers were the priority) to travel to the islands. Settlers who were already in New Zealand were also encouraged to nominate their family and friends to come (Phillips, 2013b). It was through such schemes that New Zealand's population began to gradually grow.

With the arrival of immigrants to the new British colony, measures were taken to introduce immigration policies which included some and excluded others from entering. A historical review of these policies show that the severity of the policy to exclude certain nationals was subject to waning and waxing and was (and still is) dependent on many factors. Policies which preferred migration from predominantly "white" nations are referred to as the "white New Zealand policy" (Skilling, 2012, p. 367; Ward \& Masgoret, 2008, p. 228). 


\subsection{Non-Anglo Saxon immigration to New Zealand}

During the $19^{\text {th }}$ century, there were sporadic arrivals of non-Anglo Saxon immigrants who had emigrated to New Zealand mainly for the purpose of trade and gold mining. According to Taher (1970), the "Asians" (a term used by Taher) were among these and are stated to have arrived in New Zealand in three waves (Taher, 1970, p. 38).

The first wave consisted of Chinese gold miners who arrived in Otago in the second half of the $19^{\text {th }}$ century with the hope of achieving prosperity. Some Chinese immigrants were also brought into New Zealand from Australia to work in the Dunedin gold fields. For this reason "early Chinese migration to New Zealand may... be seen as an extension of that to Australia" (Taher, 1970, p. 38). However, this was not the case with Indian immigrants. Towards the end of the century, people from India were also eager to find new countries to migrate to so they could further their economic prospects. Many found out about New Zealand as they travelled on their route to and from Fiji. These Indians mainly consisted of pedlars, hawkers and domestics (Taher, 1970, p. 39).

However, towards the end of the 19th century and at the beginning of the 20th century, numerous legislative measures such as the 1881 Chinese Immigrants Act and its subsequent amendments were passed. These meant that the number of Chinese immigrants carried on any ship closely depended on the tons of cargo that it carried. In addition, Chinese immigrants were required to pay a poll tax (Roy, 1970, p. 17). These obstacles were used as means of limiting the number of Asian immigrants who could enter.

With the arrival of the $20^{\text {th }}$ century, New Zealand underwent a number of changes in its immigration policies partly due to international events such as the World Wars, the American Civil Rights movements, and partly because of economic recessions it faced. During World War I, officials were preoccupied with more important matters than immigration (Roy, 1970). After World War I, with sea travel again deemed safe, there was a revival of immigrant numbers. 
In the 1920s, a permit system was also implemented which meant that Asian immigration numbers fell significantly due to both the stricter regulations and the economic depressions of the time. Despite this, a number of Chinese refugees were admitted into the country in 1939 (Taher, 1970, p. 39).

Akbari \& MacDonald (2014) confirm the existence of a cultural bias towards immigrant selection in New Zealand prior to World War II:

Prior to World War II ... countries used immigration for nation-building, that is, to promote societal culture; thus, cultural homogeneity of the population was the main concern. This approach to immigration was manifested in various restrictions on country of origin. (Akbari \& MacDonald, 2014, p. 805)

It was not until after World War II that despite the existence of restrictions, special permission was given for larger numbers of Asians to be allowed into the country marking the third wave of immigrants. This meant that higher numbers of Indians from Fiji and students from China arrived in search of quality education.

In addition, there were also numerous non-Asian immigrants and refugees. For example, Jews fleeing Nazi Germany were allowed into the country. Despite the acceptance of these refugees, they were carefully "picked" in order to guarantee that they would "conform with existing interests" (Kasper \& Roundtable, 1990, p. 26). The largest non-British group comprised the Dutch who emigrated to the islands not only from the Netherlands but also from its closer colony of the time, Indonesia. The Dutch were looked upon favourably as it was believed that they would easily assimilate to the dominant British culture. Members of other nationalities including Cook Islanders, Tokelauans, and Niueans also became citizens of New Zealand after their countries' annexation by the British empire. Western Samoa was a New Zealand trust territory and therefore Samoans were also allowed into the country based on an annual quota (Mckinnon, 1996, p. 40). Nevertheless, the majority of the immigrants were still predominantly of British origin and white immigrants were 
heavily prioritized, with immigration policy "aiming to preserve cultural and racial homogeneity by giving preference to British stock" (Kasper \& Roundtable, 1990, p. 26). It is interesting to note that the similarities sought were understood "as relative to white, British settlers, not to the indigenous Māori” (Skilling, 2012, p. 367).

\subsection{Late twentieth century immigration policies}

It was not until the second half of the $20^{\text {th }}$ century (in 1986 to be precise) that the exclusive preference for white immigrants was gradually challenged. As a consequence, an important change in the immigration policies of the country followed. This change in attitude came partially due to the change in the colour of the nation itself (the change of colour was due to a more visible presence of non-Pākehā $\bar{a}^{2}$ members) but was also "instigated by a neoliberal agenda" (Simon-Kumar, 2015, p. 1173). This change in attitude was reinforced by international events such as the civil rights movements in the United States. According to Roy (1970)

This is a world in which racist attitudes, once regarded as perfectly natural and needing no apology in an age of European domination of the non-Europeans' world, are now looked at askance, even when they are not condemned outright. (p. 22)

With this change in attitudes came a change in policy. In 1986 the New Zealand government decided to abolish the White New Zealand policy which gave preference to certain source countries such as Britain (Kasper \& Roundtable, 1990, p. 33; Spoonley, 2006, p. 19). Prior to the implementation of the 1986 Immigration Act, selection of immigrants was based solely on nationality and race; mainly British subjects were allowed to enter freely into the country, and immigrants from Asia were restricted. However, after the implementation of the 1986 immigration policy review, immigrants from a variety of countries were selected mainly on their education, professional and age merits (Beaglehole, 2012). This review in policy in 1986 was also made to accommodate the new economic

\footnotetext{
${ }^{2}$ Pākehā refers to New Zealanders of European descent.
} 
and political considerations of the time which consisted of adopting neo-liberal principles such as privatization and free trade (Simon-Kumar, 2015, p. 1173). With these new principles, political discourses regarding national identity also shifted and comprised a more inclusive discourse where politicians argued that New Zealand has always been an immigrant country (Skilling, 2012, p. 372). As a consequence of the leniency in the new 1986 policy, immigration from non-traditional source countries followed in the hope that it would help to fulfill the increasing demand for the "stock" of skilled immigrants necessary in the labour market and would also help to create better "trading relations" with economically significant countries in Asia (Spoonley, 2006, p. 20). The recent changes in immigration policies described above have meant that in addition to the liberalization of entrance criteria, New Zealand developed a very specific approach where the state would promote and aim to attract "desirable" immigrants (Trlin, 1997).

\subsection{The point system}

In 1991, an immigration amendment act introduced a point system for the first time where applicants would be awarded points based on their age, qualifications, employability, and proficiency in English (Beaglehole, 2012; Bedford \& Spoonley, 2014). In this system, applicants who acquired a certain level of points were automatically eligible to apply. In the following couple of years, the formation of the European Union in 1993 would lead to a trend in which fewer applicants would apply to emigrate to New Zealand:

The formation of the European Union (EU) allowed for greater mobility of workers within Europe, which further exacerbated this trend. The 1990s reunification of Germany and the expansion of the EU also allowed greater mobility of European workers within the continent and expanded economic opportunities. As a result, shortages of skilled labor began to emerge in developed economies outside of Europe which had welcomed European workers for many years. (Akbari \& MacDonald, 2014, p. 806)

This drop in the number of applicants who wanted to come to New Zealand was followed 
by an adjustment of the 1991 policy. In 1995, adjustments were made to ensure that the right immigrants, i.e. those "who would most benefit the country" (Beaglehole, 2012, para. 11) were still applying. One of the changes made was the addition of a pass mark, or a threshold, in order to qualify for applying. This would help to control the number of immigrants who could apply. In addition, stricter English language requirements were enforced (Beaglehole, 2012).

The next significant change came in 2003 when the Expression of Interest model (EOI) was implemented for the first time. By this time, immigration policies in most countries including New Zealand were "more sensitive to economic outcomes" (Akbari \& MacDonald, 2014, p. 806). New Zealand's immigration Minister announced that changes would be made to policy to prioritize a more targeted and active selection of immigrants based on the demand in the labour market. A new Skilled Migrant Category was introduced while the former general skills category was dropped (Bedford \& Spoonley, 2014, p. 894). Prior to the adoption of the EOI model, a broader human capital model dominated the policies. In the human capital models, points were assigned for education without consideration of its importance in the labour market (Akbari \& MacDonald, 2014), whereas, with the implementation of the EOI model, immigration selection became more targeted and points were "awarded in a way that is thought to promote a selection of "the most productive' [his emphasis] applicants" (Rainer, 2000, p. 11). It also helped manage the number of applicants who apply for residency. It was New Zealand who first proposed and adopted this model. The model was closely monitored by other countries and was later adopted by Australia and Canada due to its success in New Zealand (Akbari \& MacDonald, 2014, p. 802). Bedford and Spoonley (2014) give a description of what the EOI model entails:

Instead of lodging applications for residence, potential migrants will, in future, register an expression of interest, based on the existing pre-requisites of health, character and English language. In order to register, a minimum number of points will be required. The current points system will be expanded to include bonus 
points, for example, by meeting a specific skill shortage or having a skilled job offer in a region outside Auckland.... Those who register their interest will be pooled, and those achieving the highest level of points will be invited to apply for residence. Where no invitation to apply has been issued by the end of the registration period, the registration will lapse. (pp. 894-895)

This change in selection process differed from the previous one in the sense that no preference is given to tertiary-trained graduates which was the feature of the 1991 point system. Applicants who had acquired trade qualifications which were accepted and recognized in New Zealand were given the same number of points as applicants who held post-graduate qualifications (Bedford \& Spoonley, 2014, p. 895). The minimum threshold required also changed a number of times. Bedford and Spoonley argue that it in 2004 the minimum threshold was set extremely high at 195 points. In other words, 195 points needed to be acquired for the applicant to be invited to apply for residency. However, with the passage of time, the minimum points threshold was gradually reduced to 100 (Bedford \& Spoonley, 2014, p. 897).

Currently, the threshold still sits at 100 although two tiers were introduced to the EOI system in 2005. The two tier system fast tracks EOI with 140 or more points while those with points in the 100-135 range are arranged according to their rank and selected based on the numbers required to meet New Zealand's immigration programme. In today's immigration point system, points are awarded for qualifications, offers of employment, and years of experience in a market recognized by New Zealand. A permanent job offer from a New Zealand employer in most cases guarantees that you pass the minimum threshold of 100 points.

In the year 2007-2008 the Global Financial Crisis (GFC) began to affect immigration in New Zealand: "the GFC was having an impact on the volume as well as the composition of the applicants selected from the pool" (Bedford \& Spoonley, 2014, p. 903). During the 
first six months of National Government ${ }^{3}$, only minor changes were made to the numbers of EOI selected. In terms of composition, "the main changes were the ongoing shift in shares of applications selected from citizens of India, the Philippines and 'other countries' at the expense of those from citizens of the UK, China and South Africa"(Bedford \& Spoonley, 2014, p. 903). This increase in shares made India the top ranked country in the year 2009. This priority given to Indian applications continued in the next decade with Indian applications selected comprising 24-33\% of every fortnightly selection from the pool. Professor Bedford points out that the reason for this was that "Indians had been transitioning to residence from study in NZ. They were already in the country and on temporary work permits. They were not migrating directly from India, like the UK ones were" (Professor Bedford, email correspondence).

\subsection{Summary}

This chapter has outlined various changes which have been made to New Zealand's immigration policy, commencing with an all-white policy which gave preference to so called "white migrants" and then leading into policies influenced by neo-liberal principles where immigrants were considered necessary for fulfilling the demand in the labour market. It in particular highlights the dynamic nature of New Zealand's immigration policies. As will become evident, the neo-liberally aligned values currently dominating New Zealand immigration policies become recontextualized in the newspaper discourse of this study. In the following chapter, I provide a review of media and ownership and their implications for today's society.

\footnotetext{
${ }^{3}$ New Zealand National Party is one of the major political parties in New Zealand.
} 
"It is useful to remind ourselves that free expression is threatened not just blatantly by authoritarian governments and all those in the private sector who fear public exposure, but also more subtly by the handful of global media conglomerates that have reduced meaningful diversity of expression in much of the globe”. (Caplan, 1997)

\section{Chapter 3: Media and Ownership}

Considering that this thesis is mainly concerned with the representation of immigrants in the media, it is important to understand current discussions and concerns surrounding media ownership and the implications they have for democracy. Critical Discourse scholars emphasize the importance of "analyzing and understanding" (Wodak \& Meyer, 2009a, p. 11) the effects of the media, and as CDA studies are becoming increasingly interdisciplinary, this necessitates an understanding of discussions surrounding the role of the media and the implications they have for society. Therefore, this chapter includes a description of how journalistic practices work and in particular the sources they frequently draw on and the ethical considerations involved. Finally, I conclude the chapter with an exploration of the dialectical characteristic of discourse and why this feature alongside the non-reciprocal nature of media as well as practical considerations, warrants their analysis.

\subsection{Media ownership}

Journalism differs from other forms of media such as advertising in the sense that it does not (or at least should not) serve the interest of a certain group or organization (Tidey, 2002, p. 73). I use should in the sentence above because the reality of the matter is quite different.

Issues surrounding media ownership have a profound effect on how the practices within the institutions are shaped and hence have "significant consequences for the democratic process" (Norris, 2002, p. 34). More specifically, "the health of democracies...depends on 
having free press" (Baker, 2007, p. 5). It is commonly accepted that if democracy is to function effectively, a free press which is not dependent on any form of government and/or private business is required (Norris, 2002, p. 34).

The concentration of the ownership of media institutions raises concerns. Those critical of media ownership rightly view the media as "a huge, non-democratically organized force that has major power over politics, public discourse, and culture" (Baker, 2007, p. 3). Media ownership entails power and when the ownership of a large number of media institutions is concentrated in the hands of the few, this has immense implications for the purpose of journalism.

According to media critic McChesney (2001, p. 2) prior to the 1980s and 1990s, media institutions were locally owned, whereas now the concentration of ownership in non-local hands is the order of the day: "specific media industries are becoming more and more concentrated, and the dominant players in each media industry increasingly are subsidiaries of huge global media conglomerates" (McChesney, 2001, p. 3). This rapid pace in concentration of ownership meant that in the year 2001, there were seven multinational corporations which dominated the world media market. This shift in ownership has come about due to deregulation and the pursuit of profit that is the main goal of capitalism (McChesney, 2001, pp. 4-5).

The implication of concentration of media ownership is the increased potential for power abuse. With profit as the main if not sole purpose of these companies, there has been an increased push for the use of recycled newspaper articles, otherwise known as syndicated articles, and fewer on the ground journalists, in order to reduce costs. These measures all in turn affect the quality and the diversity of ideas offered by individual companies. But diversity in the media is an essential ingredient of democracy. Elwyn Brooks White, an American writer and long serving contributor to The New Yorker, underlines the importance of diversity in the media in his eloquent statement which was initially sent to his local newspaper in the form of a letter: 
As long as there are many owners, each pursuing his own brand of truth, we the people have the opportunity to arrive at the truth and dwell in the light. The multiplicity of ownership is crucial. It's only when there are few owners, or, as in government-controlled press, one owner, that the truth becomes elusive and the light fails. For a citizen in our free society, it is an enormous privilege and wonderful protection to have access to hundreds of periodicals, each peddling its own belief. There is a safety in numbers: the papers expose each other's follies and peccadillos, correct each other's mistakes and cancel each other's biases. The reader is free to range around in the whole editorial bouillabaisse and explore it for the one claim that matters - the truth. (White, as cited in McGregor, 1992, p. 34)

This quote, published in a local newspaper in the United States in the 1990s (and hence unavailable on Victoria University of Wellington's database) perfectly highlights the importance of diversity and why the ownership by just a few multi-billionaires of the world's media companies is a perilous situation to find oneself in; a free society should not endow so much power over knowledge and information to just a few in society.

Baker also strongly argues in favour of media dispersion and gives three dominating reasons as to why media ownership is problematic. The first reason he discusses is what he calls "the democratic distribution principle" (Baker, 2007, p. 9). From a normative perspective, Baker defines democracy as "respecting the view that each person equally should have a say, at least a formally equal right to have a say, in choosing at least its officials and, ultimately, its laws and policies and maybe its culture" (Baker, 2007, p. 6). He also believes that media should work for a "common good" and, in order to achieve that, it "requires an inclusive discourse involving the whole society". In other words, media that appeal to "all elements of public and that fairly include the voice of all" (Baker, 2007, p. 8). He believes that this is only achievable in situations where the media are diversified and not concentrated. 
Secondly, having a dispersed media ensures that power is not concentrated in the hands of a few and as a consequence reduces the likelihood of "abuse of concentrated communicative power" to choose and control the government. Finally, the third main reason he argues for is that "relentless pursuit of profits and constant focus on the bottomline... is most extreme among larger conglomerates". Baker also points to a few subsidiary reasons. With concentration of media institutes, they become more "vulnerable to outside pressures" which use economic leverage to "mute critical reporting". In my opinion, these reasons are valid and require careful consideration (see Baker, 2007 for full account).

It is argued that the cause of this problem (concentration of ownership) is the waning of legislative protection. Hence the remedy, at least in theory, lies in changes in policy with the interest of the public at heart (McGregor, 1992, p. 36). The legislative effect on media concentration will be outlined in the section below which deals with press ownership in New Zealand.

\subsection{Media ownership in New Zealand}

The media in New Zealand are characterized by concentration and foreign ownership. Rosenberg (2008) highlights the grave situation of the broader New Zealand news media:

four companies, all overseas owned, dominate the New Zealand news media. There is a near duopoly in two of the three main media - print and radio - a monopoly in pay television, and only three significant competitors in free-to-air television including the state-owned channels. (Rosenberg, 2008)

Judy McGregor, an expert in media sociology and media representation, believes the grave situation is brought about because "the dilution of legislative protection has roughly paralleled the concentration in newspaper ownership" (p. 36). Due to very relaxed legislation in New Zealand, all prominent media companies are currently foreign owned. The repeal of two acts has significantly affected New Zealand's current media ownership for the worse. The New Media Ownership Act and the Commerce Act 1975 (both repealed 
now) are underlying factors in the concentration of media in New Zealand. For example, prior to the repeal of the Commerce Act 1975, "the Commerce Commission was able to take into account the public interest and had a wide discretion in deciding whether to approve mergers and acquisitions" (McGregor, 1992, p. 36). For example, the Commission refused to allow Brierley Investments to increase its shares in 1985 and in response said:

We consider that it is a protection to the public that no one shareholder so dominates any one of the big three newspaper companies as to place that shareholding in a position of dominant influence in respect of that company. (McGregor, 1992, p. 36)

Therefore, previous legislation provided a certain level of protection and reassurance for the interest of the public which is no longer available: "the basis for that reassurance has long since disappeared.... Now it is no longer obligatory to seek clearance for take-overs or mergers although the parties may apply if they wish" (McGregor, 1992, p. 37).

In addition to this, there is no limit to cross-media ownership which means that a single media company has the right to own various forms of media such as radio, television, newspaper etc. simultaneously and within the same market (Norris, 2002, p. 36). To further aggravate the problem, in 2011, APN and Fairfax media who were the biggest shareholders of New Zealand Press Association (NZPA) decided to pull out which resulted in a loss of jobs for journalists and a loss in non-commercialized news. Fairfax initially withdrew its shares from NZPA and justified this by stating that it wanted to provide its own unique content. APN subsequently withdrew as it could not sustain its shares without the support of Fairfax media (Myllylahti \& Hope, 2011).

Currently the print media in New Zealand are dominated by two foreign owned companies (Rosenberg, 2008), namely Fairfax New Zealand Media and New Zealand Media and Entertainment (NZME); for details on the shareholders of these two giants see Myllylahti 
\& Hope, 2011, pp. 190-191. More recently in May 2016, there are discussions around the likelihood that Fairfax and NZME will merge by the end of the year.

The Australian owned company Fairfax New Zealand Media owns a variety of daily and community newspapers which were formerly owned by Independent Newspapers Limited. Among their most prominent newspapers is the Dominion Post which is a daily newspaper published in New Zealand's capital city, Wellington.

The majority of other dailies in New Zealand are published by NZME who also own The Radio Network, eight regional daily newspapers, numerous community papers and GrabOne (a daily deal site). NZME is in turn 100\% owned by the Australian-based Australian Provincial Newspapers (APN) whose shareholders are a number of investment funds and News Corporations (15\%). APN's name change to NZME was due to a change in the company's interests as it expanded to metropolitan media (personal communication with Tim Murphy editor-in Chief, New Zealand Herald, May 15, 2015). This concentration of news media companies has meant that there is, surprisingly, only one daily newspaper published in Auckland which is New Zealand's largest city (Norris, 2002, p. 38), and consequently NZME owns one of New Zealand's most prominent daily newspapers, called the New Zealand Herald. It is this newspaper which is the data source for the analysis in this thesis.

\subsection{Sources of news}

One part of journalistic practice is to gather news which will be of interest to the public. The gathering of news involves getting information from various sources. It is essential to understand that, no source is an unbiased source (Hurst, 1997). However, as long as journalism draws upon various sources, this should not pose a problem. It does however create a problem when journalists only draw upon very limited sources who define what should or should not be considered news. 
Nowadays, a large proportion of the news is acquired from media releases from official bodies or from various public relations (PR) firms rather than on the ground investigative reporting (Comrie, 2002, pp. 162-163). Although gathering news from press releases and PR sources is not necessarily a bad thing in itself, it does however pose problems when journalists become dependent on this source of information (Comrie, 2002, p. 166). PR professionals for example, have a duty to support the interests of the organization they work for. Hence, the news that they give to the journalists tends to have a "spin". A spin is defined as "the slant that is given to a news item - usually for political purposes (hence 'spin doctor' - the PR person who is responsible for bringing off the spin)" (Peart \& Macnamara, 1987, p. 217). The awareness that PR specialists have of journalist practices and values means that they are able to use various techniques or strategies to slant or manipulate the news in a way which suits the interests of their organizations.

Another source of news is politicians. The relationship between journalists and politicians has aptly been dubbed a "tug of war" (Gans, 1980, p. 117), that is, while one attempts to control/influence the news, the other attempts to control the source. Politicians, nevertheless, are privileged as they have direct access to journalists. The preference given by journalists to information gained from politicians means that they are often referred to as "primary definers" (Hall, Critcher, Jefferson, Clark, \& Roberts, 1978, p. 58) of the news which means that they have the opportunity to offer the initial interpretation on a topic which in turn leads the discussion and

sets the terms of reference within which all further coverage of debate takes place. Arguments against a primary interpretation are forced to insert themselves into its definition of what is at issue - they must begin from this framework of interpretation as their starting point. (Hall et al., 1978, p. 58)

This makes it very difficult for other interpretations to have influence as politicians have already imposed their own interpretations on a specific event. Of course news sources can come from anywhere and are not limited to politicians and public relations. Nevertheless, 
it is important to understand that certain groups or organizations have privileged access which is reflective of the social hierarchies in place in societies. The implication of this privileged access is that journalists tend to draw upon relatively stable (and powerful) sources, which means that the voices of minority groups and less powerful members of the society often go unheard.

The sections above have discussed the fundamental role of the media in a democratic society, and the implications of ownership. The following section focuses on media regulations and the role of media discourse and its 'dialectic' feature.

\subsection{Media regulation}

Considering that media companies have a lot of power and very little regulation to control what they produce, it becomes important to ask who regulates. Media companies themselves have developed codes of practice which guide their members on ethics. Nevertheless, journalists working under "the pressure of tight deadlines" are thus discouraged from making reference to codes of ethics. Instead, they are often guided by "newsroom learning" which is based on "anecdotal knowledge" about what is or is not acceptable (Tully, 1992, p. 146). This practice which is frequently witnessed in newsrooms means that media company employees may make unethical decisions with regards to their news pieces and journalists may "abuse" the freedom bestowed on them. In such cases, "self-regulation" through means of codes of practice is "not considered effective" and a different means of regulation and control is necessary (Tully, 1992, p. 143).

Press councils have become primary regulators in most cases. The New Zealand Press Council, for example, was established in 1972 and provides a stage for members of the public to make complaints or express their concerns about media content. The Press Council members usually consist of retired judges acting as chairpersons, executive directors, public representatives, and media company representatives. Previously the New Zealand Press Council did not have any power to inflict sanctions on the media companies (Tully, 1992, p. 147). However, there have been changes. The media companies must now 
sign an agreement whereby they agree to comply with the complaints procedure which includes the adjudication of publication requirements. However, as rightly pointed out, rarely do people who actually consume media make contact with the media institutions or the press council (Bell, 1991). A complaint to the press council is time-consuming and there is no guarantee that the perspective of the person making the complaint against a certain message or representation will receive similar coverage and hence reach the same audience as the initial message. In cases when the newspaper is required to make an official apology for ethical breaches, the apology may not receive the same amount of attention due to size and positioning.

Given the potential effects of the media in general and of media discourse in particular, and the inadequacies of various forms of regulation, the analysis of media 'discourse' has become important in the fields of media studies and (critical) discourse analysis.

\subsection{Dialectic media discourse}

It is fundamental to gain a better understanding of the discourses which frequently get disseminated through the media in light of the importance of media ownership and sources. The importance of media discourse is further underlined by the fact that all forms of media are social institutions which present various aspects of culture, politics and society (Bell, 1998, p. 64). However, it is equally important to highlight that not only does media discourse reflect various aspects of society, but it also shapes society while doing so. This "dialectical" feature is not unique to media discourse and in fact applies to any discourse. In other words, as noted above, discourse in general is both "socially constitutive as well as socially conditioned" (Fairclough \& Wodak, 1997, p. 258) which means that it both shapes society and is shaped by it. Due to its high reach and because it is so powerful in shaping our thoughts and opinions, it has become an important object of study. Ruth Wodak, a professor at Lancaster University, specializes in analysing media discourse and believes that newspapers: 
write only those kinds of reports and appeal only to those prejudices which they expect will find resonance among their readership. Yet their reporting strengthens existing stereotypes and frequently offers arguments or metaphors which can serve to legitimate prejudiced attitudes. Media reports and political discourse in general thus exercise a certain influence on the forms and intensity of prejudiced discourse. (Wodak \& Matouschek, 1993, p. 226)

Media institutions have the power to strengthen certain representations of reality and disregard others. Talbot (2007) points to the powerful influence the media have and states: “since discourse plays a vital role in constituting people's realities, the implications for the power and influence of media discourse are clear" (p. 3). Miller also reiterates that the representations we see in the media in turn affect our actions and decisions:

What they (media) exercise is the power to represent the world in certain definite ways. And because there are many different and conflicting ways in which the meaning about the world can be constructed, it matters profoundly what and who gets represented, who and what regularly and routinely gets left out; and how things, people, events, relationships are represented. What we know of society depends on how things are represented to us and that knowledge in turn informs what we do and what policies we are prepared to accept. (Miller, 2002, p. 246)

Quinkert and Jager (1991), written originally in German, also emphasize that discourses are powerful because they bring about actions (as cited in Wodak \& Matouschek, 1993, p. 226). The media, like most other institutions, will present aspects of reality that best serve its interest. This makes it particularly interesting and equally dangerous and as scholars have previously pointed out, the sources from which media institutes such as newspapers draw are never unbiased (Hurst, 1997). 


\subsection{Non-reciprocal nature of mass media}

Newspapers, as a form of media, are often criticized for not allowing two-way communication. Communication in mass media differs from any other form of communication in the sense that it is largely non-dialogical ${ }^{4}$. The direction of communication is usually one way. Opinions and information are the product of the institution and are transmitted to people who are distant from the original setting in which it was produced (Thompson, 1995, p. 25). Thompson states that this feature of media discourse means that "recipients of media messages are not so much partners in a reciprocal process of communicative exchange but rather participants in a structured process of symbolic transmission". Hence, with media discourse, members of the audience do not usually have an opportunity to ask for clarification, criticize, or provide opposing arguments. The direction of the communication is mainly from the media institutions towards the audience and not vice versa. Bell (1991) reiterates this point when he refers to mass communication as a "one-way traffic" (p.106). He argues that mass media audiences are "deprived of the usual means of inducing communicators to modify their production" (p.87). The point of view of various community members who have less power does not usually get represented in the media which mainly opt to provide the point of view of the mainstream. Furthermore, although a letter can be sent to the editor of a newspaper, there is no guarantee that the letter will be published, as "direct feedback by the audience is subject either to delay - influencing subsequent but not immediate production — or to reduction: the audience member's response remains under the editorial control of the communicators" (Bell, 1991, p. 87). This point is confirmed by the newspapers with many newspaper websites announcing that "letters are not normally acknowledged and may be edited, abridged or discarded" (New Zealand Herald).

\footnotetext{
${ }^{4}$ New media which allow their users to post public comments do challenge the non-reciprocal nature of mass media to an extent.
} 


\subsection{Summary}

In summary, this chapter has outlined the fundamental role that the media play in a democratic society. If a democracy is to function properly, a country needs de-concentrated media institutions and systematic regularization of their performances. Considering the current climate of New Zealand's media institutions and the probability of further concentrations, and hence monopolization, it becomes important to critically evaluate the quality of the circulating representations of immigrant minorities as these are the most vulnerable members of a society due to their fewer numbers. The rather limited sources of information currently drawn on by media practitioners is also a matter of grave concern as it means that the voices of the few powerful members who have privileged access to media practitioners will continue to dominate. This in turn affects public perceptions and social treatment of immigrants. The following chapter provides a discussion of key concepts pertaining to the theoretical background of the analytical framework used in this study. It also reviews relevant literature which has adopted a critical stance on media representations of immigrants. 
"Critical discourse scholars should also be social and political scientists, as well as social critics and activists". (Van Dijk, 1993, p. 253)

\section{Chapter 4: Theoretical Background}

The aim of this chapter is to explain the theoretical background of this thesis by reviewing the literature of previous scholars with a similar approach. The chapter first provides a trajectory of Critical Discourse Analysis (CDA) and how it has been shaped over the years by its precedents such as the Frankfurt School of thought and Critical Linguists. While the chapter discusses the key concepts in CDA, it refrains from presenting the main methodological aspects of the Discourse-Historical Approach (DHA) of this thesis, as this specific analytical framework is discussed in detail in Chapter 5. This chapter also provides a review of numerous studies which have adopted a critical approach to the representation of immigrants in the media and ends with a discussion on metaphors.

\subsection{Critical Discourse Analysis}

CDA has gained popularity recently in a variety of disciplines and fields. The term CDA has since mainly been used to refer to what was previously known as Critical Linguistics (Wodak \& Meyer, 2009a, p. 1) which in turn can be traced back to the Frankfurt School of thought (also known as the Institute of Social Research). Therefore, both the research of the Frankfurt School and Critical Linguistics are considered to be the forerunners of CDA (Chilton \& Wodak, 2007, p. xi).

The Frankfurt School from which CDA receives its critical stance, is itself not a homogenous and "tightly woven" school as some may believe. CDA is similar to the Frankfurt School as it too is often referred to as a school because of its various approaches following a myriad of different theories and methodologies (see Miller, 2014, pp. 1-36 for a discussion on the concept of "school"). 
In addition, the Frankfurt School is said to have "developed daringly innovative, interdisciplinary critical approaches to the emerging phenomena of modern life", such as interdisciplinarity and critical features which are also characteristic of CDA approaches (Miller, 2014, p. 6), in particular the DHA (Reisigl \& Wodak, 2009). The Frankfurt School was not only interested in "what is" but was more interested in "what could be" or "what, realistically, could be changed in the interest of greater human freedom and rationality and what social forces specifically might bring about that change" (Miller, 2014, p. 9). Critical theories, and hence CDA also, share a common goal which is that of enabling humans to "emancipate themselves from forms of domination through self-reflection...such theories thus seek not only to describe and explain, but also to root out a particular kind of delusion" (Wodak \& Meyer, 2009a, p. 7). Therefore, it becomes clear that critical theories work towards an ideal, a utopia or a better world. "Critical theory" is in this sense different from "traditional theory" as it aims to critique and change society rather than solely understand and explain it (Wodak \& Meyer, 2009a, p. 6).

The next section focuses on one prominent figure of the Frankfurt School, Habermas, whose ideas have been considered highly significant in both social and media studies. This will be followed by some criticism directed at his conceptualizations.

\subsection{Jurgen Habermas and the Frankfurt School}

According to Miller (2014, p. 10) the Frankfurt School has experienced three different phases in its historical development after the Second World War. The first phase includes the re-establishment of the school in the post-war context. The second phase is identified with the Frankfurt School theory gaining popularity among the people. The third phase, frequently referred to as the "Communicative Turn", refers to the period in which critical theory became "rooted in language, communication, and the progressive democratization of society" (Miller, 2014, p. 10). Due to reasons of space, I discuss the third phase referred to as a communicative turn as it is the most relevant. Habermas was a prominent figure in this turn. He introduced a new paradigm of critical theory which had language and communication as its focus (Miller, 2014, p. 10). His concept of "public sphere" has 
contributed significantly to media theory. Due to their significance, some of Habermas's ideas will be summarized here. This summary will be followed by a summary of criticism concerning the deficiencies of his concept of "public sphere" which he discusses at length in his book; see Habermas (1989), a translated version of the original book written in German, for a lengthy discussion on the term "public sphere". The "public sphere" is something of the past, characteristic of $17^{\text {th }}-19^{\text {th }}$ century and can be defined as

A bourgeois public sphere which consisted of private individuals who had come together to debate among themselves, and with state authorities concerning the regulation of civil society and the conduct of the state. The medium of this confrontation was significant and unprecedented: it was the public use of reason, as articulated by private individuals engaged in argument that is in principle open and unconstrained. (Thompson 1990: 110-11)

Habermas's concept of "public sphere" consisted of a space where people from all walks of life could come together "as if equals [his emphasis]" (Petley, 2012, p. 141) and freely discuss important issues pertaining to the society. Salons and coffee houses were one of the places where people could gather and rationally debate social topics relating to the good of the public. At the time, the role of the press was to act as mediator between the people and the state, bearing the responsibility of familiarizing the state with the debates and expectations of its people (Petley, 2012, pp. 141-142).

As outlined above, the "public sphere" according to Habermas was characteristic of a period in the past where people would debate and rationalize on fundamental topics about their society. For Habermas, this idyllic space was transformed with the arrival of refeudalization. Habermas believed that refeudalization arrived in the second half of the $19^{\text {th }}$ century when "private institutions began increasingly to assume public power and to intervene in the political process, whilst at the same time the state progressively entered the private realm and took on ever greater responsibility for managing citizens' welfare" (Petley, 2012, p. 142). This refeudalization, he argued, led to an exclusion of the public as 
debates were primarily conducted between the state and private institutions instead of the between the public and the state:

The process of the politically relevant exercise and equilibration of power now takes place directly between the private bureaucracies, special interest associations, parties, and public administration. The public as such is included only sporadically in this circuit, and even it is brought in only to contribute its acclamation. (Habermas, 1989, p. 176)

Habermas also criticized the mass media and believed that the arrival of mass media is "a public sphere in appearance only" (Habermas, 1989, p. 171). This disguise, he argues, dispossesses people of the right to say anything, to disagree or to think critically. Instead it encourages people to talk about "tastes and preferences" (Habermas, 1989, p. 171).

He also makes a distinction between what he calls "critical publicity" and "manipulative publicity". The first is bottom up where the public sphere's opinion affects the state actions and guarantees "the connection between rational-critical public debate and the legislative foundation of domination", whereas "manipulative publicity" is top down and generated from above "and serves the manipulation of the public... in order to create an aura of good will for certain positions" (Habermas, 1989, pp. 177-178).

Habermas asserts that with the privatization of spheres which formally used to be part of the state, "critical publicity" needs to be extended to these private corporations as well. What he means by this is that the media formerly was part of the state and was controlled and scrutinized by the "public sphere". Now, it has become privatized but still needs to be under the scrutiny/supervision of the "public sphere" and the actions of these companies "should be as open to scrutiny as those of the state itself (Habermas, 1989, p. 209). 


\subsubsection{Critics of Habermas's public sphere}

Being the prominent figure of the third phase of the critical theory movement, Habermas is referred to as the "heir" to critical theory (Pennycook, 2001, p. 6). Nevertheless his concept of "public sphere" has been criticized on various grounds.

One of the first criticisms directed at Habermas is that the "public sphere" was not ever as public as Habermas claimed it to be. In fact, it not only excluded women but also excluded the working class (Petley, 2012, p. 145). Habermas is also criticized for representing the $17^{\text {th }}-19^{\text {th }}$ century as too rosy and idyllic while criticizing more modern times (mid- $19^{\text {th }}$ century onwards) as problematic on account of the "public sphere" becoming contaminated by commercially motivated media. Habermas

doesn't look at 'penny dreadful', lurid crime and scandal sheets and other less than rational - critical branches of the press or at the demagoguery of travelling orators, and glances only in passing at the relationship of crowds to political discourse. (Calhoun, 1992, p. 33)

Habermas' analyses of the past are said to ignore the media which was popular among the "plebian public sphere" (Calhoun, 1992). Plebian refers to common folk, or low brow, and therefore Habermas is criticized for ignoring the more politically radical newspapers of the time which were read by the "plebian public sphere".

The criticisms directed at Habermas suggest that he may have been depicting a very rosy picture of the past, and was too critical of more modern times. Nevertheless, this does not mean that the principles which he strived for, i.e. a world with more dialogue, rationality, critical thinking, openness and publicity; a world which serves the greater good, should be disregarded. 


\subsection{Critical Linguistics}

Frequently the terms CDA and Critical Linguistics are used in place of each other (Wodak, 2006 , p. 1) where CDA is a more "refined, broadened and changed" approach compared to its ancestor (Wodak, 2006, p. 5). In this section, I provide a brief historical note on this ancestral school which influenced the development of CDA so strongly.

In the 1970s, scholars at the University of East Anglia began to use the term Critical Linguistics in their studies on language use in various institutional settings. The early discourse analysts tended to focus mainly on surface and structural features of language. However, this changed with what is commonly known as the "Cultural Turn" in discourse analysis (Mason, 2006) when social elements were also brought into the picture. Pioneers in Critical Linguistics proposed that language should be related to people and social processes (Mason, 2007, p. 341). The pioneers of this turn, Roger Fowler, Robert Hodge, and Gunther Kress assumed that there was a strong link between linguistic structure and social structure (Wodak, 2006, p. 5) and discuss the relations between linguistic processes and their ideological motivations (Kress \& Hodge, 1979).

Mason (2007) identifies two further assumptions that underlay their approach. The first is that language plays a pivotal role in constructing social realities. The second is that language, in addition to having a communicative role/function, serves as a means of control (Mason, 2007, p. 342). These radical proposals for the study of language were unprecedented up to that date and were not received well by mainstream linguists. Mason argues that the main criticism directed towards Critical Linguistics was that it was either "too context-dependent for the formalists and paid insufficient attention to linguistic orthodoxy" or there was "too much detailed linguistic analysis (transitivity, modality, negation and so on) for prospective users from other disciplines" (for an extensive account of criticism see Mason, 2007, pp. 242-244).

Despite the myriad instances of criticism, Critical Linguistics did leave legacies, such as CDA which is considered a broader and more refined approach. One reason for the move 
towards interdisciplinary research was that, at the time, scholars from a variety of disciplines such as literary studies, sociolinguistics, social psychology and formal linguistics believed that the study of discourse is complex and therefore requires interdisciplinary research (Wodak, 2006, p. 5). Therefore Critical Linguistics evolved and developed an interdisciplinary character to it which later led to the development of various trends. For reasons of space, I will not rehearse all of these trends/approaches here. A brief introduction to Fairclough's and Van Dijk's approaches will be given in the following section as both scholars and their approaches are central to CDA. As discussed in section 1.3, the DHA approach is discussed under Chapter 5, the methodology chapter of the thesis as it provides the analytical framework, tools and strategies to analyze the data (for an extensive introduction to these various approaches see Wodak, 2006; Wodak \& Meyer, 2009b).

\subsection{Approaches in Critical Discourse Analysis (CDA)}

The CDA School has expanded into a variety of approaches which tend to differ in their focus despite sharing similarities in their fundamental principles. These approaches tend to focus on different theories. Wodak \& Meyer (2009a) do not see this as a problem and clearly state that CDA has never tried to be a single theory or methodology and it is this heterogeneous nature of CDA which allows for ongoing debates and novelty (p. 5). Therefore, CDA scholars view this multifaceted-nature as a strength rather than a weakness:

We see CDA as bringing a variety of theories into dialogue, especially social theories on the one hand and linguistic theories on the other, so that its theory is a shifting synthesis of other theories, though what it itself theorises in particular is the mediation between the social and the linguistic — the 'order of discourse', the social structuring of semiotic hybridity (interdiscursivity). The theoretical construction of discourse which CDA tries to operationalize can come from various disciplines, and the concept of 'operationalisation' entails working in a transdisciplinary way where the logic of one discipline (for example, sociology) 
can be 'put to work' in the development of another (for example, linguistics). (Chouliaraki \& Fairclough, 1999, p. 16)

This statement underlines the interdisciplinary nature of CDA which derives from it embracing multi-theories and methodologies. CDA scholars believe that in order to understand how a complex phenomenon such as language functions, one needs to be equipped with interdisciplinary knowledge and tools (Wodak \& Meyer, 2009a, pp. 20-21). Despite the fact that CDA as a school is heterogeneous, there are a few approaches which are very well known namely Fairclough's Dialectical-Relational Approach, Van Dijk's Socio-Cognitive Approach and finally the DHA. This multi-theoryness is illustrated in Figure 4.1.

As evident from this figure, these approaches differ in the research strategies and theoretical backgrounds they draw on, and also with regards to the level of deduction as well as "selection of topics for research" (Kendall, 2007). Fairclough's DialecticalRelational Approach for example takes "a rather grand-theory-oriented position: Fairclough focuses upon social conflict in the Marxian tradition and tries to detect its linguistic manifestations in discourses, in specific elements of dominance, difference and resistance" (Wodak \& Meyer, 2009a, p. 27). Van Dijk's approach as is clear from its name however, draws on cognitive psychology, public perception and consciousness. His SocioCognitive approach focuses on the role of cognition in CDA and maintains that CDA is/should be primarily concerned with accounting for the triangle of discourse, society and cognition (Van Dijk, 2009). Compared to Van Dijk's approach, the DHA draws on critical theory and symbolic interactionism. It is the most inductive approach and deals with "indepth case studies and ample data collection" (Wodak \& Meyer, 2009a, p. 19) and also makes provision for an account of broader societal and political mechanisms of the processes of production and interpretation of discourse. I have chosen to use the DHA (Reisigl \& Wodak, 2009) for this study. For a more detailed description of this approach and my rational for using it see Chapter 5. 


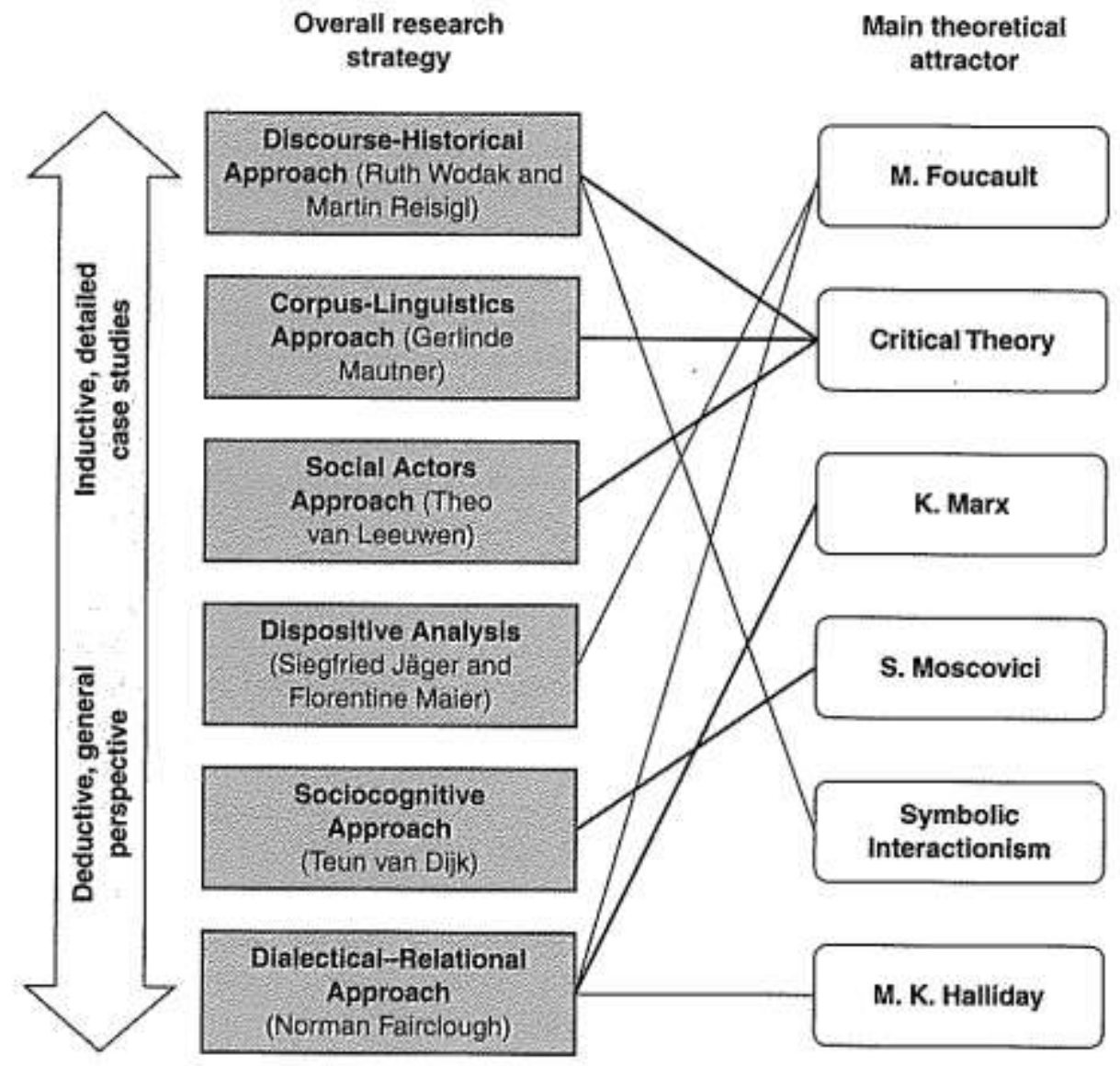

Figure 4.1 CDA approaches and their theoretical backgrounds (Reproduced from Wodak \& Meyer 2009a, p.20)

\subsection{Discourse in Critical Discourse Analysis}

The term discourse has been used extensively across disciplines for the past three decades. During this time, it has been used by different scholars and hence has acquired a certain level of ambiguity as its meaning. The definitions given to the term differ in the various approaches available. Van Dijk (2009) refers to the vastness of the notion of discourse and states: 
Discourse is a multidimensional social phenomenon. It is at the same time a linguistic (verbal, grammatical) object (meaning sequences or words of sentences), an action (such as an assertion or a threat), a form of social interaction (like a conversation), a social practice (such as a lecture), a mental representation (a meaning, a mental model, an opinion, knowledge), an interactional or communicative event or activity (like a parliamentary debate), a cultural product (like a telenovela) or even an economic commodity that is being sold and bought (like a novel). In other words, a more or less complete 'definition' of the notion of discourse would involve many dimensions and consists of many other fundamental notions that need definition, that is theory, such as meaning, interaction and cognition. (Van Dijk, 2009, p. 67)

This quote clearly highlights the vast (and complicated!) definition that the notion of discourse can take. Fairclough also highlights the fact that discourse is frequently used in different senses:

(a) meaning-making as an element of the social process, (b) the language associated with a particular social field or practice (e.g. 'political discourse'), and (c) a way of constructing aspects of the world associated with a particular social perspective (e.g. 'neo-liberal discourse of globalization') (Fairclough, 2009, pp. 162-163)

Despite this ambiguity in its meaning, some definitions of discourse have become more popular among scholars and they mainly agree on one important aspect of the notion of discourse, namely that it involves an 'action'. In other words, discourse not only takes effect from society but is also affected by social practice. The first one of these definitions is:

CDA sees discourse - language use in speech and writing — as a form of 'social practice'. Describing discourse as social practice implies a dialectical relationship between a particular discursive event and the situation(s), institution(s), and social 
structure(s), which frame it: The discursive event is shaped by them, but it also shapes them. That is, discourse is socially constitutive as well as socially conditioned. (Fairclough and Wodak, 1997, p. 258)

Candlin (1997) also refers to discourse as "language in use and socially situated":

'Discourse'... refers to language in use, as a process which is socially situated. However...we may go on to discuss the constructive and dynamic role of either spoken or written discourse in structuring areas of knowledge and the social and institutional practices which are associated with them. In this sense, discourse is a means of talking and writing about and acting upon worlds, a means which both constructs and is constructed by a set of social practices within these worlds, and in so doing both reproduces and constructs afresh particular social-discursive practices, constrained or encouraged by more macro movements in the overarching social formation. (Candlin, 1997, p. iix)

Both the definitions above, highlight the "dialectical" or constructive nature of discourse. That is, discourse contributes to constructing our objects of knowledge, and our realities and it is through this very discourse that we express ourselves. It is worth noting that discourse can help maintain the status quo as well as change it.

All the definitions given above refer to both written and spoken forms of discourse. However, it is important to note that more recent trends in discourse analysis have given discourse an even more expansive definition. As Van Leeuwen (2006) indicates, "[c]ritical discourse analysis has also moved beyond language, taking on board that discourses are often multimodally realized, not only through text and talk, but also through other modes of communication such as images" (p. 292). Therefore, some linguists consider multimodal forms such as visual imagery, topography, gaze, gesture, colour etc. as aspects of discourse too (Kress \& Van Leeuwen, 1996, 2001). The DHA (Reisigl \& Wodak, 2009) 
also assumes a broad meaning of discourse to include oral, written and visual language. As the main analytical framework of this study, the DHA considers discourse to be

- A cluster of context-dependent semiotic practices that are situated within specific fields of social action.

- Socially constituted and socially constitutive

- Related to a macro topic

- Linked to the argumentation about validity claims such as truths and normative validity involving several social actors who have different points of view. (Reisigl \& Wodak, 2009, p. 89)

As is evident from the features outlined above, the DHA also assumes discourse to be a "social action" which constructs society. However, it also emphasizes the "contextdependent" nature of discourse and asserts that discourse is used to construct arguments.

\subsection{Critique in Critical Discourse Analysis}

As with the term 'discourse', CDA scholars have differing opinions on what the term 'critical' in CDA means. Fairclough (2010) indicates that being critical means to unravel the complex relationship among social structures which are otherwise blurred out of the vision of the layperson: "in human matters, interconnections and chains of cause and effect may be distorted out of vision. Hence 'critique' is essentially making visible the interconnectedness of things" (Fairclough, 2010, p. 39). Elsewhere he states CDA is critical in the sense that it deals with "social wrongs of the day (in a broad sense - injustice, inequality, lack of freedom, etc.) by analyzing their sources and causes, resistance to them and possibilities of overcoming them. We can say that it has both a 'negative' and a 'positive' character" (Fairclough, 2009, p. 163).

Wodak \& Meyer (2009a) add that the simple act of describing does not suffice and maintain that "such theories seek not only to describe and explain, but also to root out a particular 
kind of delusion" (p. 7). Hence, critical theories seek to make changes and are emancipatory by nature.

Van Dijk (2009) on the other hand states that the term critical in critical discourse studies (note that CDS is an alternative term for CDA coined by Van Dijk himself, see Van Dijk, 2009, p. 62 for discussion on this) actually refers to the scholars and not the method itself. He believes that this critical characteristic of CDA scholars shows itself when formulating goals for their research, selecting the theories they will use, and specifying and enhancing their methods (Van Dijk, 2009, p. 63).

In line with this, Angermuller et al (2014) point out that being critical implies being critical of the self and not just others and that it is through these critical practices that social change is achieved (p. 362).

The DHA approach to CDA on the other hand, proposes three levels of critique and argues that the concept of critical in CDA is a combination of these three levels. The three level concept of critique comprises, (1) text or discourse-immanent critique, (2) socio-diagnostic critique and (3) prospective critique. These are defined as follows:

1. Text or discourse-immanent critique aims at discovering inconsistencies, selfcontradictions, paradoxes and dilemmas in the text-internal or discourse-internal structures. 2. socio-diagnostic critique is concerned with demystifying the manifest or latent - persuasive or 'manipulative' character of discursive practices. Here, we make use of our contextual knowledge and draw on social theories as well as other theoretical models from various disciplines to interpret the discursive events. 3. Future related prospective critique seeks to contribute to the improvement of communication (for example, by elaborating guidelines against sexist language use or by reducing 'language barriers' in hospital, schools and so forth). (Reisigl \& Wodak, 2009, p. 88) 
The DHA approach also perceives the term critical or critique to mean distancing oneself from the data, placing the data in its relevant social context, categorizing the social positioning of the social actors within the discourse, repeatedly reflecting on one's self and one's decisions while conducting the study, and making transparent the researcher's own position (Reisigl \& Wodak, 2009, pp. 87-88). This aspect of the term critique plays an important role in this present thesis.

\subsubsection{Criticism of critique}

CDA has often been criticized for dealing with rather negative topics. Martin (2004) for example, has argued that CDA has not been successful in achieving its goals mainly due to its obsession with negative instances and what he refers to as "demonology" (p. 197). He suggests a complementary approach to CDA which comprises looking into "heartening accounts of progress" rather than solely "discouraging analysis of oppression". He believes that CDA research lacks what he has subsequently called Positive Discourse Analysis (PDA). CDA, he maintains

cripples our understanding of how change happens, for the better, across a range of sites - how feminists re-make gender relations in our world, how Indigenous people overcome their colonial heritage, how migrants renovate their new environs and so on. And this hampers design, and perhaps even discourages it since analysts would rather tell us how struggle was undone than how freedoms were won. (Martin, 2004, p. 184)

Nevertheless, CDA scholars have replied to this comment with some criticism of their own. Wodak in an interview with Gavin Kendall stated that the term "critical"

is not to be understood in the common sense of the word, i.e. criticizing, or being negative. Thus, 'positive' is in no way to be understood as the counterpart of critical research as recently proposed by Jim Martin in his version of "Positive Discourse Analysis!” (Kendall, 2007) 
Angermuller et al (2014) seek to clarify this common (mis)interpretation of the term "critical" in the field of Critical Discourse Studies (CDS) and state that

The objects under investigation do not have to be related to what is widely perceived as problematic or negative; this is a frequent misunderstanding of the aims and goals of CDS and of the term 'critical', since any social phenomenon can lend itself to critical investigation, to being challenged and not taken for granted. (p. 362)

Others assert that focusing on the positive changes in discourse would mean CDA scholars are "condescending and implicitly perpetuating unequal power relations" and that they are endorsing a "a sit-back-n-enjoy break in the struggles of social change" (KhosraviNik, 2007). This response ignores the word "complementary" used by Martin in the abstract of his article: "in this paper I suggest a complementary perspective, on language and semiosis, which functions to make the world a better place — which I refer to as Positive Discourse Analysis (PDA)" (Martin, 2004, p. 179). Martin was not arguing that PDA could be an alternative to CDA but that it could complement it. Despite CDA scholars' emphasis that the term "critical" does not necessarily mean negative, a great number of their studies have indeed only focused on negative instances (e.g. injustice, inequality, lack of freedom) within the discourse.

Moreover, in my view, the importance of counter-discourse (e.g. discourses which represent immigrants favourably) in the pursuit of eliminating racist discourse should not be underestimated. We cannot eliminate/reduce racist discourse without illustrating a certain ideal that we hope to reach. Therefore, as has become clear, the term "critical" or "critique" has taken on a myriad of definitions which is representative of its multifarious nature. 


\subsection{Ideology in Critical Discourse Analysis}

Language and ideology are intertwined and therefore one means of studying ideology is to study language. Thompson (1986) points out that "if language is a principle medium for the mobilization of meaning in the social world, then the study of ideology must be centrally concerned with the analysis of language" (p. 66). Wodak ( 2007) reiterates this point and argues that "language is seen as intricately connected with ideological means without being ideological per se" (p. 1). In other words, language can at times function as ideological, but it does not necessarily have to be ideological and can be used in nonideological ways as well. But why is it important to study the relationship between ideology and language one may ask? Thompson (1986) emphasizes the need to study ideology in order to see how it contributes to the sustaining of relations of domination and since one means through which ideology is mediated is language, it is important to study language. He believes that simplistic definitions of ideology as a "system of beliefs" or "political ideas" or "symbolic practices" neutralize the view that ideology throughout history has provided "a means of maintaining asymmetrical relations of power" (Thompson, 1986, p. 66). The ideological function of language is extremely important since it is through this feature that language not only indicates, describes, or reflects "social and political situations", but also acts as the "driving force directed at changing politics and society" (Wodak, 2007, p. 1). Therefore, language both affects society and politics and in turn is affected by it. Therefore, there is a close relationship between people's perceptions, opinions, ideologies and language (Weiss \& Wodak, 2003). Critical discourse analysts are therefore interested to see how language (discourse) is used ideologically and to analyse the power structure reflected in discourse. The following paragraphs briefly explore the concept of ideology and what it means for CDA.

CDA pertains to a Gramscian model of ideology (Wodak \& Meyer, 2009a, p. 8). Gramsci introduces a broader concept of ideology which he refers to as hegemony. Gramsci defines hegemony as "a practice of power that rests substantially on the consent of various strata achieved by groups possessing or seeking state power" (Noaman, 2015, p. 241). He places 
hegemony in opposition to coercive force (or dominance) which can also be used to dominate. However, Gramsci argues that in the modern world, hegemony is becoming more commonplace than coercive power (e.g. physical force or violence). The binding between the dominated group and dominating group is therefore created through "consent". This "consent" is achieved through establishing "moral, political and intellectual leadership in social life by diffusing one's own 'world view' throughout the fabric of society as a whole, thus equating one's own interests with the interest of society at large" (Eagleton, 1991, p. 116). An example of hegemony would be the commonly accepted idea among the public that women should eventually marry and bear children.

Therefore, hegemony can also be referred to as "invisible power" as it is not directly felt by the dominated group and is "disseminated through the texture of social life and thus 'naturalized' as custom, habit, spontaneous practice” (Eagleton, 1991, p. 116). The study of ideology through the study of language has occupied a privileged position as "it is primarily within language that meaning is mobilized in the interests of particular individuals and groups" (Thompson, 1984).

In CDA, ideology, contrary to what many critics of CDA propose, does not have a "positivistic" meaning (Wodak \& Meyer, 2009a, p. 8). In other words, CDA analysts accept that there are multiple realities and that a certain ideology cannot be "subjected to the process of falsification" (Wodak \& Meyer, 2009a, p. 8). Wodak and Meyer point out that the concept of ideology has been given various colours throughout human history. Nevertheless at its most basic definition ideology is defined as "a coherent and relatively stable set of beliefs or values" (Wodak \& Meyer, 2009a, p. 8). The goal of CDA analysts in relation to ideology is to denaturalize ideologies that have become naturalized. In other words, "what we assume to be background knowledge or common sense in fact are always ideological representations; that is to say, what we assume to be common everyday knowledge is in fact always the particular worldview (ideology) of a particular social group" (Pennycook, 2001, p. 81). 
CDA scholars are not really interested in explicit forms of ideology. What is of particular interest to CDA analysts is ideology which is hidden in discourse, i.e. the ideology which people who hold power in society use to paint a certain way of life as the one and only alternative, i.e., as the status quo. Fairclough (2003) defines ideologies as

representations of aspects of the world which contribute to establishing and maintaining relations of power, domination and exploitation. They may be enacted in ways of interaction (and therefore in genres) and inculcated in ways of being identities (and therefore styles). Analysis of texts...is an important aspect of ideological analysis. (p. 218)

Hence, CDA aims to show that there are alternative world views which are being suppressed or subdued by people in power as they do not serve their interest. It becomes clear from the quote that discourse is one manifestation of the ideologies and power struggles at play in society and that through analysis of such discourse one can gain knowledge and understanding of these aspects. Weiss and Wodak (2003) also touch on this point and state that "ideology is seen as an important means of establishing and maintaining unequal power relations" (p. 14). They also continue to assert that "language is not powerful on its own - it gains power by the use powerful people make of it...Therefore texts are often sites of struggle in that they show traces of differing discourses and ideologies contending and struggling for dominance" (pp. 14-15).

Van Dijk (2006) provides an introduction to some of the most prominent features of ideology. He defines ideology as having four main features. The first is that ideologies are some form of "idea" or "belief system". Secondly, ideologies do not pertain to a single individual but rather have to be "socially shared" by a group of people: in other words, "ideologies consist of social representations that define the social identity of a group, that is, its shared beliefs about its fundamental conditions and ways of existence and reproduction" (Van Dijk, 2006, p. 116). The third feature of ideologies is that they have to be "fundamental" or "axiomatic" beliefs, that is, beliefs that affect various aspects of our 
lives and "control and organize other socially shared beliefs" ( Van Dijk, 2006, p. 116). For example, one's feminist ideologies will affect how one treats or behaves towards women in general. Finally, he mentions that ideologies can be learnt and acquired and hence can also be unlearned, i.e. they are created and changed "gradually" by one's "experiences and discourses" (Van Dijk, 2006, p. 116). Therefore, according to the features outlined above, it can be summarized that ideologies are axiomatic and acquirable (and hence revisable) socially shared belief systems that affect various aspects of our lives. Consequently, CDA analysts hope that through the analysis of discourse they are able to help offer alternative perspectives which would otherwise have been unrecognized or underestimated.

\subsection{Criticism of Critical Discourse Analysis}

CDA has been criticized on various grounds. The first criticism commonly directed at CDA focuses on issues surrounding data collection and interpretation. CDA analysts are often criticized for not analysing representative texts, i.e. researchers are accused of cherry picking the data or relying too heavily on singular instances which best fit their purpose. Widdowson (1998) argues that CDA analysts read meaning into texts:

But if you know the provenance of a particular text (The Sun newspaper, for example) you will obviously, as a matter of rudimentary pragmatic fact, position yourself accordingly and be primed to find confirmation of your own prejudice. (p. 148)

Widdowson is arguing that CDA analysts have a pre-conditioned perception of what they expect to see in the data and hence focus on or pick out instances from the data which confirm their preconceptions.

Another criticism comes from Blommaert who emphasizes the importance that "framing" plays in the interpretation of discourse (Blommaert, 2001, p. 15). He argues that "even the most mundane talk can be transformed into an instance of vulgar power abuse if framed 
properly...power relations are often predefined and then confirmed by features of discourse" (Blommaert, 2001, p. 15).

Other scholars have also criticized CDA studies for drawing on limited examples from the data to support their arguments. In this respect, Breeze (2011) argues that CDA scholars only focus on a few instances from the data:

Many CDA scholars tend to prefer to concentrate on single instances or genres, rather than tracing the 'natural history' of discourses across a range of settings and texts types, which may lead to a slanted view or, at best, an incomplete picture. (2011, p. 515)

Some critical discourse analysts have accepted this criticism. The DHA variant of CDA does advocate the use of multi-methodological approaches and "triangulation" precisely to reduce such shortfalls in the analysis (Wodak \& Meyer, 2009a, p. 31). The use of a mixed analytical framework can offer a good solution to this problem. For example, in the methodology chapter of this thesis, I have outlined why I decided to adopt a corpus-assisted approach to the study of discourse prior to using a more in-depth CDA approach. The use of a corpus-assisted approach to discourse analysis reduces the chances of cherry picking (Baker \& Levon, 2015, p. 2; Wodak \& Meyer, 2009a, p. 11) as it is statistical significance which determines the entry points into the data (for more elaboration on DHA and corpusassisted approach to discourse analysis see Chapter 5).

Another criticism addressed here is from Billig in his article the language of critical discourse analysis: the case of nominalization where he raises the following question: "How can we be sure that our own use of language is not marked, even corrupted, by those ideological factors that we seek to identify in the language of others?" (Billig, 2008, p. 783). Billig argues that CDA scholars need to be critical of their own writing. Billig believes that "critical" in CDA should mean being reflective of one's self or "self-critically vigilant" as he calls it (Billig, 2008, p. 798). He argues that CDA scholars use 
nominalizations and passive structures despite advising others not to do so: "if Halliday is correct, then we do not have to nominalize processes and use passives: there are always other possible options. With effort, we can try to avoid the standard habits of academic writing" (Billig, 2008, p. 797).

He asks CDA scholars to make an effort and avoid using the common place structures of academic discourse. However, Van Dijk in responding to this criticism describes what Billig has pointed out as a "pseudo-problem"(Van Dijk, 2008, p. 821). He refers to it as a pseudo problem because he argues that in order for Billig's argument to be valid, he would need to demonstrate that CDA analysts use nominalization and passivization in order to hide agency:

For Billig's criticism to apply to CDA itself, according to the norms just formulated, he would have to show that (many or most of) the nominalizations used in CDA discourse are a form of power abuse. This would imply, for example, that by using nominalizations in their analyses, CDA scholars are hiding or mitigating the negative agency of powerful authors....That CDA itself uses nominalizations, as is the case in most academic texts, is nothing special, and would only be a problem under the conditions mentioned earlier, namely when such nominalizations are abused to protect the elites. (Van Dijk, 2008, p. 823)

In my view, Van Dijk makes a valid point. The use of nominalization or passivization per se should not be considered a problem. It is only when their use is accompanied with hidden personal interest that critical discourse analysts render it problematic and this can only become clear with in-depth contextual analysis of the discourse. In fact, CDA scholars have previously warned against over-interpretation of such syntactic features:

However, we should be careful not to over-interpret discourse data. Often passive sentences and nominalizations are used when agents are unknown, when they have just been mentioned and should not be repeated, or when the current focus is on 
other participants - such as the victims of violent actions rather than on the actors. This means that such data should never be described in isolation, but in relation to the text (co-text) as a whole and in relation to the context — who is speaking to whom, when, and with what intention. Most importantly, also theoretically, is to realize that discourse is not just to express or reproduce ideologies. People do many other things with words at the same time. (Van Dijk, 2006, p. 129)

Therefore, CDA scholars are not necessarily critical of all forms of passivization or nominalization and caution people against over interpreting.

A third criticism that has been directed at CDA is that scholars tend to overestimate the influence of linguistic form on the thoughts and perceptions of people. In the words of Widdowson, "the meanings that are constructed by linguistic analysis, then, cannot be equated with those that are constructed by language users in the discourse process" (Widdowson, 2004, p. 75). The various interpretations of a linguistic form can only really be determined through ethnographic work which focuses on reader reception. Due to the time consuming nature of ethnographic work, this is an area which has often been neglected and could receive more practical attention in CDA.

Another criticism raised by Widdowson is the claim that CDA is not genuinely interdisciplinary:

Of course it is unfair to expect scholars to make comprehensive reference to every other area of intellectual enquiry which might have possible relevance to their own, no matter how interdisciplinary they might claim to be. But critical discourse analysts, in fact, pay scant attention to any work on language other than their own. They draw their intellectual inspiration from socio-political theory and in so doing invoke the idea of interdisciplinarity. (Widdowson, 1998, p. 149) 
CDA studies do advocate and practice interdisciplinarity although with limitations as Widdowson has pointed out. The large interdisciplinary scope that CDA aspires to cover is too broad for one individual. A practical solution for this problem is extensive collaboration with scholars from other fields. It is only through collaboration, adequate funding, human resources, and time that CDA can in fact achieve this rather ambitious aim.

A fifth criticism is that there are those who want to claim scientific status for applied linguistics and therefore remove CDA from the scientific domain. In response to this, CDA practitioners argue that taking a political line is no less scientific. Thus many of these authors are "socially committed to a rationalist and scientific enterprise" (Wodak, 1996, p. 20) and, as Kress (1990) summarizes, "while their activity is politically committed, it is nonetheless properly scientific, perhaps all the more so for being aware of its own political ideological and ethical stance" (p. 85).

Finally, CDA approaches have commonly been criticized for ignoring thorough micro linguistic analysis and only focusing on random instances or the broader macro context (Widdowson 1998). The DHA which I have adopted is the most linguistically oriented and inductive approach to CDA and typically relies on data to support its claims.

Having discussed various criticism and responses by CDA practitioners, in the next section, I provide a summary of some exemplary studies which have adopted a CDA approach to conduct research into the representation of immigrants in various countries. These studies highlight current knowledge on how immigrants are represented by media institutions in various countries.

\subsection{Critical studies on immigration}

Many researchers have adopted a critical perspective on the representation of immigrants. Research conducted internationally and in Europe in particular shows a relatively stable representation of immigrants irrespective of where they come from or what ethnic group 
they belong to (Wodak \& Matouschek, 1993). Most studies related to the construction of immigrants demonstrate the macro strategy proposed by Teun Van Dijk years earlier, namely that of "positive-self and negative-other" (Rojo \& Van Dijk, 1997). In this strategy, negative characterization of the Other and positive attributes of the Self are highlighted while the positive attributes of the Other and negative attributes of the Self are mitigated or neglected. The following section reviews literature which adopts a critical perspective and stance on immigrant representation despite adopting a myriad of analytical frameworks and a colourful variety of data. In the discussion, I review literature which points to the most prominent media depictions of immigrants.

\subsubsection{Problematization}

One area of consensus among scholars is that immigrants are generally constructed as a problem and more specifically frequently depicted as being involved in crime. While some studies have pointed to nuances where the term 'migrant' appeared in more positive cotext than the term 'immigrant', more generally, the consensus is that both terms are often used in context which constructed them as the source of a problem. (Baker et al, 2008, p.288).

Del-Teso-Craviotto (2009) interestingly shows, in her study on the representation of immigrants in Spain, that there is a correlation between "crime rates" and "illegal immigration" (Del-Teso-Craviotto, 2009, p. 582). Immigrants who are perceived to be in the country illegally, are more likely to be constructed as committing crimes.

In line with this finding, Lirola (2014) also illustrates that in some cases Sub-Saharan immigrants are described as being passive and inactive. However, when they are represented as agents of actions, it is to describe immigrants as being involved in criminal activities.

Lynn \& Lea (2003) also explore the construction of criminality of asylum seekers. Their study explores racism directed at immigrants and asylum seekers in the readers' letters 
section of British newspapers. Their analysis offers an interesting insight as it focuses on the common-place opinions of members of the public rather than political figures as such. Their findings show that letters published in British newspapers tend to construct two categories of asylum seekers: "genuine" versus "bogus ones" with the latter commonly becoming associated with criminal activities. Interestingly, the "bogus" refugees are constructed as a threat to the "genuine" ones as well as the larger host country population. In cases like this, the discourse of "bogus asylum seeker" has become so "naturalized within the UK, that from an argumentative viewpoint it is perhaps no longer necessary to defend the accusation that many asylum seekers are not fleeing from oppressive and hostile conditions in their home country" (Lynn \& Lea, 2003, p. 433). An interesting aspect of this study is also the few counter-discourses which are identified and discussed at the end of their article. This indicates that despite the majority of letters that "actively encourage discriminatory practices", there were a few letters which highlight the unacceptable condition of (detention) centers where asylum seekers were kept. These letters resulted in a more sympathetic discourse of immigrants.

Another group which is frequently associated with crime is that of the Roma. Malmqvist (2015) examines the representation of this commonly misunderstood group. His research explores online discussion forums in a Swedish website called "Flashback" and explores discussions into the "problem" of the Roma who "steal", "rob", "thieve", and "beg" on Swedish streets. The analysis centers around an online forum where one participant uses satire and suggests begging could be turned into a job. However, this satirical endeavor is met with "unlaughter" (Billig, 2005) by his online peers. Eventually the participant is peer pressurized and encouraged into more "explicit" forms of discriminatory discourse. Despite the study offering interesting insight into "in-group normative order"(Malmqvist, 2015, p. 736) the title of the article "Satire, racist humour and the power of (un)laughter: On the restrained nature of Swedish online racist discourse targeting EU-migrants begging for money" is rather misleading as there is only one example of racist humour throughout the article. 
Van der Valk (2003) provides a sterling discussion of persuasive language in political discourse of parliamentary debates. This well-written article deals with argumentation theory and rhetorical strategies and provides an excellent discussion (and one could argue much needed; see Žagar, (2010) on criticism of CDA scholars' use of topoi) on the often controversial definitions of topoi, fallacies and rhetoric. A topic analysis of 40 plenary French parliamentary debates shows that immigrants are frequently discussed in the context of fraud and abuse by a politically right-wing party.

Muslims are also commonly represented as involved in crime. Richardson's study into the representation of Muslims in British newspapers has shown how discursive constructions of Muslims are in line with traditional Orientalist discourses (see Said, 1978 for more on Orientalist discourse) which portray Muslims as "barbaric" and "medieval" (Richardson, 2001, p. 151) and Muslim males in particular as people who treat women poorly (Richardson, 2001, p. 154). In his study, Richardson demonstrates how the hijab, commonly worn by Muslim women, becomes associated with a tool that villains could use when committing crimes to conceal their identities (Richardson, 2001, p. 157). Richardson provides a through exploration into the argumentation strategies adopted in the news discourse. He also provides a clear and comprehensive explanation of his (choice of) data. Despite these strengths, his interpretation of a response by a Muslim woman in one instance shows limited understanding of the concept of hijab in Islamic law.

The representation of immigrants as a problem is not limited to linguistic analyses of media. A movement away from purely linguistically serialized discourse to multimodal discourse analysis embraces the analysis of non-linguistic elements of discourse such as visual artefacts (Kress \& Van Leeuwen, 1996, 2001; Lirola, 2014; Richardson \& Wodak, 2009; Van Leeuwen \& Jaworski, 2002). Richardson and Wodak for example, aim to highlight the importance of visual discourse analysis in an attempt to reveal argumentation. While focusing on visuals from the two contexts of Austria and Britain, they show that posters displayed by right wing parties incorporate "Nazi" rhetoric both in "choice of words, and in the use of visual metaphors, insinuations, and symbols" (Richardson \& 
Wodak, 2009, pp. 56-57). In line with the dominant theme of criminalization discussed above, their visual data propagated by an Austrian right-wing party portrays immigrants as "drug dealers", "thieves", and as "dirt" which need to be cleaned off the streets of Austria (pp. 56-57). The right-wing anonymizes immigrants by referring only to their first names followed by the initial of their second name. In addition to their "foreign sounding" names, immigrants are visually depicted as hidden either behind a "balaclava" or behind a "censored rectangle". Therefore, it could be argued that the posters predicationally depict immigrants as criminals. The derogatory representation of immigrants becomes even more evident when compared with visuals which represent the right-wing political leaders of the party. These depict them not as generic figures, but as specific figures. They have "full given and family" names (unlike immigrants who are only known by their first names). Their poster is "colourful" and they are depicted as "handsome" and "smiling" while “cleansing” the streets (Richardson \& Wodak, 2009, p. 57).

Shifting away from mainly European literature, studies in the context of the United States (e.g. Galindo, 2012; Mehan, 1997; Santa Ana, 1999; Stewart, Pitts, \& Osborne, 2011) also provide interesting findings. Historically, illegal immigration has been present for centuries in the United States. However, it is only since the 1970s that the concept of illegality has really gained prominence (Ackerman, 2014). In a diachronic study of media texts, Ackerman explores the possible underlying and hidden interests of different sectors and layers of society, e.g. bureaucrats, trade unions and ethnicity-based organizations who perpetuate the concept of illegality in pursuit of personal interest.

On the other side of the northern border, the situation is quite similar. Studies of four mainstream Canadian newspapers show the representation of Chinese refugees as being problematic (Hier \& Greenberg, 2002). The problematization of Chinese refugees is achieved through repeated reference to collocational patterns such as "illegal Chinese", “illegal Asians", “illegal Aliens" (Hier \& Greenberg, 2002, pp. 498-499). The newspaper discourse in turn creates a sense of alarm among the general public and constructs Canada as a country with poor immigration and refugee policies. In other studies, the "immigrant 
body" is problematized as "disease breeder" and "health fraudster" (Reitmanova, Gustafson, \& Ahmed, 2015).

In the context of New Zealand, studies also indicate a tendency to depict immigrants as criminals (Baker \& Benson, 2008; Ross, 1994). In particular, Asians are often portrayed as one "homogenous" group. The use of the term "Asian" in essence conflates geographical, ethnical, cultural and national boundaries. Baker \& Benson (2008) illustrate how during the reporting of two incidents which involved Chinese nationals, TVNZ and TV3, prominent sources of news in New Zealand, failed "to distinguish between Asians as victims of crime as a separate category to Asians as perpetrators of crimes" (Baker \& Benson, 2008, p. 183) and lumped both in one group and referred to them using racialized terminology.

Hannis (2009) adopted a content analysis of the representation of immigrants in a New Zealand magazine called North \& South which published a very controversial news article entitled "Asian Angst" depicting Asian immigrants as contributing to rising high crime rates in New Zealand. Following investigations, information provided in the magazine was dubbed inaccurate and misleading. These (inaccurate) constructions of criminality and threat echo historically stereotypical representation of East Asians as "Yellow Peril": "the countless millions believed to be waiting to swarm down from Asia to the [then] thinly populated lands of the South Pacific" (Ross, 1994, p. 18). Figure 4.2 is an illustration printed in New Zealand Truth depicting the threat through constructing Asians as a hideous monster. Studies argue that the discourse of an Asian threat was mainly disseminated by the Pākehā who considered themselves superior (Ross, 1994). Yet, the victim in this image is depicted to be Māori wearing traditional Māori attire. This is interesting as the Māori were, in fact, themselves the victims of colonial/postcolonial racism (Ross, 1994).

Therefore, despite the initial use of this colour metaphor in reference to Chinese immigrants who arrived in New Zealand centuries ago in search of gold, studies show that it is still recycled in modern day constructions of Chinese immigrants. Negative 
representations however, are not exclusive to Chinese immigrants in New Zealand. Russian immigrants are also considered a double-edged sword in that, despite having positive impacts on New Zealand, they are also represented in negative constructions (e.g. contributing to crime) (Maydell, 2010).

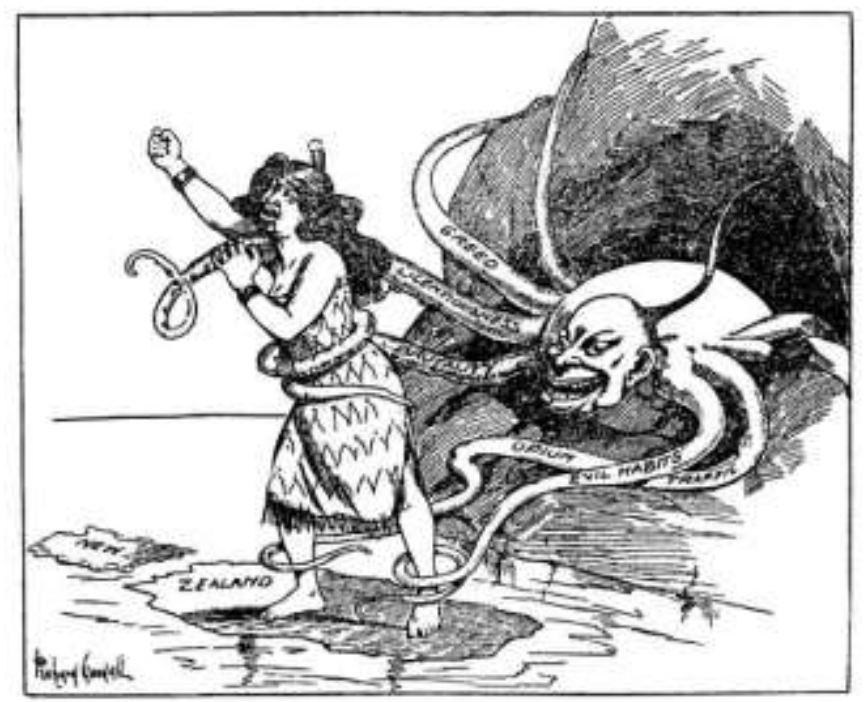

THE YELLOW PERIL.

Figure 4.2 The Yellow Peril, Published in New Zealand Truth 16 Feb 1907, Courtesy of Alexander Turnbull Library

Across the Tasman, findings on immigrant representation resonate with previous literature. Teo (2000) analysed the representation of a Vietnamese gang in two Australian newspapers. Adopting a CDA approach, Teo (clearly and effectively) shows how discursive devices are employed by the newspapers to construct " $5 T$ ", "a Vietnamese gang", as the negative Other. His analysis focuses on the lexical and syntactic compositions used in the newspaper headlines to construct the Australian police and authority as active, dominant and powerful while constructing the Vietnamese as violent and involved in criminal activities. More importantly, the study illustrates how the negative attributes of this particular gang is generalized to whole nationalities and ethnic groups. The criminal activities of a gang are generalized to wider groups, e.g. "Vietnamese", "Southeast Asians" and "Asians" (For a comprehensive review of discourse of the Other, refer to Augoustinos 
\& Every, 2007). Therefore, as is evident from the literature introduced above, there is consensus among scholars that problematization of immigrants is a core theme in the representation of immigrants.

\subsubsection{Victimization}

On the other side of the spectrum, another common finding among critical scholars is the representation of immigrants as either victims or as people who are in need of help. One study in particular, which suggests that refugees are constructed as victims, was conducted at Lancaster University under the abbreviation RASIM referring to Refugees, Asylum seekers and Migrants (Baker et al., 2008; KhosraviNik, 2008). The strength of the project lies in its "double-angled" (KhosraviNik, 2008, p. 11) characteristic. Its qualitative analysis which draws on the DHA and Van Leeuwen's (1996) Socio-Semantic Approach is further validated using a more quantitative-oriented approach to discourse, that of corpus-assisted discourse analysis. Centered around prominent world events such as the NATO invasion in Kosovo and resulting Kosovar refugees, the analysis shows that the British newspapers draw heavily on argumentation strategies (e.g. "topoi of victimization") which highlight the "helpless, desperate, powerless" (KhosraviNik, 2008, p. 16) state that refugees were in. Despite an overall tendency to depersonalize RASIM, the sympathetic construction of the refugees in the NATO invasion became apparent by referring to the refugees using proper names.

Other studies show how immigrants are described as "beneficiaries" (Rasinger, 2010, p. 1024). Shifting from prevalent research into representation in national and international media outlets, Rasinger (2010) explores the representations of immigrants from Eastern European countries in a regional newspaper in Cambridgeshire. Relying on a combination of tools and strategies of both CDA and corpus-assisted discourse analysis, actor analysis of the headlines demonstrates a tendency to position immigrants as agents of negative actions. This aside, "seven of the selected headlines represent migrants in the role of beneficiaries, and of those, three make explicit reference to migrants receiving help" (Rasinger, 2010, p. 1024). Critical corpus-assisted discourse studies on significant 
collocations in UN and British newspapers also have a tendency to construct a discourse of help towards refugees who are victims (Baker \& McEnery, 2005). Finally, in the coverage of Asians in New Zealand media, when immigrants are represented as victims, “there is tendency for victim's actual identity to be lost in the drama that surrounds the case" (Baker \& Benson, 2008, p. 192). It therefore could be argued that even when immigrants are represented as victims, personalization which could have had a sympathetic outcome is absent.

\subsubsection{Homogenization}

Homogenizing the diversity among the immigrant community members is also a feature of immigration discourse (Phillips, 2011). The homogenizing is often followed by associations with a negatively perceived action and can have disastrous effects. For example, research in immigrant representation frequently shows how immigrants and asylum seekers are collapsed into one group. This overshadows the different needs that each have: while an asylum seeker is forced to leave their country because they are likely to persecuted or because they are at risk, an immigrant chooses to leave for economic purpose, or to experience living somewhere new. Therefore, it is crucial that these two are not used interchangeably to mean the same person. Unfortunately, however, in reality, this is not always the case. Studies show asylum seekers are often lumped into the same group as illegal immigrants (Burroughs, 2015) which in turn leads to a lot of misunderstanding of their needs and rights. Elsewhere, Sudanese refugees have been portrayed as a threat: "Sudanese refugees are constituted as performing frequent category-bound asocial and violent acts because as prescribed group members, organized as part of a homogenized moral collective, they share 'race', educational deficits and pre-arrival deprivations in common" (Hanson-Easey \& Augoustinos, 2010, p. 307). Other studies which adopted critical analysis of British newspaper texts using corpus tools also indicated that British tabloids are more likely to construct refugees, asylum seekers, and immigrants as a “homogenous group" (Baker et al., 2008, p. 291). Phillips (2011), while drawing on postcolonial theories, looks at the importance of labels and names and illustrates how broad and homogenizing labels used in the Australian context to refer to "new entrants" into a 
country can be misleading and can arouse stereotypical pictures in the minds of those in the host country.

Others even criticize the use of the generalizing label "refugee" arguing that it encourages exclusive practices (Kumsa, 2006). In other words, labels such as "refugee" used to refer to a former refugee despite having gained residence in a country, can be considered a distancing strategy between the host population and the former refugee population. I share this concern but also believe that the term can work to former refugees' advantage at least during the early stages of their resettlement into a country as it foregrounds the fact that refugees will require access to different services than ordinary citizens. Yet, what is equally important is that this identity (the identification as a refugee) should not be fixed and should not overshadow the person's future.

\subsubsection{Dehumanization}

Studies show that immigrants are also dehumanized through various means. Lirola (2014), for example, argues in her visual analysis of print media in Spain that immigrants are often portrayed in "groups" and their "identities as individuals is avoided" (p. 491). "Long shots"

of immigrants and photos with immigrants avoiding eye contact with the camera mean that interaction of any kind between the viewer and the immigrants is to be avoided. When the immigrants are looking at the camera, however, it is usually in order to create pity in the viewer.

The use of statistics to refer to people is another means of dehumanizing people. McConell (2011) in her analysis of a mainstream newspaper argues that statistics are used more frequently when describing Latinos and Asians in comparison to White or Black Americans and the size or growth of the non-white population is frequently associated with negative issues. While reference to statistics is commonly perceived to be providing objective information, this study argues that the statistics are often framed or selected subjectively to convey racial and ethnic growth while ignoring the overall growth of the population. 
Other studies argue that a comparison between immigrants and a non-human entity is made which in turn leads to immigrants being perceived as non-human (KhosraviNik, 2009; Santa Ana, 1999). This is mainly achieved through metaphorical constructions, which is an international feature of discourses about immigrants and hence deserves thorough and separate discussion which can be found in the final section of this chapter.

In this section, I have provided a review of dominant depictions of immigrants in the news media and some frequent discourse strategies for achieving those depictions that the critical literature has identified. Numerous studies also show that immigrants are also frequently described as moving/arriving in large numbers which is usually achieved using conceptual metaphors (Hier \& Greenberg, 2002; KhosraviNik, 2008; Rasinger, 2010; Santa Ana, 1999; Van der Valk, 2003). This literature requires introduction hence is introduced and explored in the next section which itself is divided into two parts. The first part embarks on discussions regarding the functions of metaphors, what they are, and what role they play and why they are important conceptual tools. The second section has a narrower focus and discusses previous studies which have analysed the relationship between liquid metaphors and immigration.

\subsection{What is a metaphor?}

The study of metaphor dates back to Aristotelian era. Aristotle comments on the value of learning and using metaphors in his earliest surviving book on literary theory, Poetics:

But the greatest thing, by far, is to be a master of metaphor. It is the one thing that cannot be learnt from others; and it is also a sign of genius since a good metaphor implies an intuitive perception of similarity of dissimilars. (House, 1956, p. 121)

So according to Aristotle, it is with the help of metaphors that things which are unclear or unknown to us are made clearer. However the theory of metaphor is complex. Rhetorical theory and cognitive science demonstrate that metaphors are not just artistic and decorative 
features of language. Lakoff \& Johnson (1980) reiterate this point and state that "metaphor is not just a matter of language, that is, of mere words... on the contrary, human thought processes are largely metaphorical" (p. 6). Metaphors are "significant rhetorical tools that affect political behavior and cognition" (Beer \& Landtsheer, 2004, p. 6). Lakoff \& Johnson (1980) state that "the essence of metaphor is understanding and experiencing one kind of thing in terms of another" (their emphasis, p. 5). Cunningham-Parmeter endorses this when he states that "in attempting to comprehend new ideas, people borrow from familiar concepts" (Cunningham-Parmeter, 2011, pp. 1547-1548). Therefore it can be understood that with metaphors, two things are compared with each other to reveal similarities with the familiar concept that aid the understanding of the new concept.

Extending this definition to immigrants, Cunningham-Parmeter (2011) links the idea of unfamiliar concept to immigration and US law. According to him, in the discourse of U.S law, immigrants are commonly considered foreign and unfamiliar. Therefore, metaphors are employed in order to understand them: "if human beings comprehend foreign concepts through metaphors, then we would expect the law to employ many metaphors to describe immigrants and immigration (i.e., people and processes perceived as 'different' or 'foreign' and therefore in need of greater explanation)" (Cunningham-Parmeter, 2011, p. 1556).

However it is crucial to understand that metaphors are not precise and accurate representations of a certain reality and can often lead to misrepresentations (as well as enlightenment). Lakoff \& Johnson (1980) contend that

the very systematicity that allows us to comprehend one aspect of a concept in terms of another...will necessarily hide other aspects of the concept. In allowing us to focus on one aspect of a concept... a metaphorical concept can keep us from focusing on other aspects of the concept that are inconsistent with that metaphor. (p. 10) 
An example discussed by Cunningham-Parmeter (2011) is the metaphor "IMMIGRATION IS A FLOOD" which draws upon certain features of a flood such as its destructive force while ignoring other more positive features such as the fertile soil it leaves behind. Therefore, metaphors by drawing upon certain features and leaving out others can be misleading (Cunningham-Parmeter, 2011, p. 1556). In fact, this feature of metaphor which highlights some features of two objects, concepts, or processes, but ignores others, is vital in the act of classification and categorization. When categorizing, some features are taken into account while other possible features which would lead to a different yet equally valid categorization are disregarded. It is through this classification feature of language that "representation of experience on the basis of selective perception and selective ignoring of aspects of the world" (Goatly, 2011, p. 3) are constructed.

\subsubsection{Immigrant metaphors of numbers}

Previous research in various fields confirms the existence of metaphors referring to the size or the large numbers of immigrants: Baker et al., 2008; Baker \& McEnery, 2005; Cunningham-Parmeter, 2011; Gabrielatos \& Baker, 2008; KhosraviNik, 2009, 2010a.

According to KhosraviNik (2009) "there is an ample use of the metaphors of large quantities such as water bodies, e.g. floods, influx or 'exodus' which have been found to construct a negative representation in other studies and contexts" (p. 486). Elsewhere, with regards to Refugees and Asylum Seekers, abbreviated as RAS, he states that "a common strategy was to quantify RAS in terms of water metaphors (pour, flood, stream), which tend to dehumanize RAS, constructing them as an out-of-control, agentless, unwanted natural disaster" (KhosraviNik, 2009, p. 287).

A concept which is of central importance to my study and to the analysis of metaphors, is that of semantic prosody. Semantic prosody is "the spreading of connotational colouring beyond single word boundaries" (Partington, 1998, p. 68). Louw (2000) also defines it as 
a form of meaning which is established through the proximity of a consistent series of collocates, often characterisable as positive or negative, and whose primary function is the expression of the attitude of the speaker or writer towards some pragmatic situation. In other words, the connotational meaning of one word can be passed on to its frequent collocates. (Louw, 2000, p. 9)

Stubbs (2001) illustrates how semantic prosody functions with an example. He argues that the verb "cause" co-occurs significantly with words which are associated with unpleasant events whereas on the other hand the verb "provide" occurs with pleasant denotations. The result is that the verb "cause" acquires a negative semantic prosody whereas the verb "provide" acquires a positive one.

Linking this to the study of metaphors, Gabrielatos \& Baker (2008) discuss how liquid metaphors, e.g. flood/river/tide/wave tend to carry negative semantic prosodies and how these are passed on to words in their close proximity. Readers tend to accept these metaphors and their premise-conclusions without critically engaging with them (p. 22). Therefore with the existence of these metaphors such as flood/river/tide/wave etc. which refer to the number of immigrants, a negative aura that these phenomena carry is passed on to their collocates and hence the collocate also acquires a negative semantic prosody. In other words, if a word frequently keeps bad company, it soon becomes bad company itself.

In their corpus-based research on discourses of refugees and asylum seekers in the British newspapers Baker and McEnery (2005) show how refugees are talked about in terms of masses and liquids. These metaphors construct immigrants as straining and filling beyond capacities. Rasinger's corpus on Lithuanian immigrants' representation in local/regional print media in the UK also shows that immigrants are described via explicit watermetaphors which all represented the migrant group negatively (Rasinger, 2010, p. 1026). Finally, Wodak (2000) asserts that water metaphors are used to talk about immigrants as people who need to be contained: "Water, natural disasters like avalanches and flood 
disasters... all persuasively representing immigration or immigrants as something that has to be 'dammed"' (p. 26; see also p. 59).

As is evident from the literature described above, prior research mainly argues that immigrants are talked of in terms of alarming numbers with a focus on water metaphors which create a certain sense of fear and contribute to negative representations regarding immigrants. However, KhosraviNik (2009) also states that with regards to some UK newspapers

the use of metaphors like 'flood' and 'tide' do not seem to be working towards a negative representation of the refugees in this event and in fact they seem to argue for more humanitarian help. This indicates that the use of typical metaphors for refugees or immigrants (or perhaps any social group) does not automatically create a negative representation of them, and the function of metaphor use strictly depends on the social, cultural, political, and cognitive elements constituting the 'interpretive context'. (p. 487)

The concordance line that KhosraviNik (2010a) is using to make this argument is given in an article with the heading "The authorities and aid groups were unprepared for yesterday's influx". The extract is given below; it is taken from an article published on 29 March 1999 in The Times, a British newspaper.

The refugees were welcomed by families in Kukes, but the ever-swelling numbers could not be accommodated...Albania flooded by the rising tide of refugees. (from KhosraviNik, 2009, p. 486)

With such an inadequate context provided, it may be contestable whether the example given above is in fact using liquid metaphors to talk about immigrants positively. Nevertheless, it raises the issue that liquid metaphors, can in fact be used more positively than previously thought, as the analysis in this thesis will demonstrate. 
To conclude, the extensive review of the literature above indicates that in comparison to other countries, studies in the context of New Zealand are limited. For one thing, a large number of the studies which have looked at immigrant representation in New Zealand print media have either adopted content analysis (Loto et al., 2006; Spoonley \& Butcher, 2009), or have focused on a particular ethnic minority such as Russian (Maydell, 2010) or the Chinese diaspora (Duan, 2011). To my knowledge, studies have not focused on the broader discourse patterns and argumentation strategies used in the discourse. Moreover, studies in the context of New Zealand have not focused on the period 2007-2008. This is a crucial period as I argue in Chapter 5, as the effects of the Global Financial Crisis were starting to be felt in New Zealand.

\subsection{Summary}

The chapter above aimed to reiterate the role of the media in creating a democratic society by drawing on Habermas's concept of “public sphere". Habermas raised valid concerns about the role of mass media very early on. Considering the implications of power in today's societies, this concept, i.e. "public sphere" provides us with an ideal to work towards, namely, the creation of equilibrium where members of society can have dialogue and communicate as equals and the media plays a crucial role in achieving this ideal.

The literature discussed above also provided definitions of key notions relevant to this study, namely those of discourse and critique. For example, the discussion highlighted the dialectical feature of discourse and it is precisely this characteristic of discourse that makes it of concern for discourse analysts and in particular critical discourse analysts who are interested in researching the ways discourse is used to construct realities. Critique is also of importance in this study. In addition to the three levels of critique suggested by the DHA approach where the manipulative nature of discourse is focal, being critical in this study will refer to the researcher and their ability to distance themselves from the data when and where needed. The literature above also summarized some of the criticism directed at CDA as well as responses to these criticisms. Using Angermuller et al's (2014) notion of critique, 
that is critique of the self, this study will also aim to partially remedy the criticism directed at CDA approaches by previous scholars.

In addition, a review of critical research on immigrant representation indicates that while there has been extensive research on immigrant representation in the context of Europe and the United States, research in this area in the context of New Zealand is rather limited.

In the following chapter, I make the case that methodic triangulation is beneficial and I introduce the data and the analytical frameworks, namely corpus-assisted discourse analysis and DHA (Reisigl \& Wodak, 2009). 
"The combination of methodologies traditionally associated with CDA (DHA) and CL in research projects, and their potential theoretical and methodological cross-pollination, seem to benefit both CDA and CL". (Baker et al, 2008, p. 297)

\section{Chapter 5: Methodology}

This chapter is divided into four main sections. The first section describes the data of the study and means of data selection. The newspaper, article types and selection of period under investigation is described. This is followed by a discussion of collocation analysis which comprises the first phase of analysis of this study. Then, an argument as to why I have adopted methodic triangulation is presented. The drawbacks of Corpus Linguistics (CL) and Critical Discourse Analysis (CDA) are both outlined and hence the justification for a mixed methodology is highlighted. This is followed by a discussion of the DiscourseHistorical Approach (DHA) and an elaboration on the methods of downsizing data for further qualitative analysis.

\subsection{The data}

The data for this study consists of articles selected from the New Zealand Herald. The New Zealand Herald is a daily newspaper which is published in Auckland, New Zealand's biggest and most populated city. It is probably New Zealand's most important daily newspaper due to its large readership (see Table 5.1 for readership figures). This metropolitan newspaper is owned by NZME (see Chapter 3 for more information of ownership in the context of New Zealand) and has the largest readership among all metropolitan and regional newspapers. It is, surprisingly, the sole daily for the Auckland region which constitutes approximately 33\% of New Zealand's population (Statistics New Zealand, 2016) although it does circulate in other cities (particularly in the North Island) of New Zealand as well. Although some newspapers in countries like the United Kingdom or the United States have clear political alignments, in New Zealand there is no clear cut 
categorization (Maydell, 2010, p. 67). The New Zealand Herald follows a weekday compact format and a Saturday broadsheet format. It also has a Sunday edition.

\begin{tabular}{|l|l|l|}
\hline Year & NZ Herald (Mon-Sat) & Herald on Sunday \\
\hline 2005 & 547,000 & 332,000 \\
\hline 2006 & 568,000 & 326,000 \\
\hline 2007 & 585,000 & 345,000 \\
\hline 2008 & 583,000 & 382,000 \\
\hline 2009 & & \\
\hline 2010 & 560,000 & 371,000 \\
\hline 2011 & & 379,000 \\
\hline 2012 & 599,000 & 382,000 \\
\hline 2013 & 570,000 & 362,000 \\
\hline 2014 & 531,000 & 382,000 \\
& & \\
\hline
\end{tabular}

Table 5.1 New Zealand Herald Readership Figures (New Zealand Audit Bureau of Circulation)

Table 5.1 shows the readership figures of the New Zealand Herald and its Sunday edition over the past 10 years. The readership figures given above are based on an average figure for people aged 15 and older. As is evident from the table, the readership figures have fluctuated slightly over the last decade before decreasing after 2013. Despite this, the New Zealand Herald still has the largest readership figures among all other newspapers in New Zealand. These large readership figures highlight the importance of this daily newspaper and hence its selection as the source of data for this study. 
More importantly, Auckland has the highest number of immigrants residing in it in comparison to other cities in New Zealand. Therefore, it was expected that a large number of articles published in the New Zealand Herald would address the issue of immigration in one way or another.

In sum, I believe that an analysis of the New Zealand Herald offers interesting insights into how immigrants are represented in the print media in New Zealand. The following section outlines the article types selected for inclusion.

\subsubsection{Article types}

Newspapers consist of various types of articles. The articles were initially selected from NewzText Newspapers. NewzText Newspapers is an online Newspaper database which Victoria University of Wellington has subscribed to and includes a collection of New Zealand's daily metropolitan and provincial newspapers. The article types selected from this archive were associated with the following newspaper sections: national, international news and features (letters to the editor, editorials). While looking at the article types of the New Zealand Herald, I noticed that the topic of immigration and immigrants also appeared frequently in the Business section of the newspaper. Therefore I decided to include business articles in addition to national news, international news and features sections.

However, while collecting the articles from the New Zealand Herald for the corpus, I realized that from November 2007 onwards, the database started to use a different labelling scheme for the article types. Specifically, before November 2007, each article was explicitly labelled as news, sports, entertainment, features etc. which made it extremely convenient as I could easily choose the articles I wanted by referring to their labelling. However after November 2007, the articles were given a letter from the alphabet followed by a number (e.g. A01, J12). After contacting the New Zealand Herald for further clarification on what this new labelling meant, a rough guideline was given: the letter refers to the newspaper section and the number refers to the page. However, upon meticulous analysis of the microfilms available at the Wellington City Library and comparing them 
with the online database, it became clear that this guideline had many exceptions, e.g. sport articles were published in the business section and vice versa which meant that there was no accurate categorization of the article types in the online archive after November 2007. Categorizing the articles by myself may have resulted in errors and could easily be criticized for researcher bias. For this reason, I had to disregard my initial decision of only including articles from the national/international news, features, and business sections and decided to include all article types available on the online archive Newztext Newspapers in my corpus.

In addition to this, a decision had to be made with regards to whether syndicated articles would be included or not. Syndication offers reprint rights and permission to other parties to republish content from newspapers. This is a common process in today's print media industry and therefore needs to be addressed here. According to Bell (1991) "establishing which outlets to gather news from requires a decision in principle between receiveroriented and sender-oriented definitions" (p. 20). In other words, one has to decide whether to analyse all media content which is received by a particular group of people in a particular location or only that which is produced in that area. However, rarely does language produced in a particular place originate from just one outlet. In fact, "in most places, the majority of media content originates elsewhere" (Bell, 1991, p. 20).

Syndicated articles have been consciously selected by the editors to appear in the New Zealand Herald and hence have become part of the newspaper's discourse. Therefore, a number of syndicated articles were included in the corpus. Consequently, the articles collected for this research will not only represent views and values of people working for the New Zealand Herald, but also the values of other international media agencies such as the American Associated Press, Reuters etc. In addition, syndicated articles printed in the New Zealand Herald inevitably influence the local public's perceptions regarding immigrants in general. Therefore, I believe that these articles should be included in the analysis and will provide fruitful information on immigrant representations in New Zealand itself. 


\subsubsection{Period under study}

It has been hypothesized that at times of economic hardship in a country, immigrants are often blamed and made the scapegoat (Brimelow, 1995; Hoffman, 1974). I hypothesized that the analysis of the period before and after the domestic and Global Financial Crisis (GFC) hit New Zealand might shed light and further understanding on whether this was the case or not. Therefore, the period of interest for this research are the years 2007 and 2008. The domestic recession of the 2007/2008 summer was subsequently followed by the Global Financial Crisis whose impact was felt later in 2008. According to the New Zealand Treasury (2010)

The New Zealand economy entered recession in early 2008, before the effects of the global financial crisis set in later in the year. A drought over the 2007/08 summer led to lower production of dairy products in the first half of 2008. Domestic activity slowed sharply over 2008 as high fuel and food prices dampened domestic consumption while high interest rates and falling house prices drove a rapid decline in residential investment. (New Zealand Economic and Financial Overview, para.3)

Therefore, in this study I aimed to examine whether there was a change in how immigrants were represented in the New Zealand Herald before and after the economic recession hit New Zealand in early 2008.

\subsubsection{Search words for the corpus}

With the newspaper decided upon, it was necessary to determine which words would be used to search the online archive of the newspaper for the relevant articles. In order to do this, I conducted a trial analysis. I initially went through a large number of newspaper

articles in the database NewzText Newspapers provided by a company called the Knowledge Basket. This mini trial analysis was used to see which words kept recurring in 
articles regarding the topic of immigration and immigrants in the years 2007 and 2008. This process finally yielded a list comprising 16 words which had potential to be used as search words in the article search. The words were: immigrant, migrant, immigration, settler, Asian, Indian, foreigner, Samoan, Middle Eastern, British, Pacific Islander, European, Fijian, Latin American, African and finally Irish. Then through extensive discussions with my supervisors, these key words were narrowed down even further to just three key words which were expected to play a key role in the New Zealand context. The key words chosen ideally needed to avoid being too specific (referring to a particular nationality) as this would mean immigrants from other nationalities would be left out. Nevertheless, the search word Asian, despite being more specific than the other two search words, namely migrant $(s)$, and immigrants $(s)$, was thought to be of great importance considering the New Zealand demographics. This term needed to be included as Asians are the largest populations of immigrants in New Zealand, making up approximately 19 percent of the whole population in the year 2006. The word Asian however was excluded. Examination of the data suggested that it mainly functioned as a modifier describing the Asian economy or Asian business and rarely referred to Asian people. In other words, the majority of the articles were not discussing Asian people but were discussing economic and business matters in Asia. Although some would argue that this still could give insight to the representation of Asian people, I felt that focusing on more directly relevant material was more beneficial for the overall purpose considering the limitations in time. Therefore, the three search words (five including relevant plural forms) which are used as search words to identify the articles which comprise the dataset of this study are migrant $(s)$, immigrant (s), and Asians.

\subsubsection{Compilation of the corpora}

Two corpora were created. One for the year 2007 and another for the year 2008. The newspaper articles selected (refer above for details of the article types and the search words used to locate them) for the corpora were manually copy pasted from the Newztext Newspapers database into a .txt file. The reason for saving them in .txt format was that most concordance applications can only analyse documents which are in this format. 
During this stage, it was observed that the online archive contained duplicate articles, i.e. articles with matching headlines and contents. Articles with the same heading and exact content (duplicates) were excluded from the corpora in order to prevent the skewing of the results. Other articles which were highly similar but not identical were allowed to remain in the corpora.

Another factor which may lead to skewed results is the corpus size, i.e., it was important that both the 2007 and 2008 corpora and the articles within each were similar in size. Fortunately, in this case, both corpora were similar in size with the 2008 being just slightly larger (see appendix $\mathrm{C}$ for access to both corpora). The number of words in each corpus is given in Table 5.2.

\begin{tabular}{|l|l|}
\hline 2007 & 337,040 \\
\hline 2008 & 358,590 \\
\hline Total No. Words in Both Corpora & 695,630 \\
\hline
\end{tabular}

Table 5.2 Number of words in each corpus

A collocation analysis of both of these corpora was carried out during the first phase of analysis. The software application used for the analysis of the data, key concepts related to collocation analysis, and the criteria adopted for the selection of collocations involved in this study are elaborated in the next section.

\subsection{Corpus-Assisted Discourse Analysis (Collocation analysis)}

It is important to bear in mind that the corpus per se is nothing but a large amount of raw data. The corpus cannot provide any form of intelligence by itself. Rather it is the operations applied to the corpus by the researcher that yield meaningful results. A common way of analysing is through the use of concordance applications. The use of computer software to analyse texts, in particular, the analysis of word collocations, provides the 
researcher with great advantages such as accuracy, speed and statistical reliability. Currently there are many different applications available for the analysis of a corpus. Each have their own advantages and disadvantages and are designed to perform specific statistical analysis on the corpus. Some are quite old and only work with MS-DOS operating systems, and others are currently being developed. AntConc, developed by Laurence Anthony, is a cost free software. Video tutorials of it are also available on Youtube which makes it very easy to learn. However, the statistical measures that one can perform on the data using AntConc are more limited in comparison to Wordsmith. Wordsmith, developed by Mike Scott, although requiring purchase of license, offers more statistical variety than Antconc. However, it does take more time to learn as there are no online video tutorials available. Instead, there is a Wordsmith Google group where you can post your questions and problems to fellow researchers as well as to Mike Scott himself. For the purpose of this study, I decided to use Wordsmith. The reasons for this choice were (a) Victoria University of Wellington had already purchased licensing for this application and (b) Wordsmith has the capability to compute a variety of statistical measurements to analyse relevant collocations within the corpus.

In the following sections, I define what is meant by a concordance line and a collocate. Then I detail two statistical measures which have proved pivotal to the identification of collocations in this research.

\subsubsection{Concordance lines and collocations}

A collocation analysis of the data involves close reading of concordance lines. Concordances are a list of all the sentences within the corpus which contain a particular search word. They help the researcher to look for patterns of language use. The search word is often referred to as a node. In other words, the computer application searches the corpus for the node word and finds every single instance with the particular node word in it. Concordances usually show the immediate co-text of the search word, i.e. few words to the right of the word and a few words to the left of the word. The number of words is determined by the researcher and can vary from just a few words on each side of the node 
to a whole paragraph or even the whole article depending on the time available to analyze only the collocations. In this study, the span was set to three as it yielded a reasonable amount of data to be analyzed within the timeframe of the study. In contrast to a traditional corpus analysis, in a CADS [Corpus-Assisted Discourse Studies] analysis the use of concordances with much larger co-texts is quite common (Partington, 2010, p. 96).

A collocation can be defined as the tendency for words to co-occur. Scholars specializing in collocations define them as "the occurrence of two or more words within a short space of each other in a text"(Sinclair, 1991, p. 170). Words which occur in close proximity to the node are referred to as collocates. Collocates are also informally referred to as the company a node keeps. The renowned linguist John Rupert Firth states that "you shall know a word by the company it keeps"(Firth, 1962, p. 11). In other words, the company a word keeps has a considerable effect on its meaning. According to Stubbs (1996) "words occur in characteristic collocations, which show the associations and connotations they have, and therefore the assumptions which they embody" (p. 172). In addition, Baker (2010) believes that

collocates (words which frequently or significantly co-occur near or next to each other) can become fixed phrases that represent a packaging of information. Such phrases thus become entrenched in language use, and the information within them becomes difficult to pick apart or criticize. (pp. 127-128)

In other words, the frequent use of particular words in close proximity to the node or search word could mean that they are often taken as a fixed phrase. This frequent connectedness among the words leads to connectedness in meaning. This is what Leech (1974) refers to as a collocative meaning. Leech draws on different types of meaning, one of which is created through collocations: "collocative meanings consist of the associations a word acquires on account of the meanings of words which tend to occur in its environment" ( $p$. 17). A good example is given by Hunston (2002): 
the collocation between illegal and immigrant...suggests that this is a fixed, 'unanalyzed' phrase. The existence of such a fixed phrase might be said to lead people to accept without question that the movement from one country to another under some circumstances is reprehensible, and, further, that all immigration is illegitimate. (p. 119)

Therefore, collocation analysis is important as it provides insight into how concepts, objects, persons, and phenomenon are understood in society. The strength of a particular collocation is also of importance and can be established through statistical calculations. Two of the most commonly used statistical measures for the strength and significance of a collocation are: Mutual Information (MI) and Log-Likelihood (LL) score. These are described in the following section.

\subsubsection{Collocation significance and strength}

It is necessary to calculate certain scores for each collocation to determine that it is not random. Significant collocations are those which do not occur by chance. There are many different measures which can be calculated to show the degree of significance. The particular score that a researcher decides to choose can depend on the type of words they are interested in. According to Baker (2006)

the best technique to use, then, should be dependent on the sorts of words that the researcher is interested in obtaining - high frequency function words (rank by frequency), low frequency content words (MI, Z-score, log-log, observed/expected), or a mixture of both (MI3, log likelihood). (Baker, 2006, p. 102)

For the purpose of this study, LL was selected to measure the level of significance of the collocation. The choice of which statistical tool to use also depends highly on the range of statistical measurements that each concordancer provides. Moreover, after extensive discussion with Dr Costos Gabrielatos and Dr Ramesh Krishamurthy experts in corpus 
studies and upon considering the statistical measurements available on Wordsmith, I decided to use LL in order to measure the statistical significance of the collocations. In a nutshell, LL is measured by measuring the number of times a word (e.g. node) occurs without another word (e.g. a word within the span of the node) and comparing this with how many times the second word comes without the first word. If they frequently occur together, and are rarely apart, the two words would receive a high score and are considered significant (see Formulae under the Wordsmith Manual Tool for a full description on the formula for various measurements used to measure collocation strength).

However an additional measure, namely Mutual Information (MI), was used to measure the strength of the collocation. According to Hunston (2002)

Very generally, an MI-score indicates the strength of a collocation. It compares the actual co-occurrence of the two items with their expected co-occurrence if the words in the corpus used were to occur in a totally random order. In other words, the MI-score measures the amount of non-randomness present when two words cooccur. An MI-score of 3 or higher can be taken to be significant. (p. 71)

Mutual information is defined with a more statistical explanation as "probability of two things happening together compared with the probability of their occurring independently; it is thus a statistical measure of the degree of relatedness of two elements" (Oakes, 1998, p. 253). Hunston also elaborates on how the calculation of the MI score is established using the following variables and the formula below:

How many instances of the co-occurring words are found in the designated span of the node word (the Observed), and how many instances might be expected in that span, given the frequency of the co-occurring word in the corpus as a whole (the Expected). The MI-score is the Observed divided by the Expected, converted to a base-2 logarithm. (Hunston, 2002, p. 70) 
After having calculated the MI and LL scores for the collocation, it is necessary to determine a cut-off point or a threshold for these scores. Collocations need to have a certain level of LL in order to be considered significant. With regards to a cut off point for the loglikelihood score, certain decisions have to be made. According to the Lancaster University CL website, there are four cut-off points for the log-likelihood score: 3.84, 6.63, 10.83, 15.13 as shown below.

$95^{\text {th }}$ percentile; $5 \%$ level; $\mathrm{p}<0.05$; critical value $=3.84$

$99^{\text {th }}$ percentile; $1 \%$ level; $\mathrm{p}<0.01$; critical value $=6.63$

$99.9^{\text {th }}$ percentile; $0.1 \%$ level; $\mathrm{p}<0.001$; critical value $=10.83$

$99.99^{\text {th }}$ percentile; $0.01 \%$ level; $p<0.0001 ;$ critical value $=15.13$

The $\mathrm{P}$ value shows that probability of the collocates occurring by chance varies in each case. With a decrease in the $\mathrm{P}$ value, the cutoff point increases. In other words, the higher the cutoff point, the less likely that the collocates occur by chance. Selecting a high cut off point for the Log-Likelihood score would insure that the collocates being analysed are highly significant. Therefore a threshold of 15.13 was set for the collocation to be selected for further analysis. Therefore, only collocations which had a log likelihood score equal to or more than 15.13 were analysed.

It is usually agreed by scholars that the cut-off point for MI is $\geq 3$ meaning that if the MI score of two collocates is three or above, there is a significant relatedness between two words and this collocation needs to be analysed further (Hunston, 2002, p. 71). Therefore, for my research, I too decided that an MI $\geq 3$ would be my cut off point and only collocates which meet this requirement would be considered for further analysis. However, this is not the only condition. The following section discusses the additional criteria applied to the collocations. 


\subsubsection{Collocate types: content versus function}

The second approach to narrowing down the number of collocations for further analysis was to only consider content word collocates rather than function word collocates. Content words such as nouns, adjectives, adverbs, verbs contribute more to the creation of meaning than do function words and are therefore useful words to include for further analysis. Functions words such as definite articles and conjunctions usually have a high frequency and occur relatively often in most corpora but do not contribute to representation of any kind. This point is confirmed by Baker (2006) when he states

One of the problems with using a frequency-based technique to calculate collocates is that these high frequency words generally tend to be function words - which does not always reveal much of interest, particularly in terms of discourse. (p. 100)

Therefore for this research project, only the collocates for nouns, adjectives, and verbs were taken into consideration and other functional collocates were disregarded entirely.

\subsubsection{Sorting of collocations}

Once the collocates were filtered according to the minimum thresholds for MI \& LL and collocate types, the list of collocates for each of nodes were sorted according to the MI. The collocates at the top of the list have a higher MI score. The MI score decreases as one moves down the list. For the purpose of this study, the top 20 collocations with the highest MI score for each node word (migrant (s), immigrant(s) and Asians) were analysed

\subsubsection{Expanding concordance lines}

As each concordance line only gives limited information, which can be misleading and inaccurate at times, the concordance lines were expanded every time and the co-text (three sentences before and after each concordance sentence) was taken into consideration to ensure valid interpretations. When still vague and unsure, an even broader co-text was 
taken into account. Baker et al (2013) also confirm the importance of the broader co-text when analysing concordance lines:

while it is often easy to get the 'gist' of how a particular word phrase or collocational pair is used in context through reading concordance lines, in some cases, we require even more co-text, and the line needs to be expanded so that we can access the rest of that article. (p. 40)

The expanded co-text was used to contextualize the findings, and certain extracts from this expanded co-text are given as further contextual evidence. Therefore, the broader co-text played a fundamental role in the interpretation of the concordance lines during the first phase of my data analysis.

\subsection{Methodic triangulation}

As outlined above, this study has adopted methodic triangulation. Triangulation in research is defined by Olsen as

the mixing of data or methods so that diverse viewpoints or standpoints cast light upon a topic. The mixing of data types, known as data triangulation, is often thought to help in validating the claims that might arise from an initial pilot study. The mixing of methodologies, e.g. mixing the use of survey data with interviews, is a more profound form of triangulation. (2004, p. 3)

The use of two distinct analytical frameworks such as corpus-assisted discourse analysis as well as the DHA (Reisigl \& Wodak, 2009) is one example of methodic triangulation. The need for a methodic triangulation in this study arises from the criticism directed at each analytical framework which highlight their weaknesses. The following section, outlines the weakness of both traditional CL and CDA approaches, and illustrates how the combination of these two methods can help reduce the effect of such weaknesses and exhibit patterns unattainable through manual means of analysis and reduce researcher bias. 


\subsection{Limitations of Corpus Linguistics \& Critical Discourse Analysis}

Hardt-Mautner (2007), a pioneer in corpus-driven discourse analysis highlighted the fact that although a traditional approach to corpus analysis which draws on a large amount of data compiled into a corpus has its own merits, it also has its disadvantages. She argues that one of the main weaknesses of a purely corpus linguistic approach is that it ignores the context in which the discourse took place: "what large-scale data are not well suited for... is making direct text-by-text links between the linguistic evidence and the contextual framework it is embedded in" (p. 65). The context of any linguistic phenomenon contributes a great deal to the interpretation of its meaning. Hardt-Mautner (2007) comments on the Wordbanks Online corpus and states that it has been stripped of any contextual information which could be crucial for sociolinguists and discourse analysts when analysing the concordance lines:

For newspaper data, for example, we are given the name of the paper and the date of publication, but there is no information on which journalistic subgenre (e.g., an editorial or a news feature) each extract comes from. Also, as Wordbanks and similar corpora work with text-format only, the accompanying visuals are lost. In the "Spoken" section of the corpus, speakers' gender is identified, but that is the only demographic or situational information that is given. (Hardt-Mautner, 2007, p. 65)

Gabrielatos and Baker (2008) reiterate that purely corpus-driven studies lack comprehensive analysis of the context from which the data has been taken due to the fact that there are large amounts of data:

A traditional corpus-based analysis is not sufficient to explain or interpret the reasons why certain linguistic patterns were found (or not found). Corpus analysis does not usually take into account the social, political, historical, and cultural 
context of the data. For this reason, a multidimensional CDA analysis that also goes beyond the 'linguistic' elements of the text is instrumental ... (p. 33)

It is this social, political, historical and cultural information which will help with the interpretation of the data. O'Halloran (2009) believes that the concordance lines in a corpus-driven approach do not provide any clue to the inferences a reader may make:

Where it is often limited is in providing evidence for the kinds of inferences readers are likely to make, as a result of this exposure, in accordance with text structure (which may stretch over sentences and thus not be captured in a single concordance line). (p. 28)

For (critical) discourse analysts however, all these components of context would convey insightful meanings and representations. An enlightening point by Critical Linguistics pioneer, Roger Fowler, is that "critical interpretations require historical knowledge and sensitivity, which can be possessed by human beings, not by machines" (Fowler, 1991, p. 68). In other words, although corpus tools can help us identify a certain pattern in a particular discourse, it is the researcher who holds the historical and contextual knowledge to make interpretations. Elegantly put, Widdowson (2002) in a keynote speech notes that in CL studies "the text travels but the context does not travel with it". This means that with the compilation of a corpus, the language becomes non-authentic to a certain extent. As Widdowson points out, meaning does not reside purely in the language itself but it also resides in the minds of the people and the contextual elements surrounding the discourse.

The second reason why traditional CL has been criticized is because corpus data comprise only language data in written and spoken form. However, meaning can also be conveyed with the use of a simple photo or a gesture. Baker (2006) also points to this limitation of $\mathrm{CL}$ and argues that "the fact that discourses are communicated through means other than words indicates that a corpus-based study is likely to be limited to the verbal domain" ( $p$. 17). 
Another reason for adopting methodic triangulation is the limitations of CDA or traditional discourse analysis. One of the main criticisms directed at discourse analysis, in particular CDA, as discussed more fully in the previous chapter, is the lack of representativeness of the data analysed. In other words, CDA is commonly criticized for the fact that researcher bias may influence which data the researcher chooses for analysis, picking those data which favour his/her bias. This bias may also influence how the researcher interprets the data. One way to counterbalance the limitations outlined above, is to integrate a quantitative CL approach with a qualitative discourse analysis approach.

The methodic triangulation adopted in this study was therefore used to counter the drawbacks of both CDA and CL. Baker (2008) believes that "the combination of methodologies traditionally associated with CDA (DHA) and CL in research projects, and their potential theoretical and methodological cross-pollination, seem to benefit both CDA and CL" (p. 297). Therefore, a methodic synergy is beneficial as each approach complements the other and compensates for its inadequacies and thus finally provides more valid results. Baker et al (2008) expound that

In examining the combination of methods normally used by CDA and CL, we undertake to show that neither CDA nor CL need be subservient to the other (as the word 'assisted' in CADS [Corpus-Assisted Discourse Studies] implies), but that each contribute equally and distinctly to a methodological synergy. (p. 274)

Discussing why it is useful to use CL tools in a discourse analysis project, they note that

at the simplest level, corpus technology helps find out other examples of a phenomenon one has already noted. At the other extreme, it reveals patterns of use previously unthought of. In between, it can reinforce, refute or revise a researcher's intuition and show them why and how much their suspicions were grounded. (p. 285) 
Despite these benefits, relatively few discourse analysts have opted to implement corpus linguistic techniques to their studies in response to the criticisms received. Biber et al (1998) maintain that the amount of corpus based research in discourse analysis has been quite small. However, despite the initial gradual building of the relationship between these once separate approaches, namely CL and CDA, there is now a substantial and growing body of research in this area. According to Hardt-Mautner, CL has only recently become accepted in the field of CDA:

All in all, it has been with some time lag that critical discourse analysts have begun to appreciate the potential lying in this methodology, and there is still no consistency. Even in fairly recent, quasi-canonical works, consolidating CDA, showcasing seminal research and presenting essential toolboxes - corpus linguistics methodology does not feature predominantly. (Hardt-Mautner, 2009, p. 36)

Baker et al (2008) and the interdisciplinary team of the RASIM (Discourses of Refugee, Asylum Seekers and Immigrants) project believe that the amount of research done in the fields of CL and CDA independently outnumbers the amount of research using the integrated approach (pp. 274-275). This reflects the slow shift towards the inclusion of quantitative methods in qualitative analysis such as CDA. This point is reiterated by HardtMautner (1995) who pleads that

Finally and emphatically, I want to make the point that the approach discussed in this paper is intended to supplement, not replace, the methods normally used in CDA. Qualitative and quantitative techniques need to be combined, not played off against each other. (p. 2)

CDA scholars also acknowledge that triangulation in general (and in methodology) can help lead to increased validity in qualitative research. As early as 1988, Van Dijk 
recognized the need for an integrated approach to enhance the strengths of both quantitative and qualitative approaches. While conducting large scale research on newspaper discourse, he noted that "the combination of quantitative and qualitative analysis is the only adequate approach to the study of mass media messages..." (Van Dijk, 1988, p. 66). Wodak \& Meyer (2009a) also explain that the DHA is triangulatory in its theory and concept of context. In addition, DHA scholars encourage the use of "methodical triangulation by using multimethodical designs on the basis of a variety of empirical data as well as background information" (p. 31). In fact, in their second edition, the editors have added a whole chapter dedicated to using corpus tools for discourse analysis.

Consequently, having researchers from both the fields of CL and CDA working together on a single project is an ideal approach to research but requires "appropriate institutional structure and adequate funding" if it is to yield "in depth qualitative work on different text types" (Hardt-Mautner, 1995, p. 4).

In the section above, I aimed to present an argument in favour of methodic triangulation by presenting the strengths and weaknesses of each analytical framework. In the following section, I elaborate on the DHA. This is followed by an explanation of the techniques used to downsize the corpora for the qualitative analysis.

\subsection{Discourse-Historical Approach (DHA)}

The DHA was developed by the Vienna School of Discourse Analysis in a study which aimed at analysing how anti-Semitic discourse emerged in public discourse in the Austrian presidential campaigns in the year 1986. Since then, it has gained momentum and has been adopted and developed by scholars throughout many areas of discourse analysis research. Its linguistic tools and strategies are especially well developed for the study of discourses regarding minority groups. DHA also draws heavily on linguistic theories, in particular argumentation theories. This can be beneficial for topics such as the representation of minority groups as we can analyse texts to see what justification strategies are commonly 
used. This has led to scholarly praise from academics who regard this approach to CDA as “more developed" (Breeze, 2011, p. 494).

Some of the main principles of this approach are outlined by Reisigl and Wodak in their book chapter. It is useful to quote at length the main features outlined:

1. The approach is interdisciplinary. Interdisciplinarity involves theory, methods, methodology, research practice and practical application.

2. The approach is problem oriented.

3. Various theories and methods are combined, wherever integration leads to an adequate understanding and explanation of the research object.

4. The research incorporates fieldwork and ethnography (study from 'inside') where required for a thorough analysis and theorizing of the object under investigation.

5. The research necessarily moves recursively between theory and empirical data.

6. Numerous genres and public spaces as well as intertextual and interdiscursive relationships are studied.

7. The historical context is taken into account in interpreting texts and discourses. The historical orientation permits the reconstruction of how recontextualization functions as an important process linking texts and discourses intertextually and interdiscursively over time.

8. Categories and tools are not fixed once and for all. They must be elaborated for each analysis according to the specific problem under investigation.

9. 'Grand theories' often serve as a foundation. In the specific analysis, however, 'middle-range theories' frequently supply a better theoretical basis.

10. The application results is an important target. Results should be made available to and applied by experts and be communicated to the public. (Reisigl \& Wodak, 2009, p. 95) 
Therefore, the DHA approach can be summed up as an interdisciplinary problem-oriented approach which is often diachronic and places great emphasis on triangulation, history and context and which seeks to make its findings known to the public and to institutions in order to achieve its emancipatory aims.

\subsubsection{Context in Discourse-Historical Approach (DHA)}

In DHA, context is mainly considered to be historical. The historical aspect can be addressed in two ways. The first is through the "integration of all available information on the historical background...in which the discursive events are embedded" and the second is through exploring how "genres of discourse are subject to diachronic change" (Van Leeuwen \& Wodak, 1999, p. 91). Analysis of context is central to the DHA and is defined at four different levels. The first comprises a descriptive level whereas the other three regard intertextuality, meso and macro theories as levels of context too:

- the immediate, language or text internal co-text;

- the intertextual and interdiscursive relationship between utterances, texts, genres and discourses;

- the extralinguistic social/sociological variables and institutional frames of a specific 'context of situation' (middle-range theories);

- the broader sociopolitical and historical contexts, which the discursive practices are embedded in and related to. (Weiss \& Wodak, 2003, p. 22)

\subsubsection{Tools for Discourse-Historical Approach (DHA)}

As previously pointed out, the DHA was initially developed to deal with racial, national and ethnic issues and therefore their tools are well developed for dealing with the topic of this thesis. The DHA confirms that the most general strategy used when talking about ingroup and out-group relations is the four polarizing moves associated with the Ideology Square initially developed by Van Dijk. Van Dijk summarizes the ideology square and its moves and states that: 
The complex meta-strategy of the ideological square tells us that group members will tend to speak or write positively about their own group, and negatively about those out groups they define as opponents, competitors or enemies, if only because the Others are different. (Van Dijk, 2011, p. 397)

Therefore, in line with this overall strategy, Reisigl and Wodak identify five discursive strategies which are used to achieve this overall aim, namely, positive-Self representation and negative-Other representation. In line with the discursive strategies they have identified, they also pose five questions which a researcher can ask when conducting discourse analysis using the DHA approach. These questions are:

1. How are persons, objects, phenomena/events, processes and actions named and referred to linguistically?

2. What characteristics, qualities and features are attributed to social actors, objects, phenomena/events and processes?

3. What arguments are employed in the discourse in question?

4. From what perspective are these nominations, attributions and arguments expressed?

5. Are the respective utterances articulated overtly; are they intensified or mitigated?

(Reisigl \& Wodak, 2009, p. 93)

These five questions are pivotal questions in the analysis of the data of this thesis and have been further elaborated in Table 5.3. This table, in addition to listing the discursive strategies which may be adopted in various discourses, outlines the possible objectives and linguistic realizations of each strategy. According to Reisigl \& Wodak (2009) strategies are defined as "more or less accurate and more or less intentional plan of practices... adopted to achieve a particular social, political, psychological or linguistic aim" 
(p. 94). These strategies are achieved via discursive devices which can be identified during the analysis process

\begin{tabular}{lll}
\hline Strategy & Objectives & Devices \\
\hline Referential/nomination & $\begin{array}{l}\text { Construction of in- } \\
\text { groups and out-groups }\end{array}$ & $\begin{array}{l}\text { - membership categorization } \\
\text { - biological, naturalizing and depersonalizing } \\
\text { metaphors and metonymies }\end{array}$ \\
Predication & $\begin{array}{l}\text { Labelling social actors } \\
\text { more or less positively } \\
\text { or negatively, } \\
\text { deprecatorily or } \\
\text { appreciatively }\end{array}$ & $\begin{array}{l}\text { - stereotypical, evaluative attributions of } \\
\text { negative or positive traits }\end{array}$ \\
$\begin{array}{l}\text { Justification of positive } \\
\text { or negative attributions }\end{array}$ & $\begin{array}{l}\text { - implicit and explicit predicates } \\
\text { Argumentation }\end{array}$ & $\begin{array}{l}\text { exclusion, discrimination or preferential } \\
\text { treatment }\end{array}$ \\
$\begin{array}{l}\text { Perspectivation, framing } \\
\text { or discourse } \\
\text { representation }\end{array}$ & $\begin{array}{l}\text { Positioning speaker's } \\
\text { point of view }\end{array}$ & $\begin{array}{l}\text { reporting, description, narration or quotation } \\
\text { of (discriminatory) events and utterances }\end{array}$ \\
$\begin{array}{l}\text { Intensification, } \\
\text { mitigation }\end{array}$ & $\begin{array}{l}\text { Modifying the epistemic } \\
\text { status of a proposition }\end{array}$ & $\begin{array}{l}\text { - intensifying or mitigating the illocutionary } \\
\text { force of (discriminatory) utterances }\end{array}$ \\
\hline
\end{tabular}

Table 5.3 A selection of discursive strategies; reproduced from Reisigl and Wodak, 2009, p.94

Referential strategies are used to construct boundaries (Hart, 2010, p. 56). A broad definition of the strategy is given by Reisigl and Wodak: "strategies by which one constructs social actors: for example, ingroups and outgroups" (Reisigl \& Wodak, 2001, p. 45). Hart (2010) provides a more specific and cognitively oriented description of referential strategies and defines them as "strategies which mark membership of coalitional in-group and out-group" (p. 56) (for further elaboration on referential strategies, and their definitions and/or examples, refer to Hart, 2010, pp. 56-57; Reisigl \& Wodak, 2009, p. 94.

Predication strategies can be defined as "the very basic process and result of linguistically assigning qualities to persons..., objects, events, actions and social phenomena"(Reisigl \& Wodak, 2001, p. 46). Referential strategies are closely tied to predication strategies. In fact, "referential expressions may simultaneously realise referential and predicational 
strategies" (Hart, 2010, p. 66). For example, referring to immigrants as aliens not only indexes the referential strategy of dissimilation but could also be argued to describe immigrants as inhuman and unworldly. In other words, the noun carries "particular connotations with regard to their referents" (Hart, 2010, p. 66).

In addition to referential and predication strategies which mainly deal with how ingroup/out-groups are labelled, categorized, and described, the argumentation strategy outlined above refers to the arguments used for including or excluding a particular group. These arguments are realized by means of a variety of topoi (the plural for topos). Topos translated loosely can be described as the place where one can find arguments (Hart, 2010, p. 66). Kienpointner (1992, p. 194), written originally in German, defines topos and asserts:

Within argumentation theory, 'topoi' or 'loci' can be described as parts of arguments which belong to the obligatory, either explicit or inferable premises. They are the content-related warrants or 'conclusion rules' which connect the argument or arguments with the conclusion, the claim. As such they justify the transition from the argument or arguments to the conclusions. (as cited in Reisigl \& Wodak, 2009, p. 110)

The discourse-historical team have identified the 15 most common topoi used when arguing for and against racism. These are presented in Figure 5.1.

\begin{tabular}{llrl}
\hline 1 & Usefulness, advantage & 9 & Finances \\
2 & Uselessness, disadvantage & 10 & Reality \\
3 & Definition, name-interpretation & 11 & Numbers \\
4 & Danger and threat & 12 & Law and right \\
5 & Humanitarianism & 13 & History \\
6 & Justice & 14 & Culture \\
7 & Responsibility & 15 & Abuse \\
8 & Burdening, weighting & & \\
\hline
\end{tabular}

Figure 5.1 List of most common topoi, reproduced from Wodak, 2001, p.74 
The topos of usefulness or advantage can be defined as "if an action under a specific relevant point of view will be useful, then one should perform it" (Wodak, 2001, p. 74). For example, if in a particular discourse, the arrival of immigrants is argued to be to the benefit of the country, then the topos of usefulness or advantage is being used. Due to lack of space, I will refrain from detailing each topos listed above. However, they will be defined during the analysis stage when and where needed.

In conclusion, this study adopts the proposed methods of the DHA as its main analytical framework. The discursive strategies which I focus on and identify in the data are (a) referential strategies (how are immigrants named and categorized), (b) predication (what positive or negative attributes are immigrants associated with), (c) argumentation strategies (how is the need for immigrants or need for absence of immigrants justified), (d) perspectivization (whose points of views are being represented) and, (e) mitigation and intensification (reducing or intensifying the force of an utterance).

\subsection{Data sampling for qualitative Critical Discourse Analysis}

The corpora are ideal forms of data for the corpus assisted discourse analysis. However, conducting a qualitative CDA of each and every article in the corpus would not be possible within the timeframe of a PhD. Therefore it was necessary that a suitable number of articles from the corpora were selected for detailed qualitative analysis. Most CDA research analyses typical texts. However defining what is typical and what is not typical can be problematic and can lead to criticism of partiality (Wodak \& Meyer, 2009a, p. 23). In order to avoid criticism of "cherry picking" of the data, I used a three layer downsizing approach to sampling.

In the first layer of down-sizing, a line graph was used to help identify months where there was an increase in reference to the three search terms. The second layer of down-sizing, consisted of choosing articles which were directly relevant to the representation of immigrants. The third layer of down-sizing was to conduct a topic analysis of the data in 
order to help with proportional sampling. The layers of downsizing are illustrated in Figure 5.2 and elaborated below.

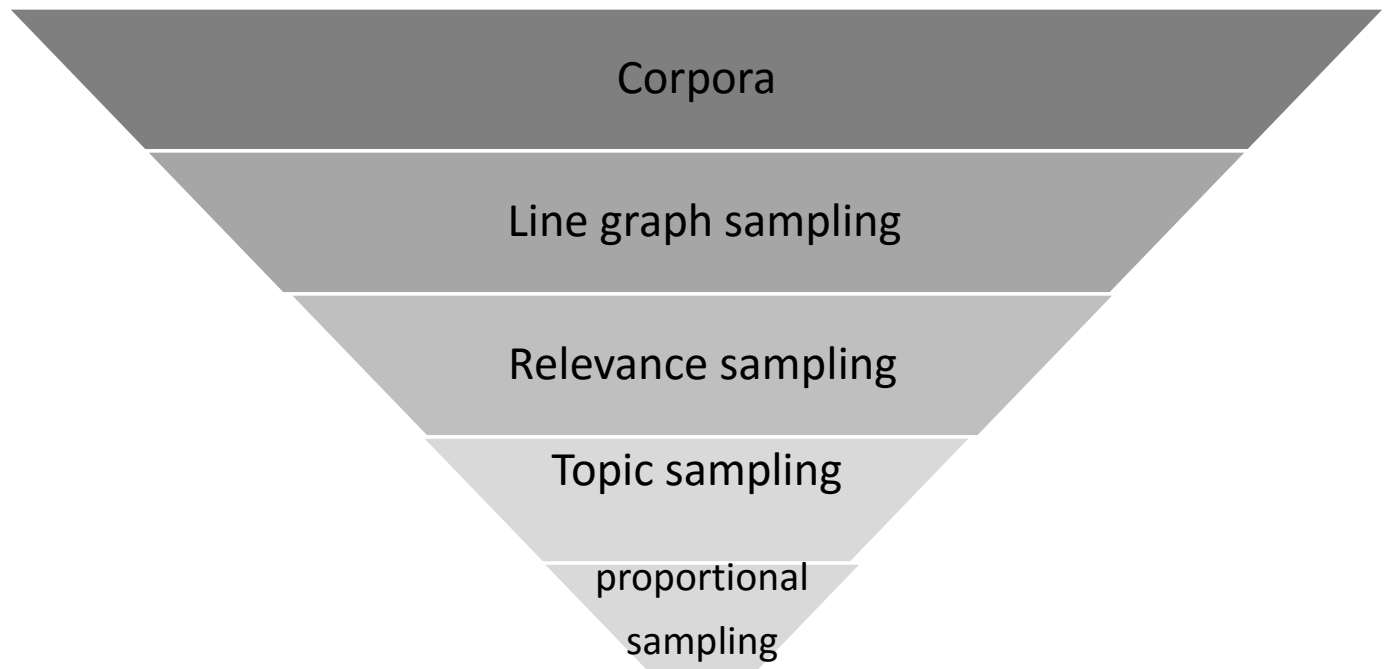

Figure 5.2 Illustration of the various stages of downsizing

\subsubsection{Down-sampling based on line graph}

The line graph approach used for downsizing the data was used in the RASIM study at Lancaster University. They devised a line graph which showed the frequency of articles on the topic of RASIM (Refugee, Asylum Seekers \& Immigrants) in British newspapers between 1996 and 2006. The peaks in this line graph showed that in particular years, there was a rise in the number of articles published regarding the topic of RASIM. These peaks tell critical discourse analysts that these periods were periods in which there was increased public debate and attention focused on the topic of refugees and asylum seekers. According to KhosraviNik (2010)

This selection of periods based on the events and the spikes on the one hand helps the CDA strand to apply a preliminary restrictive factor in down-sampling the texts and on the other hand makes the data selection sensitive to the aims of CDA 
research - in linking the linguistic analysis to socio-political context — instead of applying to purely randomized text selection. (pp. 5-6)

It is the view of this researcher, too, that a random sampling (at this preliminary stage of downsizing) would result in the elimination of those salient patterns which show the social prominence placed on the topic in particular periods which in turn is in line with the principles of CDA namely to study language in its context. Therefore a similar line graph was designed for this research. The peaks in this chart helped in the down sampling for the qualitative study of the discourse of immigrants. Figure 5.3 is a line graph which shows the total number of references to all of the search words during the period of the study.

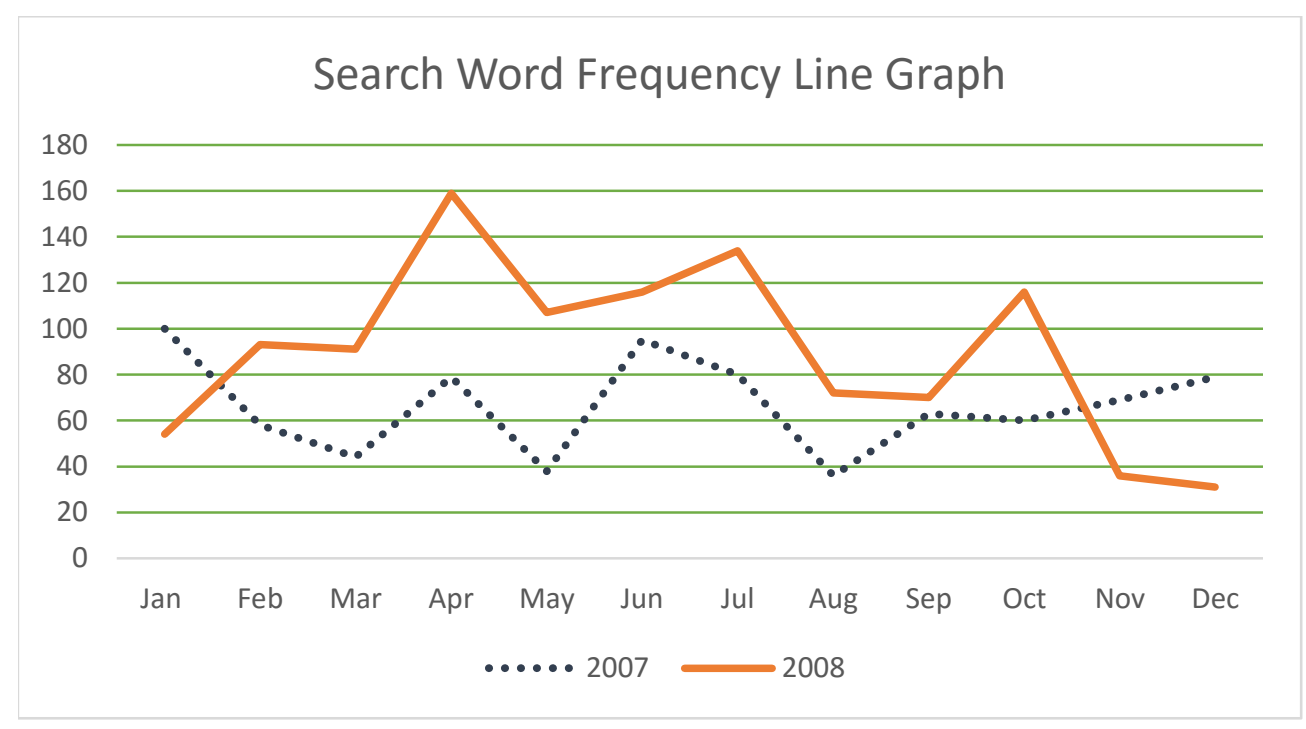

Figure 5.3 Search Word Frequency Line Graph

As is evident from this graph, there is an increase in the numbers of references to the three search words (migrant(s), immigrant(s), Asians) during certain months. This suggests that there has been an increase in interest in immigration related topics. Articles from these peak periods (January, April and June, December for 2007 and April, July, October for the year 2008) were selected for further sampling. 
5.6.2 Down-sampling based on relevance

Every article which appeared in any one of the seven peaks was manually read and categorized either as relevant or not relevant. The categorization was based on the following criteria:

a. Articles pertaining to issues regarding immigration and immigrants or Asian immigrants were selected for further qualitative analysis. The macro topic of the article needed to be about immigration or immigrants.

b. Articles about immigration/immigrants which were the cause of the apparent peaks were selected. Articles which described a particular event related to immigration or immigrants and which were the likely reason for a peak during the year.

c. Articles which referred to themes which frequently appeared during the corpus analysis stage of the study and which constituted at least an important sub-topic (if not a major topic) rather than just comprising a mention of the search words were selected.

d. Articles which were irrelevant or made an unimportant reference to the search words were excluded. In other words where the topic of immigration and immigrants was neither a macro topic nor a major sub-topic of the article. (see appendix A for a list of topics and sub-topics)

Once the articles during the peaks were sorted according to relevancy, the data was narrowed down to approximately 75 articles per year. This down sampling stage was followed by close manual reading of the articles and the headlines to determine the topic. This stage of down sampling is detailed in the next section. 


\subsubsection{Down-sampling based on topic analysis}

At this stage, a topic analysis of these selected articles was conducted to help with the proportional down sampling stage. The articles were read carefully. The topic analysis helped in identifying the key topics/themes of the newspaper debates surrounding immigration/immigrants (see appendix A for list of topics and sub-topics). Then a mini analysis was conducted to help determine the approximate number of articles which could be analysed in the time frame available. Subsequently, it was decided that a maximum of 10 articles from each year would be chosen for detailed manual CDA analysis.

\subsubsection{Proportionate down-sampling}

A proportionate sampling of the data (based on the topic analysis) was then used to identify how many articles would be chosen from each topic category. The table below outlines the topic categories in the first column, the percentage allocated to each theme in each year, which are coded under the second and fourth column, and the number of articles to be selected from each topic category in each year in the third and fifth column. For example, if the theme of election and immigration dominated $25.4 \%$ of the data in 2008, and if 10 articles were to be chosen for analysis from each year, then three (2.54 was rounded up to 3 ) of these 10 articles would be chosen from the topic category election and immigration. This would apply to all the topic categories in order to obtain a reasonably representative sample of the various topics of the data. Therefore, as per Table 5.4, 20 articles were selected (see appendix $\mathrm{C}$ for access to full data set). The 20 articles selected were analysed in detail and a record of the discursive strategies used within each were made. Of these 20 articles, a further five were chosen to be presented in this thesis. The choice of these five articles from the initial 20 was based on the fact that between them, these five articles used all the discursive strategies which had been identified within the broader 20 news articles. This means that the five offer a representative sample of the 20 and illustrate all the 
dominating perspectivization, nomination, predication, mitigation, intensification and argumentation strategies.

\begin{tabular}{|c|c|c|c|c|c|}
\hline & Topic Categories & $\%$ in 2007 & $\begin{array}{l}\text { No. of } \\
\text { article } 2007\end{array}$ & $\%$ in 2008 & $\begin{array}{l}\text { No. of } \\
\text { article } 2008\end{array}$ \\
\hline 1 & Victimization & $0 \%$ & 0 & $12.7 \%$ & $1.27 \approx 1$ \\
\hline 2 & Recruitment & $8.3 \%$ & $0.83 \approx 1$ & $5.9 \%$ & $0.59 \approx 1$ \\
\hline 3 & Racism and discrimination & $9.7 \%$ & $0.97 \approx 1$ & $18.6 \%$ & $1.86 \approx 2$ \\
\hline 4 & Migrant Statistics & $8.3 \%$ & $0.83 \approx 1$ & $2.5 \%$ & $0.25 \approx 0$ \\
\hline 5 & Loss of population & $12.5 \%$ & $1.25 \approx 1$ & $7.6 \%$ & $0.76 \approx 1$ \\
\hline 6 & Immigration/Citizenship Policies & $16.6 \%$ & $1.66 \approx 2$ & $3.3 \%$ & $0.33 \approx 0$ \\
\hline 7 & Housing in New Zealand & $16.6 \%$ & $1.66 \approx 2$ & $1.6 \%$ & $0.16 \approx 0$ \\
\hline 8 & Health/Health Funding & $1.3 \%$ & $0.13 \approx 0$ & $0.8 \%$ & $0.08 \approx 0$ \\
\hline 9 & Election & $2.7 \%$ & $0.27 \approx 0$ & $25.4 \%$ & $2.54 \approx 3$ \\
\hline 10 & Education & $2.7 \%$ & $0.27 \approx 0$ & $0 \%$ & 0 \\
\hline 11 & Culture/Diversity/Integration & $6.9 \%$ & $0.69 \approx 1$ & $5.0 \%$ & $0.50 \approx 0$ \\
\hline 12 & Crime & $12.5 \%$ & $1.25 \approx 1$ & $16.1 \%$ & $1.61 \approx 2$ \\
\hline 13 & Banking & $1.3 \%$ & $0.13 \approx 0$ & $0 \%$ & 0 \\
\hline & Total & $\approx 100 \%$ & 10 articles & $\approx 100 \%$ & 10 articles \\
\hline
\end{tabular}

Table 5.4 Proportionate sampling of data based on topic analysis (N.B Percentage may not add up to 100 due to rounding off) 


\subsection{Summary}

This study adopts a methodic synergy; it analyses the data set using corpus tools to perform a collocation analysis, as well as qualitative analysis using tools from the DHA. While the collocation analysis (Chapter 6 to follow) provides a better understanding of the company that the relevant search words keep in the newspaper discourse, the discourse-historical analysis (Chapter 7) provides a more in-depth insight into the nominalization, predication, argumentation, perspectivization, intensification and mitigation strategies adopted by the newspaper. In addition, careful consideration was given to ensure that the sampling of the data for the qualitative analysis was as systematic as possible. This methodic triangulation will ensure the findings benefit from higher validity. 
"You shall know a word by the company it keeps"

(Firth, 1962, p. 11)

\section{Chapter 6: Corpus Assisted Discourse Analysis (A Collocation Analysis)}

This chapter deals with the analysis of collocations which include the search words Asians, migrant(s), and immigrant (s). The chapter is divided into seven sections which each report on dominant discourses regarding immigrants which became clear after the analysis. These seven sections are: immigrants as numbers; immigrants as desirable; problematizing immigrants; immigrants and refugees; homogenous immigrants; integration of immigrants; and immigrants as victims. These categories emerged during the analysis and are not discussed in any particular order. Each of these seven categories is further divided into subcategories. These categories introduce and discuss the significant collocates, the collocations they form and their co-texts which all contribute to the construction of a particular category.

\subsection{Issues relating to analysis}

A collocation, defined as "above-chance frequent co-occurrence of two words within a predetermined span" (Baker et al., 2008, p. 278), is important in the analysis of representations because, as the quote by John Rupert Firth at the top of this chapter highlights, one can learn about a word or concept (in this case immigrants) by looking at the company that it keeps. Therefore, this chapter of the thesis sets out to provide insight into significant collocations which contain one of the search words. There are a few points which need to be reiterated at this point.

Firstly, only highly significant collocates, that is collocates whose Mutual Information (MI) and Log Likelihood (LL) scores exceed the thresholds (3 and 15.13 respectively) and which appear in the top 20 when ordered according to the highest MI (for a list of top 20 collocates for each node and their relevant MI and LL scores see Appendix B), are included in this 
study. This chapter provides an analysis of the top 20 collocates for each node in 2007 as well as 2008. The node and the significant collocate are bolded in the extracts to help identify which collocation pattern is being discussed.

Secondly, with the widespread distribution of news articles and columns via print syndication, that is, the offering of reprint rights and granting of permissions to other parties for republishing content, there are a number of articles within the dataset which are in fact syndications. The representation of immigrants outside New Zealand is important as these representations are circulated within the New Zealand context and hence contribute to the construction of public perceptions in New Zealand. Therefore, although some of the concordance lines are not directly related to immigrants within New Zealand, they are still relevant to this study. Wherever the concordance lines do not relate directly to immigrants in New Zealand, this is stated.

Finally, each concordance line only gives limited information, which can be misleading and inaccurate at times. For this reason, the concordance lines were expanded and the cotext (three sentences before and after each concordance sentence) was taken into consideration to ensure valid interpretations. When still vague and unsure, an even broader co-text was taken into account. Baker et al (2013) also highlight the importance of the broader co-text when analysing concordance lines:

while it is often easy to get the 'gist' of how a particular word phrase or collocational pair is used in context through reading concordance lines, in some cases, we require even more co-text, and the line needs to be expanded so that we can access the rest of that article. (p. 40)

I have argued that the collocations of a particular word play an important role in identifying the way that word or subject (in this case immigrants) is perceived. The expanded co-text of a collocation is also important. The co-text was used to contextualize the findings, and certain extracts from this expanded co-text are given as further contextual evidence. The 
broader co-text played a fundamental role in the evaluation and interpretation of the concordance lines. Therefore, where necessary the study examines the semantic prosodies (see Chapter 4 for discussion on semantic prosodies) of words by referring to a general corpus, namely, the British National Corpus (BNC).

\subsection{Immigrants as numbers}

Immigrants are frequently talked about in terms of their large numbers. In the 2007 and 2008 corpora, $63.8 \%$ and $38.4 \%$ (respectively) of collocates which refer to the number of immigrants use metaphors and $36.2 \%$ and $61.5 \%$ refer to their numbers nonmetaphorically. Table 6.1 summarizes the MI, LL and frequency of all the collocates which refer to immigrants as numbers. These collocates will be discussed at length in the following sections.

\begin{tabular}{|l|l|l|l|l|l|}
\hline Corpus year & Significant Collocate & Node & LL & MI & Freq \\
\hline 2007 & INFLOWS & (migrant) & 26.59261 & 10.57771 & 2 \\
\cline { 2 - 6 } & NUMBERS & (migrant) & 22.32734 & 6.753285 & 3 \\
\cline { 2 - 6 } & DWINDLED & (migrants) & 29.23858 & 10.53924 & 2 \\
\cline { 2 - 6 } & INFLUX & (migrants) & 32.42184 & 8.954277 & 3 \\
\cline { 2 - 6 } & INFLOW & (migrants) & 83.03323 & 8.681258 & 8 \\
\cline { 2 - 6 } & WAVES & (immigrants) & 32.18837 & 8.898424 & 3 \\
\cline { 2 - 6 } & WAVES & (immigrants) & 32.18837 & 8.898424 & 3 \\
\cline { 2 - 6 } & WAVE & (immigrants) & 17.9359 & 7.782947 & 2 \\
\cline { 2 - 6 } & INFLOW & (immigrants) & 24.38275 & 7.210368 & 3 \\
\cline { 2 - 6 } & OUTNUMBERED & (Asians) & 25.26551 & 10.20471 & 2 \\
\hline 2008 & INFLOW & (migrant) & 32.78299 & 9.160237 & 3 \\
\cline { 2 - 6 } & 4400 & (migrants) & 28.46922 & 10.26316 & 2 \\
\cline { 2 - 6 } & INFLOW & (migrants) & 77.84731 & 9.070516 & 7 \\
\cline { 2 - 6 } & INFLUX & (migrants) & 26.5181 & 7.678198 & 3 \\
\cline { 2 - 6 } & FLOOD & (immigrants) & 17.01012 & 7.449139 & 2 \\
\hline
\end{tabular}

Table 6.1 Collocates relating to immigrants as numbers 
The first subsection discusses liquid metaphors within both corpora which depict immigrants' roles in various ways, i.e. representing them in positive, ambivalent (referring both to their benefits and their drawbacks) and negative ways. The second sub-section discusses non-metaphorical collocations which discuss immigrants in terms of their numbers. The analysis provided in this section confirms the complexity involved in the representation of immigrants in the New Zealand context.

\subsubsection{Liquid metaphors}

The following concordance line contains a liquid metaphor and is an example of the positive representation of immigrants. These extracts have been labelled positive as they highlight the positive impact of immigration and mainly argue for more immigrants:

(1) The net inflow of migrants dwindled to 520 last month, a possible early signal of weaker economic growth and a more subdued housing market ahead. It was the second consecutive month in which net immigration, seasonally adjusted, was weak. In January it was 410. These figures contrast with an average monthly inflow of 1235 over the past year. (New Zealand Herald, March 21, 2007)

With regards to the first concordance line above, the reduction in the 'inflow of migrants' is associated with a sign of a 'weaker economic growth' and 'a subdued housing market' which mainly represents the arrival of fewer immigrants in New Zealand as problematic. Later the co-text refers to the number of 'migrants' entering as being 'weak', again testimony to the representation of immigrants as contributing to the economy. The next extract, in line with the first, presents the positive impact of immigration by drawing on the point of view of real estate developers.

(2) Ian Mitchell predicted an influx of migrants would spark development and said the market would pick up again. (New Zealand Herald, February 26, 2007) 
The large number of 'migrants' conveyed through the metaphorical construction 'influx of migrants' is represented positively here. This large number is also the given agent for progress in the real estate market as indicated by the use of the phrase 'spark development' and the phrasal verb 'pick up'. Therefore, the two extracts above construct immigrants as beneficial both to the economy and the real estate market in New Zealand. Other examples also construct immigrants as positive in more subtle ways. In both of the extracts below, the co-text supports the interpretation that the 'inflow of migrants' is regarded as desirable:

(3) Migrant inflow grows to a trickle: The net inflow of migrants, which had all but dried up by last December, continued to recover last month but only to less than half the long-run average rate. (New Zealand Herald, April 22, 2008)

(4) The net inflow of migrants dried up in December, providing no support for a sagging housing market and no relief for employers grappling with a scarcity of workers. (New Zealand Herald, February 05, 2008)

In extracts (3) and (4), when the number of 'migrants' decrease, the situation is described as having 'dried up'. As discussed previously, liquid metaphors can have both positive and negative effects, e.g. positive effects like soil fertilization or negative features like destruction (Cunningham-Parmeter, 2011, p. 1556). The use of the word 'dried up' indicates the writer is drawing upon the beneficial features of the natural phenomenon evoked. The use of the word 'recovery' to refer to the increase in immigrant numbers is also interesting as it creates the impression that the country was in a state of depression or crisis when fewer immigrants were arriving. Extract (4) also states that immigrants provide 'support' for the housing market and also 'relief' in terms of skills shortage. The words 'sagging' and 'grappling' suggest that the entrance of fewer number of immigrants is putting pressure on the housing market and skills shortage. This, in turn, is constructed as a problem for the employers. 
Nevertheless, some concordance lines express ambivalence towards the arrival of large numbers of immigrants to New Zealand, i.e., they simultaneously represent both the benefits and the drawbacks of this mass movement. This ambivalent representation is evident in the examples below:

(5) ANZ National Bank chief economist Cameron Bagrie expected signs of softening in housing market activity later in the year as well as an easing in house price growth. "However, easing migration represents a double-edged sword to monetary policy as it will accentuate skill shortages." The net inflow of migrants was 360 last Month. If current trends continue, a net 5000 migrants will arrive this year, well down on the average of 12,000 . The drop is likely to relieve pressure on house prices but add to a skill shortage. (New Zealand Herald, June 21, 2007)

(6) Trickle of migrants double-edged sword. The net inflow of migrants has dwindled to a trickle this year, easing pressure on the housing market but doing little to relieve labour shortages. (New Zealand Herald, June 21, 2007)

Extract (5) reports a 'drop' in the net migration. The sentences following express both the benefits and the disadvantage of these numbers: 'the drop is likely to relieve pressure on house prices but add to a skill shortage'. In both these lines, the impact of immigration is referred to as being a 'double-edged sword' thus highlighting the benefits and the drawbacks of immigration. The co-text of this concordance line indicates that immigrants make a contribution in terms of their skills to the country and that fewer immigrants will mean a very tight labour market (i.e. there are usually more vacancies than employees/workers).

Extracts (1) to (6) adopt an economic justification when arguing for more immigrants in New Zealand. The data confirms that there is a perceived economic benefit of immigration that is used to justify the presence and arrival of immigrants in New Zealand. Nevertheless, 
alongside the liquid metaphors which present immigrants positively, and as beneficial to the economy, there are cases where the New Zealand Herald represents immigration as indisputably problematic. As exemplified below, large numbers of immigrants are associated with a rise in the interest rates:

(7) Low migration 'good news': A continued weakening in the net inflow of migrants could be good news for the Reserve Bank but is unlikely to have any effect on short-term decisions about interest rates. (New Zealand Herald, April 21, 2007)

Fewer numbers of immigrants coming into New Zealand are represented positively as it will ease pressure on the 'Reserve Bank' to keep the house prices low. In fact throughout the whole corpus, when talking about the drawbacks of the arrival of immigrants in New Zealand, the main complication associated with immigrants is the rise in the housing prices.

However, an interesting characteristic of concordance lines which depict immigration as problematic is that a large number are from syndicated articles. This means they mainly address the issue of immigration in countries other than New Zealand. In other words, a large number have either been written by journalist and newspaper agencies outside of New Zealand (e.g. Observer, Reuters etc.) or are written by local reporters but discuss the topic of immigration in other countries. As mentioned earlier, the recycled articles are included in the data set because they have New Zealand readership and influence local perceptions. Extracts from these articles are discussed below.

Extract (8) offers a good example of the negative representation of immigrants outside New Zealand. It uses the liquid metaphor 'wave' to refer to the large number of immigrants. A common feature of waves is their sheer force and destructive and uncontrollable nature:

(8) She was robbed, stripped of most of her clothes and ferociously beaten in a lonely part of northern Rome, but one that was until recently considered safe and 
respectable enough for officers' married quarters. In just a few years, it has become a haunt for prostitutes and pimps, dotted with encampments set up by the latest wave of immigrants from eastern European [sic]. (New Zealand Herald, November 05, 2007)

Extract (8) collocates words like 'haunt', 'prostitutes', 'pimps', 'encampments' with 'wave of immigrants' thus already creating a negative aura surrounding the search word. Furthermore, other words in the co-text of 'wave of immigrants' with negative connotations such as 'robbed', 'stripped of her clothes', 'ferociously beaten' contribute to the representation of immigrants (particularly Romanians) within Italy as violent and aggressive. The broader co-text of the extract shows that it is these immigrants who were held responsible for a gang attack on women in Italy.

Extract (9) does not refer to immigrants within New Zealand either, but talks of Hispanic immigrants in the United States:

(9) But there is another side of the Hispanic wave - the illegal immigrants, who probably measure about 12 million. These are the "wetbacks" who cross the border from Mexico, risking their lives. These are the people whose bodies are found in the desert and who are at the bottom of America's low-wage economy. (New Zealand Herald, November 10, 2007)

The concordance line describes Hispanics as a threat through exaggeration of their numbers. The term 'Hispanic wave' constructs their movement as a large one. The size of this 'wave' is estimated to be 'about 12 million'. Further, this large group of people is linked to crime. They are described as being 'illegal' by referring to them as 'wetbacks' which is a derogatory term used by Americans to talk about non-Americans, particularly those who enter the United States illegally. This pejorative term is often used to show antiMexican sentiments towards immigrants who have entered the USA through the Rio Grande river which runs across the border. Operation Wetback was an operation launched 
in 1954 by the Immigration and Naturalization Service which was at the time in charge of inspecting people arriving at an official port of entry, detecting and deterring illegal entry (mainly from Mexico), conducting investigations of criminal and administrative violations, and naturalizing foreign born people (Astor, 2009).

The next example refers to the case of a Chinese immigrant who murdered his wife in New Zealand and fled with his daughter to Australia where he abandoned her at a station only to flee to the United States. Interpol was trying to track him down in the States. The following extract describes the whereabouts of his hiding place and refers to 'illegal immigrants' as accomplices in helping the murderer hide:

(10) She said that if he had not left Los Angeles, he would be in Monterey, where there were illegal immigrants who were good at hiding people. (New Zealand Herald, September 22, 2007)

These immigrants are not only considered 'illegal' because they reside in or enter the country without permits, but their negative status as 'illegal' is reinforced by portrayals of them as involved in criminal activities, e.g. helping a murderer hide while he is being pursued by the police. This doubly negative representation means that they are commonly talked of in a co-text of crime and lack of order. Burroughs (2015) also notes that "illegal immigrants" are "represented as dangerous people and associated with criminal activities" (p. 174). Their claimed inclination to commit crime is then used to influence and legitimize government actions such as controlling and curbing immigration through the implementation of stringent anti-immigration policies (Burroughs, 2015, p. 167).

Extract (11) depicts Chinese immigrants living in Hong Kong:

(11) With just a 30km sliver of border dividing Hong Kong from its poorer Chinese mainland, the port city has long been a haven of opportunity and stability for waves of Chinese immigrants and refugees - fleeing poverty, war and communism 
since the tumultuous 1940s up until the 1970s. (New Zealand Herald, May 26, 2007)

Extract (11) contains words like 'war' and 'fleeing poverty' which both carry negative connotations. The immigrants are represented as running away from the bad situations in their home countries. The representation of immigrants fleeing from unfavourable plights is a common theme in immigration discourse (Gabrielatos \& Baker, 2008). However a closer look at the broader co-text of the extract is revealing:

(12) Since then, more than half a million Chinese such as Lang have spilled across the border to live in Hong Kong - pushing the city's population up to almost seven million. (New Zealand Herald, May 26, 2007)

Words like 'spilled' and 'pushing' contribute to the representation of immigrants being talked about in terms of large and uncontrollable numbers. The action of spilling is usually an unplanned and undesired action. Random concordance lines from the BNC show that the word 'spilled' does have a negative discourse prosody with many of the examples using spilled in contexts of:

War and violence as in the examples below:

- Worse, the effects of the war spilled over into almost every aspect of American life, leaving bitterness and division in their wake.

- After the fighting had spilled over into Thailand, Thai forces responded with helicopter and fighter-bomber attacks against Khun Sa's soldiers.

Liquids such as blood, toxins, tears:

- At Jennetts in Bideford, north Devon, on 15 May 2,300 litres of aluminium sulphate spilled when a hose came loose from a tank.

- Divisional Fire Officer Brian Bell, who led a 25-strong team at the scene said: 'If just one tanker of acid had spilled, it could have wiped away half of North Tees.' 
Large uncontrollable crowds of people, such as in a demonstration:

- There was to be no repetition of the disaster two years previously in 1896, when a crowd in excess of 60,000 had spilled on to the pitch.

○ The workers in gold spilled out of the Goldsmiths' Bazaar and into the surrounding streets and alleyways.

(Examples from British National Corpus)

The verb is also commonly used to talk about negative thoughts coming to mind, the spreading of disease and to talk about actions which happen by accident such as the spilling of drinks etc. As is evident from examples from the BNC, 'spilled' is commonly associated with negatively loaded actions. However, there are exceptions where it is used to talk about light entering a place.

Extracts (1) to (12) underscore the relatively unique and complex ways used to talk about immigrant numbers in the New Zealand Herald. This complexity derives from the fact that (a) immigrants entering New Zealand are represented in positive, (b) ambivalent and (c) negative ways. The analysis also points to a more negative representation of immigrants in other countries than those in/entering New Zealand. That is, the majority of the concordance lines which depict immigrants in explicitly negative ways refer to immigrants in countries other than New Zealand.

\subsubsection{Non-metaphorical references}

The same ambivalence in the representation is also evident in non-metaphorical collocates which refer to the numbers of immigrants. In other words, there are both references to the positive effects of immigrant numbers and to their drawbacks.

An interesting example is the use of the collocate 'outnumbered' $(10.2,25.2)$ in proximity to the node Asians. This collocate has the highest MI score with the node Asians which shows that there is a very strong link between these two words. In both the concordance lines below, a comparison is drawn between the number of Asians and other groups: 
(13) The figures for Auckland are even more staggering. One in four people are Asian and for the first time since the census began, Asians have outnumbered Pacific people in the Auckland region. (New Zealand Herald, January 1, 2007)

(14) An estimated 20,000 Asians outnumbered less than one-fifth of that number of Europeans on a day that was quite bizarre. (New Zealand Herald, February 19, 2007)

The term 'outnumber' is commonly used in specific contexts. A look at BNC shows that it is commonly used in context of war, conflict, rivalry and comparison of (the features of) binary opposites. Following, are examples from the BNC:

o THE 120,000-strong GDR army, alone among the Warsaw Pact armies, is under the direct operational control of the Soviet forces stationed alongside them, who outnumber them by about three to one.

- Sergeants and corporals outnumber private soldiers.

- It is girls who tend to stay at school longer and in the secondary cycle outnumber boys (making up 52 per cent of total enrolment in 1985).

- Although male offenders still heavily outnumber female offenders, these changes have led to an alteration in the male-female ratio for crime and delinquency.

- Women outnumber men by three to one in residential care.

$\bigcirc$ Yet in the long run, diet failures vastly outnumber the successes.

(Examples from the British National Corpus)

The use of 'outnumbered' in close proximity to the node 'Asians' as in extracts (13) and (14), places Asians in the position of a rival or enemy and constructs them not only as standing in opposition to other nationalities or ethnic groups but as a threat of some sort. In addition, the co-text shows that the number of Asians in Auckland is referred to as being 
'staggering' and 'bizarre' which commonly carry the negativity associated with shocking when compared with its more positive synonym surprising.

On a more positive note, extract (15) suggests immigrants are an asset. It uses specific numbers to refer to fewer immigrants coming into New Zealand:

(15) Immigration has also fallen to its lowest level in nearly seven years. In the year to September, the country gained only $\mathbf{4 4 0 0}$ migrants down from 8300 last year. (New Zealand Herald, October 23, 2008)

The words 'gained', 'only', 'fall', and 'lowest' all contribute to this decrease in immigrant numbers being represented as something to be deplored. The verb gain is commonly used to refer to achieving something positive and beneficial, e.g. gain employment opportunities, gain experience, gain support etc. A look into a broader corpus such as the BNC also suggests that gain has a positive discourse prosody with the majority of the collocates of 'gained' expressing a positive attitude. A few of the phrases from the 50 random hits given out by the BNC which contain the word 'gained' are given here:

the enjoyment gained - gained access - gained in sharpness (in contrast to vanishing) - the advantage gained - entry was gained - value can be gained - gained confidence - benefit to be gained - experience gained - gained encouragement... (Examples from British National Corpus)

Examining the collocates of the verb 'gained', it becomes clear that it has acquired a positive discourse prosody because the verb is typically followed by words and phrases with positive connotations. Stubbs (2001) states that "discourse prosodies express speaker attitude" (p. 65) and in this case the use of 'only' which specifies restriction, next to 'gained' suggests the writer's regret concerning the very few and limited number of immigrants coming into the country. 
The analysis suggests that throughout both corpora, immigrants are represented in ambiguous ways. Some concordance lines talk about how large numbers of immigrants are beneficial to the New Zealand economy as they fill the skills shortages. On the other hand, immigrants are represented as problematic because they cause an inflation in house prices within New Zealand. This variable representation is characteristic of concordance lines from both 2007 and 2008 .

However, there does seem to be a more consistently negative and unfavourable representation of immigrants arriving into countries other than New Zealand. This is achieved through the association of immigrants with criminal activities, talking about them mainly in contexts of conflict, and the collocation of the nodes in co-texts with negatively loaded lexical items.

\section{3 Immigrants as desirable}

A closer look at certain collocations shows that there is a tendency to view immigrants positively mainly for the contributions they make to a country, particularly the economy of a country. The data shows that they are represented as being conducive to a stronger economy through two means: a) by providing their skills and helping reduce the skills shortage and b) by bringing capital into the country and investing within New Zealand. These two categories, and the collocations associated with each are discussed below.

\subsubsection{Skilled}

As evident from Table 6.2, the collocate 'skilled' is the most significant collocate in the study as not only does it occur frequently, but also holds high MI and LL scores. It has occurred 29 and 15 times in the 2007 and 2008 corpora respectively. The high frequency of occurrence of this collocate in comparison to other collocates along with the high MI and LL scores point to the fact that these are not random collocations but that they are statistically significant. 


\begin{tabular}{|l|l|l|l|l|l|}
\hline Corpus year & Collocate & Node & LL & MI & Freq \\
\hline 2007 & SKILLED & (migrant) & 150.7026 & 8.495919 & 15 \\
\cline { 2 - 6 } & INVESTOR & (migrants) & 85.84672 & 8.895384 & 8 \\
\cline { 2 - 6 } & TARGETING & (migrants) & 20.86947 & 8.731885 & 2 \\
\cline { 2 - 6 } & MILLIONAIRE & (migrants) & 20.24922 & 8.53924 & 2 \\
\cline { 2 - 6 } & ATTRACT & (migrants) & 80.64593 & 8.494845 & 8 \\
\cline { 2 - 6 } & TARGETS & (migrants) & 19.7132 & 8.369314 & 2 \\
\cline { 2 - 6 } & WEALTHY & (migrants) & 45.80536 & 7.906971 & 5 \\
\cline { 2 - 6 } & QUALIFIED & (migrants) & 25.81404 & 7.539239 & 3 \\
\cline { 2 - 6 } & SKILLED & (immigrants) & 116.3155 & 7.302057 & 14 \\
\cline { 2 - 6 } & WEALTHY & (Asians) & 28.32333 & 8.157406 & 3 \\
\hline \multirow{5}{*}{2008} & SKILLED & (migrant) & 70.85201 & 8.60127 & 7 \\
\cline { 2 - 6 } & SKILLED & (migrants) & 68.49545 & 7.481802 & 8 \\
\cline { 2 - 6 } & TARGET & (migrants) & 25.51826 & 7.455806 & 3 \\
\cline { 2 - 6 } & QUALIFIED & (immigrants) & 22.99432 & 6.87656 & 3 \\
\hline
\end{tabular}

Table 6.2 Collocates referring to immigrants as desirable

Therefore the data shows that there is a tendency for the news discourse to describe immigrants in terms of the skills they possess. The news discourse depicts 'skilled migrants' not only as people who are desirable but also as people who are sought after. The following concordance lines show the collocation 'skilled migrants' in its co-text:

(16) New Zealand is not looking too far afield in its latest push to attract skilled migrants, with a campaign launched yesterday to lure expats and Australians across the Tasman. (New Zealand Herald, March 12, 2007)

Extract (16) mentions the launch of a campaign to 'attract' or 'lure' skilled migrants and expats from Australia into New Zealand. The metaphor 'lure' is commonly used in the context of wild animals who try to 'lure' their prey towards them. The use of this verb to talk about people suggests 'skilled migrants' are crucial and indispensable to New Zealand 
society and economy just as a prey is necessary for the survival of the predator. In addition, it suggests a certain level of resistance on behalf of the immigrants being invited to come to New Zealand, possibly because they perceive that there are more opportunities in some other countries.

The dependence of New Zealand on 'skilled immigrants' is further constructed in concordance lines which refer to the process of attracting immigrants as a 'competition'. The next concordance line is from a column entitled ' $\mathrm{NZ}$ loser in international race for skilled migrants' which compares the ways Singaporean employers treat prospective employees with those of New Zealand:

(17) This move would pose a challenge to New Zealand in the face of competition for skilled immigrants, Minister for Immigration David Cunliffe said last week. (New Zealand Herald, June 11, 2007)

In extract (17), Lincoln Tan who himself is a Singaporean immigrant working as a columnist for the New Zealand Herald criticizes New Zealand employers for only considering Kiwi work experience as relevant. In addition to depicting immigrants as desirable because they have skills, this extract depicts them as desirable by representing them as eagerly sought after. The newspaper discourse constructs immigrants as objects of a 'competition'. The broader co-text of the concordance lines points to an 'international race' where various countries are battling to attract 'skilled immigrants'. The discourse of competition for 'skilled migrants' is also prevalent in the 2008 corpus:

(18) As global competition for skilled migrants heated up it was important for New Zealand to have systems in place to attract "the people we want and need". "Skill shortages are a concern and if left unchecked, this shortage can threaten economic growth. Immigration is a vital ingredient in New Zealand's ongoing economic development. Migrants drive innovation, give our businesses 
international connections, and provide a range of skills to transform our economic landscape". (New Zealand Herald, July 24, 2008)

In extract (18), immigrants are constructed as desirable for a number of reasons. First of all they have skills. But more importantly, they are needed and wanted in New Zealand, e.g. 'the people we want and need' as they fill 'skills shortages'. Without 'skilled migrants' New Zealand is constructed as being in danger, e.g. 'threaten economic growth'. A situation with fewer 'skilled migrants' is described as a threat to the New Zealand economy. These 'skilled migrants' help to compensate for the brain/skill drain that New Zealand faces with so many New Zealanders leaving the country.

(19) Sutton urges other export businesses not to be afraid of using New Zealand as a brand. "We have an excellent reputation worldwide for innovation and creativity. You have to be different to be competitive in the world market". He believes another strength of the company is its multi-cultural employee mix. "We speak Russian, German, French, Mandarin and Cantonese in the office". Skilled migrant employees "add a whole new dimension" to business. Richard Manthel, managing director of Robert Walters recruitment, agrees there is some exceptional talent around "and if you can't find it in New Zealand you should be looking offshore- it's not a massive barrier". (New Zealand Herald, July 13, 2008)

In extract (19) 'skilled migrants' from various countries are represented as having characteristics which local employees may not have. 'Innovation' and 'creativity' is said to be the corollary of diversity in the workplace. The main focus of the article containing extract (19) is about successful businesses during a time of economic recession and it once again becomes clear that 'innovation' and 'creativity' in the workplace are valuable for the economic profits they bring the company.

It could be argued the discourse of need for 'skilled migrants' which is prevalent in the newspaper discourse is a recontextualization of the Labour Government's globalization 
discourse of the time. From 1999-2008 the coalition-led Labour Government appropriated a discourse of globalization where globalization was depicted as the only way forward (Skilling, 2011). Skilling contends that the Labour Party managed this by conceiving New Zealand as one homogenous nation with a common interest while "celebrating" internal diversity within this "collective identity" (p. 79):

Ethnic diversity was acknowledged within the representation of national identity and of a national purpose, but it was addressed in terms of its instrumental rather than its intrinsic value. That is to say, minority ethnic groups were addressed as means to a national end rather than as important in themselves. (p. 81)

Skilling points to an important idea, namely that of "instrumental" versus "intrinsic value". The discourse of competition for skilled immigrants also resonates with this point that immigrants, despite being represented positively (i.e. desired), are required only to serve an economic purpose, namely to enable the country to benefit (economically) from cultural diversity as demanded by the global economy. In other words, immigrants are needed for the sake of national interest and not for their own sakes. I have attempted to illustrate the reliance on economic justifications for bringing in skilled immigrants.

\subsubsection{Investor, millionaire, wealthy}

The second most dominant discourse as to why immigrants are desirable is because they bring capital to the country and invest. This discourse is highlighted by the collocates 'investor', 'millionaire' and 'wealthy'. The importance of 'investor' and 'wealthy' immigrants is also made clear by governmental initiatives. For example, in a cabinet paper David Cunliffe, the immigration minister in 2007, proposes a new Active Investor Migrant policy that "can make a critical contribution to New Zealand's economic transformation through both their human and financial capital contribution" (Cunliffe, n.d, p. 2). Elsewhere he states "investor migrants are highly sought after internationally and competition for them is fierce" (Cunliffe, n.d, p. 2). Finally, with regards to the 2005 policy, the minister says "the current policy is, however, not delivering adequately for New 
Zealand" (Cunliffe, n.d, p. 3). Discussions surrounding the desirability of 'wealthy' and 'investor' immigrants and the barriers that they have to face due to bad immigration policies is a focal point in the newspaper discourse, and concordance lines containing the collocates 'millionaire', 'wealthy' and 'investor' highlight the problems surrounding immigration policies. There are eight references to the collocation 'investor migrants'. The MI and LL scores for this collocation in the 2007 corpus are 8.8, 85.8 respectively. The MI and LL scores show the collocation is highly significant and that the strength between the node and the collocate is strong.

(20) Mr Walsh, an adviser who specialises in business and investor migrants, said the new policy did remove many of the flaws of the existing policy by allowing investors to make a commercial return on the money, rather than handing it over to the Government. (New Zealand Herald, June 7, 2007)

Extract (20), and extracts (21) and (22) which are from its broader co-text, either highlight the benefits of the new and more lenient policy for 'investor migrants' or the drawbacks of the old and strict policy. The old policy, which resulted in fewer 'investor migrants' entering the country, is described as having many 'flaws'. The new policy on the other hand compensates these flaws. The broader co-text of extract (20) quotes Bernard Walsh, the chairman for the Association of Migration and Investment and Lockwood Smith who was the National immigration spokesman:

(21) Association for Migration and Investment chairman Bernard Walsh said immigration policy alone would not result in a flood of millionaires. "We are competing against many other economies for investors, and without more harmonisation between immigration and taxation laws and general investment policies, I don't think this will be enough to attract the kind of investor we are hoping to get."(New Zealand Herald, June 7, 2007) 
(22) National immigration spokesman Lockwood Smith said Labour was mopping up the mess it had made with its initial 2005 policy but the new policy was a step in the right direction. (New Zealand Herald, June 7, 2007)

In extract (21) Bernard Walsh refers to New Zealand being in a competition for investors and reiterates the importance of having investor friendly immigration policies if New Zealand is to become successful in this global competition. In extract (22) new policies with more relaxed criteria which will encourage more 'investor migrants' to enter New Zealand are regarded as a 'step in the right direction' by the national representative and previous policies with tighter prerequisites are labelled as a 'mess'.

In addition to 'investor migrants', 'millionaire migrants' are also described in the terms of the capital gain they can provide New Zealand. In extract (23), the newspaper discourse describes 'millionaire migrants' who get certain privileges during their immigration application, e.g. 'first dibs on places', 'fast tracking of their application' for the contributions they make to the economy. The lines following the concordance lines use economic development to justify why these immigrants have such privileges:

(23) NZ on hunt for more millionaires: A Government bid to attract more millionaire migrants gives the richest first dibs on places, fast tracks their applications and removes most of the obstacles other aspiring residents face. In return, the millionaires have to actively invest a portion of their money by buying into or setting up local businesses to boost employment and the economy. (New Zealand Herald, June 7, 2007)

The headline of the article for this concordance line makes interesting use of an animal metaphor 'hunt'. The verb 'hunt' is commonly used to refer to animals and here it creates a sense of immigrants being portrayed as prey to be caught and manipulated and utilized for the benefits they bring to New Zealand. Therefore, similar to extract (16), the use of animal metaphors to describe skilled and wealthy immigrants constructs New Zealand as 
desperately in need of immigrants and, as a consequence, immigrants as highly sought after and needed beings.

However, even though the majority of the concordance lines with this collocate represent wealthy immigrants positively, there are instances within the corpora where 'wealthy migrants' are constructed as a threat:

(24) Wealthy migrants from China, Taiwan and Korea were particularly active, hunting for those opportunities, he said. (New Zealand Herald, June 23, 2007)

(25) Speculators are hunting Auckland's urban fringes for land banking deals. Like bounty-hunters riding the boundaries, groups of millionaires and wealthy migrants are looking to lock away land on the city's rural outskirts for big gains. (New Zealand Herald, June 23, 2007)

Extracts (24) and (25) are both from the same article and construct 'wealthy migrants' as a threat to local New Zealanders as they buy land and property. They discuss 'wealthy migrants' from different Asian countries wanting to 'hunt' land on Auckland's urban fringes in order to make 'big' profits. 'Wealthy migrants' are likened to 'bounty-hunters' who are on the prowl waiting to profit from buying land. The use of the adjective 'active' creates a sense of proximity of threat. The threat is furthered evoked in the co-text of these extracts. The following are from the co-text which draw upon concepts commonly associated with hunting:

(26) But the ARC's submission counterattacked, hitting out at those wanting Auckland to sprawl into rural-zoned areas. (New Zealand Herald, June 23, 2007)

(27) The city had more than enough urban land and sensitive rural and coastal areas must be protected, it said. (New Zealand Herald, June 23, 2007) 
The words 'hunt', 'protect' and 'hit' in the surrounding co-text constructs these immigrants as wanting to 'attack' and the Auckland Regional Council (ARC) needing to protect its fragile and 'sensitive' lands. These metaphorical references, which create a negative representation of wealthy immigrants as people who are only here to achieve monetary gains, are rare.

Therefore, as is evident from the concordance lines above, collocates like 'wealthy', 'millionaire', and 'investor', are used to construct immigrants as desirable because they bring wealth to New Zealand. Animal metaphors are used to construct wealthy immigrants as indispensable to New Zealand's future economic growth. When represented positively, they are likened to the prey which need to be hunted down and 'lured' into the country. Therefore, there seems to be a certain utilitarian discourse of immigrants where immigrants are perceived to be desirable as long as they are contributing to the economy in some way. In constructing immigrants as solely useful for economic benefits, the newspaper adopts a neoliberal discourse. This representation contributes to the public's perception of immigrants as people who are here solely to be used and benefited from financially. Nevertheless, these representations are perceived as a positive way of representing immigrants when compared with representing immigrants as a burden (Van Dijk, 2000, p. 494), i.e. who just take advantage of the facilities, services and resources of country and hence create pressure on the economy of the country without contributing anything in return.

\subsubsection{Qualified}

Immigrants are also constructed as desirable because they are 'qualified'. The collocate 'qualified' occurs three times in the 2007 corpus with the node migrants. The MI and LL scores for this collocation in the 2007 corpus are 7.5 and 25.8 respectively. The collocate 'qualified' also occurred five times in 2008 with two nodes. It appeared with 'migrant' with MI and LL scores of 7.7 and 17.5. It also collocated with 'immigrants' with MI and LL scores of 6.8 and 22.9 respectively. The newspaper constructs immigrants as qualified but unemployed or in jobs which do not match their areas of expertise. Rigid and 
impractical immigration policies are also criticized here. In doing so, the newspaper constructs a sympathetic discourse of underemployed immigrants and gives voice to those who blame bad immigration policies. Extract (28) is a good example where 'highly qualified migrants' are said to be settling for lower status jobs where their skills and qualifications are not needed due to restrictions on their visas. The six-month work-toresidence visa allowed skilled immigrants to come to New Zealand to work. However, most immigrants complained that the six months allowed was not sufficient time to find a job. In addition, a large number of employers were hesitant to offer a job to somebody who was on such a short visa.

(28) It adds: "It is also common for highly qualified migrants to accept more junior positions than they held at home. Disappointing as this may be, it does provide new migrants with the New Zealand work experience most employers demand". (New Zealand Herald, January 5, 2007)

The viewpoints of the immigrants are provided in the co-text where they voice their concerns and criticize the immigration policies which have led to their 'dilemma':

(29) Another visa holder, Melinda (not her real name), said in exasperation: "This is now my dilemma. How can I get my permanent residence status if I will not be able to work in a related job where I do not stand a chance [of getting employed]?" (New Zealand Herald, January 5, 2007)

The newspaper sympathizes with the plight of the immigrants too: 'It is unfair, if not absurd, for Immigration NZ to have issued the six-month work-to-residence policy'. The discourse indicates sympathy towards qualified immigrants who are victims of immigration policies which have been inadequately thought through. Concordance lines with 'qualified migrants' as the significant collocate highlight the fact that immigrants are qualified yet do not get appropriate employment and therefore become disadvantaged due to New Zealand immigration policies. In addition, the newspaper discourse shows awareness of the 
discrimination that immigrants face. Although it does not go into detail, it nevertheless draws on immigrants' own experience. Examples such as extract (30) refer to discrimination against immigrants with the necessary set of skills within the New Zealand context:

(30) What happens, she asks, when two equally qualified migrant women, one an ethnic minority, the other of European descent, start job hunting? "The chances of the person who is not an ethnic minority are better, primarily because of their dominant ethnicity.” (New Zealand Herald, May 10, 2008)

By giving voice to immigrants, the newspaper discourse is able to describe the problems they are facing; they are qualified but are faced with discrimination.

\subsubsection{Attract and target}

The construction of immigrants as a necessity is also implied through the newspaper's choice of verbs. The verbs 'attract' and 'target' are also given as important collocates for the node migrants in 2007. 'Attract' $(8.4,80.6)$ and 'targets' $(8.3,19.7)$ occur eight and two times in 3L-3R horizon respectively. Of these eight concordance lines, seven of them construct wealthy and investor immigrants as being necessary for the country. These verbs also occur two times each in their progressive forms as significant collocates, e.g. 'attracting' $(7.3,16.7)$ and 'targeting' $(8.7,20.8)$ :

(31) The campaign, dubbed New Zealand Now, is taking a dollar each way. A joint Department of Labour/Tourism New Zealand promotion, it is targeting potential migrants and holidaymakers. (New Zealand Herald, March 12, 2007)

Despite having lower frequencies, the collocates 'target' $(7.4,25.5)$ and 'attracted' $(6.9$, 23.2) have also occurred in the 2008 corpus. Surprisingly, they seem to function differently here and are used to highlight the negative stance towards immigrants. In the 2008 corpus, immigrants are mainly targets of criticism and it is the immigrants who are attracted to 
New Zealand rather than the New Zealand government making attempts to attract immigrants into the country. The following extracts are from the 2008 corpus:

(32) Mr Peters popped up in Nelson demanding migrant numbers be cut. The prompt was the grim economic outlook and forecasts of job losses, and the target was migrants. (New Zealand Herald, October 20, 2008)

(33) NZ First leader Winston Peters has predictably played the immigration card, saying numbers should be cut to protect Kiwi jobs during tough economic times. Mr Peters used a campaign speech in Nelson to say "when times are tough internationally immigrants are attracted to New Zealand like moths to a neon light”. (New Zealand Herald, October 17, 2008)

Therefore, there appears to be a difference in how these collocates are used in the two corpora. The 2007 corpus highlights the importance of immigrants for the economy and for filling skill shortages whereas the 2008 corpus uses these collocates to draw attention to the fact that immigrants are contributing to the loss of jobs.

To sum up, considering all collocations which contribute to the representation of immigrants in positive and desirable ways, it could be argued that, according to the New Zealand Herald, there is a strong willingness to attract capital and skills (i.e. immigrants with capital and desired skills) into the country. Animal metaphors are used in counterintuitive ways in the majority of the concordance lines. Through the use of metaphorical language, the newspaper is constructing immigrants as prey that need to be enticed and coaxed into coming to New Zealand.

Therefore, a key theme within both corpora is talking about immigrants in New Zealand with regards to the financial contributions they bring either through direct capital investment or through their skills and qualifications. It must be highlighted that the theme of immigrants as economic resources is not created solely through the appearance of highly 
salient terms like 'skilled migrants' or 'qualified migrants' and certain words, metaphorical structures and phrases (e.g. 'make use of') in the co-texts. This discourse also becomes more visible by reason of the fact that there are very few instances of immigrants being described in terms of their non-economic benefits, such as examples which emphasize the cultural richness that they bring.

Furthermore, there does seem to be a more positive representation in the 2007 corpus in comparison to the 2008. This becomes apparent with the higher frequency of the modifier 'skilled' and with the use of 'investor', 'millionaire' and 'wealthy' to refer to immigrants in 2007. In addition, as mentioned above, the verbs 'attract' and 'target' were being used in two different ways in each corpora with the 2007 offering a more positive take and the 2008 a more negative one.

\subsection{Problematizing immigrants}

Immigrants are often constructed as a problem. As evident from previous research presented in Chapter 4, immigrants are often portrayed as contributing to the problems of a society. The negative construction of immigrants is also evident in the New Zealand Herald. This section discusses collocates which contribute to this negative representation of immigrants. A list of all the collocates which contribute to this negative representation are given in Table 6.3 below. 


\begin{tabular}{|l|l|l|l|l|l|}
\hline Corpus year & Collocate & Node & LL & MI & Freq \\
\hline 2007 & WORKER & (migrant) & 31.01878 & 8.770359 & 3 \\
\cline { 2 - 6 } & WORKERS & (migrant) & 147.6083 & 8.355321 & 15 \\
\cline { 2 - 6 } & ILLEGAL & (immigrant) & 25.62016 & 7.531876 & 3 \\
\cline { 2 - 6 } & ILLEGAL & (immigrants) & 239.1216 & 9.231848 & 21 \\
\cline { 2 - 6 } & SUSPECTED & (immigrants) & 20.71421 & 8.676031 & 2 \\
\cline { 2 - 6 } & DEALINGS & (immigrants) & 30.15372 & 8.483386 & 3 \\
\hline & MUSLIMS & (migrant) & 16.81657 & 7.445992 & 2 \\
\cline { 2 - 6 } & ILLEGAL & (migrants) & 81.25477 & 7.78923 & 9 \\
\cline { 2 - 6 } & ILLEGAL & (immigrant) & 44.50482 & 7.760951 & 5 \\
\cline { 2 - 6 } & BLAMES & (immigrants) & 22.61159 & 9.149579 & 2 \\
\cline { 2 - 6 } & ILLEGAL & (immigrants) & 176.0759 & 8.593185 & 17 \\
\cline { 2 - 6 } & BLAMED & (immigrants) & 26.41987 & 7.647079 & 3 \\
\cline { 2 - 6 } & COMPETE & (immigrants) & 16.12112 & 7.149579 & 2 \\
\cline { 2 - 6 } & TARGET & (Asians) & 17.1271477 & 7.53421879 & 2 \\
\cline { 2 - 6 } & V & (Asians) & 59.6463928 & 7.48596382 & 7 \\
\hline
\end{tabular}

Table 6.3 Collocates referring to immigrants as problematic

\subsubsection{Illegal}

As displayed in Table 6.3, the collocate 'illegal' plays an important role in both corpora. In the 2007 corpus, the collocate 'illegal' plays a significant role in the negative construction of immigrants. It occurs mainly to the left of the search word acting as a modifier. It occurs with two out of five of the nodes and has both a very high MI and LL as well as a high frequency in comparison to some of the other collocates. As with the 2007 corpus, the collocate 'illegal' also plays a significant role in the negative construction of immigrants in 2008. It occurred with three out of five of the nodes and has a very high MI and LL as well as a high frequency in comparison to some of the other collocates. With 
reference to the above given LL scores, it becomes clear that this is an important collocate relating to the topic of immigration.

Table 6.3 gives more information with regards to the MI, LL and frequency of this collocate with the nodes. As evident, the collocation 'illegal immigrants' is used 21 times. Considering that the collocation 'illegal immigrant' itself carries a negative connotation, it is not surprising that the co-text of the concordance lines also points to a certain level of fear of 'illegal immigrants'. Interestingly enough, in the 2007 corpus, 12 out of these 21 lines refer to 'illegal immigrants' within the United States. Four of these concordance lines refer to 'illegal' immigrants in countries in the European Union, four to 'illegal' immigrants New Zealand, and finally there is one reference to illegal immigrants in Libya. In the 2008 corpus, of the 31 collocations which have 'illegal' as the collocate, only eight refer to 'illegal' immigrants within New Zealand or are linked to New Zealand in some way.

Therefore, it is of key importance to highlight that this modifier is mainly used to talk about immigrants in other countries rather than in New Zealand. This section presents concordance lines which refer to immigrants in other countries being described as 'illegal'. The following concordance lines talk of 'illegal immigrants' in the United States:

(34) She said that if he had not left Los Angeles, he would be in Monterey, where there were illegal immigrants who were good at hiding people. (New Zealand Herald, September 22, 2007)

(35) The United States is in the grip of a demographic change the like of which has not been seen since the 19th century. A mass immigration is taking place that dwarfs the flow of Irish, Germans, Jews and Italians that, 100 years ago, saw America rise to a superpower. It is a movement of Hispanic immigrants - legal and illegal - and the explosive growth of their descendants. (New Zealand Herald, November 10, 2007) 
(36) At least 200 children were stranded after United States officials detained 350 suspected illegal immigrants at a Massachusetts factory. (New Zealand Herald, March 9, 2007)

(37) I wanted to get her purse back, of course, but anger spurred me on too. It was bad enough he had swum the river to commit a crime and scare this woman, but he also had hurt his own people by giving ammunition to those who demonise illegal immigrants. (New Zealand Herald, October 24, 2007)

These 'illegal immigrants' are not only considered as 'illegal' because they reside in or enter the country without permits, but their status as 'illegal' is further emphasized by portrayals of them as involved in criminal activities. This doubly negative representation means that they are commonly associated with crime and lack of order. The co-text accentuates the threat by constructing illegal immigration as a 'mass' movement and their increasing numbers as an 'explosive growth' as well as by making specific reference to numbers. They 'commit' crimes and steal from women. They are 'suspected' and 'detained' of carrying out wrong doings. All in all, quite a grim picture of immigrants in the United States. A similar narrative is told of migrants in the European Union. The concordance lines below also construct immigrants as 'illegal':

(38) Nine hundred soldiers are to be deployed in Rome to make the Italian capital a cleaner, quieter and more decorous place, under a law and order package approved by Parliament which targets the country's illegal immigrants. (New Zealand Herald, July 25, 2008)

(39) The European Union's feeble gestures towards curbing illegal immigrants from Africa with fences around the Spanish enclaves of Ceuta and Melilla on the Moroccan coast, and naval patrols off the Canary Islands seem merely pathetic. (New Zealand Herald, February 12, 2007) 
(40) A proposed EU constitution was emphatically ditched by French voters in a 2005 referendum, and many French people appear to feel that the EU's "Big Bang" enlargement from 15 to 27 countries has left their country less capable of policing its borders against poor or illegal immigrants or criminals. (New Zealand Herald, April 21, 2007)

The use of the comparative 'cleaner' in extract (38) suggests that 'illegal immigrants' are some sort of malignancy which need to be treated and cleaned. The terms 'quieter and more decorous' imply that 'illegal' immigrants in Italy lead to rowdiness and a lack of civilization in the streets and that police should deal with them. Extracts (39) and (40) refer to 'illegal immigrants' in the European Union. 'Illegal immigrants' are collocated with 'criminals', further criminalizing immigrants by association. Efforts to prevent their entrance are dubbed 'pathetic', and 'curbing' is called for. Current prevention measures such as 'fences' and 'naval patrols' are inadequate and referred to as feeble gestures towards the control of illegal immigrants. Scholars such as Cunningham-Parmeter (2011) warn against the consequences of criminalizaton of immigrants and reference to them as illegal immigrants. He argues that the modifier 'illegal' leads to an inaccurate construction of the direness of the crime or offence committed:

the nuanced nature of immigration status, the illegal alien metaphor distorts the severity of an immigrant's offense. For example, entering the country without inspection (i.e. crossing the border illegally) is a first time misdemeanor that federal officials rarely prosecute. Further, nearly half of all people described as "illegal aliens" obtained their "illegal" status by overstaying valid visas - a civil immigration violation that involves no criminal conduct whatsoever. (p. 1575)

Therefore Cunningham-Parmeter (2011) argues that the use of 'illegal' is misleading and associating 'illegal' immigrants with words like 'criminals' equates misdemeanors to serious criminal acts. He continues to argue that 
once understood as "illegal aliens", immigrants garner little sympathy from a public accustomed to punishing its convicts. A society that constantly seeks to separate the "wicked" from the "righteous" relies on the sorting function provided by the illegal frame. If a crime has been committed, then arrests must be made, convictions obtained, and penalties assessed. (p. 1576)

Therefore, Cunningham-Parmeter (2011) is arguing that immigrants who do not have a valid visa or who have overstayed are not necessarily criminals and they have not directly done wrong to anyone as is the case with other criminal activities such as theft, murder etc.

Despite the frequent use of the modifier 'illegal' to talk about immigrants in the New Zealand Herald, only a few of the instances refer to immigrants in New Zealand. Three instances in particular led to more media representation of immigrants as illegals. One of those relates to Ahmad Zaoui, an Algerian who came to New Zealand in 2002 on a fake passport. After he arrived, he sought refugee status. His status as a refugee was controversial and gained a great deal of public attention as some believed that he had been involved in criminal activities and terrorism prior to his arrival. He was imprisoned while his case was undergoing scrutiny. In September 2007, the Security Intelligence Service withdrew the security risk certificate against Zaoui. He was finally granted refugee status and now lives in New Zealand. The second incident was the Taito Philip Field case. In the 2008 corpus, of the eight concordance lines which talk about illegal immigrants in New Zealand, four of them refer to the former MP Taito Philip Field. Since the year 2005, speculations had mounted about certain activities of the MP and he was accused of giving Thai immigrants immigration assistance in return for free work on his properties. Allegations were made against him and his case was taken to court and therefore this event received a great deal of media focus. Finally, other concordance lines refer to the case of Nai Yin Xue who was the New Zealander who murdered his wife in Auckland and abandoned his child in Australia only to be later caught in the United States. Extracts (8) to (11) describe immigrants in New Zealand as illegals: 
(41) But New Zealand First leader and Foreign Minister Winston Peters said it "advertised New Zealand once again as the number-one soft touch for illegal immigrants". (New Zealand Herald, September 14, 2007)

(42) Overstayers are being offered amnesties as Immigration New Zealand enlists the help of Asian community leaders to flush out illegal migrants. Through a pilot programme, those identified as being unlawfully in New Zealand have been asked to attend education clinics where their immigration status is reassessed and those asked to leave the country can reapply to return lawfully. (New Zealand Herald, August 22, 2008)

(43) There are 17,485 illegal migrants in New Zealand including 4198 Samoans, 2312 China nationals and 2294 Tongans. In other Asian communities, those with the most overstayers are Malaysians (695), Indians (620) and South Koreans (573). (New Zealand Herald, August 22, 2008)

In extract (41), the New Zealand Herald voices the opinion of Winston Peters on the Zaoui case who states that he believes that accepting Mr.Zaoui as a refugee means that New Zealand is represented as 'a soft touch for illegal immigrants'. Extracts (42) and (43) refer to immigrants as 'overstayers'. Reference to these immigrants as 'overstayers' attributes the negative connotation of this word to immigrants. The prefix 'over' is often used as a prefix to denote surplus, e.g. overdose, overdo, overcast, overweight, overwhelmed etc. The use of overstay to refer to immigrants creates the notion that these people are and have always been mere guests despite having lived and contributed to society like all other citizens by working. In addition, extract (42) uses the phrasal verb 'flush out' when talking about immigrants. This implies that 'illegal migrants' secretly and deceitfully hide away from governmental officials. The remaining concordances discuss more general issues regarding 'illegal immigrants' in New Zealand such as the possibility that they are 'exploiting ID screening' and 'slipping illegally' into the country. 


\subsubsection{Compete}

Other collocates come with both negative as well as positive co-text. The collocate 'compete' $(7.1,16.1)$ is used in this way. The word compete is used in the phrases 'compete with immigrants' and 'compete for immigrants' each creating a different stance towards immigrants and immigration:

(44) Mr Peters used a campaign speech in Nelson to say "when times are tough internationally immigrants are attracted to New Zealand like moths to a neon light”. “During times when New Zealanders' jobs are at risk, immigration will be cut to ensure Kiwis did for not have to compete with immigrants jobs." Mr Peters said this suggested reducing the immigration quota from 50,000 to 10,000. (New Zealand Herald, October 17, 2008)

(45) Both countries are a whole lot richer than we are and better placed to compete for immigrants (including Kiwis) in an era of labour mobility. That may be particularly true for those drawn from the footloose Generation Y for whom instant gratification takes too long. If the baby boom generation had invented the teenager, Salt said, generation Y had extended adolescence until the late 20s. (New Zealand Herald, June 26, 2008)

Extract (44) is the voice of Peters where he likens immigrants to 'moths', implying that immigrants are always where they can benefit, i.e. taking away jobs from New Zealanders (a detailed analysis of this news article is provided in the next chapter). This extract draws on immigrant-as-scapegoat discourse, where immigrants are blamed or perceived to be taking jobs away from locals particularly during times of economic difficulty (Spoonley, 1988, pp. 14-15). In contrast, extract (45) depicts a different picture where immigrants are regarded as a commodity that is internationally fought for. 


\subsubsection{Blamed}

The verb 'blamed' also appears as a significant collocate in 2008. A look at examples from the BNC shows that this verb carries a negative discourse prosody as it is mainly used in contexts where people are held liable for financial loss. Other contexts in which it is used are violent behavior, deaths, failure in general and unsuccessful relationships. Previous research also show that immigrants have often been 'blamed' for burdening and abusing the country's social welfare (Wodak, 2001, p. 88). The next examples are from the 2008 corpus. The co-text of the concordance lines plays a significant role in the categorization of each.

(46) Immigrants can be four times more valuable to the New Zealand economy than those born here, an immigration conference in Wellington has been told. Academics and researchers at the conference, "Pathways, Circuits and Crossroads", said that while immigrants were blamed for many things - from soaring house prices to soaking up social and health benefits - in truth they were vital contributors to economic growth. (New Zealand Herald, June 10, 2008)

(47) Mr Peters blamed immigrants for infrastructure problems in Auckland, citing traffic congestion, increased pressure on power and water resources, pollution, shellfish pillage and threatened recreational areas. (New Zealand Herald, April 5, 2008)

Despite 'blamed' itself having a negative semantic prosody, in the first example, the writer is challenging common perceptions regarding immigrants being a burden by providing references from academia. Their contributions to New Zealand economy are highlighted and discussed throughout the rest of the article. Extract 47, on the other hand, presents the perspective of Mr.Peters who constructs immigrants as the root of multiple problems in the city of Auckland. 


\subsubsection{V (Versus)}

In the next concordance, the single letter collocate ' $v$ ' (meaning versus) is the fourth most highly significant collocate for the node Asians. It has occurred seven times in the 2008 corpus both as headlines and within the main articles. The ' $\mathrm{v}$ ' collocate is often used to draw a comparison or highlight opposition and conflict between two things. With a look at the concordance lines, it becomes clear that this conflict involves Winston Peters and Peter Brown (both members of the New Zealand First Party) who have been placed in opposition to 'Asians':

(48) Winston Peters v Asians. Mr Peters described immigration as "a time bomb with a slow burning fuse", and blamed Asian migrants for petrol tax increases and growing hospital waiting lists. He said he wanted immigration levels cut and said it should be the top election issue. "The unpalatable fact is that the consequence of ever-larger numbers of unassimilated people in New Zealand will be heightened tension and social conflict," he said. (New Zealand Herald, April 5, 2008)

(49) Peter Brown v Asians. Deputy leader Peter Brown spoke out about projections showing the Asian population will reach 790,000 by 2026 . He warned that people would form into "mini-societies" and said there was a danger New Zealand would be "inundated with people who have no intention of integrating into our society". (New Zealand Herald, April 5, 2008)

(50) Winston Peters $\mathbf{v}$ Asians. In a speech in Howick, Mr Peters criticised the Government's immigration policy as something which "sees rows of ostentatious houses in this very suburb, occupied in some cases by children whose parents have no ties in this country other than the price they paid for the house and who prefer to remain outside its shores". (New Zealand Herald, April 5, 2008)

Extracts (48) to (50) all construct Asian immigrants in opposition to members of New Zealand First Party such as Winston Peters and Peter Brown; and then give voice to these 
figures who oppose immigrants coming to New Zealand. Considering the date of the news articles, that is, 2008, and since 2008 was an election year, it is no surprise that the newspaper presents the voice of political members who are engaged in "political rivalry discourse" (KhosraviNik, 2010, p. 15; N.B. more elaboration regarding the position of the New Zealand First Party is given in the next chapter). In extracts (48) to (50), the newspaper gives the perspective of Winston Peters and Peter Brown who both draw upon arguments which highlight that immigrants are different and hence undesirable. Immigrants are not wanted because they are 'unassimilated' people who might form 'mini-societies' with 'no ties' to the rest of New Zealand. Rhetorically, extract (48) constructs immigration as a threat as it draws a comparison between immigrants and a 'time bomb' in order to intensify the need to prevent immigrants from coming to New Zealand. Reference to immigrants as numbers, e.g. '790,000' is also used rhetorically to foreground the supposed threat. In extract (49), the newspaper expresses (in third person) the voice of Peter Brown who gives an estimate of the Asian population. He refers to the future Asian population, i.e. '790,000' which is nearly equivalent to one fourth of the current New Zealand population. This projection makes the figure appear very high. However he neglects to talk about the overall increase in population. The estimate figure for the overall population increase could mean that the figure of estimated immigrants is relatively small compared with the overall population increase.

\subsubsection{Worker/Workers}

'Worker' and its plural form have collectively appeared 18 times in the 2007 corpus and three times in the 2008. The majority of the co-texts of this collocate point to the construction of 'migrant workers' as unskilled, uneducated, poor, uncontrollable and working unlawfully:

(51) An employers survey released alongside the labour force research showed the impact of migrant workers was generally seen as positive, but that training opportunities needed to be made available for such workers, especially if English was not their first language...Employers also said a drop in basic numeracy and 
literacy skills was a major issue for all workers in the industry. (New Zealand Herald, September 13, 2007)

(52) "The whole thing was a shock to the employer," says Hewison. "Losing that person set the firm back between six and 12 months. The employer was not aware that the worker was here unlawfully". Hewison says they helped to get the migrant worker out of custody and returned to the employer, but it was just a matter of time before the person was returned to China. (New Zealand Herald, April 26, 2008)

Extract (51) constructs 'migrant workers' as unskilled and uneducated. While extract (51) describes immigrants as struggling with adding, subtracting, reading and writing, i.e. 'basic numeracy and literacy', extract (52) constructs an immigrant as working 'unlawfully' in a 'firm'. When describing 'migrant workers' outside New Zealand, immigrants are constructed as poor non-members of a society where their presence in large numbers is a cause of concern:

(53) Wang is one of about four million migrant workers who live in Beijing but are not counted in its official population of 15 million....The dire poverty in China's heartland has created a drama played between Government officials determined to rid the city of its urban underclass and migrant workers equally determined not to leave. (New Zealand Herald, May 19, 2007)

(54) "The fact that the Government did not know the true number of overseas workers who have come to the UK ... is profoundly worrying, and confirms fears that ministers have simply lost control of our systems for migrant workers." (New Zealand Herald, October 31, 2007)

Extract (53) describes the plights of 'migrant workers' as an 'underclass' who are in 'dire poverty' and who are a mere nuisance which the 'government' needs to get 'rid' of. The 
use of 'rid the city of', a phrase commonly used for objects and rubbish, creates a very belittling image of 'migrant workers' as if they are mere items who can be easily dispensed with. Both extract (53) and (54) construct the number of 'migrant workers' as problematic and as needing to be reduced. While extract (54) refers to their numbers in the millions, e.g. '15 million', extract (54) construct 'migrant workers' who go to the UK as a threat. Their number is 'profoundly worrying', 'confirms fears' and may lead to chaos and lack of 'control'.

\subsubsection{Suspected and dealings}

The collocates 'suspected' and 'dealings' which I discuss in this section are specific to the 2007 corpus. A search of the BNC for instances containing the verb 'suspected' suggests that it is often associated with criminal activities. A close reading of the lines indicate a tendency to use this verb in contexts which present illegal activities such as bombing, trafficking, terrorism etc.:

○ He was arrested in 1980, with hundreds of other members of the Oromo ethnic group who were suspected of links with an Oromo guerilla group.

- BOGOTA (Reuter) - Colombia was reported yesterday to be seeking the extradition of a suspected cocaine baron held in neighbouring Ecuador as a wave of bombings, believed to have been carried out by drug traffickers, continued.

- Later in the same judgment, Scott LJ referred to the appropriateness of delaying arrest where 'there [was] no probability... of the suspected person running away'. (Examples from the British National Corpus)

Extracts (55) and (56) from the 2007 corpus also draw on this meaning of the verb 'suspected' and use it in the context of criminal activity: 
(55) At least 200 children were stranded after United States officials detained 350 suspected illegal immigrants at a Massachusetts factory. (New Zealand Herald, March 9, 2007)

(56) The US Government also has referred to the ITS for background checks on immigrants it suspected of lying about their past. (New Zealand Herald, December 1, 2007)

The verb 'suspected' is collocated with words like 'detained', 'illegal', 'background checks' and 'lying', all commonly associated with fraudulent activity. Another collocate which has a similar connotation is 'dealings'. 'Dealings' is used extensively in the BNC to talk about monetary and trade negotiations between governments, groups, corporations, monarchies, banks. However, there is also substantial evidence that it is used to describe fraudulent negotiations, i.e. illegal, unfair, lawless negotiations. While 'suspected' is used to describe immigrants outside New Zealand, 'dealings' is a significant collocate of the node immigrants and has been used for incriminating actions of Asians in New Zealand and in particular when referring to the Taito Philip Field case:

(57) At no point has principle played a part in Labour's handling of allegations about the Mangere MP's dealings with prospective immigrants. (New Zealand Herald, February 17, 2007)

(58) Among those allegations were claims that Field had benefited from his dealings with Asian immigrants and other constituents. (New Zealand Herald, February 18, 2007)

The broader textual vicinity of the collocation all point to the construction of immigrants (as well as politicians) being involved in violating the law. Therefore, the co-text of the collocations points to a rather negative semantic/discourse prosody for the word 'dealings'. 


\subsubsection{Muslims}

Finally, the collocate 'Muslims' is also discussed in this section. Previous studies argue that the media frequently depicts Muslims as a collective threatening "other" (Saeed, 2007). Others such as Baker et al (2014) confirm that Muslims are often talked about in contexts of conflict:

The presentation of Islam and Muslims in UK newspapers in the twelve year period from 1998 to 2009 was predominantly carried out in a context of conflict, and the religion and its faithful were frequently portrayed as causes for concern, if not sources of threat. (Baker et al., 2013, p. 65)

The discourse of threat is also evident in this study. The collocate 'Muslim' has appeared as a highly significant collocate with two nodes, namely migrant and Asians in the 2008 corpus.

(59) If only many migrant Muslims would be equally appalled by so-called honour killings, some of which are accompanied by the sexual assault of the victim. For Western Muslims, perhaps the most disturbing and embarrassing reality was the complete political and military impotence of the 50-plus states that made up the Organisation of Islamic Conference. Despite numerous emergency summits and passionate resolutions, the OIC was powerless to stop the carnage. (New Zealand Herald, August 18, 2008)

A closer look at the concordance lines of these collocations shows that Muslim immigrants are discussed in contexts of conflict. Extract (59) for example, uses the collocation 'migrant Muslims' in the co-text of conflict and crime indicated by phrases such as 'honour killings', 'sexual assault', 'military' and 'carnage'. The newspaper also presents the perspective of New Zealand First who contribute to the construction of Muslims as a problem. In the extract below, 'Muslims' as well as immigrants are constructed as a burden, 
i.e. as the source of housing problems and burdening the social welfare services such as hospital care:

(60) Every three years there's an attack on migrants, Asians, Muslims, or ultrawealthy capitalists from NZ First. The problems of hospitals are caused by migrants, housing problems are, according to them, caused by refugees. (New Zealand Herald, August 06, 2008)

In other concordance lines from the corpus, Muslim immigrants and Muslim Asians are represented as parts of militant groups or are talked of in the context of the Bosnian war. Although we cannot generalize about Muslims in this study, all five of the concordance lines in the 2008 corpus nevertheless confirm that there appears to be a tendency to discuss them in terms of the threats they bring to the country. Moreover they are referred to in contexts of conflict or as a social burden as illustrated by the examples above.

In summary, a consideration of all the concordance lines discussed paints quite a sombre picture of immigrants. They are frequently associated with crime, described as a threat to local jobs, or as poor members of society who need to be dispensed with. As was evident above, one of the most prominent collocates (in terms of frequency) which contributes to this representation is the pre-modifier 'illegal'. This collocate was without doubt the most frequent collocate which contributed to immigrants being represented in a derogatory way. Nevertheless, the analysis also showed that the majority of the concordance lines which contained this collocate described immigrants in countries other than New Zealand and appeared in syndicated news articles. Other collocates were less explicitly negative. Collocates like 'compete', 'blamed', 'V', 'workers', 'suspected' and 'dealings', and 'Muslims' were used in negatively loaded co-text and hence built up a negative connotative meaning. 


\subsection{Immigrants and refugees}

The distinction between immigrants and refugees has not always been clear cut. In fact with regards to the New Zealand context, Anne Beaglehole in her book Refuge New Zealand asserts that "members of the New Zealand public, especially those opposed to the arrival of dark-skinned strangers or people who chatter loudly in foreign languages, have not always differentiated between immigrants, refugees and asylum seekers." (Beaglehole, 2013 , p. 10). Others have also pointed to ambiguity in how the terms immigrant, asylum seekers, and refugees are defined and differentiated in the media (Gabrielatos \& Baker, 2008, p. 17; KhosraviNik, 2010b, p. 7). Table 6.4 indicates that the term 'refugee' also appears as a significant collocate of the search terms 'migrant' and 'migrants' and collectively occurs 18 times. It did not collocate with the other search terms.

\begin{tabular}{|l|l|l|l|l|l|}
\hline Corpus year & Collocate & Node & LL & MI & Freq \\
\hline 2007 & REFUGEES & (migrants) & 69.28223 & 7.56196 & 8 \\
\hline 2008 & REFUGEE & (migrant) & 53.80156 & 9.039222 & 5 \\
\cline { 2 - 6 } & REFUGEES & (migrants) & 42.56456 & 7.455806 & 5 \\
\hline
\end{tabular}

In extract (61) below, 'refugees' is a significant collocate of the node migrants and is joined using the conjunction 'and':

(61) "Disabled people are two to three times less likely to be in the workforce. Even though more older people are working, I think mature men, particularly professionals made redundant, find it hard to get back into the labour market at the level they were before [sic]. "Refugees and migrants still find it hard to access work that makes use of their qualifications. So for those groups, plus women returning to work, there are still issues around whether the break in their career means they have to accept something lesser to get back in". (New Zealand Herald, November 26, 2007) 
Extract (61) discusses 'refugees and migrants' among other categories who are commonly perceived as being disadvantaged. Within this category of disadvantaged people, 'migrants', 'refugees', 'disabled people', 'older people' and 'women returning to work' are placed. This association of immigrants, with other groups such as 'disabled people', 'older people', and 'refugees' suggests that immigrants are perceived to be weak, frail, vulnerable and in need of help. Extract (62) discusses refugees in the co-text of speech therapy:

(62) Most challenging part? Children who are unable to communicate display their frustration through adverse behaviours. You need to be skilled to address this. Overall the hardest part is if a child I am working with dies. It is something you can never prepare yourself for. Interesting projects? In my Master's research, I'm looking at the best way to examine the acquisition of English in refugee and migrant children within New Zealand schools. I'm currently writing my study up. (New Zealand Herald, February 6, 2008)

\begin{abstract}
Although not apparent in the immediate co-text, the broader co-text suggests that this is an interview with a speech therapist who offers therapy for people with articulation, phonological, autism, delayed language, auditory processing and swallowing difficulties. It is within this co-text that 'migrants' and 'refugees' and their level of language competence are discussed. The third concordance line draws on the second theme of refugees and immigrants as people who contribute to more crime:
\end{abstract}

(63) Isn't it about time we brought in legislation to the effect that any migrants not just refugees - who choose to become citizens of New Zealand are automatically kicked out if they're convicted of a criminal offence within a specified time of gaining residency? (New Zealand Herald, September 23, 2007)

The news discourse uses the superordinate term 'migrants' and includes 'refugees' under this umbrella term. The extract criticizes New Zealand for being too tolerant of immigrants 
(and refugees) who are involved in criminal activities. The co-text continues to talk about immigrants (and refugees) and portrays them as ghastly and frightful with reference to them as 'rapists', 'murderers', 'child-abusers' and 'wife-beaters', e.g. 'We have more than enough rapists, murderers, child-abusers and wife-beaters in this country, born here, and whom we have no choice but to keep'? (New Zealand Herald, September, 2007). The broader co-text refers to these people as 'scums' who 'damage' or 'kill innocent women' and 'children' in New Zealand. This and other articles are testimony to the willingness of some in the mass media organizations within New Zealand to articulate negative discourses regarding immigrants.

Another common theme which becomes apparent when analysing collocates with the term 'refugees' is that immigrants as well as refugees are referred to as people who need help in settling and integrating:

(64) Like the absolute beginners he refers to, those post-World War II migrants and refugees learning the trick of standing upright in New Zealand, Cross saw himself as a learner, a novice in this country. (New Zealand Herald, August 24, 2007)

(65) Action plan to settle migrants targets young refugees. A youth worker to work with young refugees is being placed into Auckland's most multicultural suburbs as part of a regional "settlement strategy" launched last night. (New Zealand Herald, February 1, 2007)

(66) Settlement: Migrants have the same rights as other New Zealanders, with few exceptions. New migrants and refugees are entitled to support to settle and integrate successfully. (New Zealand Herald, August 29, 2007)

Extracts (64) to (66) all show concern about the 'integration' of immigrants. Phrases like 'standing upright in New Zealand', 'learner', and 'novice' all contribute to the 
representation of immigrants and refugees as people who are unable to carry out basic everyday activities as normal capable adults would. The phrases 'entitled to support and integrate', and 'help migrants and refugees to settle' construct immigrants as people who need additional support and help to settle into life in New Zealand. In fact, Beaglehole (2013) refers to New Zealand being preoccupied and obsessed with the idea of refugees needing to become absorbed into the country's macro culture. She argues that historically, refugees' (in particular Jewish and Chinese refugees') applications were rejected mainly because they were believed to have difficulty in adjusting: "the immigration authorities' selectors' first consideration was whether an applicant could be readily absorbed into the dominion's population" (p. 32). Therefore, in a way, the concordance lines above are examples of this long-lived idea that refugees need to be integrated, settled, assimilated, or absorbed into the society in one way or another which has historically been part of New Zealand's immigration policies and values.

Very closely related to the theme of refugees in need of help, the theme of services for refugees is another significant theme throughout both 2007 and 2008. However, since 2008 was an election year, the topic of budgeting for race relations services dominates. Budgets for race relations are used as part of election campaigns to win over votes. These attempts at gerrymandering are reflected in the news discourse too:

(67) He said the Government under Labour has put a lot of money into funding initiatives to help better the lives of people in New Zealand's diverse communities. “The much valued but under-resourced Māori wardens received \$17 million in the recent budget, there's \$12 million funding over the next four years for Māori nurses and we are investing \$21.2 million over the next four years in the Auckland Metropolitan Migrant and Refugee Strategy designed to assist people into work and have better access to government services”. (New Zealand Herald, August 27, 2008) 
(68) Mr Peters called for dramatic cuts from 50,000 a year to 10,000 and for family reunification to be restricted to immediate family only, saying jobs had to be protected for Kiwis. The Greens called for an increase in migrants, especially refugees, and for space to also be ensured for "climate change refugees" forced out of their countries by rising sea levels. Despite the dog-whistle style of his politicking, Mr Peters did strike at the heart of what all parties will have to wrestle with in their immigration policies. (New Zealand Herald, October 20, 2008)

(69) Mr Brown was speaking to a crowd who packed the Mt Albert War Memorial Hall yesterday to listen to eight political parties' debate immigration and say how their party would support migrants and refugees. (New Zealand Herald, September 29, 2008)

Extracts (67) to (69), all contain 'refugees' as a significant collocate. The extracts all discuss providing services to 'migrants and refugees' in the context of political rivalry with each political party making an argument as to what services they would provide should they become the next government. KhosraviNik (2010) also points to the existence of "political rivalry discourse" in British newspapers when talking about refugees, asylum seekers and immigrants (RASIM) (KhosraviNik, 2010b, p. 15). He argues that refugees, asylum seekers and immigrants have become the 'semantic components' or the 'subject matter' of election campaigns and that the 'negativisation' of immigrants and refugees is used strategically to represent the political rivals in an election campaign negatively and through this, they are "backgrounded and reduced to an issue... about whom there is debate" (KhosraviNik, 2010b, pp. 15-16). This is reflected in the New Zealand newspaper texts analysed. Considering that 2008 was an election year, it is no surprise that these refugees and immigrants have become the objects of such political discourse, i.e. the services and help they are provided is used as a means to gain support. 


\subsection{Homogenous immigrants}

There are three significant collocates which describe immigrants as a homogenous group (see Table 6.5 below). There are 11 references to the collocate 'communities' in the 2007 corpus. All 11 of these concordances talk of immigrants within the context of New Zealand. In addition, six out of $11(54 \%)$ of those references talk about immigrant culture and identity within the host countries. In the 2008 corpus, however, there were no collocates (in the top 20 with an $\mathrm{MI} \geq 3$ and $\mathrm{LL} \geq 15.13$ ) which pointed to this discourse. Similarly, homogenized discourse is also evoked through the use of the collocation 'migrant groups'. This significant collocation appears five times within the data. Three of these concordances talk of 'migrant groups' in the context of Australia and the other two in New Zealand.

\begin{tabular}{|l|l|l|l|l|l|}
\hline Corpus year & Collocate & Node & LL & MI & Freq \\
\hline 2007 & COMMUNITIES & (migrant) & 64.83528 & 8.010029 & 7 \\
\cline { 2 - 6 } & GROUPS & (migrant) & 39.68224 & 7.092287 & 5 \\
\hline & COMMUNITIES & (immigrant) & 32.40512 & 7.215731 & 4 \\
\hline
\end{tabular}

Table 6.5 Collocates referring to immigrants as a homogenous group

In addition to the description of immigrants as a single group, immigrants are often perceived as one homogenous group which is different from the mainstream in certain ways. Rather than being appreciated, this difference is seen as an obstacle which needs to be overcome as it is a source of the problem. A particular collocate which contributes to the representation of immigrants as a homogenized group is 'communities':

(70) It may transpire that the case raises questions about whether the police are adequately resourced to deal with cases within immigrant communities where cultural and language barriers stand in the way of easy resolution. (New Zealand Herald, September 23, 2007)

(71) New Zealand may still be new in the immigration game, but the situation in Europe must have opened a few eyes to see the disastrous consequences when 
immigrant communities alienate themselves from their adopted land and stick together through generations. (New Zealand Herald, November 19, 2007)

(72) It was difficult to assess the proportion of problem gamblers who were Chinese but a check at the Auckland casino would show "few people with blonde hair". Mr Stansfield said Chinese people were less likely to come forward to seek help. The foundation's Asian services team had advised him the word "counselling" was absent from Chinese culture. Problem gambling was an issue for many new migrant groups especially when they had spare time on their hands. (New Zealand Herald, February 26, 2007)

Differences in culture are dubbed 'barriers' which 'stand in the way'. In extract (71), the closeness of immigrant members to other members of their community is also represented negatively as evident in the following clause: 'when immigrant communities alienate themselves from their adopted land and stick together through generations'. So when they are not integrating, they are referred to as alienating themselves which in turn leads to 'disastrous consequences'. In other words, the optimum goal is represented as immigrants assimilating to the host country's culture and values. Extract (72), portrays Chinese immigrants as people who develop 'gambling' problems as they are 'less likely' to approach others for help. So in this extract, the problem of gambling is generalized to one specific community, namely Chinese, and the root of the problem is assigned to a cultural norm of the Chinese community, that is, the fact that they are less likely to ask for help.

\subsection{Integration of immigrants}

Once the culture of immigrant members is generalized to a whole community and referred to as problematic, the integration of immigrants becomes an issue. As became evident in the section on homogenous immigrants, immigrants and the need for their integration is a common theme in the 2008 corpus. The significant collocates which contribute to this categorization are listed in Table 6.6. 


\begin{tabular}{|l|l|l|l|l|l|}
\hline Corpus year & Collocate & Node & LL & MI & Freq \\
\hline 2008 & SETTLE & (migrants) & 16.71001 & 7.35627 & 2 \\
\cline { 2 - 6 } & INTEGRATING & (migrants) & 16.43521 & 7.263161 & 2 \\
\cline { 2 - 6 } & INTEGRATE & (immigrants) & 15.39618 & 6.901651 & 2 \\
\hline
\end{tabular}

Table 6.6 Collocates referring to the integration of immigrants

With a closer look at the concordance lines containing these collocates, it seems that the integration of immigrants into New Zealand society and kiwi culture is deemed of considerable importance, in the absence of which certain threats persist. The following is a quote from the former New Zealand First deputy leader at the time, Peter Brown:

(73) "If we don't have any controls, we'll get a society of mini-communities and there'll be a lot of friction - it builds a lot of resentment". Mr Brown said there needed to be integration programmes put in place to stop "subservient" cultures causing friction within the community. He acknowledged that there was a strong need for immigrants to integrate within Kiwi culture. "Without any integration programmes, there's going to be problems". (New Zealand Herald, July 8, 2008)

This extract compares cultures and suggests some cultures are superior while others are subordinate to others. This is indexed through the use of the modifier 'subservient' when referring to the culture of immigrants which implies the superiority of the host country's culture. The quote highlights the need for the 'integration' of these 'subservient' cultures into New Zealand culture and outlines the perceived consequences if integration programmes' are not put in place, namely 'a lot of friction', 'a lot of resentment' and some 'problems'. However not all the concordance lines are as forthright as the one above. Other concordance lines imply that immigrant integration will prevent conflicts and racial issues flaring up:

(74) But on the overall level of immigration they seem broadly content. Forty of the 96 believe the present level is about right, 26 think too many people are coming 
in, 15 want more and 15 had no view. Most of those supporting the present immigration rate cite skills shortages and the need to replace the numbers emigrating. Several said migrants were integrating well and they saw no racial issues. However, a failure to integrate or speak English was cited by many of the 26 who thought the level too high. Those who wanted more immigrants gave a range of reasons, including skill shortages, the need for an economic stimulant and the ability of a larger population to support better infrastructure. (New Zealand Herald, October 23, 2008)

(75) Employing part of your workforce from non-English speaking countries is a challenge. Taruni Falconer, a cross-cultural trainer and principal of the consultancy Intercultural Dynamics, teaches some of the new professional development courses at the University of Auckland's Centre for Continuing Education. The courses have been designed to help management and staff integrate new immigrants into the workforce. (New Zealand Herald, February 22, 2008)

Both extracts (74) and (75) show a collocation involving the verb 'integrate/integrating'. A close reading of the co-text of extract (74) represents the perspectives of the locals on the issue of integration. The local perspective is one mainly based on interest. Immigrants are sought after because of the benefits they bring, e.g. fill 'skills shortages', 'economic stimulant', 'better infrastructure'. Immigrants are expected to integrate and 'failure to integrate or speak English' is conceived as a problem. In extract (75), courses at University of Auckland are provided for staff in order to help them 'integrate new immigrants'. In this extract, immigrants are represented as people who require 'help' to 'integrate' into New Zealand society. All concordance lines containing 'integrate' as a significant collocate suggest that it is immigrants who need to adapt.

To sum up, after examining the majority of the concordance lines, it becomes clear that it is taken for granted that integration has to occur on behalf of the immigrants. Rarely, is this process presented as a two way one or a mutual responsibility of both the immigrant and 
the host country members. Throughout the corpus the act of settling and integrating is represented as the sole responsibility of the immigrants even though governments are willing to provide services to ensure this integration takes place smoothly. In other words, immigrants are placed as the actors of the action of integrating and the government has the responsibility to provide services to facilitate integration. However, there are no concordance lines which point to the fact that integration is in fact a mutual responsibility and the host country needs education and training in developing inter-cultural competence to accommodate the ever increasing diversity. In addition, immigrants are constructed as a homogenous group who are different from the rest. But very few, if any of the concordance lines draw upon the similarities between immigrant and host country values or talk about how these differences can offer understanding about ourselves.

\subsection{Immigrants as victims}

In the 2008 corpus, immigrants are talked about in terms of victims. Here the collocates surrounding the search words suggest a discourse of victimization in which immigrants are targeted and need protection. Collocates contributing to this theme are 'protect', 'vulnerable' and 'target' (see MI, LL and frequency for these in Table 6.7).

\begin{tabular}{|l|l|l|l|l|l|}
\hline Corpus Year & Collocate & Node & MI & LL & Freq \\
\hline 2008 & VULNERABLE & (migrants) & 26.89272 & 7.760661 & 3 \\
\cline { 2 - 6 } & TARGET & (migrants) & 25.51826 & 7.455806 & 3 \\
\cline { 2 - 6 } & PROTECT & (Asians) & 22.9659367 & 6.89678907 & 3 \\
\hline
\end{tabular}

Table 6.7 Collocates referring to immigrants as victims

Extracts (76), (77) and (78) below represent immigrants as in need of protection as they are 'vulnerable': 
(76) "Now we have a licensing regime in place that will not only protect vulnerable migrants, but also enhance the reputation of the industry". He said the IAA was here to protect migrants and advisers alike, and "confidentiality was a top priority". (New Zealand Herald, May 6, 2008)

(77) The targeting of Asian high rollers by the new Sky City casino boss to boost flagging profits is cynical and unethical. Asian visitors and migrants are particularly vulnerable to the blandishments of the casino because of their unfamiliarity with commercial gambling, post-migration stress and their social habits. (New Zealand Herald, March 26, 2008)

(78) About 15,000 people took part in a protest march organised by the AAG last Saturday, calling for the Government to get tough on crime. After the march, $\mathrm{Mr}$ Low told reporters he would bring in triad gangsters to protect the Asians if the authorities did not act. (New Zealand Herald, July 12, 2008)

Extract (76) refers to 'migrants' who are 'vulnerable' to fraudulent immigration advisors. The representation of Asian immigrants as people who gamble and therefore in need of help is apparent in extract (77). Asian immigrants are a community who are targeted and who fall for gambling because of 'post-migration stress' and their perceivably bad 'social habits'. A close reading of the co-text of extract (78) shows that Asian immigrants in particular, have become subject to physical attacks. On the one hand, it depicts them as active as they 'protest' and 'march' against violence towards them. This empowering representation depicts immigrants as actively standing up for their rights. However, on the other hand, they rely on 'triad gangs' for their protection.

While this representation is empowering in the sense that it does not construct immigrants as helpless, this concordance line also ironically links the struggle of the victims to 'triad gangsters', i.e. Asians in New Zealand rely on gangs to protect them against criminals which in turn raises questions about the Asians' willingness to abide by the law. 


\subsection{Summary}

The analyses above illustrated the importance of collocations and discussed the numerous significant collocates that the search words of this study have. The unique use of liquid metaphors in positive as well as negative co-texts suggests that in the New Zealand Herald liquid metaphors are often used in atypical ways compared with how they are used in the print media in other countries. Whereas previous studies typically argue that liquid metaphors are used to construct immigration as a phenomenon which lacks control (Van der Valk, 2000), my data indicates that liquid metaphors referring to immigrants also construct them as contributing to the (economy of the) society in which the newspaper is actually being printed. In other words, liquid metaphors are not always used to construct the process of immigration as destructive and uncontrollable. Rather, the analysis indicates that the metaphor IMMIGRANTS ARE LIQUIDS is sometimes used to highlight the positive economic aspects of immigration. The newspaper also makes frequent reference to collocates with positive connotations, e.g. 'skilled' and at other times with words with negative connotations e.g. 'illegal'. However, a look at the broader co-texts suggest that immigrants are only represented as constructive members of society when they are contributing to the economy. Moreover, immigrants are frequently associated with the collocate refugees who are in need of help and services or co-occur with words such as 'groups' or 'communities' which constructs them as one homogenous group. 
"The real political task in a society such as ours is to criticize the workings of institutions that appear to be both neutral and independent, to criticize and attack them in such a manner that the political violence that has always exercised itself obscurely through them will be unmasked, so that one can fight against them."

(Quote from Michel Foucault in Chomsky \& Foucault, 1971)

\section{Chapter 7: Discourse-historical analysis}

This chapter complements the collocation analysis provided in the previous chapter and adds to the understanding of the representation of the immigrant by analysing five newspaper articles in detail. The analyses in this chapter, unlike the previous chapter, do not solely focus on collocations, but take a more in-depth and comprehensive approach to the data. The analytical framework adopted is the Discourse-Historical Approach (DHA) as outlined in Chapter 5. There are a few points which need to be clarified at the outset of this chapter.

\subsection{Issues relating to analysis}

\subsubsection{Context}

Firstly, the analysis of various articles commences with a relevant but not exhaustive context window locating each article in its relevant socio-political context. This contextual information is accessed by the various social actors (e.g. reporter, editors, and/or people given voice) of the newspaper discourse. As introduced in Chapter 5, according to the DHA, the concept of context can be discussed on four levels and a DHA analysis should orient to all four levels. It is expected that the context window will provide the necessary background knowledge for the reader to easily follow the analysis. 


\subsubsection{Strategies}

Secondly, as discussed in Chapter 5, the analysis focuses mainly on the five strategies outlined by the DHA namely

1) Nomination/Referential strategies (i.e. how are immigrants named or categorized?)

2) Predication strategies (i.e. how are they described? What actions, or adjectives, etc. are associated with them?)

3) Argumentation Strategies (i.e. what arguments are used to justify the lack of need or the need for immigrants?)

4) Perspectivization Strategies (i.e. who is given voice? Whose perspectives are presented in articles?)

5) Mitigation and intensification strategies (i.e. what mitigation and intensification strategies are used to modify the illocutionary force?) (Reisigl \& Wodak, 2009, p. 93)

\subsubsection{Saliency}

Thirdly, it is important to note that not all of the strategies are discussed for each and every article analysed. The strategies perceived to be most salient (in terms of frequency) and which are foregrounded in the data are those which are taken into account. For example, in the first news report, only four out of the five strategies are discussed namely, referential, predication, argumentation, and finally perspectivization. This does not mean that the intensification and mitigation strategies were not used in the data but that they were not salient enough in terms of frequency.

In line with the concept of saliency of discursive strategies, it is helpful to acknowledge that the saliency of a discursive strategy is in fact closely tied to the genre of the news reports. For example, the higher saliency of perspectivization in a hard news report in comparison to an opinion piece is expected, as each genre carries out a different purpose. The news report should (or is expected to) present various voices and perspectives in order 
to fulfill its objective news reporting function whereas an opinion piece is likely to use more argumentation strategies than a news report as it sets out to express the writer's opinion. Hence, there is a strong link between the saliency of the discursive strategy and the types of news article being analysed. While acknowledging these conventions, the analysis below also aims to challenge to what extent achieving full objectivity is possible. William Rees-Mogg the editor of the London Times also sympathizes with the difficulty of this demanding task. He states:

It is easy to take sides. It is easy to be sentimental. It is hard not to move people's emotions. But to expand people's understandings of the innate complexity of truth, a process which the audience may well be bored by or even resent, requires a precision of language and an objectivity of approach which are rare. (as cited in Tucker, 1992, p. 57)

Rees-Mogg refers to "precision of language and objectivity of approach" as the keys to maintaining objectivity. Objectivity, however, is not solely dependent on the content of the news report and relies heavily on the organization of the news article as studies have pointed out (e.g. Teo, 2000), and as I illustrate below. It is important to acknowledge these genre-based structures. However, I also demonstrate that adhering to these conventions in newspaper report writing does not produce as much objectivity as commonly thought.

\subsubsection{Overlapping strategies}

Fourthly, while conducting the analysis, it became apparent that the strategies are not always clearly distinguishable, i.e. there is an overlap between categories across some of the strategies rendering it difficult to discuss each strategy in complete isolation from others. Although I have aimed to guide the reader with the help of sub-headings, i.e. identifying which discursive strategy is the focus of each section, nevertheless, there will be some unavoidable overlap and hence repetition in the analysis. 


\subsubsection{Articles selected for discussion}

Finally, as discussed in section 5.6.4, 20 news articles were selected for detailed CDA analysis using the DHA (Reisigl \& Wodak, 2009). These 20 articles were analyzed in detail. However, since a detailed description of all 20 news articles is not conceivable due to limitations of space, I have chosen to discuss five of these 20 . The reason for choosing these 5 news articles is that collectively they contain at least one example of each of the nomination, predication and argumentative strategies which appeared during the analysis of the 20 news articles and therefore are reasonably representative of the broader qualitative dataset. Therefore, collectively they provide a good overview of the dominant discourses within the broader dataset.

\begin{tabular}{|l|l|l|l|l|l|}
\hline $\begin{array}{l}\text { Analysis } \\
\text { No. }\end{array}$ & Headline & Month/ & $\begin{array}{l}\text { Article } \\
\text { Type }\end{array}$ & $\begin{array}{l}\text { Newspaper } \\
\text { Section }\end{array}$ & Theme \\
\hline Analysis 1 & $\begin{array}{l}\text { Peters wants } \\
\text { immigration cuts to } \\
\text { protect jobs }\end{array}$ & Oct/2008 & $\begin{array}{l}\text { News } \\
\text { report }\end{array}$ & $\begin{array}{l}\text { National } \\
\text { News }\end{array}$ & Election \\
\hline Analysis 2 & $\begin{array}{l}\text { Peters blind to } \\
\text { inconvenient truth }\end{array}$ & Jul/2008 & $\begin{array}{l}\text { Opinion } \\
\text { piece }\end{array}$ & $\begin{array}{l}\text { Opinion } \\
\text { Section }\end{array}$ & Election \\
\hline Analysis 3 & $\begin{array}{l}\text { Schemes aim to } \\
\text { make use of rich } \\
\text { migrant resource }\end{array}$ & Dec/2007 & $\begin{array}{l}\text { News } \\
\text { report }\end{array}$ & $\begin{array}{l}\text { National } \\
\text { News }\end{array}$ & Recruitment \\
\hline Analysis 4 & $\begin{array}{l}\text { Record numbers } \\
\text { leaving for } \\
\text { Australia }\end{array}$ & $\begin{array}{l}\text { Oct/2008 } \\
\text { may have exploited } \\
\text { lax ID screening }\end{array}$ & $\begin{array}{l}\text { News } \\
\text { report }\end{array}$ & $\begin{array}{l}\text { National } \\
\text { News }\end{array}$ & Loss of \\
Population
\end{tabular}

Table 7.1 Information reqarding articles selected for analysis in Chapter 7

Table 7.1 provides information of the five news articles chosen for analysis in this chapter (N.B. the relevant article is given after each context window and all articles are also available in Appendix C). During the analysis of the four news reports and the one opinion 
piece, themes and discourses common to the data set in general are identified. It is also worth noting that the news articles are not discussed in any specific order.

7.2 Textual Analysis 1: news reports entitled 'Peters wants immigration cuts to protect jobs' under the theme of 'Immigration and election'

\subsubsection{Context window}

A country's immigration policies are often a focus of attention in election campaigns to win votes. Although a detailed introduction of the political system in New Zealand is best left to experts such as Mulgan (2004) and Hayward (2015), nevertheless it is useful to know that the New Zealand election voting system is modelled on the German MMP or Mixed Member Proportional system which ensures better representativeness (i.e. fairness) than First Past the Post (FPP). In MMP any party which gains the minimum threshold of 5\% of the nation-wide party votes or at least one electorate can gain one seat in parliament (Nagel, 2012).

The year 2008 coincided with New Zealand's parliamentary election which is held every three years. For this reason, election was a dominant theme in the dataset. The articles in this thematic category mainly discuss the stances of political parties with regards to immigration. In particular, the Labour party, led by Helen Clark who was the prime minister at the time, and the New Zealand First party which has become known for its antiimmigration position and continuous explicit campaigns against immigration, receive a lot of coverage in the New Zealand Herald. New Zealand First was initially established in 1993 to represent the views of Kiwis "concerned about the economic and social direction of their country, the sale of public assets to foreign control, and the decline in employment and social services" (New Zealand First website). The party is led by Winston Peters and according to New Zealand First's official website the party is "committed to rigorous and

\footnotetext{
${ }^{5}$ Kiwi is a term commonly used to refer to people from New Zealand.
} 
strictly applied immigration policy that serves New Zealand's interest. Immigration should not be used as a source of cheap labour to undermine New Zealanders' pay and conditions" (New Zealand First official website). Their website continues to outline some of their immigration principles and ideals in more detail: giving priority to younger immigrants rather than older ones to minimize the burden on New Zealand health services, ensuring that immigrants are only brought into the country to fill skill shortages, and ensuring immigrants have a sufficient level of English before entering the country. The news report analysed below gives extensive voice to New Zealand First leader Winston Peters and his perspectives on immigration in New Zealand during the election campaign.

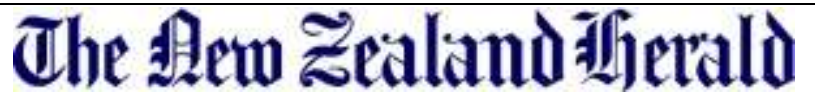

\section{New Zealand Herald - - A06 - 17 October 2008 \\ Peters wants immigration cuts to protect jobs}

By Patrick Gower political reporter

NZ First leader Winston Peters has predictably played the immigration card, saying numbers should be cut to protect Kiwi jobs during tough economic times.

Mr Peters used a campaign speech in Nelson to say "when times are tough internationally immigrants are attracted to New Zealand like moths to a neon light".

'During times when New Zealanders' jobs are at risk, immigration will be cut to ensure Kiwis did not have to compete with immigrants for jobs."

Mr Peters said this suggested reducing the immigration quota from 50,000 to 10,000.

He called for an end to the abuse of the family reunification policy "in other words, only immediate family".

Mr Peters called the free trade agreement with China "foolish", saying it would allow Chinese companies "to set up here and bring in their own labour".

"It is a great idea, as long as you are not a New Zealander looking for a job, or a manufacturer trying to compete against a foreign company that has no labour laws."

Prime Minister Helen Clark, who appointed Mr Peters Minister of Foreign Affairs, said cutting the quota would not be sensible.

"There's never been a time in New Zealand's history when we didn't need to bring in skilled people."

Ms Clark, who was speaking at a Hamilton mosque, said immigration was Mr Peters' 'bread and butter".

(C) The New Zealand Herald, nzherald.co.nz 


\subsubsection{Perspectivization}

The first article to be analysed was printed on the $17^{\text {th }}$ of October 2008 prior to the parliamentary election held in November. The article is a news report and aims to present an alignment of political party perspectives on the issue of immigration. At this stage, the newspaper more generally and the writer of the article more specifically has discretion over who to hand the stage to in this news report. Through recontextualization, that is "the dynamic transfer-and-transformation of something from one discourse/text-in-context...to another" (Linell, 1998, pp. 144-145), of arguments made in a political campaign speech into a newspaper article, the newspaper gives voice to Winston Peters, the leader of the right wing New Zealand First political party known for its anti-immigration stance. The extent of voice a newspaper gives to particular social actors within a news article is of great importance (Barclay \& Liu, 2003; Teo, 2000). Carvalho (2008) refers to "framing power" which she defines as "the capacity of one actor to convey her/his views and positions through the media, by having them represented" ( p. 168). She quotes Entman (1993) who believes that framing consists of "selection" as well as "composition" and then she elaborates that

Selection is an exercise of inclusion and exclusion of facts, opinions, value judgements, etc. Composition is the arrangement of these elements in order to produce a certain meaning. I do not view framing as an optional intervention in discourse...Instead, it is something inherent to the construction of texts. Framing is not something that you choose to do or not, but a necessary operation in talking about reality. (Carvalho, 2008, p. 169)

Therefore according to Carvalho, framing is considered as inseparable from representation. In this news report, Peters' perspective is given priority through the use of numerous direct and indirect quotes.

The news article begins with the evaluative stance of the writer who refers to Peters as 'predictably' playing the 'immigration card' during his political campaign. The use of the 
adverb 'predictably' here communicates the writer's familiarity and deprecation of Peters' speeches. It implies that the writer believes that Peters frequently uses the topic of immigration in order to win over votes. The article discourse (intentionally or not) gives more space to Peters's anti-immigrant rhetoric while less voice is given to Helen Clark's pro-immigrants voice. Word count, type of quoting (direct quote versus paraphrasing), and the juxtaposition and positioning of accounts with alternative perspectives in news report are all important as they can be used to measure the extent of voice given to each social actor within a particular discourse (Barclay \& Liu, 2003). In this news report, Peters' direct quotes comprise 92 words. That constitutes roughly $81.4 \%$ of the total direct quotes. Helen Clark's quotes on the other hand comprise 21 words which constitute the remaining mere $18.5 \%$ of the direct quotes in the article. The rest of the article is populated with the voice of these two social actors in the form of paraphrase (again Peters constitutes the majority voice with 34 words in the form of paraphrases allocated to him while Helen Clark is allocated only 11 words) and also the voice of the writer himself.

As discussed above, not only is word count an indication of the extent of voice given to a particular social actor within the discourse, but also the location allocated to each voice is of relevance to this analysis. According to the inverted pyramid model (Tucker, 1992) of a basic news report, "the story is so written - with key points first and less important ones coming later - that its paragraphs can be lopped off from the bottom up without losing basic sense" (Tucker, 1992, p. 39). In other words, news is often placed in order of importance (Fairclough, 2015, p. 152; Teo, 2000, p. 13) and the editor when reducing the volume, "cuts 'from the bottom"” (Bell, 1991, p. 76). Teo details how the use of sources can function in a restrictive way:

use of quotations becomes a gate-keeping device that admits only those in positions of power and influence while shutting out the opinions of those deemed by society to be powerless. Thus, while the powerful are further empowered through quotation patterns that enhance their status and visibility, the systematic silencing of the 
powerless - the poor, the young, the uneducated, etc. — only further disempowers them. (Teo, 2000, p. 18)

The implications of the sources drawn on and the positioning of quotes is paramount and contributes to nuances in the representation of immigrants. In the discourse under analysis, Helen Clark's pro-immigrant perspective is given less space and positioned at the very end of the article allowing the discourse to be overshadowed by Peters' perspectives on immigrants.

Regarding generic features, the provision of opportunity for a reaction to an initial voice is characteristic of news reports like this one. Bennet (1996) informs us that official figures are the dominating perspective in political stories and that "keying a story to disagreements among officials" (p. 376) is a norm in political journalism. In the context of this analysis, Peters is the initial voice and Helen Clark is used as a reaction or a disagreement, to use Bennet's terms, to this voice.

This particular reading of the supposed news report however, is not actualized solely through perspectivization. Through giving voice to Peters, certain negatively evaluative predications regarding immigrants have become part of the newspaper's discourse too.

\subsubsection{Nomination and predication strategies}

The most basic strategy of prejudiced discourse is the use of a referential strategy (Hart, 2010). Referential strategies can be used to exploit the human capacity for categorising coalitional groups in terms of a dichotomous in-group and out-group (Hart, 2010, p. 49). The discourse, through giving Peters voice, allows him to frame the debate in categorical terms, constructing a polarized discourse. Peters uses possessive determiners, e.g. 'to set up here and bring in their [my emphasis] own labour' to create an out-group (e.g. immigrants), thus implicitly constructing an in-group. He continues drawing boundaries

through the use of collective references such as nationyms (New Zealanders, a New 
Zealander, Kiwis) and metonymic toponyms (New Zealand) and places these in opposition to immigrants.

Studies into immigrant representation have shown that statistics and numbers are used more frequently to talk about immigrants in comparison to white majorities (McConnell, 2011). Such greater use of statistics to describe ethnic populations has been criticized for dehumanizing people (KhosraviNik, 2008, pp. 24, 28). The extract below offers such an example:

(1) Mr Peters said this suggested reducing the immigration quota from 50,000 to 10,000. (New Zealand Herald, 17 October, 2008)

In extract (1) immigrants are dehumanized through reference to them using terms such as numbers and quotas, e.g. ' 50,000 ' to ' 10,000 '. Other studies have argued that the treatment of immigrants as "statistics" makes them "the object of 'rational' economic calculation" and "a large horde 'legitimately' feared" (Van Leeuwen, 1996, p. 50).

As mentioned in the methodology section of this thesis, the referential strategies work hand in hand with predication strategies. Predication strategies can be defined as the "discursive qualification of social actors" (Reisigl \& Wodak, 2009, p. 94) or " the very basic process and result of linguistically assigning qualities to a person..." (Reisigl \& Wodak, 2001, p. 46). In this news report, and as will be discussed in Section 7.6, predication strategies work to achieve "emotive coercion" (Hart, 2010, p. 63). Hart (2010) defines "coercion" as "an intention to affect the beliefs, emotions and behaviours of others in such a way that suits one's own interests" (p. 63). With regards to discourse on immigration and asylum the objective is to convince text-consumers to support restrictive policies upon immigrants and asylum-seekers (Van Leeuwen and Wodak, 1999). The news discourse achieves this coercion by portraying immigrants as people who pose a threat. For example, companies owned by immigrants are referred to using dissimilation (words which denote difference) such as 'foreign company'. Van Leeuwen (1996) notes that differentiation of a social actor 
means that the discourse "differentiates an individual social actor or group of social actors from a similar actor or group, creating the difference between the 'self' and the 'other', or between 'us' and 'them' [his emphasis]' ( p. 52). The use of the word 'foreign' sketches immigrants as people who are very different from the in-group, namely New Zealanders. Later these immigrants and their 'foreign' companies are associated with a threat:

(2) "It is a great idea, as long as you are not a New Zealander looking for a job, or a manufacturer trying to compete against a foreign company that has no labour laws”. (New Zealand Herald, 17 October, 2008)

Immigrants are constructed as a threat to local jobs because they 'bring in their own labour'. The preposition in the phrasal verb 'bring in' is significant here. Prepositions among other words such as nouns, verbs and adjectives, can be used to conceptualize metaphors. A prominent metaphor present in immigration discourse is one which conceptualizes the country in terms of a container (Hart, 2010, p. 130). The use of prepositions like in/inside/out all index the existence of boundaries and hence "prompt for metaphoric conceptualizations... of non-specified container". (Hart, 2010, pp. 132-134). This metaphor construction is strengthened when the country is an island (Charteris-Black, 2006, p. 575) such as New Zealand. It can be argued that the country as a container/house metaphor is indirectly indexed here through the use of prepositions. Peters' discourse, through the use of the phrasal verb 'bring in' presents a spatial division where New Zealanders are inside and the immigrants are outside attempting to enter and hence threaten (topos of threat) the "Kiwis" by putting their jobs at risk.

The discourse also creates a sense of lawlessness among immigrants depicting them as not having any regulation or 'labour laws' (refer to extract 2 above). The discourse of lawless immigrants appears to be characteristic of Peters' speeches (see Section 7.3 for further examples). In this sense, the discourse is creating an imagined threat of a lawless invader. Hart provides a fascinating insight into how these stereotypes (i.e. threatening Other) have long historical, cognitive and psychological bases and how humans "perceive" threats even 
though they may not exist in "reality" (Hart, 2010, p. 54). In fact, the discourse of threat permeates the news report. This particular interpretation is supported by the use of the word 'compete' within a quote by Peters and a paraphrase in the news report:

(3) "During times when New Zealanders' jobs are at risk, immigration will be cut to ensure Kiwis did not have to compete with immigrants for jobs". (New Zealand Herald, 17 October, 2008)

The very word 'compete' creates a polarized image and sense of opposition and rivalry between two groups of people where one group, the out-group, is undermining the livelihood of the Other, the in-group. The solution given to this competition is to restrict and restrain the number of immigrants who enter New Zealand, securing the safety (against the proposed threat) of New Zealanders.

The threat discourse is also evident in the headline of the news report. The choice of the word 'protect' by the subeditor in the headline 'Peters wants immigration cuts to protect jobs' also presupposes the presence of a threat. The use of the verb 'protect' implies the existence of two categories, where one is perceived as a victim and the other as the attacker. Interestingly, a comparison of the actual election campaign speech indicates that the verb 'protect' used in the headline of the news report was not actually used by Peters and therefore this particular verb was chosen from a myriad of other potential verbs by the newspaper. This confirms the idea outlined at the beginning of the chapter that while news reports are commonly perceived to be objective, they can in fact become a vehicle for ideology.

Finally, closely related to the discourse of threat, is the discourse of abuse. Immigrants are not only a threat because they take away jobs, but, it is suggested, because they also abuse laws and policies. This discourse conceptualizes immigrants as social cheats. The writer's paraphrase of Peters' speech depicts immigrants as abusing New Zealand policies. 
(4) He [Peters] called for an end to the abuse of the family reunification policy. (New Zealand Herald, 17 October, 2008)

The agent of the action of abusing is left implicit by the writer. So the predications work hand in hand to portray immigrants as a threat, not only to the jobs of the local New Zealanders but also through the use of strong nouns like 'abuse' which portray immigrants as people who are non-law-abiding and are a threat to the safety of the people. This predication simultaneously serves an argumentative function which is discussed further below.

The news report quotes Helen Clark towards the end as using the noun phrase 'skilled people' to refer to immigrants. This is the only positive predication regarding immigrants in the whole news report. Simultaneously this noun phrase creates a sense of categorization and selection as well.

(5) "There's never been a time in New Zealand's history when we didn't need to bring in skilled people." (New Zealand Herald, 17 October, 2008)

Through the use of the adjective 'skilled', Helen Clark has specified (and hence narrowed down) a particular type of immigrant whom she perceives New Zealand to need, namely those with skills. Helen Clark identifies what she considers to be the benefits of a certain group of immigrants rather than depicting a more general positive representation of immigrants. This particular sorting of immigrants according to types (useful versus nonuseful) is evident in other articles of the New Zealand Herald (see 'NZ on hunt for more millionaires' in Appendix C where the newspaper discourse represents wealthy immigrants as desirable). In other words, the discourse creates a sense of hierarchy between various groups of immigrants which is to an extent a reflection of the immigration policies of a country. For example, in the case of New Zealand, immigration policies such as the Skilled Migrant Category (SMC) are based on a points system which prioritizes, through allocating additional points to skills and qualifications (see Chapter 2 for more information on 
immigration policies). Other studies have also pointed to such preferences being made. Wodak and Boukla, in their analysis of national immigration policies of Austria state that categorizations are being introduced in policies that welcome immigrants who are "highly qualified achievers" and reject those who are neither "educated nor qualified" (Wodak \& Boukala, 2015, p. 263). These point systems ensure that skills act as a criterion for the gatekeepers while deciding who is and is not beneficial and hence who can and cannot live in New Zealand.

\subsubsection{Argumentation strategies}

The newspaper discourse, by giving voice to Peters, presents various arguments as to why the number of immigrants needs to be 'cut'. It uses the topos of analogy, for example, to draw a comparison between immigrants and 'moths' implying that they are pests:

(6) Mr Peters used a campaign speech in Nelson to say "when times are tough internationally immigrants are attracted to New Zealand like moths to a neon light". (New Zealand Herald, 17 October, 2008)

The use of the 'moth' simile here to refer to immigrants dehumanizes immigrants by drawing a comparison between humans and insects. The simile could also imply that immigrants are a collective and homogenous group as all 'moths' are alike and travel/move (mindlessly) in groups. The negative connotation surrounding moths becomes clearer when the moth is compared with its more popular counterpart, the butterfly. The butterfly has been perceived as a symbol of beauty. It is a diurnal creature as it wanders during the light of the day. In contrast, the moth is nocturnal and wanders during the night (Brian, 2015) . While day is known in English literature to be a symbol of hope and life, night is a symbol of evil and death. The names given to butterflies and 'moths' also suggest the contrasting evocative meanings they have in the imaginations of people. Some common butterfly names are: Swallow-tails, White-peacock, Pearly-eyes, Angel-wings. On the other hand, a list of names of a variety of moth species is support that the moth is the butterfly's unwanted or less popular counterpart: Black witch, Death's-head, Hawkmoth, Imperial 
Moth, Blood-Vein. Connecting the findings from this analysis to the broader qualitative data set, it is worth noting that there are instances of verbs which denote animal metaphors being used to talk about immigrants as well (see Appendix $\mathrm{C}$ for discussion on the news articles entitled Speculators on the prowl and NZ on hunt for more millionaires).

Later the newspaper discourse provides another direct quote from Peters where he argues for the reduction of the immigration quota:

(7) 'During times when New Zealanders' jobs are at risk, immigration will be cut to ensure Kiwis did [sic] not have to compete with immigrants for jobs". Mr Peters said this suggested reducing the immigration quota from 50,000 to 10,000. (New Zealand Herald, 17 October, 2008)

The topos of exploitation is a common topos in immigrant discourse. In a broad sense, this strategy is used to depict immigrants as people who violate the basics of an unwritten social contract, namely "if an individual has access to group resources then they should contribute to the group-effectiveness" (Hart, 2010, p. 71). Based on this topos, studies show that immigrants are portrayed as people who take but do not give anything in return and hence exploit the in-group's generosity (Hart, 2010, p. 76). The news discourse draws on this topos in the extract below:

(8) He called for an end to the abuse of the family reunification policy "in other words, only immediate family". (New Zealand Herald, 17 October, 2008)

This argument can be reconstructed as below:

Topos of abuse: "if a right or an offer for help is abused, the right should be changed or the help should be withdrawn or measures against the abuse should be taken" (Wodak \& Iedema, 2004, p. 177). 
Premise: Immigrants abuse the family reunification scheme (an immigration policy) that New Zealand (generously) offers.

Conclusion: Stricter policies limiting the number of immigrants who can enter are needed.

As is evident in the extract above, the argument being made by Peters is that since immigrants exploit the in-group and 'abuse' the 'family reunification scheme', stricter policies need to be implemented. It is important to note, however, that this example portrays elements of cultural bias as the term 'immediate family' or 'nuclear family' could in some cultures include siblings, grandparents and relatives and not just parents and children as is prevalent in the Anglo Saxon or Pākehā context of New Zealand. The text presupposes that everyone in the world has a fixed meaning of what the word 'immediate family' entails. Fairclough (2015) asserts the danger of presupposition and discusses how media producers, by constructing ideal readers in the discourse, use presuppositions to construct fixed, commonsensical and taken-for-granted views of the world:

Producers in mass communication thus have a rather effective means of manipulating audiences through attributing to their experience things which they want to get them to accept. Because the propositions concerned are not made explicit, it is sometimes difficult for people to identify them and if they wish, to reject them. (Fairclough, 2015, p. 165)

In the case of extract (8), Peters is aligning himself with a certain sub-group in New Zealand, those who are from European or Anglo Saxon backgrounds while at the same time indirectly representing and also constructing a rather fixed meaning for the concept of 'immediate family'.

Elsewhere, Peters talks of how a 'free trade agreement' with China is a bad idea as it could result in 'foreign' companies establishing their own business in New Zealand and bringing 'their own labour' rather than employing from within New Zealand. 
(9) Mr Peters called the free trade agreement with China "foolish", saying it would allow Chinese companies "to set up here and bring in their own labour". (New Zealand Herald, 17 October, 2008)

The news report draws on the topos of "negative consequence". Drawing on the analysis provided by Reisigl and Wodak (2009), I will define the topos of negative consequence as:

Topos of negative consequence: If an action has a bad consequence, it should be avoided.

Premise: The free trade agreement results in the establishment of 'foreign companies' (rather than NZ owned companies) and job opportunities for foreigner labourers rather than New Zealanders.

Conclusion: The free trade agreement is 'foolish'.

In this extract, the discourse gives voice to Peters who is arguing that free trade agreements with 'China' would lead to more 'Chinese' labourers being employed rather than New Zealanders. This echoes the taking our jobs discourse which is a component of antiimmigrant discourse (Mehan, 1997).

As mentioned earlier, Peters is not the sole actor within the discourse and the initial voice of Peters is met with the very brief reaction of Helen Clark at the end of the news report:

(10) "There's never been a time in New Zealand's history when we didn't need to bring in skilled people." (New Zealand Herald, 17 October, 2008)

Helen Clark's quote draws on the topos of history. A reconstruction of the topos is as follows: 
Topos of history: Because history teaches that specific actions have specific consequences, one should perform or omit a specific action in a specific situation (allegedly) comparable with the historical example referred to. (Wodak \& Iedema, 2004, p. 177)

Premise: History shows that we have always needed skilled immigrants to fill our labour shortages.

Conclusion: Immigration quota should not be reduced.

Helen Clark draws on past experience to argue that New Zealand has at numerous stages in the past been in need of skilled immigrants to fill positions. Therefore, she uses this topos to argue that the immigration quota should not be reduced. The historical nature of her comment is also reflected in her choice of verbs, the present perfect in 'have never been' which accentuates that New Zealand has historically had problems in filling job positions and has therefore relied on immigrants.

\subsubsection{Discussion}

In the news report analysed above, the discourse offers two contrasting political perspectives on the topic of immigration. Peters makes his anti-immigration stance clear. He argues for fewer immigrant numbers stating that immigrants are a threat to locals. The news discourse presents Peters' arguments, mainly in the form of direct and indirect quotes. Helen Clark's pro-immigrant stance is made evident as well. Her pragmatic argument, i.e. New Zealand has throughout history needed immigrants, is given as a reaction to Peters' comments again both in the form of direct and indirect quotes. However, she is clearly identifying a particular type of immigrant that she proposes New Zealand needs: 'skilled' immigrants.

On initial study of the text, it appears that the newspaper provides no indication as to which stance it takes and by remaining neutral stays true to its purpose, i.e. offering objective news. However, the analysis in this section is carried out with the awareness that perspectivization plays an important role in representation. Through scrutinizing the news 
discourse and contemplating the perspectivization strategies employed, it becomes clearer that the choices (conscious or unconscious) made regarding voice allocation, positioning of these voices, and the choice of words by the newspaper mean that in this case, the antiimmigrant sentiments received more coverage and is expressed with more force than proimmigrant ones. Despite the presence of two opposing perspectives on the topic of immigration, each perspective does not get equal treatment.

The newspaper has discretion over the choice of who the reaction should be from and in this case it is noteworthy that the perspectives of important social actors, such as influential members of the immigrant communities, have been ignored. The newspaper possesses the power to "determine the selection and transformation of information communicated in particular genres. That is, the text-producer's power to dictate topics discussed and the way they are framed" (Hart, 2010, p. 63). The news discourse gives extensive voice to Peters where immigrants are stigmatized (see extracts under referential and predication strategies of this analysis for examples where immigrants are stigmatized) yet does not draw on the immigrant community as a source allowing them the opportunity respond to this. Extensive and repetitive use of this exclusion could imply that experts, politicians or officials external to the topical group are better qualified to speak about and for these people (Loto et al., 2006; Teo, 2000).

In this analysis, the news discourse through its positioning and presentation of voices contributes to a more subjective account of the events than initially expected. These observations contest the objectivity of, and raise questions about the extent to which, writers are influencing the news discourse. 
7.3 Textual Analysis 2: An opinion piece entitled 'Peters blind to inconvenient truth' under the theme of 'Immigration and election'.

\subsubsection{Context window}

In 2008, Winston Peters, the New Zealand First party leader and Foreign Minister at the time, became involved in a controversial dispute over a sum of donations (100,000 NZD) to the party which went against the parliamentary gift policy. According to New Zealand parliamentary rules, any gift over $\$ 500$ must be disclosed. When the matter became public, the Serious Fraud Office (SFO) was involved and initiated an official inquiry into the matter. The dispute led to Peters' resignation until investigations led by the SFO were complete. Peters was later cleared. This incident and the investigation by the SFO received a great deal of media attention and may have contributed to the New Zealand Party receiving insufficient votes to be elected in the 2008 election. The opinion piece below uses the fraud event described above as a way to discredit Peters and the claims he makes about immigration. While the first half of the opinion piece focuses on belittling Peters and his arguments on immigration, the second half of the body deals directly with representing immigrants in a positive light. In the following section, I provide an analysis of the strategies of this opinion piece.

This opinion piece adheres to typical features such as starting with a lead-in paragraph, followed by the main body and finally the concluding sentences (see Bell, 1991, pp. 147176 for core components of news discourse). In the main body, the writer aims to do two things:

1) De-legitimize Peters' character and, through the de-legitimization of the Other (i.e. here Peters), legitimize the presence of immigrants in New Zealand. The picture the discourse paints of Peters is that of an Other who is unreliable, and who perpetuates misinformation regarding immigrants. 
2) Present statements made by Peters during his election campaign, and subsequently rebut these racialized statements by providing statistical information about immigrants which portray them in a positive light.

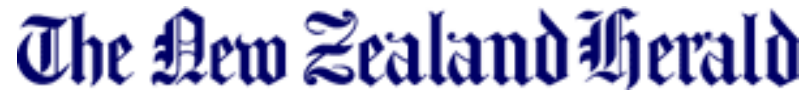

\author{
New Zealand Herald — - A17 — 23 July 2008
}

Brian Rudman: Peters blind to inconvenient truth

AT HIS pre-election rally on Sunday, New Zealand First leader Winston Peters tried to inspire his followers to cast off their walking sticks and "act today" by borrowing Brutus's famous call to arms. "There comes a tide in the affairs of men, which, if taken at the flood, leads to fortune."

What he omitted to tell his granny-packed audience was that disloyal Brutus failed to take his own advice. Having treacherously stabbed his boss Julius Caesar to death, Brutus lost the subsequent battle for power and was reduced to pleading with his Peter Brown-equivalent to hold the sword steady so he could run against it and die.

But Foreign Minister Peters has never been a great one for the small details. Like asking who was the mysterious fairy godfather who miraculously made his legal bill go down $\$ 100,000$ overnight.

Perhaps he didn't want the complication of knowing he'd been bailed out with dirty foreign cash. For as an election looms, the man who is supposed to be the acceptable face of New Zealand abroad is once again winding up his xenophobic barrel organ.

According to his speech notes, he predicted to his Alexandra Park Raceway audience that "what we know points to the dirtiest campaign New Zealand has ever seen, full of smears, allegations and lies".

Of course, it's easy to be the oracle when you're the one setting the agenda.

After his usual warm-up against gangs and white-collar criminals and foreign this and that, he was off on the anti-immigrant trail, claiming we have "the most scandalous immigration policy in the Western world".

"Look at what is happening in Auckland _ the immigration capital of New Zealand.

Just last night on TV the tragedy of our flawed immigration system was highlighted: murders and kidnapping."

He wailed that the New Zealand First convention "was pushed to third place" _ presumably a reference to its slot on the night's TV news bulletin. "Remember the years we spent warning them this would happen. The crime wave in Auckland is all too real _ as are its racial and ethnic undertones."

Only Mr Peters could turn a recent cluster of attacks against Asian immigrants into an Asian crime wave with sinister undertones. 
Brutus, who lived _ and perished _ on believing and spreading false rumours, would have recognised a kindred spirit.

What crime wave? Nationwide, homicides have dropped from 109 to 88 in the past two years. In South Auckland, which has been the recent centre of attention, there were eight homicides last year compared with 27 in 2006.

On a population basis, recorded offences have dropped over the past eight years.

As for "racial and ethnic undertones", the defining undertone in recent high-profile cases has been that it's the victims who appear to have been Asian.

Mr Peters implies the reverse, demanding that "we must support those who come to this country with a proper civics education programme which ensures our values and basic laws are taught and understood".

Given that the newcomers to this country are more likely to be the victims than the perpetrators of crime, perhaps a more vital priority would be to make such civics courses compulsory for every young New Zealandborn Kiwi.

A police report from December 2004, Working Together with Ethnic Communities, noted that Asians (which includes Indians), represent 6.5 per cent of the population but only 3 per cent of "recorded apprehensions".

As for being ropey drivers, Asian drivers represented 5 per cent of all motorists involved in recorded crashes in 2002, and only 2 per cent of fatal crash drivers.

After Deborah Coddington's anti-Asian meltdown in North \& South magazine in 2006, journalist Keith Ng analysed the figures and came up with a rather different picture.

He calculated that in 1996, Asians (including Indians) made up 3.8 per cent of the population and accounted for 1.9 per cent of those apprehended for crimes. By 2005, Asians made up 9.3 per cent of the population and represented 2.6 per cent of all apprehensions.

"So, as the proportion of Asians in the country increased threefold, their representation in crime statistics rose by only a third."

He concluded that, roughly speaking, “Asians are about a quarter as likely to be criminals as the average person in New Zealand."

It hardly backs the Asian crime wave nightmares of Coddington's and Peters' sleepless nights. Rather the reverse.

Still, Mr Peters is not likely to let such inconvenient facts get in the way of a good stir. Not when he can claim they come from a lackey like me of "the foreign-owned media".

(C) The New Zealand Herald, nzherald.co.nz 
In the lead, the writer uses the typical characteristics of a lead-in paragraph and answers the Who? What? Where? When? Why? and How? questions but does so using a touch of humour which suggests 'Winston Peters' and his elderly followers are not physically fit:

(1) At his pre-election rally on Sunday, New Zealand First leader Winston Peters tried to inspire his followers to cast off their walking sticks and "act today" by borrowing Brutus's famous call to arms. "There comes a tide in the affairs of men, which, if taken at the flood, leads to fortune". What he omitted to tell his grannypacked audience was that disloyal Brutus failed to take his own advice. (New Zealand Herald, 23 July, 2008)

The humorous expression 'cast off their walking sticks' suggests that Peters mainly has support from a particular sub-group of society namely female senior citizens as evident through the use of the phrase 'granny-packed audience' in the co-text. Reference to a Shakespearean character and a quote from him shows that the writer perceives his readership to be well educated and familiar with classical plays such as Shakespeare's Julius Caesar. In addition, from the outset the writer aligns himself with those who perceive Peters as a political failure who attempts to influence the perception of his followers, e.g. 'Winston Peters tried to inspire his followers'. The verb 'tried' presupposes that Peters frequently fails to succeed.

The writer uses humour and mockery as his point of departure but later in the body of the piece he uses various strategies to portray immigrants as good and decent citizens. The most salient strategy in this opinion piece is that of argument. The prominence of argumentative discourse is a conventional characteristic of newspaper commentaries.

\subsubsection{Argumentation strategies}

One strategy through which the writer of this opinion piece indexes and substantiates the illegitimate Other (i.e. Peters) is through the construction of arguments. The discourse draws on three main topoi, e.g. topos of ad hominem, topos of numbers, and topos of 
authority to rebut Peters' anti-immigration claims. I discuss all three in detail as they play an important role in constructing the main argument of the opinion piece, namely that Peters is an unreliable source of information regarding immigrants.

An ad hominem argument attacks a person's character rather than addressing the content of the argument (Walton, 2004). For example, as is evident in the extract below, the writer aims to discredit Peters by mentioning his past:

(2) But Foreign Minister Peters has never been a great one for the small details. Like asking who was the mysterious fairy godfather who miraculously made his legal bill go down \$100,000 overnight. (New Zealand Herald, 23 July, 2008)

This particular extract refers to what was frequently referred to as a political scandal outlined in the context window. By referring to this case, the writer aims to portray Peters as a man who lacks integrity and who cannot be trusted. The linguistic features of extract (2) also substantiate the fact that the writer conceived of Peters as always having lacked integrity. The writer uses the present perfect tense separated by the adverb 'never', e.g. 'has never been' possibly to index the historical nature of Peters' disingenuous character, i.e. Peters has never been honest in the first place. The argument can be reconstructed as follows:

Topoi of ad hominem: Because person $\mathrm{X}$ has conducted/engaged in immoral behavior, person X's argument is invalid. (see Walton, 2004 for details of the ad hominem topoi)

Premise: Peters was involved with 'dirty foreign cash' (New Zealand Herald, 23 July, 2008).

Conclusion: His argument regarding immigration should not be trusted. 
The writer uses this argumentative strategy to depict Peters as somebody who intentionally misleads his audience on various topics, among which immigration is one. Since he has a history of immoral behavior, he should not be trusted now either.

The opinion piece expresses strong disapproval of claims made by Peters on the impact of immigration during his speech, e.g. stating 'after his usual warm-up against gangs and white-collar criminals and foreign this and that, he was off on the anti-immigrant trail, claiming...' before introducing Peters' claims in the form of direct quotes, probably to distance the writer's opinions from those of Peters as much as possible:

(3) "Remember the years we spent warning them this would happen. The crime wave in Auckland is all too real as are its racial and ethnic undertones... Look at what is happening in Auckland the immigration capital of New Zealand... Just last night on TV the tragedy of our flawed immigration system was highlighted: murders and kidnapping.” (New Zealand Herald, 23 July, 2008)

However, despite the writer's distancing attempt, as is evident in the extract above, the news discourse, by giving voice to Peters, depicts immigrants as a lawless group who pose a threat. Peters makes two arguments here, namely immigrants are a threat and that this threat needs immediate attention. He achieves this through portraying immigrants as the agents of 'waves' of 'crime'. It has been previously argued that liquid metaphors are used in right-wing political communication on immigration (Charteris-Black, 2006) to construct immigration as out of control (Van der Valk, 2003, p. 331). In this case, it seems that the use of the liquid metaphor 'wave' is used for a similar purpose, that is, to construct immigrants' involvement in crime as getting out of control. Through this metaphor, Peters' discourse creates a two-fold threat alert. Immigrants are dangerous not only because they resort to crime but also because they are the agents of uncontrollable numbers of crime incidents. The use of liquid metaphors in right-wing political discourse is said to "activate both disaster and container scenarios" (Charteris-Black, 2006, p. 569). The container scenario, I argue, is indexed in the opinion piece through creating a sense of closeness of 
threat. Peters' rhetoric shows that we need to act quickly as the source of the problem is here and affecting us. This example highlights the threat through the use of proximization. Proximization occurs when "the threat depicted in the predication is presented as close to or approaching" (Hart, 2010, p. 84) the reader. This closeness can be with regards to time (i.e. temporal proximization) or with regards to space (i.e. spatial proximization). In this example, temporal proximization is indexed through the use of the adverb 'just' in 'just last night', and the use of the present continuous in 'what is happening' rather than the past simple. Spatial proximization is indexed through the prepositional phrase 'in Auckland' which indicates that the threat is close and inside the country. These features of the discourse, therefore, signal and accentuate the temporal and spatial proximity of the events and hence the proximity of the threat in general.

In the second part of the body, the news discourse refutes Peters' arguments. The writer relies on the topos of numbers and discredits Peters' claims by directing his readers to statistics which show that crime rates have decreased with the increase of immigration. He refers to 'nationwide' statistics and statistics pertaining to areas heavily populated by immigrants, such as 'South Auckland':

(4) What crime wave? Nationwide, homicides have dropped from 109 to 88 in the past two years. In South Auckland, which has been the recent centre of attention, there were eight homicides last year compared with 27 in 2006. On a population basis, recorded offences have dropped over the past eight years. (New Zealand Herald, 23 July, 2008)

The writer continues his argument by providing more statistics which show that immigrants, and in particular Asians, commit fewer crimes in proportion to the size of their population (N.B. this extract is also discussed under topos of authority; see below).

(5) A police report from December 2004, Working Together with Ethnic Communities, noted that Asians (which includes Indians), represent 6.5 per cent of 
the population but only 3 per cent of "recorded apprehensions". (New Zealand Herald, 23 July, 2008)

The writer relies on providing statistics to his readers to convince them that immigrants do not cause an increase in crime. So the topos of numbers is used here to construct a different conclusion rule than previously formulated by discourse analysts. While in other studies, the discourses analysed are shown to consistently construct immigrants as a large uncontrollable threat, here the analysis indicates that they are not involved in criminal activities. The writer uses this particular argumentative strategy repeatedly, rebutting Peters' arguments using statistics. The topos of numbers can be reconstructed as follows:

Topos of numbers: "if the numbers prove a specific "topos", a specific action should be performed/not be carried out" (Wodak \& Iedema, 2004, p. 177).

Premise: Statistics show that crimes rates are not higher among the Asian community.

Conclusion: Peters' claims regarding the increase in numbers of crimes are baseless.

The use of topos of numbers to counteract Peters' statements is given resonance by the mere fact that this topos is used nine times throughout the opinion piece. In other words, the writer uses statistics (nine times) in an attempt to refute the claim that immigrants cause problems or crimes in New Zealand. The repetition of this topos in itself mitigates Peters' claims and strengthens the force of the writer's.

Finally, in extract (5) above, the writer, in addition to referring to statistics (hence the topos of numbers) adopts the topos of authority by referring to 'police reports' which prove that immigrants, relative to their general numbers in New Zealand, are less likely to be recorded for apprehensions: 
Through reference to reports and data given out by reputable and reliable sources such as a 'report' by New Zealand police, the writer aims to persuade his readers that his propositions are valid. The topos of authority is discussed in more detail in Section 7.4. The discourse, however, does not rely solely on argumentation strategies to discredit Peters.

\subsubsection{Predication strategies}

Similar to the argument outlined above, the article employs a combination of predications to support its anti-Peters position and as a consequence indicates its pro-immigrant position. It does this mainly through discrediting claims that Peters makes with regards to the role of immigrants in New Zealand and secondly through painting a more positive representation of immigrants by providing statistics which refute Peters' claims that they lead to 'crime waves' in New Zealand.

In this process, Peters is portrayed in a negative light in numerous ways. He is mainly identified as the agent of actions with highly negative connotations. Elsewhere, the discourse relies on figures of speech such as similes by drawing a comparison between Peters and a well-known literary character known for his misdoings, Brutus. For example, Peters is described as somebody who is blind to the truth as conveniently summarized in the headline 'Peters blind to inconvenient truth'6 (New Zealand Herald, 23 July, 2008). He is also represented as an unacceptable face of New Zealand who (1) irritates people with his xenophobic comments, e.g. 'For as an election looms, the man who is supposed to be the acceptable face of New Zealand abroad is once again winding up his xenophobic barrel organ' (New Zealand Herald, 23 July, 2008), (2) exaggerates crime figures, e.g. 'only Mr Peters could turn a recent cluster of attacks against Asian immigrants into an Asian crime wave with sinister undertones' (New Zealand Herald, 23 July, 2008), (3) spreads false information 'Brutus, who lived and perished on believing and spreading false rumours, would have recognised a kindred spirit' (New Zealand Herald, 23 July, 2008) and (4) omits

\footnotetext{
6 "An inconvenient truth" is also the name of Davis Guggenheim's award winning documentary film.
} 
to tell the public what is 'inconvenient' for his (political) purpose, e.g. 'Mr Peters is not likely to let such inconvenient facts get in the way of a good stir' (New Zealand Herald, 23 July 2008).

More importantly, these evaluative attributions of negative traits and analogies are accompanied by more positive evaluations of immigrants. Immigrants are described as less likely to cause accidents, e.g. 'as for being ropey drivers, Asian drivers represented 5 per cent of all motorists involved in recorded crashes in 2002, and only two per cent of fatal crash drivers'(New Zealand Herald, 23 July, 2008). They are also described as less likely to commit crime than locals, e.g. "Asians are about a quarter as likely to be criminals as the average person in New Zealand' (New Zealand Herald, 23 July, 2008). Moreover, they are referred to as being victims of hate crime rather than perpetrators of them, e.g. 'given that the newcomers to this country are more likely to be the victims than the perpetrators of crime, perhaps a more vital priority would be to make such civics courses compulsory for every young New Zealand-born Kiwi' (New Zealand Herald, 23 July, 2008).

\subsubsection{Mitigation strategies}

Mitigation "involves weakening rather than the strengthening of the force with which the illocutionary point of particular speech act is presented" (Holmes, 1984, p. 345). Holmes (1984) continues to outline one of the reasons mitigation is used which is to convey "the speaker's [in this analysis the writer's] attitude to the content of the proposition"( p. 348). It is important to note that this opinion piece was one of very few texts of the broader qualitative dataset which consisted of 20 articles that contains salient mitigation strategies. As a consequence, it can be argued that the absence of mitigation strategies in the newspaper discourse in these five news articles is marked. The use of mitigation strategies in this opinion piece suggests that the propositions made are contestable and not certain.

Being an opinion piece, the dominating perspective is that of the writer, who in this instance places himself in direct opposition to Peters and his anti-immigration rhetoric. When Rudman gives voice to Peters, this is mainly done in the form of direct quotes to distance 
himself from the content of Peters' claims. The direct quotes are frequently introduced by verbs which have a mitigating effect on Peters' statements and suggest doubt about their

validity. Some of the verbs the writer uses to introduce Peters' statements are 'claims', 'wailed', 'implies'. For example, in the following extract the use of the verb 'claim' is of interest as it could be argued it is used to distance the writer from Peters and to indicate the writer questions the validity of the proposition advanced by Peters. The analysis of the various strategies (e.g. topos of ad hominem) point to not only a high level of skepticism but also contempt on behalf of the writer himself towards Peters. This may lead to the assumption that the word 'claim' here is not only used to distance but at the same time seriously question Peters' statements:

(6) After his usual warm-up against gangs and white-collar criminals and foreign this and that, he was off on the anti-immigrant trail, claiming we have "the most scandalous immigration policy in the Western world". (New Zealand Herald, 23 July, 2008)

The analysis above has shown that there are numerous lexical linguistic cues, e.g. argumentative, predication, and mitigation strategies throughout the column which all deprecate Peters' anti-immigrants discourse.

\subsubsection{Discussion}

This opinion piece is punchy and direct and uses humour to make its point. It has one overarching argument, namely that Peters is misleading the public in his pre-election campaigns about immigration. It expresses this argument through two moves. The first is an attempt to discredit Peters and his arguments on immigration. The second is an attempt to rebut Peters' claims on immigration by relying on statistics to justify why immigrants should be welcomed and included in New Zealand society rather than excluded.

By adopting the argumentative topoi of ad hominem and numbers the newspaper discourse achieves two broad purposes. It attempts to discredit Peters and his anti-immigrant views 
and to advocate for immigrants. The initial argument is that Peters is unreliable and should not be trusted. This is supported by referring to past fraud incidents in which Peters was accused of accepting money discreetly during his position as a politician. In the second part of the opinion piece statistical evidence to support the claim that immigrants, contrary to Peters' claims, are in fact involved in fewer crimes and road accidents, is provided. As mentioned earlier, this constructs a different conclusion rule as the topos of numbers is previously argued to be used to construct immigrants as a threat.

In addition to the two argumentation strategies which were the most salient strategies and consistent with the fact that the news article is an opinion piece, predication, perspectivization and mitigation strategies were used to distance the writer from and demean Peters. In doing so, the discourse not only presents Peters as the Other, but also presents a favourable portrayal of immigrants, namely as people who are law-abiding, rather than people who cause problems.

This opinion piece offers a unique representation in the sense that it clearly places the local kiwi politician in the position of the Other, and embraces immigrant communities as the Self. The writer takes the position of a 'defender and supporter' of immigrant communities. However, it needs to be acknowledged that this was only achieved by distancing immigrants from actions that they are commonly portrayed to be contributing to, such as committing crime, and that the article continues to describe immigrants in terms of statistics. In other words, immigrants are still talked about against a backdrop of crime. An even more favourable representation would have been one where the opinion piece referred to personal stories of immigrants which represent them as agents of positive deeds and actions such as volunteering or contributing their time to local charities. 
7.4 Textual Analysis 3: News report entitled 'Schemes aim to make use of rich migrant resource' under the theme of 'Recruitment'.

\subsubsection{Context window}

This news report introduces two schemes provided for immigrants with the purpose of aiding immigrants to find suitable and relevant jobs based on their skills and qualifications. The first scheme is called the Omega Mentoring Programme and is funded by the Tindall Foundation. The Tindall Foundation is a private family foundation which provides funding to communities throughout New Zealand. According to their website, the Omega Mentoring Programme aims to "build diverse and effective workplaces by linking immigrants with similarly skilled business professionals, who offer sector-specific mentoring with the aim of removing the barriers preventing entry to the workforce" (Tindall website). The second scheme is called the Migrant Action Trust and focuses on the settlement and integration of immigrants and refugees: "Migrant Action Trust (MAT) helps migrants and refugees to settle in New Zealand. We offer support from the moment migrants arrive, and continue to help them become fully integrated into New Zealand society" (Migrant Action Trust website).

The writer initially introduces the two schemes and then argues these schemes are useful as they provide immigrants with a smoother transition into the New Zealand workplace. The news report appears to be offering immigrants information about services and for this reason alone can be perceived as working to immigrants' advantage. However, on a more critical note, through subtleties in its referential and predication strategies, the discourse simultaneously represents immigrants as commodities, unemployed and passive, and in need of help. These points are elaborated below. 


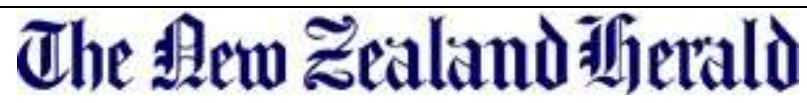

New Zealand Herald -22 Dec 2007

Schemes aim to make use of rich migrant resource

By Simon Collins Social Issues Reporter

Almost every New Zealander can tell a story about a taxi driver with an advanced degree in engineering or business.

Next year, at last, two new schemes will be launched to make better use of migrants' skills, estimated to cost the country billions of dollars in lost potential.

The Tindall Foundation has given $\$ 450,000$ to a programme, backed so far by 34 of Auckland's biggest businesses, that will provide mentors and internships to migrants seeking jobs in their skilled areas.

And the ASB Trust and Lottery Grants Board are funding a smaller scheme to help refugees into work.

Committee for Auckland director Kaaren Goodall, who has helped put the first scheme together, says Auckland is wasting billions of dollars of economic potential by letting highly qualified immigrants drive taxis or work in warehouses or supermarkets.

"We are one of the top cities in the world for the number of people foreign-born, with one in three of us. We are a wonderfully diverse bunch," she said.

The committee modelled the new scheme on one in Toronto, Canada, which has found skilled jobs for 85 per cent of its clients.

A trial this year found jobs for four out of nine migrants, including an Indian software specialist who had driven a taxi for five years. He found a job in his field in three weeks through his mentor's networks.

"The way most people get jobs in New Zealand is through word of mouth and networks," said Simon Vannini, a lawyer at Simpson Grierson who helped organise the trial as part of a leadership training scheme.

A refugee from Burundi, Odetta Ntezicimpa, has found a job at the Christian charity Child Fund through the second new scheme, run by the Auckland Regional Migrant Services Trust in Mt Roskill.

A trained teacher in her home country, she was forced to flee because of war in 1993 and spent five years as a refugee in Tanzania and Kenya before gaining resettlement in New Zealand in 1999 with her partner and their first two children, then aged 3 and just two months.

She worked as a caregiver but her goal is to qualify here as a teacher or a social worker.

She attended the migrant trust's pilot employment programme for refugees, and found a job when Child Fund asked the trust to recommend someone who knew about the countries where it runs development programmes. She now liaises with the fund's 25,000 child sponsors in this country.

"I do like to talk to people. That is my vocation," she said.

The migrant trust's director, Dr Mary Dawson, said the scheme would be extended next year to new places such as Selwyn College, which already runs English language courses for refugees.

Massey University sociologist Paul Spoonley said New Zealand had taken a long time to realise that it needed to work actively to make the best use of the diverse migrants who have come here.

"I think we assumed that they would just adjust without any help from ourselves, and it's now great to see that there are some programmes that are actually beginning to deliver good jobs to the immigrants."

(C) The New Zealand Herald, nzherald.co.nz 


\subsubsection{Nomination and predication strategies}

The first feature of this news report is its adherence to lexical structures that highlight that the value given to immigrant communities is one of a utilitarian form. In other words, there is a strong economic base to the news report and immigrants are discussed in terms of how they result in losses to the country's economy or how they can contribute to the economy. This is achieved through the choices the writer makes when referring to immigrants and the verbs the writer uses.

In line with the argument that the news report adopts a utilitarian or capitalist perspective, one notes that immigrants are represented as commodities which need to be used adequately and efficiently in order to lead to a good economy. There are studies which show that the discourse of the media does not necessarily contradict those produced by other organs within a society and that in fact these discourses are "jointly produced, each acting within its own sphere of influence and control, but each also dependent on the other" (Van Dijk, 1995, p. 29). Supporting Van Dijk's (1995) observation that discourses are "jointly" produced by various organs of a society, this "instrumental" perspective of immigrants is also reflected in this news report. For example, the headline uses the economic anthroponym 'rich migrant resource' to refer to the immigrants. The word 'resource' is commonly used to refer to the collective wealth of a country or its means of producing wealth. This noun phrase along with the phrasal verb 'make use of' indexes a very instrumental, utilitarian, and neoliberalist discourse regarding immigrants where they are perceived as mere commodities that need to be utilized for economic and financial benefits. In addition, the use of the term 'resource' to refer to immigrants can also be argued to be dehumanizing, converting human beings into what is commonly perceived as physical stocks, supplies, money etc. The phrasal verb is used once again in the body of the text. However, there, 'migrant resource' is replaced with 'migrants' skills':

(1) Next year, at last, two new schemes will be launched to make better use of migrants' skills, estimated to cost the country billions of dollars in lost potential. (New Zealand Herald, 22 December, 2007) 
This creates the concept that 'migrants' skills' is an entity external to the 'migrants' themselves, whereas in fact, these skills are an internal entity and thus it can be argued that 'make use of migrants skills' is in fact synonymous to 'make use of migrants' themselves. The verb 'use' also indexes a utilitarian perspective of immigrants. In particular, it has a negative connotation when used with a human object. When the verb 'use' occurs with a non-animate object, it has no negative connotation, e.g. use the computer. However, when the verb 'use' occurs as the verb with an animate direct object, e.g. He used her, its negative connotation becomes visible.

The capitalist discourse is realized further through referential strategies where capitalist oriented subject identities such as 'clients' are used to refer to immigrants, and through the use of discourses denoting profit and loss, such as ' ... estimated to cost the country billions of dollars in lost potential' in extract (1) and 'wasting billions of dollars of economic potential' in example 2 below:

(2) Committee for Auckland director Kaaren Goodall, who has helped put the first scheme together, says Auckland is wasting billions of dollars of economic potential by letting highly qualified immigrants drive taxis or work in warehouses or supermarkets. (New Zealand Herald, 22 December, 2007)

As is evident in the extract above, capital gains and loss are used as a yardstick to determine whether immigrants ought to find jobs or not. The broader qualitative data set confirms that immigrant groups benefits are pre-dominantly discussed within an economic framework, i.e. le migrateur pour l' économie and not le migrateur pour le migrateur.

The second dominant discourse of this news report is that of underemployment. Immigrants are represented as occupying jobs and roles which do not match their skills or as underemployed, i.e. despite having skills and qualifications they are employed in professions which do not 'make use' of them. The news report discourse in the opening line represents this state of immigrants as given knowledge among the public in New 
Zealand and states that 'almost every New Zealander can tell a story about a taxi driver with an advanced degree in engineering or business' (New Zealand Herald, 22 Dec, 2007). The text makes reference to various professional anthroponyms, e.g. 'taxi drivers', and the more professional positions, e.g. 'software specialist', 'teacher', 'social worker'. The latter professional positions are only mentioned as jobs which immigrants succeeded in finding after enrolling in the programme or as positions that immigrants hope to hold one day.

(3) She worked as a caregiver but her goal is to qualify here as a teacher or a social worker. (New Zealand Herald, 22 December, 2007)

The discourse highlights a gap between the position immigrants hold and the professional positions that they would ideally like to be in.

Finally, the text indexes the passiveness of immigrants in a variety of ways. Previous studies also substantiate a representation of immigrants as passive. Lirola ( 2014) in her study of the representation of sub-Saharan immigrants in Spanish newspapers found that, in terms of linguistic features, immigrants are represented as passive "in all the news items" (Lirola, 2014, p. 488). In the context of Britain, studies also indicate that immigrants are constructed as people in need (Andreouli \& Dashtipour, 2014, p. 105). This is typically achieved through the use of the passive voice, i.e. "to make clear that immigrants need the help and support of the Spanish population" (Lirola, 2014, p. 488). Van Leeuwen ( 1996) defines activation as "when social actors are represented as the active, dynamic forces in an activity" and passivation of social actors as "when they are represented as 'undergoing' the activity or as being 'at the receiving end of it' [his emphasis]" (Van Leeuwen, 1996, p. 44). He further elaborates on the subcategories of "subjected" passivization versus "beneficialised" passivization. In the first, the social actors are placed in the position of objects, whereas in the latter, the social actors benefit (positively or negatively) from the action. Passivization of immigrants in this news report is achieved by representing immigrants as people who need help or as beneficiaries. The extracts below are two such examples: 
(4) The ASB Trust and Lottery Grants Board are funding a smaller scheme to help refugees into work. (New Zealand Herald, 22 December, 2007)

(5) "I think we assumed that they would just adjust without any help from ourselves, and it's now great to see that there are some programmes that are actually beginning to deliver good jobs to the immigrants". (New Zealand Herald, 22 December, 2007)

Although the discourse expresses a sympathetic tone, these extracts foreground a discourse in which immigrants are represented as people who need schemes and help from the New Zealand government in order to find suitable jobs. The first extract describes funds which are allocated to immigrants — in particular refugees — to find jobs. The co-text indicates that immigrants are represented as being highly skilled and qualified yet in need of various programmes and schemes to help them become employed. The second example above describes how previously immigrants were not offered any help and were expected to adjust.

In line with this point, it is worth noting that, in this news report, the newspaper discourse does not assign any form of agency to immigrants. In extract (5), despite the facts that immigrants are placed in agent positions, the co-text suggests that the expectation that immigrants would find jobs by themselves is a false expectation. In addition, the news discourse gives the impression that not only are immigrants not able to find jobs by themselves, but that jobs are 'delivered' to them. In extract (5), the discourse assigns agency to 'programmes' rather than immigrants and states that it is programmes and schemes which deliver jobs to immigrants. This is also true of extract (6):

(6) The committee modelled the new scheme on one in Toronto, Canada, which has found skilled jobs for 85 per cent of its clients. (New Zealand Herald, 22 December, 2007) 
As evident in the extract above, the discourse represents immigrants as 'clients' who benefit from the schemes. It is 'schemes' which are striving to get them employed and 'make use' of immigrants' skills.

\subsubsection{Argumentation strategies}

The representation of immigrants as people who are underemployed and who require systematic help from governmental bodies and various schemes to find jobs is also realized through various argumentation strategies. The main argument of the discourse appears to be that New Zealand needs to launch and fund various programmes to ensure that immigrant skills are made use of in order to prevent economic waste. This macro argument is realized through a variety of topoi such as the topos of cost, topos of numbers, topos of positive consequence, and topos of authority (see Van der Valk, 2003; Wodak \& Iedema, 2004 for list of topoi and their definitions). It is important to note that these topoi are intertwined and work hand in hand towards the macro argument that unemployed immigrants are a problem. For example, when the news report refers to the positive consequences of employed immigrants, it draws on statistics (topos of numbers) to prove that the schemes and programmes are successful. I will use examples from the news report to reconstruct the topoi of cost, positive consequence and authority as these are the most salient in terms of frequency.

The first argumentative strategy that I discuss is the topos of cost. As highlighted in extract (1) discussed earlier, the news report is heavily economic in its perspective on immigrants and its view as to why various organizations in New Zealand need to help them. In the example discussed above, I have argued that that the discourse constructs the value of immigrants only with regards to their economic contributions. In other words, economic productivity is used as a benchmark, a measure open to much debate, against which the extent to which an immigrant is considered useful or useless is judged. The macro argument is legitimated through the topos of cost which can be reconstructed as below: 
Topos of cost: "if a specific situation or action costs too much money or causes a loss of revenue, one should perform actions which diminish the costs or help to avoid the loss". (Wodak \& Iedema, 2004, p. 177)

Premise: Having highly skilled yet unemployed immigrants, costs 'billions of dollars'.

Conclusion: Immigrants should be helped into finding jobs.

The topos of cost is further supported with reference to statistics and numbers which indicate approximately how much money is wasted, e.g. 'billions of dollars'. Both in extract (1) and in extract (2) introduced below, precise numbers referring to money in the form of direct and indirect forms are given to further accentuate the need for schemes. Financial reasons are given as to why New Zealand needs to launch programmes and schemes to help immigrants become employed, further highlighting the economic base of the news report.

The second topos, which is used three times in the discourse of this news report, is the topos of positive consequence. In the extract (6) above, the discourse depicts programs as essential by referring to similar schemes which were very successful in other countries, e.g. 'Canada'. In extract (7) below, the discourse refers to immigrants who have managed to gain employment after having participated in the programmes.

(7) A trial this year found jobs for four out of nine migrants, including an Indian software specialist who had driven a taxi for five years. He found a job in his field in three weeks through his mentor's networks.

Based on analysis by Reisigl \& Wodak (2009), this topos in these extracts can be reconstructed as follows:

Topos of positive consequence: If a particular action has a positive consequence, it should be performed. 
Premise: Schemes in other countries have helped $85 \%$ of immigrants find jobs.

Conclusion: These schemes should also be implemented in NZ.

Extract (7) has a double effect because in addition to referring to previous successes it uses numbers/statistics to further validate its arguments.

Finally, the discourse draws on authoritative figures and experts to further argue that immigrants are in need of help and that the programs and schemes will prove beneficial. Previous studies highlight the importance of authorization (reference to authority) as a means of legitimization (Van Leeuwen \& Wodak, 1999). The implementation of authoritative voice in a news discourse can be argued to legitimize the " text-producers aim for propositions to be accepted as true...such sources might include 'specialists', and "experts"' (Hart, 2010, p. 100). In this legitimization strategy, the discourse refers to three different authority voices, namely 'the migrant trust's director, Dr Mary Dawson', 'Committee for Auckland director Kaaren Goodall' and 'Massey University sociologist Paul Spoonley' to help present the schemes and programmes as highly valuable and necessary:

(8) Massey University sociologist Paul Spoonley said New Zealand had taken a long time to realise that it needed to work actively to make the best use of the diverse migrants who have come here. "I think we assumed that they would just adjust without any help from ourselves, and it's now great to see that there are some programmes that are actually beginning to deliver good jobs to the immigrants". (New Zealand Herald, 22 December, 2007)

In the case of this news report, the discourse refers to a direct quote by a well-known sociologist in New Zealand, Professor Spoonley, who also supports the idea that immigrants need help to 'adjust' to New Zealand life. Reference to Spoonley as an academic who specializes in social issues, in particular immigration, is used to validate the macro argument of the news report, namely that the government needs to encourage and support schemes and programmes. Therefore, the news report draws on a variety of 
argumentative topoi to legitimize and validate its argument for the implementation of schemes in order to 'help' immigrants find jobs.

\subsubsection{Perspectivization strategies}

In line with argumentation strategies discussed above are the voice and opportunities for expression given to various social actors within the discourse. Dependence on legitimized sources as a means of information leads to a "predominantly established view of the world" (Teo, 2000, p. 18), where the lay majority are only entitled to their "experience" but not their "opinions" (Scannell, 1989, p. 344). Therefore control of quotation patterns is a means of "gate-keeping" that allows only those in positions of power and influence to enter the discourse while excluding the perspective of those considered by society to be powerless (Teo, 2000, p. 18). The news discourse cites a range of various high official member voices such as Committee for Auckland director, Kaaren Goodall, Simon Vannini a lawyer at Simpson Grierson who organized the trial scheme, migrant trust director, Dr Mary Dawson,

Massey University sociologist, Paul Spoonley. These social actors give various pieces of information about immigrants' recruitment issues, such as the problems they face and how immigrants find jobs, the schemes themselves, and the reasons why schemes need to be implemented. The only immigrant who is given space to voice her perspective is a female immigrant, who states:

(9) "I do like to talk to people. That is my vocation", she said. (New Zealand Herald, 22 December, 2007)

The female immigrant is describing her new job which she obtained with the help of 'migrant trust's pilot employment programme'. She is describing her personal interests. Examination of the larger data set also confirms that in a large number of news articles, immigrants' perspectives are drawn on only when they express personal comments or experiences about themselves and their families (see 'Patrons adding to painful journey' in Appendix $\mathrm{C}$ for access to this article) while public persons (politicians, businessmen, authorities, experts, media reporters and commentators) are routinely called upon to 
comment on the wider implications of newsworthy events" (Scannell, 1989, p. 344; see Bell, 1991, pp. 155-160 for factors which influence the newsworthiness of an event).

\subsubsection{Discussion}

The news discourse introduces programmes which it deems beneficial. However, while doing so, it also incorporates representations of immigrants which may be considered disparaging. The discourse discusses the topic of underemployment of immigrants and presents it as a problem. It embarks on introducing schemes and programmes available for immigrants that will help them find jobs in their skilled area. While introducing programmes, it also represents immigrants as people who have benefited from pilot schemes and who have managed to find jobs relevant to their skills.

An important characteristic of a critical or CDA analysis is to investigate not only what is given or present in any particular text but also what is absent but could equally have been said (Machin \& Mayr, 2012,p. 4). Therefore, on a more critical note, it is also worth noting that the reasons why immigrants cannot find jobs (despite having the experience and qualifications) are also absent from this discourse, and in other news reports are only mentioned in passing without further elaboration. A problem, namely that of immigrant underemployment, is raised and a solution, i.e. immigrants attending schemes and programmes, is introduced. The discourse highlights the unpromising situation that immigrants are in and how the schemes can be beneficial. Immigrants need to go through training, receive information in order to 'adjust' and pave the way to their employment. However, the possibility of hidden racism and discrimination in the recruitment process, which has resulted in immigrant underemployment, is left unexplored.

Alternatively, the newspaper discourse could have given voice to immigrants who raise the elimination of discrimination in the recruitment process as a solution to the problem addressed in the news article, namely immigrant unemployment. I myself am an immigrant in New Zealand and having had a close relative of mine face discrimination during the recruitment process know that this is frequently discussed among immigrant community 
members. Yet their stories, experiences and concerns regarding discriminatory recruitment processes in New Zealand seem to be absent not just in this news report but in the data set in general. Representatives of local organizations and recruitment agencies who are responsible for hiring immigrants are not encouraged to enroll into schemes or programmes to raise their cultural awareness and to encourage a culture of tolerance for different nationalities and cultures. Instead it is immigrants who are expected to 'adjust'.

Secondly, the news report discourse indexes a very utilitarian discourse of immigrants, as people who need to be made use of. Their benefits can be summarized in the amount of work they can do and how much they can contribute to the economy. This utilitarian discourse becomes evident in noun phrase structures and in the use of phrasal verbs as illustrated in the analysis and through the macro argument which emphasizes the costs of unemployed immigrants.

Thirdly, in this news report immigrants are represented as either involved in low skilled positions or as passive recipients of help from various schemes, programmes etc. They are not represented as active participants in the struggle to find jobs but merely people who are underemployed and passive recipients of jobs which are given to them through schemes and programmes. Their struggles, aspirations, and endeavors, are downplayed and ignored. In other words, the discourse could equally have emphasized the struggles that immigrants are facing despite their willingness and eagerness to contribute to the community and society through making available their knowledge, experience, skills and expertise (hence assigning agency to them for their endeavors to find jobs).

Finally, the news report draws on the voice of experts and elite members of the community to discuss the importance of the schemes. By contrast, it only draws on immigrants' voices when they have personal comments to offer. These personalized stories are of much value; however they do lack "generalizing power" (Scannell, 1989, p. 344). The perspective of immigrants who can comment on broader social issues with wider implications for the immigrant community and beyond are missing from both this news report and the data set 
in general. The absence of immigrant community voice and perspective is of concern because it creates the impression that immigrants are unable to comment and make decisions on matters concerning themselves which in turn undermines the role of successful, influential, and powerful members and leaders of the immigrant community and creates an atmosphere where only the views of authoritative public figures are given weight and importance. Scannell refers to this issue and advises that the statements that private people make have little "subjective force" as they "lack the generalizing power of the opinions of public persons" (Scannell, 1989, p. 344).

\subsection{Textual Analysis 4: News report entitled 'Record numbers leaving for Australia' under the theme of 'Loss of population'.}

\subsubsection{Context window}

A theme which appears frequently in the New Zealand Herald is the concept of permanent and long term outward travel from New Zealand often discussed in terms of the acronym PLT (permanent and long term migration). This outward travel is also referred to as a "brain drain" which refers to the loss of the "best and brightest workers to other countries" with Australia as a popular destination (Statistics New Zealand). Although the newspaper discourse shows a concern for this phenomenon, it should be noted that, according to the New Zealand Statistics website, the concept of "brain drain" in New Zealand is a mere myth as we gain more skilled immigrants than we lose.

This myth is said to be accentuated for two main reasons: The first reason is that there have been periods in New Zealand history where higher numbers of educated people and professionals have decided to leave than those which have entered. For example, from 1998 to 2000 and in the 1980s, there were more people leaving New Zealand than there were entering. The second reason is assigned to the Overseas Experience (OE). The phenomenon of Kiwi OE is a time when young New Zealanders decide to travel abroad particularly after university to explore (Statistics New Zealand). The news discourse, however, frequently asserts that one of the reasons why New Zealand needs immigrants is because it loses its 
local population to countries with stronger economies. As is evident from the headline of this news report, the article discusses the movement of people from New Zealand to Australia. The news report is written by Lincoln Tan who is a Singaporean immigrant himself and the main immigration and ethnic affairs reporter and a columnist for the New Zealand Herald. It is worth noting that the article below is presented in the form of a news report and not an opinion column.

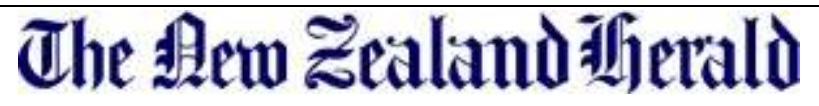

\section{New Zealand Herald — — A01 — 23 October 2008 \\ Record numbers leaving for Australia}

Struggle to replace skilled workers as immigration slumps drastically

by Lincoln Tan

New Zealanders are leaving for Australia in record numbers, while the flow of immigrants and tourists coming here has slumped.

Figures published by Statistics New Zealand yesterday show about 47,200 people left New Zealand for Australia on a permanent or long-term basis during the year to September.

About 13,200 came the other way.

That produced a net outflow of 33,900 people from NZ to Australia _ the highest since records were first compiled in 1978.

The previous peak was 33,700 in January 1989.

Immigration has also fallen to its lowest level in nearly seven years. In the year to September, the country gained only 4400 migrants _ down from 8300 last year.

Tourist numbers slumped by 11,100 in the same period as tougher economic conditions affected overseas visitors, especially from China and Australia.

Richard Howard, chairman of the NZ Association for Migration and Investment, said the immigration figures were a worry, as the country was struggling to replace skilled workers.

"The people who are moving are those with skills who see more opportunities for themselves, and the skills available here are just reducing.

"Employers seeking skilled workers in New Zealand are going to find it harder, irrespective of the economic conditions.

'Many who move perceive that they and their families' lives and future, at this point in time, are better off in Australia than it is in New Zealand ... with higher wages, more job opportunities. The weather is also a factor." 
Immigration consultant Tika Ram said his business had plummeted 30 per cent in the last year, and business migration interest had been "close to zero".

He said the "arrogance" of Immigration New Zealand and New Zealand's “impractical immigration policies" were a turn-off to would-be migrants.

"The immigration policies we have are not well thought-out, and written as knee-jerk responses _ they are ridiculous and killing the flow of migrants," said Mr Ram.

National Party finance spokesman Bill English said the statistics were a reminder that New Zealand had major fundamental economic issues long before the current international crisis, and the increasing pace of the exodus showed New Zealand needed growth so New Zealanders could earn higher wages and have a better quality of life here.

Act Party candidate and former finance minister Sir Roger Douglas warned that more New Zealanders would leave if nothing was done to the economy, which he said was " hanging in the balance".

"The avalanche of people leaving New Zealand to go to Australia over the past year will be seen as a trickle if we don't put our house in order," Sir Roger said.

"The global meltdown means we're facing a financial tsunami."

(C) The New Zealand Herald, nzherald.co.nz

\subsubsection{Nomination and predication strategies}

A close look at the data under study shows that immigrants are frequently referred to in terms of their numbers, the direction of their movement and statistical terminologies. However, unlike most studies on immigration representation, which suggest that reference to large numbers of immigrants coming into the country is used to construct them as a threat, in this news report as well as others in the dataset under study, this is not the case. Rather, the writer aims to highlight the problems associated with low immigrant numbers entering, considering the extensive number of New Zealanders who are leaving.

The news discourse uses a variety of referential strategies to refer to immigrants. These referential strategies can be classified into four broad categories. Immigrants are either referred to using metaphorical constructions, e.g. 'flow of immigrants', statistical references, e.g. '13,200', '4400', which highlight their numbers, professional anthroponyms which refer to their occupational roles in society, e.g. 'skilled workers', or in the form of collectives, e.g. 'migrants'. In fact a closer look at the broader qualitative data set of this research confirms that immigrants are predominantly referred to using 
collective nouns and there are only a few instances where immigrants are referred to by first and last name. There are only a handful of instances where immigrants are referred to using a title which reveals their status or their affiliations.

The news report begins with reference to the in-group using nationyms such as 'New Zealanders' to refer to locals who are migrating to Australia. This is contrasted with the reference to liquid metaphors in 'flow of immigrants' and 'tourists' who enter the country:

(1) New Zealanders are leaving for Australia in record numbers, while the flow of immigrants and tourists coming here has slumped. (New Zealand Herald, 23 October, 2008)

The use of the conjunction 'while' indicates that a contrast is being made between what is given in the independent clause (i.e. New Zealanders are leaving for Australia in record numbers) and the information given in the dependent clause (i.e. the flow of immigrants and tourists coming here has slumped). The conjunction 'while' indexes a contrast between the direction of movement of the people, in versus out, or a contrast between the people themselves, 'New Zealanders' versus 'immigrants'. The verb 'has slumped' has a rather negative connotation and invites the reader to infer that the current situation, where large number of New Zealanders are leaving and only fewer number of immigrants entering, should be viewed negatively. In the extract below immigrants are referred to as numbers:

(2) About 13,200 came the other way. (New Zealand Herald, 23 October, 2008)

In example (2), mere numbers are placed in the role of the agent of the action of entering New Zealand. In this news report alone, numbers have been used numerous time to refer both to New Zealanders and immigrants. As mentioned before, the use of large numbers to talk about immigrants has been argued to contribute to their dehumanization and to positioning immigrants in the role of a threat, and an invader who poses significant risks 
(Banda \& Mawadza, 2015; Lirola, 2014). However, in this news report, the co-text suggests that these immigrant numbers are perceived as beneficial:

(3) Immigration has also fallen to its lowest level in nearly seven years. In the year to September, the country gained only 4400 migrants down from 8300 last year. (New Zealand Herald, 23 October, 2008)

(4) Richard Howard, chairman of the NZ Association for Migration and Investment, said the immigration figures were a worry, as the country was struggling to replace skilled workers. (New Zealand Herald, 23 October, 2008)

As discussed in Section 6.2.1, 'gained only' indicates a concern for low numbers of 'migrants' who decide to come to New Zealand. This concern is indexed here through the noun 'a worry'. The word 'replace' is also important as it suggest that 'migrants' substitute for the locals who decide to leave (see below for further discussion).

The writer also relies on various liquid metaphors to describe the situation. Natural disaster metaphors in general and liquid metaphors particularly are used in innovative ways. Extract (5) draws on a quote from an immigration consultant who criticizes New Zealand policies for 'killing the flow of migrants' and extract (6) describes New Zealanders in terms of natural disaster metaphors:

(5) "The immigration policies we have are not well thought-out, and written as knee-jerk responses they are ridiculous and killing the flow of migrants" said $\mathrm{Mr}$ Ram. (New Zealand Herald, 23 October, 2008)

(6) Act Party candidate and former finance minister Sir Roger Douglas warned that more New Zealanders would leave if nothing was done to the economy, which he said was "hanging in the balance". "The avalanche of people leaving New Zealand 
to go to Australia over the past year will be seen as a trickle if we don't put our house in order," Sir Roger said. (New Zealand Herald, 23 October, 2008)

Extract (5) uses natural metaphors to construct the fewer 'migrants' entering New Zealand as problematic. In extract (6), interestingly enough, the sentence preceding the phrase indicates that 'New Zealanders' is the antecedent for the metaphorical phrase 'avalanche of people' and therefore a natural disaster metaphor is used to talk about the in-group. These two examples deviate from former findings on immigration discourse in two ways. Firstly neither use natural disaster metaphors to construct incoming migration as a threat. This first deviation, appears frequently in the data set. Secondly, the second extract shows that natural disaster metaphors can also be used for the in-group. This deviation however is rare as there is only one example of a natural disaster metaphor used to talk about New Zealanders in the qualitative dataset.

In extract (6), reference is made to New Zealand as being a container, i.e. a 'house'. In contrast to the function of container metaphors as described in section 7.2, I argue that in this news report, the house metaphor highlights the proximity of the problem of loss of population and creates a sense of responsibility in the reader to prevent New Zealand from losing its population to more powerful economies. Examples such as these further confirm the findings of the previous chapter, i.e. the corpus-assisted discourse analysis, and of previous literature (Semino, Deignan, \& Littlemore, 2013) that metaphors have flexible meanings. The unique use of liquid metaphors in some news articles of the New Zealand Herald belie what is frequently referred to as "universal features" (Wodak \& Boukala, 2015 , p. 258) of discourse on immigrant representation, that is, they belie describing immigrants in exclusively negative ways.

The discourse in this article creates a sense of prioritization in who New Zealand should prevent leaving and who they should welcome. The presence of a categorical prioritization is evident in the subheading of this report: 
(7) Struggle to replace skilled workers as immigration slumps drastically. (New Zealand Herald, 23 October, 2008)

The use of the word 'replace' indexes this prioritization. Immigrants are only desirable as they 'replace' kiwi 'skilled workers' who have left New Zealand. This prioritization and hierarchy become particularly clear with cross-reference to other news articles in the New Zealand Herald.

As discussed in Section 7.2 in the textual analysis of 'Peter wants immigration cuts to protect jobs', a further refinement is made among the immigrant population through descriptive adjectives such as 'skilled' to refer to only a specific type of immigrant who is considered desirable and which New Zealand is in need of. The pre-modifier 'skilled' features numerous times in the larger data set to describe immigrants and is one of the most salient positive pre-modifiers in the study (also see Section 6.3.1).

\subsubsection{Argumentation strategies and perspectivization}

In terms of argumentation, the news discourse draws on the topoi of numbers, authority and negative consequence frequently. Whereas previous studies show that these topoi are used to "justify the exclusion of migrants" (Richardson \& Wodak, 2009, p. 49), in this study they work hand in hand to argue for more lenient policies by constructing the low number of immigrants as problematic. I will reconstruct the topoi of authority and negative consequence below as these were salient.

Prominent and authoritative voices, e.g. 'Richard Howard', 'chairman of the NZ Association for Migration and Investment' are drawn on to further legitimize the main argument that New Zealand needs more lenient immigration policies in order to allow more immigrants to enter New Zealand. The topos can be constructed as:

Topos of authority: According to this type of justification a statement is valid beyond reasonable doubt if it is confirmed by a qualitatively or quantitatively 
relevant group of persons with a great deal of competence in the respective area. (Kienpointner \& Kindt, 1997, p. 560)

Premise: Chairman of a national organization and an immigration consultant say that immigration policies are not working.

Conclusion: Immigration policies need to be revised in order to allow more immigrants into New Zealand.

This topos is realized in the following extracts:

(8) Richard Howard, chairman of the NZ Association for Migration and Investment, said the immigration figures were a worry, as the country was struggling to replace skilled workers. (New Zealand Herald, 23 October, 2008)

(9) Immigration consultant Tika Ram said his business had plummeted 30 per cent in the last year, and business migration interest had been "close to zero". He said the "arrogance" of Immigration New Zealand and New Zealand's "impractical immigration policies" were a turn-off to would-be migrants. (New Zealand Herald, 23 October, 2008)

The news report also draws on authority to argue that New Zealand needs to provide more incentives for those within in order to encourage them to remain in New Zealand. Extract (10) constructs an argument where fewer immigrant arrivals are considered as having negative consequences on the overall livelihood of New Zealand:

(10) "Employers seeking skilled workers in New Zealand are going to find it harder, irrespective of the economic conditions". (New Zealand Herald, 23 October, 2008)

Based on Wodak's definition of topos of consequence (Wodak, 2015, p. 53), this topos can be defined and reconstructed as below: 
Topos of negative consequence: If an action has a negative consequence, it should be avoided.

Premise: Employers are going to have difficulty finding workers.

Conclusion: Immigration policies need to be amended.

The news report highlights a variety of (negative) consequences which are predicted to follow or which have followed the strict immigration policies. The negative consequences of the current immigration policies are stated as affecting businesses as fewer immigrants show interest in investing in New Zealand. As a consequence, employers will also face difficulties finding people to fill positions. As I have demonstrated above, the news report uses various authoritative voices to highlight the negative consequences of strict immigration policies.

\subsubsection{Discussion}

A discourse analysis which ignores the more positive representations of immigrants only provides a partial and hence inaccurate picture. The discourse of the news report in question offers a representation of immigration different from those described in previous studies. The discourse argues for the need for skilled immigrants rather than for their exclusion. The text analysed here is typical of numerous news articles within the data set which portray immigrants as beneficial because they have skills to contribute. However, as illustrated, this benefit is given within a very fixed and rigid framework of economic contribution and therefore could be argued to be utilitarian. Through the incorporation of various referential, predication and argumentation strategies to achieve this function, an argument is constructed as to why New Zealand needs more lenient policies to allow immigrants to enter New Zealand easily. Although the discourse avoids referring directly to policy makers and politicians as the source of the problem by use of passive voice, e.g. 'The immigration policies we have are not well thought-out and written as knee-jerk responses', it clearly constructs the loss of population and the harsh immigration policies as a problem and builds clear arguments drawing on economic values to legitimize its claims. The discourse mainly refers to the difficulties that employers will have in trying to 
find people to fill positions, and how that will affect the New Zealand economy, particularly considering the tumultuous economic situation at the time. In constructing immigrants as highly needed replacements for local skilled workers in New Zealand, the discourse contributes to the construction of a categorical prioritization where immigrants are desirable, but only under certain conditions and prioritization. Immigrants are merely represented as being beneficial considering the large numbers of skilled people who eventually decide to leave New Zealand. Immigrants become second priority as they replace those locals who have decided to leave the country.

7.6 Textual Analysis 5: News report entitled 'Illegal immigrants may have exploited lax ID screening' under the theme of 'Crime'.

\subsubsection{Context window}

As was evident in Section 6.4.1, the topic of illegal immigration appeared frequently within the data. In the data selected for CDA analysis, this is also an important topic. Due to the country's isolated geographical location and distance from many source countries, New Zealand is not a prime location for so called illegal immigrants (Talcott, 2000, p. 32). It is not a transit country either. Despite this, New Zealand is "an active participant in a number of initiatives"(McMillan, 2008, p. 3) to prevent "irregular migration" which is defined as "international migration that occurs outside the legal framework of the destination (and any transit) country and includes, but is not limited to, 'illegal' migration" (McMillan, 2008, p. 2). For example, New Zealand collaborates with the following organizations, as well as others, in order to prevent such migration: Bali Process on People Smuggling, Trafficking in Persons, Other Transnational Crimes; the Five Nations meetings (Bali Process); the Forum Regional Security Committee (FRSC); Asia-Pacific Economic Cooperation (APEC); the Pacific Immigration Directors' Conference (PIDC) and International Organization for Migration (IOM) (McMillan, 2008). Statistics show that in the years 2006/2007 for example, only 92 people were intercepted offshore and were prevented from boarding planes heading to New Zealand; 46 "undocumented passengers" 
arrived at the border; and only fifty people arrived at airports and claimed asylum in 2006/2007 (McMillan, 2008). As is evident, the majority of irregular migration occurs through air travel (McMillan, 2008), and due to the adverse conditions of the seas surrounding New Zealand, there are few, if any, irregular immigrants who enter New Zealand by sea. Therefore, mainly due to the country's geographical isolation, and partly the various initiatives that New Zealand is part of, scholars argue that "New Zealand's border security will be, and perhaps already is, one of the most effective in the world" (McMillan, 2008, p. 4). The following news report draws on information from a report published in 2007 by the Department of Labour entitled Management of Immigration Identity Fraud. This report uses the term "illegal immigrants" and as a consequence, the term is recontextualized in the news article.

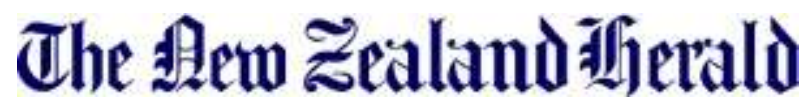

New Zealand Herald — news — general — 2007-06-27

Illegal immigrants may have exploited lax ID screening

By Claire Trevett

Immigrants may have slipped into New Zealand illegally because of gaps in systems for discovering identity fraud, the Government has admitted.

An Auditor-General's report yesterday said identity fraud was one of the "most pervasive developments in fraud in recent years" and cases were on the rise.

"A person using a false identity can pose significant risks to the country, including financial, terrorism, health, legal or criminal risks."

It said there was a significant risk posed by a backlog of 384 cases of fraud waiting to be investigated by the Immigration Service's 11 investigators, including 185 cases which were a high priority.

While there were systems to deal with it, the service was hindered by staff and technology resourcing, inadequate training, a huge backlog in fraud investigations, inconsistent record-keeping, and a failure to collate information to review and assess the success of its strategies.

The report - "Department of Labour: Management of immigration identity fraud" - made 15 recommendations, including better training, more staff for the fraud investigations unit, the electronic collection of data, and more assessment of cases to see how widespread the problem was and how successful Immigration's strategies were. 
Immigration Minister David Cunliffe said there could have been cases which compromised security. He has ordered the department to meet all 15 recommendations although some could take a long time to complete and would be costly. "Clearly when a system is not perfect there is a gap between where you are and where you want to be. The Government's clear intention is that the gap will be closed as soon as possible and I will hold the department accountable for that."

Mr Cunliffe said the report was "useful" and work was already under way, including the training of staff, as part of a broad reform of immigration laws and policies.

More investigators would be appointed to the fraud unit as soon as possible, but he could not say how many.

National immigration spokesman Lockwood Smith said the backlog in fraud cases was concerning.

"Identity fraud in immigration is very serious given the current international climate. Yet clearly the Department of Labour is struggling to do the job and it's the Government that allocates the resources and it's the Government who must get serious about it."

The report noted that Immigration also had to allow for the successful resettlement of refugees and attract good skilled migrants, NZ First immigration spokesman Winston Peters said there had been warning signs that such changes were required.

"I would have thought September 11 would have spurred anyone to do it. What amazes me is despite numerous warnings over a long period of time, they were not picked up on. They have not put the personnel, the technology and resources in place to properly scrutinise the people coming into the country." The report said such fraud could include the use of false names, or failing to declare other names a person could be known by, possibly to hide something in that person's history.

It noted that the Department of Labour had reported a rise in cases of people either lodging multiple refugee claims under different identities or returning to New Zealand under a different name after being removed.

Since August 2005, there were 257 suspected false identities referred to the police.

(c) The New Zealand Herald, nzherald.co.nz

\subsubsection{Nomination, predication and mitigation strategies}

It can be argued that the article draws on the macro discourse of fear throughout the news report. The discourse of fear is indexed through numerous means as I will illustrate in the analysis below. This news report mainly focuses on immigrants who have entered New Zealand illegally. Through its referential and predication strategies it creates categories of immigrants. The first category which is the main focus of this news report is 'illegal immigrants'. 
In terms of referential strategies, the discourse ascribes the quality of unlawfulness to immigrants by using the pre-modifier 'illegal' in its headline 'illegal immigrants may have exploited lax ID screening' (New Zealand Herald, 27 June, 2007). Other phrases used to describe immigrants include 'a person using a false identity' and plural noun phrases such as 'false identities'. Depersonalizing nouns such as 'cases' were also used five times in the news report as well as the frequent use of collectives.

Despite the fact that the collocation 'illegal immigrant' is used only once throughout the news article, the news discourse constructs immigrant illegality through the rhetorical technique of negative lexicalization, that is, by placing the above mentioned nominations which refer to immigrants in close proximity to words with negatively loaded denotative and connotative meanings. One example is where the word 'fraud' is used eight times in the 574 word news report.

In line with the concept of unlawfulness, the concepts of threat and risk permeate this news report. The risk or threat imposed by unlawful immigrants is constructed in various ways in the news discourse. One means, for example, is reference to immigrants' health as evident in extract (1) below. Literature on the negative representation of the health of immigrants here in New Zealand and elsewhere is abundant (Loto et al., 2006; Reitmanova et al., 2015) and is subsumed under the general representation of immigrants as people who pose threats. Other words used in the news report which also index a threat discourse and which are used in close proximity to the referentials outlined above are 'warning signs', 'September 11', 'compromised security', 'problem', 'terrorism', 'criminal risks', 'significant risks'. Hart discusses cognitive aspects of the discourse of threat:

a representation of a stimulus can arouse as much affect as the presence of the stimulus itself. And the human capacity to form metarepresentations and detached representations means that emotive effects may be produced through communication about some stimulus even in the absence of the stimulus itself. (Hart, 2010, p. 81) 
In other words, the discourse of fear can be strategically used for political ends, e.g. getting support for stricter immigration policies, despite the absence of a real and imminent threat or risk. In the case of this news report, the news discourse paints a picture of various threats in order to legitimize its argument for stricter immigration strategies and laws. Predication strategies also play an important role in assigning actions to immigrants. For instance, illegal immigrants are described as people who 'pose significant risks' and are a 'threat' to the well-being of New Zealand, as signaled by the collocations 'high priority' and 'significant risk(s)' used to describe immigrants below:

(1) An Auditor-General's report yesterday said identity fraud was one of the "most pervasive developments in fraud in recent years" and cases were on the rise. "A person using a false identity can pose significant risks to the country, including financial, terrorism, health, legal or criminal risks." (New Zealand Herald, 27 June, 2007)

(2) It said there was a significant risk posed by a backlog of 384 cases of fraud waiting to be investigated by the Immigration Service's 11 investigators, including 185 cases which were a high priority. (New Zealand Herald, 27 June, 2007)

By framing the issue within a threat discourse, illegal immigrants are constructed as people who have the ability to carry out terrorist acts, bring illnesses and diseases into New Zealand, or carry out crimes. They are positioned as grammatical agents of the verb 'exploit' in extract (3). In fact, throughout the whole news discourse, 'illegal immigrants' are directly or indirectly represented as the agents of malicious acts such as exploiting ID screening, committing fraud, compromising security, carrying out terrorist acts, using false names, hiding things from their pasts, lodging multiple refugee claims, and returning to NZ under different names. In extract (4) below, immigrants are positioned as the agents of the 
verb 'slipped' which is used to describe the action of immigrants entering the country. The verb conveys a sense of deceit, where immigrants sneak into the country:

(3) Illegal immigrants may have exploited lax ID screening. (New Zealand Herald, 27, June, 2007)

(4) Immigrants may have slipped into New Zealand illegally because of gaps in systems for discovering identity fraud, the Government has admitted. (New Zealand Herald, 27, June, 2007)

The use of the modal 'may' here is significant. It shows that there is no firm evidence for the proposition but simply a possibility given systematic 'gaps'. In other words, the use of mitigating modals creates a sense of uncertainty in the threat. The news report cannot state that there are so-called 'illegal immigrants' who pose a threat of some sort. It relies heavily on simply the possibility of a threat. In fact, the news report is marked by a heavy use of mitigating modals, e.g. 'may have slipped', 'can pose', 'there could have been cases which compromised security'. In the final sentence, a more certain verb, i.e. 'were', is used, i.e. 'there were 257 suspected false identities'. However the modifying adjective 'suspected' reduces the certainty here as well. This use of modality to hedge is also evident in the headline of the news article which is rare in news discourse (Bell, 1998). Despite the uncertainty in the threat, the discourse relies heavily on activating negative emotions, i.e. emotions of fear, in the reader without necessarily being able to state with confidence that there is an imminent threat of some sort. Moreover, it can be equally argued that the arrival of a number of immigrants through non-conventional routes does not necessarily result in a threat. A threat only exists when these people have malicious intentions and realize those intentions through malicious actions. Therefore, as suggested by Hart (2010), it seems that the discourse is based on fearmongering as it is not supported by examples or evidence. It relies on "communication about some stimulus [a threat] even in the absence of the stimulus itself" (p. 81). 
According to Hart (2010), the preposition 'into' is important as it creates a sense of 'spatial proximization' (Hart, 2010). The use of the word 'gaps' in extract (5) also reminds one of the country-as-a-house metaphor described earlier. New Zealand is a 'house' with walls up to prevent the Other entering. In today's modern world, there are virtual technology aided walls (i.e. systems) which prevent people from entering.

(5) "The Government's clear intention is that the gap will be closed as soon as possible and I will hold the department accountable for that." (New Zealand Herald, 27, June, 2007)

The use of the words 'gap' and 'close' here conveys a door in the house which is left open. As Hart points out, conceptualizing a country as a house

has further ideological consequences that arise from the assumptions present in one's HOUSE frame. Since one would not normally leave their house doors wide open for just anyone to wander in, the inference that arises in the blend is that one should not leave the 'doors' of the country wide open allowing just anyone to enter. (Hart, 2010, p. 139)

Therefore, immigrants who 'may' have entered 'illegally' into the country and who 'pose' risks to New Zealand need to be prevented from entering New Zealand by closing the 'gaps'.

As in the previous analyses, this news report alludes to immigrant types as well. The news report contrasts immigrants who break the law with those who are good and law abiding. Two other types of, namely 'good skilled migrants' and 'refugees', are also referred to:

(6) The report noted that Immigration also had to allow for the successful resettlement of refugees and attract good skilled migrants, [sic] NZ First 
immigration spokesman Winston Peters said there had been warning signs that such changes were required. (New Zealand Herald, 27, June, 2007)

The use of the word 'good' as a predefining adjective for 'migrants' is of interest here. A comparison of the news report with the report produced by the Labour Department illustrates that the word concept of good versus bad migrants has been recontextualized from the bureaucratic report. Although the report does not mention 'good skilled migrants' directly, it conveys the idea that there are good versus bad migrants by using the antonym 'bad people', creating a sense of categorization:

At a strategic level, the Department has identified the generic risks of what it refers to as "keeping bad people out" and "client fraud" (which it described as the effects of criminal activity that threatens law and order). (Department of Labour, 2007, p. 24)

This example further supports the argument provided in the previous analyses that there are types or hierarchies of immigrants, some more desirable than others. The news report also references good versus bad refugees, those who need to be resettled into New Zealand and those who are fraudulent because they 'lodge multiple refugee claims under different identities' (New Zealand Herald, 27 June, 2007).

\subsubsection{Argumentation strategies}

The news report relies on argumentation strategies to convey its discourse of fear. Its main argument is that risk-posing people, 'illegal immigrants', are abusing/breaking the laws and therefore stricter measures need to be taken to prevent these people from entering New Zealand. This argument is realized through the incorporation of topoi of law, threat and danger, history, and finally numbers. I will reconstruct the first three of these arguments below as they appear more frequently. The first topos is that of law. Through this topos, the news writer aims to represent these immigrants as unlawful and consequently dangerous. The topos of law is defined and reconstructed below. Immigrants throughout 
the news discourse are represented as breaking the law and dubbed 'illegal' for entering unlawfully:

Topos of Law: "If a law or an otherwise codified norm prescribes or forbids a specific politico-administrative action, the action has to be performed or omitted". (Reisigl \& Wodak, 2001, p. 79)

Premise: Immigrants bypass NZ laws

Conclusion: Immigrants who act unlawfully need to be prevented from entering.

Immigrants in the news report are represented as acting unlawfully, e.g. exploiting screening, slipping into the country illegally, using false identities, and committing 'fraud' and hence need to be 'investigated', 'dealt with' and 'scrutinized'. In addition, in extract (2), the news report uses topoi to construct the presence of 'illegal immigrants' as a threat and danger. A reconstruction of the topos of threat and danger is provided below:

Topos of threat and danger: "if a political action or decision bear specific dangerous, threatening consequences, one should not perform it". (Reisigl \& Wodak, 2001, p. 77)

Premise: Illegal immigration poses a 'financial' threat, terrorist threat, a 'health' threat, a crime threat and 'legal' threat.

Conclusion: (illegal) immigration needs to be managed or 'dealt with' more efficiently or strictly.

Elsewhere the topos of threat is used to highlight the inefficiencies that New Zealand Department of Labour has demonstrated with tackling the problem. The writer highlights the risk through listing the inadequacies of the current immigration system, and aims to argue for better services to tackle or 'deal with' illegal immigration:

(7) It said there was a significant risk posed by a backlog of 384 cases of fraud waiting to be investigated by the Immigration Service's 11 investigators, including 
185 cases which were a high priority. While there were systems to deal with it, the service was hindered by staff and technology resourcing, inadequate training, a huge backlog in fraud investigations, inconsistent record-keeping, and a failure to collate information to review and assess the success of its strategies. (New Zealand Herald, 27 June, 2007)

The discourse constructs a situation where a possible threat is always imminent. Therefore, the extract above, through highlighting the inadequacies in 'training', in the number of 'staff', in the available 'technology', 'recording keeping', and in 'review' and assessment strategies, argues for better services to 'deal with' the threat of immigration 'fraud' and the possible threats associated with it.

The third strategy used in the news report to support its discourse of fear is to draw on the topos of history to highlight the consequences that may prevail if more lenient measures and laws are not implemented. The discourse, through giving voice to Peters, refers to previous terrorist acts, such as 'September 11', which have had harsh consequences and arouse strong emotional and mental images in the minds of readers. Through reference to 9/11, it paints a picture of what New Zealanders could eventually face, i.e. a terrorist act similar to that of $9 / 11$ if it does not implement a more robust system to prevent 'illegal immigrants' from entering and hence legitimize policies which support the exclusion of ‘illegal immigrants':

(8) "I would have thought September 11 would have spurred anyone to do it. What amazes me is despite numerous warnings over a long period of time, they were not picked up on". (New Zealand Herald, 27 June, 2007)

The topos is defined and reconstructed below:

Topos of history: Because history teaches that specific actions have specific consequences, one should perform or omit a specific action in a specific situation 
(allegedly) comparable with the historical example referred to. (Wodak, 2001, p. 76)

Premise: Terrorist events around the world have shown that illegal immigrants can pose a great threat to the security of a society.

Conclusion: NZ needs to revise its current immigration security system.

The discourse, therefore, through reference to previous events where illegal immigrants have carried out terrorist acts, e.g. 9/11 in the United States, highlights the possible threat that illegal immigrants in New Zealand may pose.

\subsubsection{Discussion}

A notable feature of the news report under analysis is its reliance on constructing a discourse of threat. The news report, through its repeated reference to words which denote risk and danger, through assigning immigrants as agents of actions which are likely to be perceived negatively by its readers, and through employing various argumentation strategies which highlight immigrants' non-law abiding presence in the country, is attempting to construct immigration as a threat to New Zealanders.

The analysis demonstrates the legitimization of stricter immigration policies through reliance on a possible threat. The reliance of the news report in constructing immigrants as threatening is further enhanced when one considers the very small number of immigrants who actually manage to enter New Zealand illegally as discussed in the context window of this section. The low possibility of any threat is indexed through numerous uses of modal verbs when constructing immigrants as agents of these risk-posing acts. Nevertheless, the language used to argue for changes in policy and systems is very direct and forceful, creating the impression of an imminent threat.

Furthermore, it is worth indicating that the true intentions of immigrants who enter through non-conventional means cannot easily be judged as malicious. In reality, the situation is probably far more mundane and less malicious than is being suggested. Refugee 
advocators, for example, argue that some immigrants who enter through irregular means may in fact be asylum seekers who are fleeing their countries from some form of persecution and are victims rather than perpetrators. According to a report by ChangeMakers Refugee Forum, a non-governmental advocacy organization based in Wellington, New Zealand "asylum seekers arriving in a country who claim refugee status - even without any form of legal or identifying documentation - are not illegal immigrants; they have legal status as 'asylum seekers' in the country to which they have fled'(Bloom \& O'Donovan, 2013, p. 11). Therefore, the arrival of people through non-conventional means does not automatically mean that they are malicious or a threat. In some cases, they could be people who hope to seek asylum.

\subsection{Summary}

The analyses of the five articles illustrated the numerous predication, nomination, argumentation, perspectivization and mitigation/intensification strategies used in the newspaper discourse when representing immigrants. The newspaper discourse presented opposing representation, i.e. both positive representations as well as negative representations of immigrants depending on who was given voice.

In textual analysis 1 for example, the analysis highlighted the importance of perspectivization strategies and voice allocation and how the position and presentation of voices are more subjective than commonly perceived. Textual analysis 2 , on the other hand, illustrated how argumentation, predication and mitigation strategies were used by the writer to distance himself from Peters' anti-immigrant discourse. Textual analysis 3, brought to focus the utilitarian representation of immigrants as economic resources as well as the representation of immigrants as passive. Textual analysis 4 illustrated the importance of migration in filling positions previously held by New Zealanders who have migrated to other countries. Finally, textual analysis 5, indicated that immigrants are constructed as a threatening other. The next chapter provides an overarching discussion of both the collocation analysis and of the analyses detailed in this chapter. 
"Some citizens wonder why immigrants don't simply 'follow the rules' and do the appropriate paperwork, or renew their visas, or become citizens, thus becoming 'legal'. The reason they don't is the same as the reason that Rosa Parks didn't sit 'legally' in the front of the bus, or Harriet Tubman didn't 'legally' emancipate herself from slavery: because the law was designed not to allow certain groups of people to have the rights that others enjoy".

(Chomsky, 2007, p. 185)

\section{Chapter 8: Discussion}

The previous chapter provided an in-depth analysis of five news articles from the broader qualitative data set. The critical discourse analysis proved useful in exploring the extent of voice or agency assigned to immigrants, and demonstrated the various means through which immigrants are categorized and dehumanized. The findings from these analyses are generally applicable to the broader qualitative data set as well. This chapter provides a discussion which brings together the collocation and critical discourse analyses. In addition, it provides further examples from the broader qualitative data set which capture a nuance or an exception in the representation of immigrants which did not become apparent in the analyses above but which add to that representation.

\subsection{Ambivalence}

Overall, both modes of analysis have demonstrated that immigrants are represented in an ambivalent way in the articles analysed, i.e. the newspaper discourse reflects both the advantages and the disadvantages of immigration. Depending on which social actor is given the opportunity to voice their opinion on the topic of immigration, nuanced representations are evoked. On the one hand, New Zealand is portrayed as being dependent on immigrants for filling its skill shortage problem and therefore the newspaper articles on occasion represent immigrants as skilled, qualified and desirable. On the other hand, 
immigrants are depicted as a threat to the local housing market, safety of the locals, and to Kiwi jobs. Therefore, it can be argued that despite the fact that previous studies on immigrant representation frequently argue that print media represent immigrants as Other, the analyses conducted in this research provide a more nuanced representation where immigrants, in addition to being represented in disparaging ways, are also represented more favourably, albeit within a limited framework, that of contribution to the economy. This overarching theme is discussed further in the next two sections i.e. section 8.2 and 8.1.

\subsection{Benign/utilitarian representation of immigrants}

Both the qualitative analysis and the collocation analysis pointed to a more positive representation of immigrants in 2007 than in 2008. The qualitative analysis of the broader 20 articles shows that some of the key topics in 2007 are how immigrants are viewed more positively because they are an indispensable resource which needs to be enticed and that local companies need to appreciate the value of diversity within the workplace more. Moreover, strict immigration policies are dubbed irrational and disruptive and racism and discrimination against immigrants are explicitly denounced in the discourse. Therefore, it becomes evident that in terms of the qualitative analysis, there is a more positive representation on immigration in 2007.

In line with this, there seems to be particular interest in positive representation of immigrants, not only brought about as a result of the highly frequent collocate 'skilled', but also because of the presence of other collocates such as 'investor', 'wealthy', 'millionaire', 'attract', 'target' and 'targeting' which all suggest a desire to invite immigrants with good economic resources into the country. Table 8.1 shows the collocates and the search words that they have collocated with. All the collocations in this table contribute to immigrants being represented as benign or desired in some way. The numbers in the parenthesis refer to the frequencies of the collocation. As evident from the table, the most prominent collocate is 'skilled' which appears in both years although less frequently in 2008. So although both corpora refer to immigrants as being 'skilled', collocates which 
refer to immigrants who have good financial means to invest in businesses within New Zealand are only in the spotlight in 2007. Therefore, both the critical discourse and the corpus analysis point to a slightly more positive representation of immigrants in 2007 in comparison to 2008.

\begin{tabular}{|l|l|}
\hline 2007 & 2008 \\
\hline Skilled/migrant (15), Investor/migrants (8), & Skilled/migrant (7), skilled/migrants \\
Targeting/migrants (2), Millionaire/migrants (2), & (8), target/migrant (3), \\
Attract/migrants (8), Targets/migrants (2), & qualified/immigrants (3), \\
wealthy/migrants (5), qualified/migrants (3), & \\
skilled/immigrants (14), wealthy/Asians (3) & \\
\hline
\end{tabular}

Having said this, one finding which became apparent during both the collocation and critical discourse analysis was the limited scope assigned to immigrant benefits. In other words, the economy is the principal benchmark used to decide whether an immigrant is desirable or not. The frequent reference to the economic benefits of immigration suggests that immigrants are viewed as an economic resource and so long as they are contributing to the economy and are easing pressure on the skills shortages, and are a means of profit, they are welcomed. This utilitarian view of immigrants is prevalent throughout both corpora. For example, immigrants are perceived to be useful because they have skills which fill shortages, bring innovative ideas to business enterprises which could result in financial gain for the businesses, or because they can 'replace' locals who emigrate to other countries with stronger economies and better work prospects.

Therefore, the analyses substantiate the view that immigrants are discussed within an instrumental and utilitarian framework and seldom for the cultural richness that they bring to the country or for their intrinsic values (cf. Skilling, 2011). Examples from the broader qualitative data set also support this finding. For example, the extract below discusses and argues for diversity in the New Zealand workplace but only because it will bring innovation which can eventually lead to capital growth: 
(1) Professor Spoonley cited the work of American economist Richard Florida, which links innovative and creative cities with ethnic diversity. "That's a talent pool that Auckland has in a way that it hasn't necessarily had historically. The range of immigrants and the range of ethnic groups here is growing quite significantly. That's a talent pool". But New Zealand employers had not capitalized on this in a big way. ('Diversity a boost for bosses', New Zealand Herald, 20 April, 2007)

Extract (1) illustrates that cultural and 'ethnic diversity' is merely seen as an object which can be 'capitalized'. In other words, it is argued that the true value of cultural diversity is in the amount of capital that it can return for companies through innovation. In this sense, the findings in this analysis confirm the findings of broader sociopolitical studies which argue that the Labour Government at the time furthered neoliberal principles in New Zealand. These neoliberal values acknowledge ethnic diversity as part of the national identity but ethnic diversity is "addressed in terms of its instrumental rather than intrinsic values" (Skilling, 2011, p. 81). This utilitarian discourse in which people are valued according to the amount of benefit they bring is further accentuated by the lack of representations which highlight the non-economic benefits that immigrants offer, such as their role in creating cultural richness.

\subsection{Immigrants as a threat}

Both the critical discourse analysis and the corpus analysis illustrated that immigrants are at times described as a threat. They are either represented as being a burden to the New Zealand housing market (causing inflation in house prices) or contributing to crime (cf. Banda \& Mawadza, 2015; Hier \& Greenberg, 2002; Rojo \& Van Dijk; 1997).

The critical discourse analysis emphasizes the presence of immigrants-as-a-threat discourse, in particular in 2008, as this was an election year. Through giving voice to certain political actors, in particular to New Zealand First Party leader Winston Peters, the newspaper discourse portrays immigrants as groups of people who pose a significant threat 
to the livelihood of the locals. In the first textual analysis for example, immigrants are constructed as threatening because they set up companies in New Zealand but hire employees from abroad rather than locally; in the fifth textual analysis, a sense of danger disproportionate to the threat was constructed. While the threat was mitigated using modal verbs, the newspaper discourse relied on methods designed to arouse fear in the reader. The critical discourse analysis also demonstrated the use of 'illegal' to describe immigrants who come to the country through non-conventional means, suggesting that they are people who are not law-abiding and therefore more likely to commit crime and pose danger. The critical discourse analysis also indicated that some news reports deviated from the representation of immigrants as a threat. The opinion piece entitled 'Peters blind to inconvenient truth' was one of those which argued that immigrants are not a threat as they do not contribute to crime. However, it is important to note that both contrasting discourses, that is, discourses which construct immigrants as criminals and those which argue that immigrants do not contribute to crime, involve discussing immigrants within the framework of crime. While one tries to link immigrants to crimes, the other disassociates the two but the backdrop of crime from which they are being distanced is still present. What would be more reassuring would be to see representations of immigrants who are being genuinely portrayed for their goodness, and for their positive social, cultural as well as economic contributions to society.

This construction of immigrants as a threat also became evident in the collocation analysis. In particular, the frequency of collocates with negative denotations was higher in 2008 than in 2007. Table 8.2 shows the collocates categorized as contributing to the discourse of immigrants as problematic along with the search word that they collocate with in each year. The numbers in the parenthesis refer to the frequencies of the collocation. The most prominent collocate which contribute to the construction of immigrants as a threat is that of 'illegal'. This highly frequent collocate creates the notion that the immigrants referred to have committed a crime, and that they have wronged some people. Constantly modifying a word, such as 'immigrant' with 'illegal' contributes to the sense that this an invariable feature of immigrants. It obscures the reality that labelling people as 'illegal' is a social 
and political construction which should not just be taken for granted. In other words, immigrants are made and constructed as 'illegal' and we do not have 'illegal' immigrants by default. Such labels not only influence how government and officials perceive immigrants, but also how the general public and the civic community view them. Moreover, an analysis of the discourse prosodies of other significant collocates and their co-texts, such as 'dealings', 'suspected' and 'Muslims', also indicate a tendency to view immigrants negatively and as the main contributors of crime. This finding supports previous studies which confirm the negative othering of Muslims in the media (Baker et al., 2013; J. Richardson, 2001; Saeed, 2007).

\begin{tabular}{|l|l|}
\hline $\mathbf{2 0 0 7}$ & $\mathbf{2 0 0 8}$ \\
\hline $\begin{array}{l}\text { Poor /migrant (3), anti /immigrant (3), } \\
\text { sentiment/ immigrant (2), illegal/ immigrant } \\
\text { (3), illegal /immigrants (21), suspected } \\
\text { /immigrants (2), dealings /immigrants (3) }\end{array}$ & $\begin{array}{l}\text { Angry /migrant (2), illegal/ } \\
\text { migrants (9), drain/ migrants (2), } \\
\text { prohibited/ immigrant (2), illegal } \\
\text { /immigrant (2), blames/ immigrants } \\
\text { (2), illegal/ immigrants (17), } \\
\text { blamed /immigrants (3), brown's } \\
\text { /Asians (2), V /Asians (7), Winston/ } \\
\text { Asians (7), Triads /Asians (2) } \\
\text { Peters/ Asians (8) }\end{array}$ \\
\hline
\end{tabular}

Table 8.2 Collocates which represent immigrants as undesirable and their frequencies

Taking the information provided in Table 8.2 into consideration, it can be argued that due to higher frequencies of negative collocations in 2008, along with the presence of other collocates with negative connotations (e.g. 'dealing', 'suspect' etc.), more reference to antiimmigrants discourse (commonly linked to New Zealand First), and fewer references to benign representations (i.e. reference to immigrant skills and immigrants who invest as illustrated and discussed in section 8.2), the newspaper discourse does seem to paint a slightly grimmer picture of immigrants in 2008 when compared to 2007 . This confirms, to some extent, the initial hypothesis that during an economic depression, immigrants are represented more negatively. 
Additionally, a key point which became evident in the collocation analysis was that collocations involving the modifier 'illegal' are mainly characteristic of articles which discuss immigrants in countries other than New Zealand. In other words, even though these representations of immigrants occur in the New Zealand Herald, in the majority of the cases, they do not refer to immigrants coming into or residing in New Zealand. Nevertheless, these representations of immigrants are highly relevant as they are read by New Zealanders. This more positive take on immigrants residing in New Zealand could be partially due to immigrants playing a vital role in the New Zealand economy, mainly by filling the skills shortage and investing.

\subsection{Immigrants as passive beneficiaries}

The collocation analysis revealed that immigrants are often associated with refugees and discussed in negative co-texts. Throughout both corpora, refugees (and thus immigrants) are often represented as (a) needing help and support, (b) needing to be integrated/assimilated, and (c) weak/of no particular use to society. These themes run throughout both corpora, with the first two as the dominating themes.

Such frequent disempowering representations of refugees are problematic. The fact that refugees have faced hardships and difficulties in their lives and are in need of various services is not to be doubted and this aspect of their lives should not be ignored. Representing refugees as victims has its benefits and can help create sympathy within the public to support services and facilities being created for them. However, reliance on these representations as the dominating representation is inaccurate and can have unfavourable effects on the future lives of refugees. Examples of refugees who are technologically savvy, with a high level of education, English proficiency, valuable skills, etc., are not present within the newspaper discourse. It is important to understand that before refugees were uplifted from their home countries, many were valuable members of their societies, e.g. doctors, nurses, engineers, teachers etc. Detailed accounts of how they contributed to their home countries, and how they hope to contribute to the host country, the various skills and qualifications they have, and the cross-cultural insights that they can provide, are basically 
non-existent within the New Zealand Herald discourse. In summary, there is a marked absence within the newspaper discourse of the representation of refugees who are educated, skilled, and highly experienced. We need more representations of refugees as people who have capabilities, capacities, potentials, as well as vulnerabilities.

The critical discourse analysis further supported the evidence that immigrants are represented as people who are constantly in need of help. Furthermore, this analysis illustrates that immigrants are represented as passive recipients or beneficiaries of various schemes, programmes and services to help them find jobs.

Continuing with the topic of agency, an examination of the broader qualitative data set identifies some of the nuances involved in the representation of immigrant agency and shows that there are various levels of agency assigned to immigrants. There are instances within the broader qualitative data set where immigrants are in fact represented as performing actions. These examples can be further categorized into subcategories as illustrated below. In some cases, immigrants are represented as active agents of actions. Nevertheless, the co-text suggests that these actions are not necessarily undertaken by choice but rather out of desperation or obligation:

(2) He left his wife and three young children at home so he could find a job. ('Six month permit too tough', New Zealand Herald, 17 January 2007)

(3) He left his homeland during the tumultuous years of that nation's civil war. ('Patrons adding to the painful journey', New Zealand Herald, 4 July 2008)

(4) Millionaires have to actively invest a portion of their money by buying into or setting up local businesses to boost employment and the economy. ('New Zealand on hunt for more millionaires', New Zealand Herald, 7 June, 2007) 
Extracts (2) and (3) describe immigrants who had to leave their families and home countries behind in order to come to New Zealand either to find a job or to escape war. The action of leaving one's family or country is generally not one of choice but undertaken out of desperation. Extract (4) focuses on immigrants who invest and describes a new policy introduced by the government and the obligations or requirements that these immigrants have if they decide to migrate to New Zealand.

In line with the concept of levels of agency, in the extracts below from the broader qualitative dataset, immigrants are represented as performing actions which an authority allows or permits. In other words, considering broader knowledge of the situation, the actions could not have been performed without permission from an authority of some sort. A good example of this is the arrival of immigrants. '5000 migrants' are represented as being the agents of entering or arriving in New Zealand:

(5) If current trends continue, a net 5000 migrants will arrive this year, well down on the average of 12000. ('Trickle of migrants double-edged sword', New Zealand Herald, 21 June, 2007)

(6) Migrants managed to gain residence in New Zealand. ('Six month permit too tough', New Zealand Herald, 17 January 2007)

Examples like the ones above hide the fact that immigrants are granted residence visas or the right to enter a country by organizations like Immigration New Zealand. On the surface, one may assume that immigrants perform actions and therefore are being represented as having agency. However, the knowledge of the broader socio-political context clearly indicates that these actions could not have been performed without approval of these authorities.

In a few of the news articles within the data set, immigrants are not given any form of agency and are merely numbers or statistics which are discussed and commented on. In 
these instances, liquid metaphors (e.g. 'inflow') are often used as the syntactic agent of the sentences and are inanimate:

(7) The net inflow of migrants has dwindled. ('Trickle of migrants doubled-edged sword', New Zealand Herald, 21 June, 2007)

(8) Net migrant inflow since has been running at only half the rate the Reserve Bank assumes for 2007. ('Trickle of migrants doubled-edged sword', New Zealand Herald, 21 June, 2007)

In other news articles, immigrants are represented as performing actions which are often frowned upon. They are either agents of illegal actions, or actions indicated as problematic by the newspaper:

(9) Immigrants may have slipped illegally into New Zealand because of gaps in systems for discovering identity fraud, the Government has admitted. ('Illegal immigrants may have exploited lax ID screening', New Zealand Herald, 27 June, 2007)

(10) An Auckland vigilante group is teaching members of the Asian community how to use everything from pens to perfume as weapons to fight crime. ("Asian vigilantes hit back against crime', New Zealand Herald, 4 July 2008)

(11) Like bounty hunters riding the boundaries, groups of millionaires and wealthy migrants are looking to lock away land on the city's rural outskirts for big gains. ('Speculators on the prowl', New Zealand Herald, 23 June, 2007)

In extract (9), immigrants are represented as entering 'illegally' into New Zealand and in extract (10), the group which teaches Asians residing in New Zealand how to protect themselves against criminals is dubbed a 'vigilante' group which carries a negative 
connotation. Both examples represent immigrants as active agents albeit performing rather negative actions. In extract (11), immigrants are compared to bounty hunters because they are vigilantly seeking land for investment. Considering the broader backdrop of the discussions of extremely high housing prices in Auckland and the impact of immigration on the price, the representation of 'millionaires' and 'wealthy' immigrants as people who 'lock away' land does not represent immigrants as agents of a positive action.

Nevertheless, it is worth noting that there are also examples from the broader qualitative data set which do contradict the passive or negative representation of immigrants. In the news article entitled 'six month permit too tough', for example, immigrants are explicitly represented as forming groups, and voicing their concerns and reacting actively towards immigration policies by sending petitions:

(12) More than 1300 Filipino immigrants sent a petition to Prime Minister Helen Clark and Cabinet ministers David Cunliffe and Chris Carter on January 5 seeking a reinstatement of the original two-year term. ('Six-month permit too tough, say job-seekers', New Zealand Herald, 17 January, 2007)

(13) But migrants' groups say most employers won't employ people who are here on six-month-only permits. ('Six-month permit too tough, say job-seekers', New Zealand Herald, 17 January, 2007)

Extracts (12) and (13) represent 'Filipino immigrants' acting collectively to challenge the six month to work permit which they believe is 'too tough'. They are represented as performing actions such as sending 'petitions to Prime Minister Helen Clark', asking for a 'reinstatement' of older more flexible policies and expressing their concerns. Another news article discusses how an immigrant, after personally having faced difficulty finding a job, has now established his own organization to 'help migrants into work': 
(14) But Treagus is using his experience to head up a new organization that will help migrants into work, helping them get the Kiwi experience that may be holding them back and providing business mentors to help ease them into the culture and an all-important job. ('Kiwi experience: unemployment', New Zealand Herald, 26 April, 2008)

This news article discusses how 'Treagus' an immigrant from South Africa will 'head up a new organization' in order to 'help' fellow immigrants:

(15) Treagus, who is South African and spent time working in Britain before moving to Auckland in 2005, says the term "Kiwi experience" is sometimes justified. But he says it is frequently a disguise for discrimination. ('Kiwi experience: unemployed', New Zealand Herald, 26 April, 2008)

However, examples like this are not found frequently within the data set and only briefly refer to discrimination in the employment process. Therefore, it can be concluded that a large number of the representations in the newspaper depict immigrants in rather passive roles, and the remaining are less than positive with very few articles sharing stories where immigrants have not had to struggle. This representation ignores the endeavors of immigrants to find jobs and the challenges they have faced in the job hunting process, and thus contributes to the construction of immigrants as people who are passive. Representations where immigrants actively contribute extensively to New Zealand society are rare.

\subsection{Dehumanizing immigrants}

The analyses above suggest that immigrants are dehumanized in three ways. The most prominent way through which immigrants are dehumanized is the use of liquid metaphors to talk about migrant numbers (cf. Cunningham-Parmeter, 2011). Secondly, similes and 
comparisons with non-human entities are used to refer to immigrants and their actions. Finally, mere numbers replace nouns when referring to immigrants.

Both the collocation and critical discourse analysis showed that one of the most prevalent ways to refer to immigrants is through the use of liquid metaphors. As also mentioned in the collocation analysis itself, water metaphors which are used to reflect large numbers are at times used in counter-intuitive ways that reflect the positive impact of mass immigration to New Zealand. At other times, there is a certain level of ambivalence as to whether mass immigration is beneficial or not, i.e., both the positive impacts and the negative impacts are highlighted within the concordance lines. Large immigrant numbers are associated with contributing to filling the skills shortages and bringing wealth into the country but also with causing inflation of house prices.

Comparison with other corpora/discourse studies suggests that the use of liquid metaphors to construct mass immigration as something positive seems to be a unique feature of the New Zealand data as in a few cases the large numbers of immigrants are represented as directly contributing to relieving skill shortages and creating a stronger economy. This is quite contrary to previous findings about immigrant representation carried out mainly in Europe (KhosraviNik, 2008). Wodak (2001) for example has categorized these metaphors as negative topoi. Therefore, despite most research on immigrant representation confirming the use of liquid metaphors in derogatory terms, this study points to the presence at times of a unique and favourable representation.

However, as the discourse analysis illustrated, the newspaper discourse also uses liquid metaphors to construct the arrival of large numbers of immigrants as a threat to New Zealand. This representation of immigrants becomes predominantly visible in news reports where Peters or other members of the New Zealand First party are given voice.

In addition, there is one example in the broader qualitative data set where a natural disaster metaphor is used to construct the movement of New Zealanders out of the country. 
Although this does not appear often within the data set (certainly not as often as those which referred to immigrant groups), nevertheless, it illustrates that natural disaster metaphors, such as 'avalanches of people', which are also dehumanizing devices, can be used for referring to the in-group as well.

The second means through which the newspaper discourse dehumanizes immigrants is by comparing them to non-human entities such as insects or animals. Textual analysis 1 , for example, illustrated how immigrants are compared to insects. There are, however, other comparisons within the broader qualitative data set. In one news article, 'wealthy migrants' were placed in the position of the agent of an action commonly associated with animals. The article entitled 'speculators on the prowl' uses the word 'prowl', commonly used to refer to predators when they hunt their prey. In this case, 'wealthy migrants' are actively searching for investment opportunities. Animal metaphors are also used in the body of this news article:

(16) Wealthy migrants from China, Taiwan, and Korea were particularly active, hunting for those opportunities, he said. ('Speculators on the prowl', New Zealand Herald, 23 June, 2007)

In extract (16), Asian 'migrants' (from 'China', 'Taiwan' and 'Korea') are placed as the agents of the act of 'hunting'. The adjective 'active' further accentuates the action. Other metaphorical constructions became apparent in the choice of verbs and nouns when talking about immigrants. There are phrasal verbs and nouns, e.g. 'resources' which index a perception that immigrants are mere commodities to be used for the financial benefit they bring. Moreover, these dehumanizing instances further endorse the utilitarian perspective outlined above.

Finally, immigrants are dehumanized as some of the news reports analysed describe immigrants in terms of numbers and statistics. The dehumanizing nature of these examples 
are further accentuated as numerous examples omitted the nouns which could have followed the number.

(17) If that rate is sustained for the rest of the year the gain will be only 5000, compared with the average gain of more than 12,000 for the past 16 years. ('Trickle of migrants double edged sword', New Zealand Herald, 21 June, 2007)

The absence of a noun following these numbers further contributes to immigrant dehumanization. It constructs them as mere numbers and statistics and disguises their human nature.

\subsection{Immigration policies}

The ambivalence mentioned above is also present when the newspaper presents discussions surrounding immigration policies. Frequently the newspaper discourse argues for changes to current immigration policies and systems. On the one hand, the discourse also represents New Zealand as being in global competition for wealthy and skilled immigrants (in particular the contributions they make to the economy through their skills and investments) and argues that New Zealand needs more immigrant-friendly policies if it is to stay ahead in the competition for immigrant skills and wealth. On the other hand, the discourse argues for stricter and exclusionary policies which prevent immigrants from entering the country.

These perspectives become readily apparent when Winston Peters is given voice. In fact, the exclusionary discourse which argues for restrictive approach to immigration is frequently conveyed through quoting and paraphrasing Peters. Considering that he features so strongly in articles by the New Zealand Herald, it is possible that the newspaper strategically uses his opinions on immigration policies to attract a right-wing readership while at the same avoiding criticism of being right wing itself. Peters' opinions sell and therefore he is frequently given opportunity to voice his opinion on the topic of immigration. Through highlighting the drawbacks of immigration, the discourse argues for 
stricter policies to prevent more immigrants from arriving. Therefore, depending on who is given voice, the newspaper discourse constructs immigration policies as either too strict or too lenient.

\subsection{Categories of immigrants}

The analyses above illustrate how the discourse through the use of modifiers creates categories of immigrants. The collocation analysis illustrated that the 2007 corpus portrays immigrants as one homogenous group (cf. KhosraviNik, 2010). Collocates which convey this are nouns such as 'groups', or 'communities'. The corpus initially collectivizes immigrants and then portrays them as being different from the mainstream culture. The variety of people from many different countries, cultural backgrounds and personalities are disregarded and they are lumped under simplistic labels such as 'migrant groups' and 'migrant communities'. These large homogenous groups of immigrants are then placed in opposition to people and cultures of the host country with the expectation that they should integrate.

The discourse analysis also demonstrated that the newspaper categorizes immigrants into wanted and unwanted; good versus bad immigrants; or high quality versus low quality ones. Those who have skills and are law abiding are dubbed 'good' and those who abuse laws and come 'illegally' are considered bad (cf. Lynn \& Lea, 2003;). Therefore, the analysis illustrates how the newspaper discourse through use of various qualifiers creates a human hierarchy or a preference for certain types of immigrants.

In line with the concept of immigrant categories, the data interestingly represents local New Zealanders who emigrate abroad and live in the UK as a different type of immigrant in comparison to non-locals. Santa Ana (1999) in his study of public discourse representations of immigrants in the United States also shows how hierarchies are constructed among living beings in order to justify social inequality (p. 201). The broader qualitative data set also shows instances where locals are clearly separated and prioritized, creating a human hierarchy. Articles such as 'enticing the expats' is a good example as the 
word 'expat' is used to describe a different category of immigrants, namely New Zealanders who are living abroad. The term 'expats' is used twice in this article and is collocated with the word 'migrants':

(18) During the past 18 months, New Zealand's leading recruitment agencies have concentrated on more effective targeting. Madison Recruitment are setting up branches in Britain and Australia to attract expats and migrants. ('Enticing the expats', New Zealand Herald, 1 December, 2007)

(19) Similarly, global recruitment firm Robert Walters holds seminars in London to inform prospective migrants and expats about the New Zealand market. ('Enticing the expats', New Zealand Herald, 1 December, 2007)

In this news report, the word 'expat' refers to a different group of people than that of 'migrants' as they are connected (and hence also separated) with the word 'and'. When referring to New Zealanders who have migrated, the news discourse uses the word 'expat'. On the other hand, when the news discourse discusses non-New Zealand immigrants who want to come to New Zealand, it uses the word 'migrants'. This suggests that immigrants from certain source countries (mainly European or western countries) have been assigned a different name. To further support this argument, an exploration of the New Zealand Herald over the period 2007-2008 shows that the term 'expat' is used six times. A closer look at the co-text of these instances indicates that in each instance the term refers to either Australians, British people, or New Zealanders. A look at a larger corpus, namely the British National Corpus (BNC) also confirms the limited nationalities the referents of the term 'expats' are from. Here are some examples from the BNC:

- An American expatriate offered to take the grey.

- Sir: As a Tuscan expatriate in Britain, I feel duty bound to point out that five out of the eight Italians included in the '50 mastersingers of Europe' were from Tuscany: Dante, Michelangelo, Leonardo, Machiavelli and Galileo. 
- The amendment by an expatriate Scot, George Cunningham (Labour, Islington), by ensuring that a 40 per cent vote of the electorate (not simply of those voting) would have to be achieved for a devolution bill to go through and for a repeal order not to be tabled, made devolution, at least for Wales, virtually an impossibility. (Random Samples from BNC)

A random sample of 50 concordance lines from the BNC shows that the term 'expatriate' is used more frequently to talk about Americans, Scots, Europeans, and the British than other nationalities. The term is used once in the 50 sample to refer to people from Iran, Russia, and South Africa and at other times was used without a qualifier specifying the nationality of the expat. Furthermore, an interesting observation is that the discourse surrounding immigrants is one of either legitimizing their presence by highlighting the benefits they bring or arguing why they are a problem by expounding on their disadvantages. Interestingly, these topics do not dominate the discourse around the term 'expatriate'. In other words, this term is rarely used with argumentation strategies which justify why a country needs them or why they cause problems? ${ }^{7}$.

Therefore, collectivizing immigrants often leads to negative and inaccurate constructions of immigrants, as individual differences are ignored. Their othering, either by associating them with negative actions or using different nominalizations to refer to different types of immigrants, creates conflict among members of society rather than unity and harmony.

\subsection{Immigrant integration}

The collocation analysis indicated that immigrants are often expected to integrate to the norms and culture of the hosting country. Integration as a theme runs throughout both corpora. However, it becomes more salient in 2008 as significant collocates which convey

\footnotetext{
7 'Expat' is a complex term and needs further research. The more positive connotation of the term in comparison to 'migrant' may partially be due to its more temporary state.
} 
integration ('integrating', 'integrate', and 'settle') appear in the top 20 most significant collocates of the 2008 corpus. Interestingly enough, it is always immigrants who are expected to integrate into the host country's culture and there is very little data which shows the host country trying to make an effort to learn and adopt or adapt to the cultural values of the immigrants.

Immigrants are frequently represented as having problems such as difficulty finding jobs. The solutions given to the problem of unemployed immigrants predominantly relate to immigrants and changes that they need to make. Initiatives, programmes and schemes are frequently advertised for immigrant communities to help them 'integrate' and become familiar with New Zealand recruitment practices, values and expectations, but rarely are initiatives directed at recruiters who could receive training on how to accommodate employees from diverse backgrounds. Hence, it could be argued that the problem is seen only from one perspective and not as an issue which needs addressing from both perspectives. More importantly, the source of the problem, namely discrimination within recruitment, is seldom if ever raised and elaborated.

Taking this one-way responsibility to integrate, I agree with scholars like Van Leeuwen and Wodak (1999) who state that the word "integration" seems to be used as a "euphemism" for the word "assimilation" (p. 89). All concordance lines (except one) place the immigrants as the agents of the action of integrating. Without the mutual endeavor on behalf of both parties to understand, respect and learn from one another's cultural values, the required level of inter-cultural competence to maintain a harmonious society will not truly exist. With the integration of just one party, the integrating immigrant will never truly feel at home.

\subsection{Immigrants as victims}

The collocation analysis illustrated that in 2008 immigrants were frequently described as being victims (cf. KhosraviNik, 2010; Baker \& Benson, 2008). Collocates which point to 
this discourse are 'vulnerable', 'protect' and 'target'. As evident in the data analysis, immigrants are portrayed as passive victims of physical abuse, victims of gambling addiction or people who require services to protect them. The representation of immigrants as people who require services may be considered beneficial for refugees, but it strips immigrants of their agency and portrays them as being powerless and does not lead to a very empowering representation of immigrants. Instead it presents them as people who are weak and incapable.

More importantly, even with refugees, it is important to acknowledge that victimization should not necessarily mean passivity. Refugees for example, are not people who have immediately fled their home country for a better life but very likely have resisted and struggled against the difficulties and hardships before having made the decision to leave. The fact that they have struggled, resisted, retaliated and made decisions to move, in itself shows agency on behalf of the refugees. This aspect of refugee agency is often overlooked in their representation but deserves attention. Empowering representations of immigrants as being successful now and in their home countries are rare. Seldom are there representations of immigrants as influential academics, as world famous physicians, or acclaimed community workers who have strived to make a difference wherever they are. Without these, unbalanced representation of immigrants will prevail.

\subsection{Immigrant perspectives}

The discourse analysis demonstrated that immigrant perspectives are limited in the newspaper discourse. Paradoxically, their voices do not dominate on issues directly pertaining to themselves, namely the topic of immigration. Instead numerous politicians are given voice. Having said this, the news discourse does occasionally draw on immigrant voices, mainly to present their personal stories and to give information about their daily lives (work, family etc.). While personal stories are of much value, in the majority of the cases they acknowledge the difficulties immigrants experience and highlight the presence 
of a problem. Personal stories of a more positive nature which represent immigrants as successful and happy are scarce. Nevertheless, without more positive stories, repeated articles which highlight immigrant struggles contribute to creating a very disempowering image of immigrants which in turn encourages an image of a struggling immigrant to be taken for granted. 'Patrons adding to painful journeys' is a good example of this as it represents a grim picture of immigrant taxi drivers as victims of abuse and discrimination:

(20) While waiting in the taxi rank it is not uncommon for drunken louts to jump on his bonnet and pull the magnetic signs off his doors. He has had eggs thrown at his taxi from an apartment above. ('Patrons adding to painful journey', New Zealand Herald, 4 July, 2008)

The news article presents the experiences of the immigrant (albeit in the third person) and describes the struggles that immigrants face in the course of their jobs in New Zealand. In instances where an immigrant provides a personal story or information, they are mainly referred to using first name and their last name. Interestingly, only politicians (immigrants or not) are given titles. There are very limited instances of reference to immigrant members using titles, e.g. Dr, or affiliations to their workplaces. Therefore, a marked feature of the news discourse is the very limited references to members of the immigrants' communities using a title or using an affiliation which denotes their status in society. Given the numerous immigrants who hold influential positions in various institutions in the society, the question arises as to why the newspaper does not draw on the opinion of these immigrants.

\subsection{Summary}

This chapter has provided a discussion of the various representation of immigrants that became apparent during the collocation and critical discourse analyses. As the discussion illustrated, the representation of immigrants in the New Zealand Herald is complex and in most cases rather ambivalent. Despite both the critical discourse analysis and the corpus analysis revealing a slightly more positive representation in 2007 than 2008, there is no 
fixed and static representation of immigrants in the newspaper's discourse. In numerous cases, immigrants are represented as being both beneficial and threatening. In addition, numerous instances within the data pointed to the construction of immigrants as a homogeneous passive group who are in need of help and services or in need of integrating to the dominant host culture. While in other instances, immigrants were described using dehumanizing metaphors which referred to their large numbers as both beneficial and problematic. Therefore, it can be summarized that ambivalence was the dominating representation of immigrants. The next and final chapter discusses the contributions and the limitations of this study and elaborates on future studies which are needed in the area of immigrant representation. 


\section{Chapter 9: Conclusion}

Research into the representation of immigrants within New Zealand is crucial as its diversity is ever-increasing. With so many ethnicities making up this small isolated country, issues of media representation come into the spotlight as it has been argued that media representations of minority groups contribute significantly to maintaining social harmony among members of the community (Mastro, 2015). Against this contextual backdrop, this thesis has attempted to unpack the representation of immigrants in the New Zealand Herald, the main daily newspaper printed in New Zealand's biggest and most populated city. More specifically, the research has addressed the following research questions:

- How are immigrants represented in the New Zealand Herald during 20072008 ?

- What collocations do the search words, 'migrant (s)', 'immigrant (s)', and 'Asians' have in the New Zealand Herald?

- How are immigrants referred to, described, and how often are they given voice in the New Zealand Herald?

- What argumentation strategies are used to argue for/against immigrants in the New Zealand Herald?

- How do the findings from the corpus analysis contribute to the findings from a traditional Critical Discourse Analysis approach? (N.B. this research question is addressed in section 9.1)

In addressing these questions, the findings from the study suggest an ambivalent representation of immigrants in the New Zealand Herald. The ambivalent representation is a result of positive representations coexisting in the corpus with more negative 
representations of the immigrant diaspora. The positive constructions of immigrants became evident during both the collocation analysis as well as the discourse-historical analysis. The analyses demonstrated that immigrants are depicted as skilled, qualified and wealthy and needed for New Zealand's economy. These all contributed to the positive construction of immigrants; in particular the positive effects of immigration on the economy were emphasized. Nevertheless, both analyses (collocation and discoursehistorical) also suggested a derogatory representation of immigrants. Immigrants were constructed in a pejorative light as people who put pressure on the housing market, are involved in criminal activities or are passive victims and always in need of help and services.

Furthermore, the findings from the critical discourse analysis and the corpus analysis both indicated, as hypothesized, that the representation of immigrants in 2007 was more positive than in 2008. There was a higher frequency of collocates with positive connotations occurring in the proximity of the search words in 2007 and there were also fewer derogatory representations. Moreover, the critical discourse analysis illustrated that in 2008 more derogatory representation of immigrants were introduced due to certain politicians with anti-immigration stances being given extensive voice. However in 2007, the financial benefits of having more immigrants in the country was the focus. This finding confirms to an extent the hypothesis that immigrants are represented in more derogatory ways during hard economic times.

In terms of the collocations of the search words and the discursive strategies used, the analyses illustrated that liquid metaphors, e.g. 'inflows', collocate with positive connotations, e.g. 'skilled', as well as collocates with negative connotations which construct immigrants as wrong-doers, e.g. 'illegal', were salient (see Chapter 6 for comprehensive analysis of salient collocations).

The discourse-historical analysis on the other hand, illustrated that collective, metaphorical and professional anthroponyms were highly frequent nomination/referential strategies used 
to construct immigrants. In terms of predication strategies, the broad categories of immigrants are problematic and immigrants are beneficial were highly frequent strategies used to describe immigrants. Finally, the analyses also demonstrated that topos of consequence (whether positive or negative consequence), topos of numbers, topos of cost, and topos of authority were very frequent within the dataset. Moreover, the opinions and perspectives of influential immigrants were rarely found in the dataset analysed. Mitigation and intensification strategies were also rare particularly in news reports (see Chapter 7 for a detailed discussion of discursive strategies).

This study has implications for media practitioners, encouraging them to think deeply and critically about the implications of their institutionalized practices. The privileged access to the media of certain members of the society typically results in the voice of minority groups fading into the background. This was particularly true of the data collected in this study, as immigrant voices were seldom present. The analysis suggests that media practitioners should give more voice to influential immigrant community members particularly as debates on immigration concern immigrants directly. More importantly, we need to question to what level journalistic objectivity is actually achievable. As the analyses illustrated, even news reports which are frequently perceived to be providing objective hard news, may favour one perspective more than the other. The choice of social actors who are given opportunity to voice their opinions, the positioning and framing of their and the writer's perspectives, and the number of voices allocated to each perspective mean that certain perspectives receive greater focus, even in so-called hard news pieces. For these reasons, achieving a balance of viewpoints in presenting the news is indeed a challenge and needs a great deal more thought and careful consideration.

\subsection{Methodological contributions}

Previous studies on the representation of immigrants in the context of New Zealand are relatively few. Studies in this context have either adopted a content analysis which offers useful, although often rather limited, insight into immigrant representation, or have looked 
at the representation of one particular diaspora rather than immigrants in general. More importantly, no studies have focused on the years 2007-2008 with the aim of shedding light on the role and effect of the Global Financial Crisis on the representation of immigrants in the print media.

In addition to these contributions, another important contribution of this study lies in its rigorous methodology. This study, in addition to a topic analysis, relied on a thorough twopronged analytical approach. Through methodic triangulation, I analysed the same data set with two different analytical frameworks, namely a corpus-assisted discourse analysis followed by an application of the Discourse-Historical Approach (DHA) (Reisigl \& Wodak, 2009). As indicated in the introduction, the more methodically oriented research question of this thesis was how the findings from the corpus analysis contributed to the findings from a traditional Critical Discourse Analysis approach. This research question is addressed here.

The combination of the two approaches had numerous advantages including counteracting the criticism that has been directed at each approach specifically. Firstly, the use of a corpus-assisted approach reduced the chances of cherry picking the data as it was the statistical information provided by this approach which helped identify entry points into the data. Moreover, the use of statistical measurements such as the Mutual Information and Log Likelihood scores, rather than mere frequency measures as common in content analysis, ensured that the collocations identified and discussed in this study are highly significant, i.e. they are not random occurrences within the data set. Therefore, triangulation is a useful means of distancing oneself from the data and hence adhering to a critical stance as advocated by previous scholars (Reisigl \& Wodak, 2001, p. 87). Conducting a corpus-assisted discourse analysis prior to the purely qualitative discourse analysis also ensured that meaning was not read into the data, a point scholars have criticized (Widdowson, 1998, p. 148). The statistical information provided by the concordances guides the researcher to information, patterns and discourses which they may not have thought would be present and protects the researcher from reading meaning into 
the texts based on pre-conditioned perceptions that they may have of the data. While the intuition of the researcher is invaluable and indispensable, this preliminary corpus-assisted approach directs the researcher to parts of the data that they may have missed. For example, in the case of this study, the statistical information pointed to concordances which helped to shed light on numerous positive representations of immigrants by indicating highly frequent and significant collocational patterns which I may have ignored or dubbed not significant enough to be discussed had I conducted the qualitative DHA analysis first.

Secondly, while scholars have criticized traditional qualitative discourse analysis for concentrating on single instances (Breeze, 2011, p. 515), the methodic triangulation applied in this study ensures that the findings are not just representative of the smaller dataset but hold for the larger corpus as well. The corpus-assisted approach to discourse analysis provided a bird's eye view of the whole data set. So the corpus analysis scans the larger dataset horizontally ensuring that the entire corpus is analysed for significant collocations. The DHA (Reisigl \& Wodak, 2009), on the other hand, allowed for more vertical, in-depth, inductive, detailed and qualitative analysis of a smaller dataset. It considered questions concerning the characteristics of the process of production, the people who were given voice, the extent of voice given to each social actor, the generic features of the news articles, as well as the discourse, rhetorical and argumentation strategies used in the representation of immigrants. The combination of these two approaches to Critical Discourse Analysis means that the findings of this study may be more confidently generalized. In most cases, the findings from the discourse-historical analysis, while focusing on various discourse strategies and hence adding depth, confirmed the findings from the collocation analysis. This methodic rigour reinforces the validity and reliability of the findings and to my knowledge has not been conducted in the context of New Zealand research before. 


\subsection{Contributions to literature}

The findings from the analysis clearly showed a tendency to talk about immigrants in a positive light. This became apparent particularly in the use of liquid metaphors in rather unique co-texts which clearly pointed to large numbers of immigrants coming to New Zealand being constructed positively rather than pejoratively as suggested by previous studies. This representation of immigrants, to my knowledge, is absent from mainstream critical studies of media representations of immigrants. The rather unique use of liquid metaphors in positive co-texts, constructing immigrants as highly sought after, is a new finding. Of course, it needs to be reiterated that this positive representation was mainly expressed within an economic framing of immigration issues. The majority of the cotextual information in both stages of analysis suggest that immigrants were constructed as beneficial only because of the financial and economic profits that they could potentially bring to the country. In other words, immigrants were constructed as economic resources to be made use of. In fact, the construction of immigrants as beneficial for the cultural richness they bring was noticeably absent from the data set. These findings highlight the importance of the socio-political and geographical context in the interpretation of discourse. Some of the socio-political, and geographical conditions which may have led to this rather unique representation of immigrants are discussed below.

The first reason for a more positive construction of immigration (i.e. in comparison to the findings of previous studies) in this New Zealand newspaper is emigration. Demographics show that New Zealand has a relatively small population of just over 4.5 million (Statistics New Zealand, 2015) and that significant emigration in addition to immigration contributes to continuous changes in its demographics. New Zealand's population is reduced through emigration to countries like Australia which have bigger and stronger economies, and hence provide immigrants with more job opportunities and higher pay. The number of New Zealanders living overseas 'is estimated to be in the range of 700,000 to 1 million, of whom 95,000 are living in Australia' (New Zealand Department of Labour, 2012, para. 3). Thus, immigration in New Zealand tends to be viewed as 'replacement migration' where the 
immigrants are replacing New Zealanders who have decided to live abroad (Bedford, 2006, p. 229). This is strongly supported by the data in the corpus where loss of population to neighboring countries is one of the dominant concerns.

The second possible explanation for a more positive attitude to immigration is the unique geographical distance of New Zealand from immigrants' countries of origin. New Zealand is a far-flung and isolated country. The closest countries are either tiny South Pacific islands or Australia to its west, and all require several hours of flight time. The fact that it is an island in the middle of an ocean also means that the sea is difficult to traverse should asylum seekers try to come. In addition, New Zealand rarely features in the news or media of other countries and not many people have a good understanding of the opportunities available here. This distance factor means that New Zealand does not tend to attract the same interest from migrating communities as countries which are closer (i.e. to the country of origin) and better known (e.g. European countries, USA etc.).

A third reason is the relatively small economy of New Zealand in comparison to other OECD countries. The country's economy heavily impacts its immigration policies (Skilling, 2012). Enthusiasm to attract (skilled) immigrants is the result of the view that 'immigration is fundamentally about securing value-adding human capital in a competitive global environment' (Skilling, 2012: p. 368; see Chapter 2 for a discussion on immigration policies). As a consequence of this perspective towards immigration, a certain narrative has developed where emphasis is given to the urgency to attract and retain skilled individuals in order to ensure national competitiveness. This narrative is also recontextualized within the newspaper's discourse.

Fourthly, the New Zealand Herald is printed in New Zealand's most immigrant-populated city, Auckland. According to Statistics New Zealand in 2014, '39 percent of the Auckland population was born overseas (up from 37 percent in the 2006 census)'. Naturally, these immigrants also make up a significant proportion of the newspaper's readership. Asian immigrants in particular make up a large part of the audience (Spoonley \& Butcher, 2009, 
p. 366). Newspaper companies are aware that the immigrant population contributes to the newspaper's sales and therefore cannot afford to represent immigrants too negatively as this could result in a loss of its customers.

Finally, the existence of a more positive representation of immigrants can be attributed to an overall more positive attitude towards immigration. According to recent research, New Zealanders perceived multiculturalism more positively than people in Australia and numerous European countries: over 80 percent of the population in New Zealand agreed that it is a "good thing for a society to be made up of people from different races, religions, and cultures" (Ward \& Masgoret, 2008). Johnston et al (2010) also confirm the importance of contact as their study shows that attitudes towards immigrants in New Zealand are geographically skewed, meaning that people perceive immigrants more favourably in cities like Auckland where they are more likely to have had contact with immigrants, and less favourably in smaller cities with fewer opportunities for contact (Johnston et al., 2010, p. $362)$.

Within the New Zealand context, then, various factors can be regarded as contributing to how immigrants are perceived and represented. Unlike the UK and other European countries where large numbers of immigrants are mainly constructed as a hindrance and a problem, in New Zealand a range of factors result in a more complex and complicated perspective on immigrants and immigration. The following two sections outline the limitations of this study as well as recommended future studies.

\subsection{Limitations}

This study has limitations which are mainly a result of restrictions in time and human resources. One of those concerns the size of the corpus. The corpus for this study was approximately 700,000 words. I quote an important sentence from Kennedy (1998) who states that "there is no point in having bigger and bigger corpora if you cannot work with the output" ( p. 68). Ideally, the corpus would have been bigger and the data for the current 
research would have been collected from a number of prominent daily broadsheet newspapers which are distributed in New Zealand's main cities. Regional newspapers would have also given insight into regional differences in immigrant representation throughout the whole of New Zealand. However, a small sampling of the data showed that focusing on the key terms in these newspapers for the period between 2007-2008 would yield far too many results. To put things into perspective, I should mention that there are 394 articles during the 2007-2008 period for the New Zealand Herald alone when searching for the key word migrant(s). This yields a corpus of 257, 310 words for this one key word. With a higher number of newspapers, a two-phase analysis would be unmanageable, i.e. a corpus assisted discourse analysis of all these articles followed by a qualitative (critical) discourse analysis of a portion of these was deemed impossible considering the time frame for a PhD study.

A second limitation of this study which is closely related to the first concerns the time period, i.e. 2007 and 2008, selected for this study. As indicated in the methodology, the reason for selecting this period was that it was hypothesized that immigrants would be represented more unfavourably in harsher economic times. As the Global Financial Crisis took its toll in 2008, a more unfavourable representation of immigrants was expected in 2008 in comparison to 2007. While this expectation was met and the findings indicated that there is a slight tendency to represent immigrants more positively in 2007 than in 2008 , it is conceivable that the representations would have changed more strongly in the longer aftermath of the recession compared to immediately following it. A more ideal situation would have been one where the time span considered for this study was increased to a few years before and after 2008 in order to fully capture any change.

\subsection{Direction for future research}

A possible next step in this research would be the analysis of immigrant representations using a larger data set which includes both regional as well as metropolitan newspapers. In addition, the incorporation of numerous genres (e.g. political pamphlets and leaflets, policy 
documents, political speeches) which is highly recommended in a DHA approach (Reisigl \& Wodak, 2009, p. 95) would yield a more comprehensive understanding of immigrant representation in the broader New Zealand context.

On an even more ambitious level, a comparative study which compares the representation of immigrants between New Zealand and an economically comparable country or the representation of immigrants among the various Organisation for Economic Co-operation and Development (OECD) countries would yield fruitful findings and highlight the discrepancies among countries. Such a study would require extensive human and financial resources, however.

More importantly, considering the on-going global refugee climate, an analysis of the representation of asylum seekers and refugees during the recent so called 'refugee crisis' is much needed. During the heightened period of coverage of the 'crisis' in 2015, it became clear that the (new) media played a crucial intermediary role between the members of the public and the government, with numerous news articles and social media posts voicing concerns over the rather low refugee quota that New Zealand is currently committed to. Considering the moral, human and legal obligations of countries such as New Zealand who are signatory to the 1951 Human Rights Convention Relating to the Status of Refugees as well as the 1967 Protocol Relating to the Status of Refugees, such a study would examine not only how asylum seekers and refugees are discursively constructed and hence perceived but also highlight the important role the media play in reminding and reinforcing government officials of these obligations.

\subsection{Closing remarks}

As CDA scholars point out "critical discourse scholars should also be social and political scientists, as well as social critics and activists" (Van Dijk, 1993, p. 253) and "the application of results is an important target” (Reisigl \& Wodak, 2009, p. 95). Bluntly put, we as critical discourse analysts have formidable duties which cannot be met solely through 
sitting in our ivory towers or working alone. We require researchers from different disciplines collaborating together. While the findings of this research will be made available through journal publications, and presentations at governmental institutions such as Immigration New Zealand and Non-Governmental Organizations such as Change Makers Refugee Forum, I have also volunteered to participate in a documentary series called Neighbourhood which celebrates the cultural diversity in New Zealand by presenting immigrant stories.

Moreover, in this era of technology one means through which social activism can be achieved with reasonable ease is social media networks such as Twitter and Facebook. These social media networks provide an avenue for critical scholars to have a voice, raise questions and disseminate research findings to the general public and while it would be ambitious to expect it to be as far-reaching as mass media, it nevertheless provides another avenue for critical voices to raise critical questions in a world where many perspectives are taken for granted.

Therefore, being a critical scholar using a critical approach to immigrant representation entails bringing about change. And as Tom Stoppard eloquently puts it in the following quote "if you can get the right words in the right order, you can nudge the world a little"(Stoppard, 1982, p. 55); this study was carried out with the aim of nudging the world to a better place. A better place, I argue, is one where the multicultural reality of societies is reflected in institutional practices such as those of the media, where immigrant voices are celebrated rather than silenced, and where immigrant contributions are not judged solely within a capitalized framework but are embraced for the cultural richness they bring. 


\section{References}

Ackerman, E. (2014). “What part of illegal don't you understand?”: Bureaucracy and civil society in the shaping of illegality. Ethnic and Racial Studies, 37(2), 181203. https://doi.org/10.1080/01419870.2012.705008

Akbari, A. H., \& MacDonald, M. (2014). Immigration policy in Australia, Canada, New Zealand, and the United States: An overview of recent trends. International Migration Review, 48(3), 801-822.

Andreouli, E., \& Dashtipour, P. (2014). British citizenship and the "Other": An analysis of the earned citizenship discourse. Journal of Community and Applied Social Psychology, 24(2), 100-110.

Angermuller, Johannes, Maingueneau, D., \& Wodak, R. (2014). Introduction. In Johnnes Angermuller, D. Maingueneau, \& R. Wodak (Eds.), The discourse studies reader: Main currents in theory and analysis (pp. 359-364). Amsterdam: John Benjamins.

Arnold, R. (1981). The farthest promised land: English villagers, New Zealand immigrants of the 1870s. Wellington: Victoria University Press. Retrieved from http://nzetc.victoria.ac.nz/tm/scholarly/tei-ArnFart-c4.html

Astor, A. (2009). Unauthorized immigration, securitization, and the making of Operation Wetback. Latinos Studies, 7(1), 5-29.

Augoustinos, M., \& Every, D. (2007). The language of "race" and prejudice: A discourse of denial, reason, and liberal-practical politics. Journal of Language and Social Psychology, 26, 123-141. 
Baker, E. (2007). Media concentration and democracy: Why ownership matters. Cambridge: Cambridge University Press.

Baker, P. (2006). Using corpora in discourse analysis. London: Bloomsbury.

Baker, P. (2010). Sociolinguistics and Corpus Linguistics. Edinburgh: Edinburgh University Press.

Baker, P., Gabrielatos, C., \& McEnery, T. (2013). Discourse analysis and media attitudes: The representation of Islam in the British Press. New York: Cambridge University Press.

Baker, P., KhosraviNik, M., Krzyzanowski, M., McEnery, T., \& Wodak, R. (2008). A useful methodological synergy? Combining Critical Discourse Analysis and Corpus Linguistics to examine discourses of refugees and asylum seekers in the United Kingdom press. Discourse and Society, 19(193), 273-306.

Baker, P., \& Levon, E. (2015). Picking the right cherries? A comparison of corpus-based and qualitative analyses of news articles about masculinity. Discourse and Communication, 9(2), 1-16.

Baker, P., \& McEnery, T. (2005). A corpus-based approach to discourses of refugees and asylum seekers in United Nations and newspaper texts. Journal of Language and Politics, 4(2), 197-226.

Baker, S., \& Benson, J. (2008). The suitcase, the samurai sword and the Pumpkin: Asian crime and New Zealand news media treatment. Pacific Journalism Review, 14(2), 183-204. 
Banda, F., \& Mawadza, A. (2015). "Foreigners are stealing our birth right": Moral panics and the discursive construction of Zimbabwean immigrants in South African media. Discourse and Communication, 9(1), 47-64.

Barclay, K., \& Liu, J. (2003). Who gets voice? (Re)presentation of bicultural relations in New Zealand print media. New Zealand Journal of Psychology, 32(1), 3-12.

Beaglehole, A. (2012). 1986-2003: selection on personal merit - Immigration regulation - Te Ara Encyclopedia of New Zealand. Retrieved from http://www.teara.govt.nz/en/immigration-regulation/page-5

Beaglehole, A. (2013). Refugee New Zealand: A nation's response to refugees and asylum seekers. Otago: Otago University Press.

Bedford, R. (2006). Skilled migration in and out of New Zealand: Immigrants, workers, students and emigrants. In B. Birell, L. Hawthorne, \& S. Richardson (Eds.), Evaluation of the general skilled migration categories. Australia: The Department of Immigration and Citizenship, Commonwealth of Australia.

Bedford, R., \& Spoonley, P. (2014). Competing for talent: Diffusion of an innovation in New Zealand's immigration policy. International Migration Review, 48(3), 891911.

Beer, F., \& Landtsheer, C. (2004). Metaphorical world politics. East Lansing: Michigan State University.

Bell, A. (1991). The language of news media. Oxford: Blackwell.

Bell, A. (1998). The discourse structure of news stories. In A. Bell \& P. Garrett (Eds.), Approaches to media discourse (pp. 64-104). Oxford: Blackwell. 
Bennet, L. (1996). An introduction to journalism norms and representations of politics. Political Communication, 13(4), 373-384.

Biber, D., Conrad, S., \& Reppen, R. (1998). Corpus Linguistics: Investigating language structure and use. Cambridge: Cambridge University Press.

Billig, M. (2005). Laughter and ridicule: Towards a social critique of humour. London: SAGE.

Billig, M. (2008). The language of Critical Discourse Analysis: The case of nominalization. Discourse and Society, 19(6), 783-800.

Blommaert, J. (2001). Context is/as critique. Critique of Anthropology, 21(1), 13-32.

Bloom, A., \& O’Donovan, T. (2013). “Marking time”: Experiences of successful asylum seekers in Aotearoa New Zealand (A discussion document). ChangeMakers Refugee Forum.

Breeze, R. (2011). Critical Discourse Analysis and its critics. Pragmatics, 21(4), 493525.

Brian, P. (2015). Butterflies and moths - Te Ara Encyclopedia of New Zealand. Retrieved June 6, 2016, from http://www.teara.govt.nz/en/butterflies-and-moths Brimelow, P. (1995). Alien nation: Common sense about America's immigration disaster. New York: Random House.

Burroughs, E. (2015). Discursive representation of "illegal immigration" in the Irish newsprint media: The domination and multiple facets of the "control" argumentation. Discourse and Society, 26(2), 165-183.

Calhoun, C. (1992). Habermas and the public sphere. Cambridge: MIT Press. 
Candlin, C. (1997). General editor's preface. In B. L. Gunnarsson, P. Linell, \& B. Nordberg (Eds.), The construction of professional discourse (pp. x-xiv). London: Longman.

Caplan, G. (1997). Advancing free media. Open Media Forum.

Carvalho, A. (2008). Mediated discourse and society. Journalism Studies, 9(2), 161-177.

Charteris-Black, J. (2006). Britain as a container: Immigration metaphors in the 2005 election campaign. Discourse and Society, 17(5), 563-581.

Chilton, P., \& Wodak, R. (2007). Preface. In Ruth Wodak \& P. Chilton (Eds.), A new research agenda in (Critical) Discourse Analysis (pp. xi-xviii). Amsterdam: Benjamins.

Chomsky, A. (2007). "They take our jobs!” and 20 other myths about immigration. Boston: Beacon Press.

Chomsky, N., \& Foucault, M. (1971). Human nature: Justice versus power. Retrieved from https://chomsky.info/1971xxxx/

Chouliaraki, L., \& Fairclough, N. (1999). Discourse in late modernity: Rethinking Critical Discourse Analysis. Edinburgh: Edinburgh University Press.

Comrie, M. (2002). Spin in the news. In J. McGregor \& M. Comrie (Eds.), What's news? Reclaiming journalism in New Zealand (pp. 158-172). Palmerston North: Dunmore Press.

Cunliffe, D. (n.d). Active investor migrant policy (Cabinet Paper) (pp. 1-16). Ministry of Business, Innovation and employment.

Cunningham-Parmeter, K. (2011). Alien language: Immigration metaphors and the jurisprudence of Otherness. Fordham Law Review, 79(4), 1545-1598. 
Del-Teso-Craviotto, M. (2009). Racism and xenophobia in immigrants' discourse: The case of Argentines in Spain. Discourse and Society, 20(5), 571-592.

Duan, D. (2011). The changing representation of the Chinese diaspora in New Zealand print media (Master's thesis). Auckland University of Technology, Auckland.

Eagleton, T. (1991). Ideology: An introduction. London: Verso.

Entman, R. (1993). Framing: Toward clarification of a fractured paradigm. Journal of Communication, 43(4), 51-58.

Fairclough, N. (2003). Analysing discourse: Textual analysis for social research. London: Routledge.

Fairclough, N. (2009). A dialectical-relational approach to Critical Discourse Analysis. In Ruth Wodak \& M. Meyer (Eds.), Methods of Critical Discourse Analysis (pp. 162-186). London: SAGE.

Fairclough, N. (2010). Critical Discourse Analysis: The critical study of language. London: Routledge.

Fairclough, N. (2015). Language and power. Oxon: Routledge.

Fairclough, N., \& Wodak, R. (1997). Critical Discourse Analysis. In T. A. van Dijk (Ed.), Discourse as social interaction. Discourse studies: a multidisciplinary introduction (Vol. 2, pp. 258-284). London: SAGE.

Fairclough, N., \& Wodak, R. (2010). Critical Discourse Analysis in action. In Applied Linguistics methods: A reader (pp. 98-112). London: Routledge.

Firth, J. (1962). A synopsis of linguistic theory, 1930-1955. In J. Firth (Ed.), Studies in linguistic analysis (pp. 1-32). Oxford: Blackwell. 
Fowler, R. (1991). Language in the news: Discourse and ideology in the press. London: Routledge.

Gabrielatos, C., \& Baker, P. (2008). Fleeing, sneaking, flooding: A corpus analysis of discursive constructions of refugees and asylum seekers in the UK press 19962005. Journal of English Linguistics, 36(5), 5-38.

Galindo, S. (2012). Media representation of immigration in a migrant provider and migrant receptor country: A Critical Discourse Analysis (Doctoral thesis). University of Texas, San Antonio.

Gans, H. J. (1980). Deciding what's news: A study of CBS evening news, NBC nightly news, "Newsweek" and "Time” (Vol. 12). London: Constable.

Goatly, A. (2011). The language of metaphors. Abingdon: Routledge.

Habermas, J. (1989). The structural transformation of the public sphere: An inquiry into a category of bourgeois society. Cambridge: MIT Press.

Hall, S., Critcher, C., Jefferson, T., Clark, J., \& Roberts, B. (1978). Policing the crisis: Mugging, the state, and law and order. London: Macmillan Press.

Hanson-Easey, S., \& Augoustinos, M. (2010). Out of Africa: Accounting for refugee policy and the language of causal attribution. Discourse and Society, 21(3), 295323.

Hardt-Mautner, G. (1995). “Only connect”: Critical Discourse Analysis and Corpus Linguistics (Vol. 6). Lancaster University. Retrieved from http://ucrel.lancs.ac.uk/papers/techpaper/vol6.pdf

Hardt-Mautner, G. (2007). Mining large corpora for social information: The case of elderly. Language in Society, 36, 51-72. 
Hardt-Mautner, G. (2009). Corpora and Critical Discourse Analysis. In P. Baker (Ed.), Contemporary Corpus Linguistics (pp. 32-46). London, New York: Continuum International Publishing Group.

Hart, C. (2010). Critical Discourse Analysis and cognitive science. Basingstoke: Palgrave Macmillan.

Hayward, J. (Ed.). (2015). New Zealand government and politics. Melbourne: Oxford University Press.

Hier, S., \& Greenberg, J. (2002). Constructing a discursive crisis: Risk, problematization and illegal Chinese in Canada. Ethnic and Racial Studies, 25(3), 490-513.

Hoffman, A. (1974). Unwanted Mexican Americans in the Great Depression: Repatriation pressures. Tucson: University of Arizona Press.

Holmes, J. (1984). Modifying illocutionary force. Journal of Pragmatics, 8(3), 345.

House, H. (1956). Aristotle's Poetics: A course of eight lectures. London: Rupert HartDavis. Retrieved from https://archive.org/stream/aristotlespoetic032945mbp\#page/n125/mode/2up/searc $\mathrm{h} /$ intuitive+perception

Hunston, S. (2002). Corpora in Applied Linguistics. Cambridge: Cambridge University Press.

Hurst, J. (1997). News sources. In M. Oakham (Ed.), Don't bury the lead (pp. 15-27). Geelong: Deakin University Press.

Johnston, R., Trilin, A., Gendall, P., \& Spoonley, P. (2010). Immigration, multiculturalism and geography: Inter-group contact and attitudes to immigrant 
and cultural diversity in New Zealand. Asia Pacific Migration Journal, 19(3), $343-369$.

Kasper, W., \& Roundtable, N. Z. B. (1990). Populate or languish? Rethinking New Zealand's immigration policy. Wellington: New Zealand Business Roundtable. Retrieved from www.summon.com

Keeley, B. (2009). International migration: The human face of globalisation. Paris: OECD.

Kendall, G. (2007). What is Critical Discourse Analysis? Ruth Wodak in conversation with Gavin Kendall. Forum Qualitative Social Research, 8(2). Retrieved from file://C:/Users/Neda\%20Salahshour/Downloads/255-727-1-PB.pdf

Kennedy, G. (1998). An introduction to Corpus Linguistics. London, New York: Longman.

KhosraviNik, M. (2007). Positive Discourse Analysis? Retrieved from http://lancastermaze.blogspot.co.nz/2007/02/positive-discourse-analysis.html

KhosraviNik, M. (2008). British newspapers and the representation of refugees, asylum seekers and immigrants between 1996 and 2006. Centre for Language in Social Life, 1-40.

KhosraviNik, M. (2009). The representation of refugees, asylum seekers and immigrants in British newspapers during the Balkan conflict (1999) and the British general election (2005). Discourse and Society, 20, 477-498.

KhosraviNik, M. (2010a). Actor descriptions, action attributions, and argumentation: Towards a systematization of CDA analytical categories in the representation of social groups. Critical Discourse Studies, 7, 55-72. 
KhosraviNik, M. (2010b). The representation of refugees, asylum seekers and immigrants in British newspapers: A Critical Discourse Analysis. Journal of Language and Politics, 9(1), 1-28.

Kienpointner, M. (1992). Alltagslogik: Struktur und funktion von argumentationsmustern. Stuttgart-Bad Cannstatt: Frommann-Holzboog.

Kienpointner, M., \& Kindt, W. (1997). On the problem of bias in political argumentation: An investigation into discussions about political asylum in Germany and Austria. Journal of Pragmatics, 27(5), 555-585. https://doi.org/http://dx.doi.org/10.1016/S0378-2166(96)00035-5

Kress, G. (1990). Critical Discourse Analysis. Annual Review of Applied Linguistics, 11, 84-99.

Kress, G., \& Hodge, R. (1979). Language as ideology. London: Routledge.

Kress, G., \& Van Leeuwen, T. (1996). Reading images: The grammar of visual design. New York: Routledge.

Kress, G., \& Van Leeuwen, T. (2001). Multimodal discourse: The modes and media of contemporary communication. New York: Arnold.

Kumsa, M. K. (2006). “No! I'm not a refugee!” The poetics of be-longing among Yound Oromos in Toronto. Journal of Refugee Studies, 19(2), 230-255.

Lakoff, G., \& Johnson, M. (1980). Metaphors we live by. Chicago: University of Chicago.

Leech, G. (1974). Semantics: The study of meaning. Hamondsworth: Penguin. 
Linell, P. (1998). Discourse across boundaries: On recontextualizations and the blending of voices in professional discourse. Text-Interdisciplinary Journal for the Study of Discourse, 18(2), 143-158.

Lirola, M. (2014). Approaching the representation of sub-Saharan immigrants in the sample from Spanish press. Critical Discourse Studies, 11(4), 482-499.

Loto, R., Hodgetts, D., Chamberlain, K., Nikora, L., Karapu, R., \& Barnett, A. (2006). Pasifika in the news: The portrayal of Pacific people in the New Zealand press. Journal of Community and Applied Psychology, 16, 100-118.

Louw, B. (2000). Contextual prosodic theory: Bringing semantic prosodies to life. In C. Heffer \& H. Sauntson (Eds.), Words in context: A tribute to John Sinclair on his retirement. Birmingham: University of Birmingham.

Lynn, N., \& Lea, S. (2003). A phantom menace and the new apartheid: The social construction of asylum seekers in the United Kingdom. Discourse and Society, $14(4), 425-452$.

Machin, D., \& Mayr, A. (2012). How to do Critical Discourse Analysis: A multimodal introduction. London: SAGE.

Malmqvist, K. (2015). Satire, racist humour and the power of (un)laughter: On the restrained nature of Swedish online racist discourse targeting EU-migrants begging for money. Discourse and Society, 26(6), 733-753.

Martin, J. R. (2004). Positive Discourse Analysis: Solidarity and change. Revista Canaria de Estudios Ingleses, 49, 179-200. 
Mason, I. (2006). Ostension, inference and the visibility of translator moves. Presented at the 1st Athens International Conference on Translation and Interpretation. Retrieved from http://translation.hau.gr/ctran/content/Home.aspx

Mason, I. (2007). Critical Linguistics, language and ideology. The Translator, 13(2), 341-346. https://doi.org/10.1080/13556509.2007.10799244

Mastro, D. (2015). Why the media's role in issues of race and ethnicity should be in the spotlight. Journal of Social Issues, 71(1), 1-16.

Maydell, E. (2010). The making of cosmopolitan selves: The construction of identity of Russian-speaking immigrants in New Zealand (Doctoral Thesis). Victoria University of Wellington, Wellington.

McChesney, R. (2001). Global media, neoliberalism, and imperialism. Monthly Review, 52(10), 1-19.

McConnell, E. (2011). An “incredible number of Latinos and Asians": Media representations of racial and ethnic population change in Atlanta, Georgia. Latino Studies, 9(2), 177-197.

McGregor, J. (1992). Who owns the press in New Zealand? In M. Comrie \& J. McGregor (Eds.), Whose news? Palmerston North: Dunmore Press.

Mckinnon, M. (1996). Immigrants and citizens: New Zealanders and Asian immigration in historical context. Wellington: Institute of Policy Studies, Victoria University of Wellington.

McMillan, K. (2008). Irregular migration: New Zealand's experience and response. New Zealand International Review, 33(4), 2-6. 
Mehan, H. (1997). The discourse of the illegal immigration debate: A case study in politics of representation. Discourse and Society, 8(2), 249-270.

Miller, D. (2002). Promotion and power. In A. Briggs \& P. Cobley (Eds.), Introduction to media. London: Longman.

Miller, T. (2014). Modernism and the Frankfurt School. Edinburgh: Edinburgh University Press.

Moon, P. (2013). Thomas Shepherd and the first New Zealand Company. New Zealand Journal of History, 47(1), 22-38.

Mulgan, R. (2004). Politics in New Zealand. Auckland: Auckland University Press.

Myllylahti, M., \& Hope, W. (2011). Global capital and media communication ownership in New Zealand. Pacific Journalism Review, 17(2), 188-209.

Nagel, J. (2012). Evaluating democracy in New Zealand under Mixed Member Proportional. Policy Quarterly, 8(2), 3-11.

Noaman, A. (2015). Reading Gramsci through Fanon: Hegemony before dominance in revolutionary theory. Journal of Economics, Culture and Society, 27(2), 241-257.

Norris, P. (2002). News media ownership in New Zealand. In J. McGregor \& M. Comrie (Eds.), What's news? Reclaiming journalism in New Zealand (pp. 33-55).

Palmerston North: Dunmore Press.

Oakes, M. (1998). Statistics for Corpus Linguistics. Edinburgh: Edinburgh University Press.

O’Halloran, K. (2009). Inferencing and cultural reproduction: A corpus-based Critical Discourse Analysis. Text and Talk, 29(1), 21-51. 
Olsen, W. (2004). Triangulation in social research: Qualitative and quantitative methods can really be mixed. In M. Haralambos \& M. Holborn (Eds.), Developments in sociology. Causeway Press.

O’Sullivan, D. (2008). The Treaty of Waitangi in contemporary New Zealand politics. Australian Journal of Political Science, 43(2), 317-331.

Palmer, J., Turney, C., Hogg, A., Hilliam, N., Watson, M., van Sebille, E., ... Petchey, F. (2014). The discovery of New Zealand's oldest shipwreck - possible evidence of further Dutch exploration of the South Pacific. Journal of Archaeological Science, $42,435-441$.

Partington, A. (1998). Patterns and meanings: Using corpora for English language research and teaching. Amsterdam: John Benjamins.

Partington, A. (2010). Modern Diachronic Corpus-Assisted Discourse Studies (MDCADS) on UK newspapers: An overview of the project. Corpora, 5(2), 83-108.

Peart, J. D., \& Macnamara, J. (1987). The New Zealand handbook of public relations. Lower Hutt: Mills Publications.

Pennycook, A. (2001). Critical Applied Linguistics: A critical introduction. Mahwah: Lawrence Erlbaum Associates.

Petley, J. (2012). Jurgen Habermas: The modern media on the public sphere. In D. Berry (Ed.), Revisiting the Frankfurt school: Essays on culture, media and theory (pp. 139-160). Farnham: Ashgate.

Phillips, J. (2013a). British immigration and the New Zealand Company - History of immigration - Te Ara Encyclopedia of New Zealand. Retrieved April 9, 2015, from http://www.teara.govt.nz/en/history-of-immigration/page-3 
Phillips, J. (2013b). Early years - History of immigration - Te Ara Encyclopedia of New Zealand. Retrieved April 9, 2015, from http://www.teara.govt.nz/en/history-ofimmigration/page-1

Phillips, M. (2011). Convenient labels, inaccurate representations: Turning Southern Sudanese Refugees into “African-Australians.” Australian Review of African Studies, 32(2), 57-79.

Quinkert, A., \& Jagar, A. (1991). Die rassistische Hetze von Bild gegen Fluchtlinge im Herbst 1991. Duisburg: DISS-Papers Nr.4.

Rainer, W. (2000). Immigration policies and their impact: The case of New Zealand and Australia. IDEAS Working Paper Series from RePEc, 169.

Rasinger, S. (2010). Lithuanian migrants send crime rocketing: Representation of "new" migrants in regional print media. Media, Culture and Society, 32(6), 1021-1030.

Reisigl, M., \& Wodak, R. (2001). Discourse and Discrimination: Rhetorics of racism and antisemitism. London: Routledge.

Reisigl, M., \& Wodak, R. (2009). The Discourse-Historical Approach (DHA). In Ruth Wodak \& M. Meyer (Eds.), Methods of Critical Discourse Analysis (pp. 87-121). London: SAGE.

Reitmanova, S., Gustafson, D., \& Ahmed, R. (2015). "Immigrants can be deadly": Critical Discourse Analysis of racialization of immigrant health in the Canadian press and public health policies. Canadian Journal of Communication, 40, 471487.

Richardson, J. (2001). "Now is the time to put an end to all this": Argumentative discourse theory and letters to the editor". Discourse and Society, 12(2), 143-68. 
Richardson, J. E., \& Wodak, R. (2009). The impact of visual racism: Visual arguments in political leaflets of Austrian and British far right parties. Controversia, 6(2), 4584.

Rojo, L. M., \& Van Dijk, T. (1997). “There was a problem, and it was solved!”: Legitimating the expulsion of "illegal" migrants in Spanish parliamentary discourse. Discourse and Society, 8(4), 523-566.

Rosenberg, B. (2008). News media ownership in New Zealand. Cyberspace Canterbury. Retrieved from http://canterbury.cyberplace.org.nz/community/CAFCA/publications/Miscellaneo us/mediaown.pdf

Ross, T. B. (1994). New Zealand's “overstaying islander”: A construct of the ideology of "race" and immigration (Master's thesis). Victoria University of Wellington, Wellington.

Roy, W. (1970). Immigration policy and legislation. In A. Trlin \& K. Thomson (Eds.), Immigrants in New Zealand (pp. 15-24). Palmerston North: Massey University.

Saeed, A. (2007). Media, racism and Islamaphobia: The representation of Islam and Muslims. Sociology Compass, 1(2), 443-462.

Said, E. (1978). Orientalism. New York: Pantheon.

Said, E. (1997). Covering Islam: How the media and the experts determine how we see the rest of the world. New York: Vintage.

Samers, M. (2010). Migration. London: Routledge.

Santa Ana, O. (1999). "Like an animal I was treated": Anti-immigrant metaphor in United States public discourse. Discourse and Society, 10(2), 191-224. 
Scannell, P. (1989). Public service broadcasting and modern life. In P. Scannell, P. Schlesinger, \& C. Sparks (Eds.), Culture and power. London: SAGE.

Semino, E., Deignan, A., \& Littlemore, J. (2013). Metaphor, genre, and recontextualization. Metaphor and Symbol, 28(1), 41-59.

Simon-Kumar, R. (2015). Neoliberalism and the new race politics of migration: Changing profiles of the desirable migrant in New Zealand. Journal of Ethnic and Migration Studies, 41(7), 1172-1191.

Sinclair, J. (1991). Corpus, concordance, collocation. Oxford: Oxford University Press.

Singham, M. (2006). Multiculturalism in New Zealand: The need for a new paradigm. Aotearoa Ethnic Network Journal, 1, 33-37.

Skilling, P. (2011). "We must agree on our vision": New Zealand Labour's discourse of globalisation and the nation from 1999-2008. Journal of Language and Politics, $10(1), 68-87$.

Skilling, P. (2012). Immigration policy in New Zealand: Divergent narratives, shared assumptions and national identity. Critical Policy Studies, 6(4), 363-378.

Spoonley, P. (1988). Racism and ethnicity. Auckland: Oxford University Press. Spoonley, P. (2006). A contemporary political economy of labour migration in New Zealand. Tijdschrift Voor Economische En Sociale Geografie, 97(1), 17-25.

Spoonley, P., \& Butcher, A. (2009). Reporting superdiversity. The mass media and immigration in New Zealand. Journal of Intercultural Studies, 30, 355-372.

Statistics New Zealand. (2014). Alternative methods for measuring permanent and longterm migration. Retrieved March 13, 2017, from 
http://www.stats.govt.nz/browse_for_stats/population/Migration/internationaltravel-and-migration-articles/alternative-methods-plt-migration.aspx Statistics New Zealand. (2015). Population Clock. Retrieved from http://www.stats.govt.nz/tools_and_services/population_clock.aspx

Statistics New Zealand. (2016). QuickStats about a place. Retrieved from http://www.stats.govt.nz/Census/2013-census/profile-and-summaryreports/quickstats-about-a-place.aspx?request_value $=13170 \&$ tabname $=$

Stewart, C., Pitts, M., \& Osborne, H. (2011). Mediated intergroup conflict: The discursive construction of illegal immigrants in a regional United States newspaper. Journal of Language and Social Psychology, 30(1), 8-27.

Stoppard, T. (1982). The real thing: A play. London: Faber and Faber.

Stubbs, M. (1996). Texts and corpus analysis: Computer assisted studies of language and culture. Oxford: Blackwell.

Stubbs, M. (2001). Words and phrases: Corpus studies of lexical semantics. Oxford: Blackwell.

Taher, M. (1970). The Asians. In K. W. Thomson \& A. Trilin (Eds.), Immigration in New Zealand (pp. 38-64). Palmerston North: Massey University.

Talbot, M. (2007). Media discourse: representation and interaction. Edinburgh: Edinburgh University Press.

Talcott, G. (2000). The context and risk of organised illegal immigration to New Zealand. Wellington: Centre for strategic studies, Victoria University of Wellington.

Teo, P. (2000). Racism in the news: A Critical Discourse Analysis of news reporting in two Australian newspapers. Discourse and Society, 11(1), 7-49. 
The Treasury. (2010). New Zealand Economic and Financial Overview (pp. 1-10).

Retrieved from http://www.treasury.govt.nz/economy/overview/2010/nzefo-101.pdf

Thompson, J. (1984). Studies in the theory of ideology. Cambridge: Polity Press.

Thompson, J. (1986). Language, ideology and the media: A response to Martin Montgomery. Media, Culture and Society, 8, 65-79.

Thompson, J. (1995). The media and modernity: A social theory of the media. Cambridge: Polity Press.

Tidey, J. (2002). Well-informed sources. In What's news?: Reclaiming journalism in New Zealand (pp. 72-80). Palmerston North: Dunmore Press.

Trlin, A. (1997). For the promotion of economic growth and prosperity: New Zealand's immigration policy. In New Zealand and international migration: A digest and bibliography (pp. 1-27). Palmerston North: Massey University.

Tucker, J. (1992). Kiwi journalist: A practical guide to news journalism. Auckland: Longman Paul.

Tully, J. (1992). Media ethics....Holding on to the high ground. In M. Comrie \& J. McGregor (Eds.), Whose news? (pp. 143-153). Palmerston North: Dunmore Press.

United Nations Educational, Scientific and Cultural Organization. (n.d.). Migrant. Retrieved March 13, 2017, from http://www.unesco.org/new/en/social-andhuman-sciences/themes/international-migration/glossary/migrant/

Van der Valk, I. (2000). Parliamentary discourse on immigration and nationality in France. In Ruth Wodak \& T. Van Dijk (Eds.), Racism at the top: Parliamentary 
discourse on ethnic issues in six European states (pp. 221-260). Klagenfurt: DRAVA-Verlag.

Van der Valk, I. (2003). Right-wing parliamentary discourse on immigration in France. Discourse and Society, 14(3), 309-348.

Van Dijk, T. (1988). News analysis: A case study of international and national news in the press. Hillsdale: Lawrence Erlbaum Associates.

Van Dijk, T. (1993). Principles of Critical Discourse Analysis. Discourse and Society, 4(2), 249-283.

Van Dijk, T. (1995). Power and the news media. In D. Paletz (Ed.), Political communication and action (pp. 9-36). Cresskill: Hampton Press.

Van Dijk, T. (1996). Discourse, power and access. In C. R. Caldas-Coulthard \& M. Coulthard (Eds.), Texts and practices: readings in Critical Discourse Analysis (pp. 84-104). London: Routledge.

Van Dijk, T. (2000). The reality of racism: On analyzing parliamentary debates on immigration. In G. Zurstiege (Ed.), Festschrift für die Wirklichkeit (pp. 211-225). Bonn: Westdeutscher Verlag.

Van Dijk, T. (2006). Ideology and discourse analysis. Journal of Political Ideologies, 11, $115-140$.

Van Dijk, T. (2008). Critical Discourse Analysis and nominalization: Problem or pseudoproblem. Discourse and Society, 19(6), 821-828.

Van Dijk, T. (2009). Critical Discourse Studies: A socio-cognitive approach. In Ruth Wodak \& M. Meyer (Eds.), Methods of Critical Discourse Analysis (pp. 62-85). London: SAGE. 
Van Dijk, T. (2011). Discourse and ideology. In T. Van Dijk (Ed.), Discourse studies: A multidisciplinary introduction (2nd ed., pp. 379-407). Los Angeles: SAGE.

Van Leeuwen, T. (1996). The representation of social actors. In C. R. Caldas-Coulthard \& M. Coulthard (Eds.), Texts and practice: Readings in Critical Discourse Analysis (pp. 32-70). London: Routledge.

Van Leeuwen, T. (2006). Critical Discourse Analysis. In K. Brown (Ed.), Encyclopedia of language and linguistics (pp. 290-294). Oxford: Elsevier. Retrieved from http://www.sciencedirect.com/science/article/pii/B0080448542005010

Van Leeuwen, Theo, \& Jaworski, A. (2002). The discourses of war photography: Photojournalistic representations of the Palestinian-Israeli war. Journal of Language and Politics, 1(2), 255-275.

Van Leeuwen, Theo, \& Wodak, R. (1999). Legitimizing immigration control: A Discourse-Historical Analysis. Discourse Studies, 1(1), 83-118.

Walton, D. (2004). Argumentation schemes and historical origins of the circumstantial ad hominem argument. Argumentation, 18, 359-368.

Ward, C., \& Masgoret, A. M. (2008). Attitudes toward immigrants, immigration, and multiculturalism in New Zealand: A social psychological analysis. The International Migration Review, 42(1), 227-248.

Weiss, G., \& Wodak, R. (2003). Theory, interdisciplinary and critical discourse analysis. In G. Weiss \& R. Wodak (Eds.), Critical Discourse Analysis: Theory and interdisciplinarity (pp. 1-34). New York: Palgrave Macmillan.

Widdowson, H. (1998). The theory and practice of Critical Discourse Analysis. Applied Linguistics, 19(1), 136-151. 
Widdowson, H. (2002). Corpora and language teaching tomorrow. Presented at the Fifth Teaching and Language Corpora Conference, Bertinoro, Italy.

Widdowson, H. (2004). Text, context, pretext: Critical issues in discourse analysis. Malden: Blackwell.

Wilson, J. (2015, January). History-European to 1840. Retrieved from http://www.teara.govt.nz/en/history/page-2

Wodak, R. (2001). The discourse historical approach. In R Wodak \& M. Meyer (Eds.), Methods of critical discourse analysis. London: Sage.

Wodak, Ruth. (2001). The Discourse-Historical Approach. In Ruth Wodak \& M. Meyer (Eds.), Methods of Critical Discourse Analysis (pp. 65-94). London: SAGE.

Wodak, Ruth. (2006). Critical Linguistics and Critical Discourse Analysis. In J.-O. Östman \& J. Verschueren (Eds.), Handbook of Pragmatics (pp. 1-24). Amsterdam: John Benjamins.

Wodak, Ruth. (2007). Language and ideology — language in ideology. Journal of Language and Politics, 6(1), 1-5.

Wodak, Ruth. (2015). The politics of fear: What right-wing populist discourses mean. London: SAGE.

Wodak, Ruth, \& Boukala, S. (2015). (Supra)national identity and language: Rethinking national and European migration policies and the linguistic integration of migrants. Annual Review of Applied Linguistics, 35, 253-273.

Wodak, Ruth, \& Iedema, R. (2004). Constructing boundaries without being seen: The case of Jörg Haider, Politician. Revista Canaria Estudios Ingleses, 49, 157-178. 
Wodak, Ruth, \& Matouschek, B. (1993). "We are dealing with people whose origins one can clearly tell just by looking": Critical Discourse Analysis and the study of neoracism in contemporary Austria. Discourse and Society, 4(2), 225-248.

Wodak, Ruth, \& Meyer, M. (2009a). Critical Discourse Analysis: History, agenda, theory and methodology. In Ruth Wodak \& M. Meyer (Eds.), Methods of Critical Discourse Analysis (pp. 1-33). London: SAGE.

Wodak, Ruth, \& Meyer, M. (Eds.). (2009b). Methods of Critical Discourse Analysis. London: SAGE.

Žagar, I. (2010). Topoi in Critical Discourse Analysis. Lodz Papers in Pragmatics, 6(1), $3-27$. 


\section{Appendix A: List of topics and subtopics}

\begin{tabular}{|c|c|c|c|c|c|}
\hline \multicolumn{6}{|c|}{2007 TOPIC ANALYSIS } \\
\hline 1 & 2 & 3 & 4 & 5 & 6 \\
\hline $\begin{array}{l}\text { Loss of } \\
\text { Population }\end{array}$ & $\begin{array}{l}\text { Victimiz } \\
\text { ation }\end{array}$ & $\begin{array}{l}\text { Immigrant } \\
\text { Statistics }\end{array}$ & $\begin{array}{l}\text { Racism and } \\
\text { Discrimination }\end{array}$ & Crime & $\begin{array}{l}\text { Immigration/Citize } \\
\text { nship Policies }\end{array}$ \\
\hline $\begin{array}{l}\text { a. NZ needs } \\
\text { strategic planning } \\
\text { to bring back } \\
\text { those who have } \\
\text { emigrated } \\
\text { b. Comparison of } \\
\text { living in AU versus } \\
\text { NZ } \\
\text { c. Sydney and } \\
\text { Melbourne versus } \\
\text { NZ } \\
\text { d. NZ's attrition of } \\
\text { British police } \\
\text { e. NZ's ranking in } \\
\text { the heritage Index } \\
\text { drops due to Kiwi } \\
\text { leaving NZ }\end{array}$ & - & $\begin{array}{l}\text { a. Asians } \\
\text { Fastest } \\
\text { growing } \\
\text { minority } \\
\text { group in NZ } \\
\text { b. Growth of } \\
\text { Muslim and } \\
\text { Hindus in NZ } \\
\text { c. Ethnic } \\
\text { minority } \\
\text { numbers in } \\
\text { NZ }\end{array}$ & $\begin{array}{l}\text { a. Manukau } \\
\text { police's } \\
\text { derogatory } \\
\text { remarks against } \\
\text { Asians } \\
\text { b. Story of } \\
\text { Chinese } \\
\text { immigrants who } \\
\text { faced racism and } \\
\text { paid poll tax } \\
\text { c. Asians struggle } \\
\text { to "feel at home" } \\
\text { d. Kiwis } \\
\text { uncomfortable } \\
\text { with immigrant or } \\
\text { homosexual } \\
\text { neighbors } \\
\text { e. Le Pen's } \\
\text { xenophobic } \\
\text { speech in France } \\
\text { f. Citadella, the } \\
\text { first city to outline } \\
\text { who can and } \\
\text { cannot live in it }\end{array}$ & $\begin{array}{l}\text { a. Philip Field case: } \\
\text { Corruption among } \\
\text { NZ's MP and } \\
\text { immigrants } \\
\text { b. Illegal immigrants } \\
\text { enter NZ } \\
\text { c. Passport fraudster } \\
\text { allowed to stay in NZ } \\
\text { d. Deborah } \\
\text { Coddington article: } \\
\text { Asians in NZ } \\
\text { responsible for crime } \\
\text { e. Ethnic minority } \\
\text { extremism in NZ } \\
\text { f. Samoan criminal } \\
\text { allowed to stay in NZ } \\
\text { g. Lebanese } \\
\text { immigrants pose a } \\
\text { threat to Australian } \\
\text { PM } \\
\text { h. Violence among } \\
\text { Croats and Serbs in } \\
\text { Australia } \\
\text { i. Jamaican } \\
\text { immigrant who killed } \\
\text { 19 people convicted } \\
\text { j. Britain out of } \\
\text { prisons }\end{array}$ & $\begin{array}{l}\text { a. Inefficiency of } 6 \\
\text { month work to } \\
\text { residency visa } \\
\text { b. Changes to } \\
\text { investor migrant } \\
\text { policy aims to draw } \\
\text { in more wealthy } \\
\text { immigrants in NZ } \\
\text { c. Changes to } \\
\text { skilled migrant } \\
\text { policy aims to draw } \\
\text { in more skilled } \\
\text { immigrants } \\
\text { d. International } \\
\text { competition for } \\
\text { skilled immigrants }\end{array}$ \\
\hline
\end{tabular}




\begin{tabular}{|c|c|c|c|c|c|}
\hline 7 & 8 & 9 & 10 & 11 & 12 \\
\hline Housing in NZ & Election & $\begin{array}{l}\text { Health/Healt } \\
\text { h Funding }\end{array}$ & Banking & Recruitment & $\begin{array}{l}\text { Culture } \\
\text { / Diversity / } \\
\text { Integration }\end{array}$ \\
\hline $\begin{array}{l}\text { a. Migration } \\
\text { acts as a } \\
\text { double edged } \\
\text { sword } \\
\text { b. Immigrants } \\
\text { provide } \\
\text { buoyancy } \\
\text { to/underpin } \\
\text { the NZ } \\
\text { housing } \\
\text { market } \\
\text { c. Lack of land } \\
\text { and high } \\
\text { immigrant } \\
\text { numbers, } \\
\text { reason for } \\
\text { inflation house } \\
\text { prices } \\
\text { d. High } \\
\text { immigrant } \\
\text { numbers in } \\
\text { Auckland } \\
\text { brings benefits } \\
\text { to landlords }\end{array}$ & $\begin{array}{l}\text { a. Peters' } \\
\text { Anti- } \\
\text { Immigration } \\
\text { speeches } \\
\text { during } \\
\text { campaign } \\
\text { b. Shift in } \\
\text { electorate } \\
\text { seat in } \\
\text { Australia } \\
\text { due high } \\
\text { Asian } \\
\text { population }\end{array}$ & $\begin{array}{l}\text { a. } \\
\text { Compulsory } \\
\text { HIV testing } \\
\text { of } \\
\text { Zimbabwean } \\
\text { immigrants }\end{array}$ & $\begin{array}{l}\text { a. Unique } \\
\text { banking services } \\
\text { for wealthy } \\
\text { Asians }\end{array}$ & $\begin{array}{l}\text { a. Skilled immigrants } \\
\text { essential for skills } \\
\text { shortage } \\
\text { b. NZ needs better } \\
\text { recruitment strategies } \\
\text { c. Underemployment } \\
\text { of skilled immigrants } \\
\text { d. Seasonal Employer } \\
\text { Scheme to bring in } \\
\text { Pacific Islanders not } \\
\text { well planned } \\
\text { d. Urban recruitment } \\
\text { versus rural } \\
\text { recruitment } \\
\text { e. Policy required to } \\
\text { provide free English } \\
\text { classes for immigrants }\end{array}$ & $\begin{array}{l}\text { a. Cultural } \\
\text { diversity in the } \\
\text { workplace key to } \\
\text { success } \\
\text { b. Problems } \\
\text { integrating } \\
\text { Samoans in NZ } \\
\text { c. Immigrant } \\
\text { perspective on NZ } \\
\text { culture }\end{array}$ \\
\hline
\end{tabular}


2008 TOPIC ANALYSIS

\begin{tabular}{|c|c|c|c|c|c|}
\hline 1 & 2 & 3 & 4 & 5 & 6 \\
\hline $\begin{array}{l}\text { Loss of } \\
\text { Population }\end{array}$ & $\begin{array}{l}\text { Victimizat } \\
\text { ion }\end{array}$ & $\begin{array}{l}\text { Immigrant } \\
\text { Statistics }\end{array}$ & $\begin{array}{l}\text { Racism and } \\
\text { Discrimination }\end{array}$ & Crime & $\begin{array}{l}\text { Immigration/Cit } \\
\text { izenship Policies }\end{array}$ \\
\hline $\begin{array}{l}\text { a. Concerns } \\
\text { over } \\
\text { emigration to } \\
\text { Australia } \\
\text { b. strategies } \\
\text { for retaining } \\
\text { immigrants }\end{array}$ & $\begin{array}{l}\text { a. Asian } \\
\text { dairy } \\
\text { owners } \\
\text { subject to } \\
\text { attacks } \\
\text { b. Asians } \\
\text { who have } \\
\text { become } \\
\text { victims of } \\
\text { attacks } \\
\text { take } \\
\text { matters } \\
\text { into their } \\
\text { own } \\
\text { hands } \\
\text { c. Korean } \\
\text { investors } \\
\text { lose } \\
\text { millions of } \\
\text { dollars in } \\
\text { investmen } \\
t\end{array}$ & $\begin{array}{l}\text { a. Number } \\
\text { of Asians in } \\
\text { NZ } \\
\text { b. concerns } \\
\text { over low } \\
\text { immigrant } \\
\text { numbers }\end{array}$ & $\begin{array}{l}\text { a. Lockwood Smith's } \\
\text { racist speech } \\
\text { regarding Asian hands } \\
\text { and pacific islanders } \\
\text { personal hygiene } \\
\text { b. Peters' anti- } \\
\text { immigrant campaign } \\
\text { speech } \\
\text { c. Mr.Brown speech } \\
\text { with regards to Asian } \\
\text { forming mini-societies } \\
\text { d. Racism directed at } \\
\text { Asian living in NZ } \\
\text { e. Racism directed at } \\
\text { taxi drivers in NZ } \\
\text { f. Peters' speech } \\
\text { reaches Chinese } \\
\text { newspapers } \\
\text { g. Racism directed at } \\
\text { gypsies in Italy }\end{array}$ & $\begin{array}{l}\text { a. Anti- } \\
\text { crime } \\
\text { groups } \\
\text { formed by } \\
\text { Asians/triad } \\
\text { gangs } \\
\text { b. Anti- } \\
\text { violence } \\
\text { Asian } \\
\text { protests } \\
\text { c. Taito } \\
\text { Philip Field } \\
\text { Case }\end{array}$ & $\begin{array}{l}\text { a. NZ } \\
\text { immigration } \\
\text { policies in need } \\
\text { of a change to } \\
\text { prevent exodus } \\
\text { b. Family } \\
\text { sponsored } \\
\text { immigration } \\
\text { policies } \\
\text { c. Education } \\
\text { regarding the } \\
\text { treaty of } \\
\text { Waitangi for } \\
\text { new citizens } \\
\text { d. Australia bans } \\
\text { the use of razor } \\
\text { wires to sustain } \\
\text { refugees }\end{array}$ \\
\hline
\end{tabular}




\begin{tabular}{|c|c|c|c|c|c|}
\hline 7 & 8 & 9 & 10 & 11 & 12 \\
\hline $\begin{array}{l}\text { Housing } \\
\text { in NZ }\end{array}$ & Election & $\begin{array}{l}\text { Health/Healt } \\
\text { h Funding }\end{array}$ & $\begin{array}{l}\text { Bankin } \\
\text { g }\end{array}$ & Recruitment & $\begin{array}{l}\text { Culture } \\
\text { / Diversity / } \\
\text { Integration }\end{array}$ \\
\hline $\begin{array}{l}\text { a. } \\
\text { Immigran } \\
\text { ts } \\
\text { beneficial } \\
\text { to } \\
\text { housing } \\
\text { market }\end{array}$ & $\begin{array}{l}\text { a. NZ First's } \\
\text { stance on } \\
\text { immigration } \\
\text { b. Asian votes } \\
\text { during } 2008 \\
\text { election } \\
\text { c. Asian MP } \\
\text { candidates in } \\
\text { electorates } \\
\text { d. Party views on } \\
\text { immigrant } \\
\text { numbers } \\
\text { e. The effect of } \\
2008 \text { election } \\
\text { results on } \\
\text { immigration } \\
\text { numbers } \\
\text { f. Rise of Peters' } \\
\text { popularity }\end{array}$ & $\begin{array}{l}\text { a. Public } \\
\text { funded } \\
\text { health care } \\
\text { for } \\
\text { immigrants }\end{array}$ & - & $\begin{array}{l}\text { a. Difficulties faced by } \\
\text { immigrants during } \\
\text { recruitment in NZ } \\
\text { b. Government plans to } \\
\text { recruit police officers from } \\
\text { Malaysia and Hong Kong } \\
\text { c. Government plans to } \\
\text { recruit nurses from China } \\
\text { to fill skills shortages } \\
\text { d. NZ employers expected } \\
\text { to check for valid work visa } \\
\text { e. Job opportunities for } \\
\text { Koreans in NZ } \\
\text { f. Peters: Need for } \\
\text { Singaporean jockey's in NZ }\end{array}$ & $\begin{array}{l}\text { a. Asian as a } \\
\text { vague term } \\
\text { for } \\
\text { referring to } \\
\text { minority } \\
\text { groups in } \\
\text { NZ }\end{array}$ \\
\hline
\end{tabular}




\section{Appendix B: List of significant collocations, MI, and LL scores}

\begin{tabular}{|l|l|l|l|l|}
\hline \multicolumn{5}{|l}{ 2007 (migrant) } \\
\hline Collocate & Node & LL & MI & Freq \\
\hline TRUST'S & (migrant) & 32.13651 & 11.57771 & 2 \\
\hline INDO & (migrant) & 32.13651 & 11.57771 & 2 \\
\hline UNMARRIED & (migrant) & 28.31806 & 10.99275 & 2 \\
\hline INFLOWS & (migrant) & 26.59261 & 10.57771 & 2 \\
\hline CATEGORY & (migrant) & 154.6224 & 10.3047 & 12 \\
\hline REMITTANCES & (migrant) & 22.1336 & 9.255786 & 2 \\
\hline WORKER & (migrant) & 31.01878 & 8.770359 & 3 \\
\hline SKILLED & (migrant) & 150.7026 & 8.495919 & 15 \\
\hline WORKERS & (migrant) & 147.6083 & 8.355321 & 15 \\
\hline PROFESSIONALS & (migrant) & 19.36059 & 8.329786 & 2 \\
\hline FIJIAN & (migrant) & 18.5598 & 8.054152 & 2 \\
\hline COMMUNITIES & (migrant) & 64.83528 & 8.010029 & 7 \\
\hline TRUST & (migrant) & 24.65416 & 7.304695 & 3 \\
\hline POOR & (migrant) & 23.95768 & 7.140308 & 3 \\
\hline GROUPS & (migrant) & 39.68224 & 7.092287 & 5 \\
\hline WHOLE & (migrant) & 15.62376 & 7.023125 & 2 \\
\hline SERVICES & (migrant) & 23.00598 & 6.914749 & 3 \\
\hline REGIONAL & (migrant) & 15.21418 & 6.877274 & 2 \\
\hline GENERATION & 22.32734 & 6.753285 & 3 \\
\hline NUMBERS & (migrant) & 6.849793 & 2 \\
\hline
\end{tabular}




\begin{tabular}{|l|l|l|l|l|}
\hline \multicolumn{5}{|l}{ 2007 (migrants) } \\
\hline Collocate & Node & LL & MI & Freq \\
\hline DWINDLED & (migrants) & 29.23858 & 10.53924 & 2 \\
\hline INCOMING & (migrants) & 23.69607 & 9.53924 & 2 \\
\hline CUBAN & (migrants) & 22.51246 & 9.217312 & 2 \\
\hline INFLUX & (migrants) & 32.42184 & 8.954277 & 3 \\
\hline INVESTOR & (migrants) & 85.84672 & 8.895384 & 8 \\
\hline TARGETING & (migrants) & 20.86947 & 8.731885 & 2 \\
\hline INFLOW & (migrants) & 83.03323 & 8.681258 & 8 \\
\hline MILLIONAIRE & (migrants) & 20.24922 & 8.53924 & 2 \\
\hline EXPATS & (migrants) & 20.24922 & 8.53924 & 2 \\
\hline ATTRACT & (migrants) & 80.64593 & 8.494845 & 8 \\
\hline PROSPECTIVE & (migrants) & 29.8391 & 8.423762 & 3 \\
\hline TARGETS & (migrants) & 19.7132 & 8.369314 & 2 \\
\hline SKILLED & (migrants) & 266.5212 & 8.305443 & 27 \\
\hline ENTERING & (migrants) & 18.43844 & 7.954277 & 2 \\
\hline WEALTHY & (migrants) & 45.80536 & 7.906971 & 5 \\
\hline ENTER & (migrants) & 17.77132 & 7.731884 & 2 \\
\hline 47 & (migrants) & 17.47568 & 7.632349 & 2 \\
\hline REFUGEES & (migrants) & 69.28223 & 7.56196 & 8 \\
\hline QUALIFIED & (migrants) & 25.81404 & 7.539239 & 3 \\
\hline TONGAN & 16.94341 & 7.451777 & 2 \\
\hline
\end{tabular}




\begin{tabular}{|l|l|l|l|l|}
\hline \multicolumn{5}{|c}{ 2007 (immigrant) } \\
\hline Collocate & Node & LL & MI & Freq \\
\hline COMMUTER & (immigrant) & 32.17303 & 11.59077 & 2 \\
\hline HUNGARIAN & (immigrant) & 26.62913 & 10.59077 & 2 \\
\hline POLISH & (immigrant) & 24.53741 & 10.00581 & 2 \\
\hline SCOTTISH & (immigrant) & 23.80045 & 9.783415 & 2 \\
\hline ZIMBABWEAN & (immigrant) & 23.17949 & 9.59077 & 2 \\
\hline DUTCH & (immigrant) & 23.17949 & 9.59077 & 2 \\
\hline SENTIMENT & (immigrant) & 22.64278 & 9.420845 & 2 \\
\hline DOCTORS & (immigrant) & 31.38962 & 8.853805 & 3 \\
\hline SAMOAN & (immigrant) & 30.4881 & 8.65217 & 3 \\
\hline APPROACHED & (immigrant) & 19.18118 & 8.268842 & 2 \\
\hline GENERATION & (immigrant) & 47.48042 & 8.184777 & 5 \\
\hline ITALIAN & (immigrant) & 17.63485 & 7.732789 & 2 \\
\hline ANTI & (immigrant) & 26.27005 & 7.683879 & 3 \\
\hline FARMERS & (immigrant) & 17.22947 & 7.59077 & 2 \\
\hline ILLEGAL & (immigrant) & 25.62016 & 7.531876 & 3 \\
\hline COMMUNITIES & (immigrant) & 32.40512 & 7.215731 & 4 \\
\hline SINGLE & (immigrant) & 16.02143 & 7.164505 & 2 \\
\hline GERMAN & (immigrant) & 15.17337 & 6.862849 & 2 \\
\hline RECENT & (immigrant) & 21.9693 & 6.667938 & 3 \\
\hline PARENTS & 28.77337 & 6.568402 & 4 \\
\hline
\end{tabular}




\begin{tabular}{|l|l|l|l|l|}
\hline \multicolumn{5}{|c}{ 2007 (immigrants) } \\
\hline Collocate & Node & LL & MI & Freq \\
\hline CANVASS & (immigrants) & 29.08306 & 10.48339 & 2 \\
\hline ILLEGAL & (immigrants) & 239.1216 & 9.231848 & 21 \\
\hline WAVES & (immigrants) & 32.18837 & 8.898424 & 3 \\
\hline POURED & (immigrants) & 21.45043 & 8.898424 & 2 \\
\hline SUSPECTED & (immigrants) & 20.71421 & 8.676031 & 2 \\
\hline LEBANESE & (immigrants) & 20.71421 & 8.676031 & 2 \\
\hline SLIPPED & (immigrants) & 20.71421 & 8.676031 & 2 \\
\hline DEALINGS & (immigrants) & 30.15372 & 8.483386 & 3 \\
\hline WAVE & (immigrants) & 17.9359 & 7.782947 & 2 \\
\hline FLEEING & (immigrants) & 17.9359 & 7.782947 & 2 \\
\hline PROSPECTIVE & (immigrants) & 17.9359 & 7.782947 & 2 \\
\hline THAI & (immigrants) & 17.61643 & 7.676032 & 2 \\
\hline ADVISED & (immigrants) & 17.61643 & 7.676032 & 2 \\
\hline REGARD & (immigrants) & 16.78868 & 7.395924 & 2 \\
\hline SKILLED & (immigrants) & 116.3155 & 7.302057 & 14 \\
\hline INFLOW & (immigrants) & 24.38275 & 7.210368 & 3 \\
\hline ARRIVED & (immigrants) & 48.6265 & 7.185706 & 6 \\
\hline ARRIVING & (immigrants) & 16.10468 & 7.161458 & 2 \\
\hline PARKHURST & (immigrants) & 16.10468 & 7.161458 & 2 \\
\hline FELLOW & (immigrants) & 15.70678 & 7.023955 & 2 \\
\hline
\end{tabular}




\begin{tabular}{|l|l|l|l|l|}
\hline \multicolumn{5}{|l}{ 2007 (Asians) } \\
\hline Collocate & Node & LL & MI & Freq \\
\hline OUTNUMBERED & (Asians) & 25.26551 & 10.20471 & 2 \\
\hline EUROPEANS & (Asians) & 69.80319 & 9.58804 & 6 \\
\hline INDIANS & (Asians) & 21.56856 & 9.067208 & 2 \\
\hline RANGING & (Asians) & 21.56856 & 9.067208 & 2 \\
\hline OPINIONS & (Asians) & 20.83856 & 8.8262 & 2 \\
\hline COMMITTED & (Asians) & 20.83856 & 8.8262 & 2 \\
\hline WEALTHY & (Asians) & 28.32333 & 8.157406 & 3 \\
\hline ISLANDERS & (Asians) & 28.32333 & 8.157406 & 3 \\
\hline CENSUS & (Asians) & 26.42791 & 7.719285 & 3 \\
\hline ACCESS & (Asians) & 15.65845 & 7.034787 & 2 \\
\hline SEEKING & (Asians) & 15.56921 & 7.003078 & 2 \\
\hline LESS & (Asians) & 27.81971 & 6.397357 & 4 \\
\hline SOUTH & (Asians) & 27.32014 & 6.307471 & 4 \\
\hline YOUNG & (Asians) & 26.36008 & 6.134322 & 4 \\
\hline PACIFIC & (Asians) & 25.29546 & 5.941677 & 4 \\
\hline MANY & (Asians) & 26.44605 & 5.179683 & 5 \\
\hline WERE & 43.3457 & 4.804781 & 9 \\
\hline ARE & 31.79934 & 3.83703 & 9 \\
\hline
\end{tabular}




\begin{tabular}{|l|l|l|l|l|}
\hline \multicolumn{5}{|c}{ 2008 (migrant) } \\
\hline Collocate & Node & LL & MI & Freq \\
\hline MIGRANT & (migrant) & 2129.554 & 11.57527 & 118 \\
\hline STRICKEN & (migrant) & 28.30914 & 10.99031 & 2 \\
\hline GRANADA & (migrant) & 39.90132 & 10.57527 & 3 \\
\hline RETAINING & (migrant) & 22.59738 & 9.40535 & 2 \\
\hline INFLOW & (migrant) & 32.78299 & 9.160237 & 3 \\
\hline BANKING & (migrant) & 32.78299 & 9.160237 & 3 \\
\hline REFUGEE & (migrant) & 53.80156 & 9.039222 & 5 \\
\hline SKILLED & (migrant) & 70.85201 & 8.60127 & 7 \\
\hline CATEGORY & (migrant) & 30.14561 & 8.575274 & 3 \\
\hline CANCER & (migrant) & 29.39557 & 8.40535 & 3 \\
\hline WORKERS & (migrant) & 221.8001 & 8.174025 & 23 \\
\hline ANGRY & (migrant) & 18.37363 & 7.990312 & 2 \\
\hline QUALIFIED & (migrant) & 17.5896 & 7.717294 & 2 \\
\hline WORKER & (migrant) & 26.33926 & 7.700806 & 3 \\
\hline HUNDREDS & (migrant) & 17.31481 & 7.621078 & 2 \\
\hline TRUST & (migrant) & 34.43682 & 7.575275 & 4 \\
\hline EMPLOYEES & (migrant) & 25.80192 & 7.575275 & 3 \\
\hline ACTION & (migrant) & 34.18401 & 7.530881 & 4 \\
\hline MUSLIMS & (migrant) & 16.81657 & 7.445992 & 2 \\
\hline FORCED & (migrant) & 16.27085 & 7.253347 & 2 \\
\hline 22 & 24.2312908 & 7.20604086 & 3 \\
\hline
\end{tabular}




\begin{tabular}{|c|c|c|c|c|}
\hline \multicolumn{5}{|c|}{2008 (migrants) } \\
\hline Collocate & Node & $\mathbf{L L}$ & MI & Freq \\
\hline MIGRANTS & (migrants) & 4754.973 & 10.26316 & 293 \\
\hline 4400 & (migrants) & 28.46922 & 10.26316 & 2 \\
\hline 8300 & (migrants) & 28.46922 & 10.26316 & 2 \\
\hline INFLOW & (migrants) & 77.84731 & 9.070516 & 7 \\
\hline DORCHESTER & (migrants) & 20.83752 & 8.678199 & 2 \\
\hline WELCOMED & (migrants) & 19.48156 & 8.263161 & 2 \\
\hline TRENDS & (migrants) & 19.48156 & 8.263161 & 2 \\
\hline DESERVED & (migrants) & 18.94583 & 8.093236 & 2 \\
\hline POLYNESIAN & (migrants) & 18.94583 & 8.093236 & 2 \\
\hline POSSIBILITY & (migrants) & 18.05271 & 7.80373 & 2 \\
\hline ILLEGAL & (migrants) & 81.25477 & 7.78923 & 9 \\
\hline VULNERABLE & (migrants) & 26.89272 & 7.760661 & 3 \\
\hline INFLUX & (migrants) & 26.5181 & 7.678198 & 3 \\
\hline CONTRIBUTE & (migrants) & 17.67192 & 7.678198 & 2 \\
\hline DRAIN & (migrants) & 17.67192 & 7.678198 & 2 \\
\hline SPIRITUAL & (migrants) & 17.32461 & 7.562721 & 2 \\
\hline SKILLED & (migrants) & 68.49545 & 7.481802 & 8 \\
\hline REFUGEES & (migrants) & 42.56456 & 7.455806 & 5 \\
\hline TARGET & (migrants) & 25.51826 & 7.455806 & 3 \\
\hline SETTLE & (migrants) & 16.71001 & 7.35627 & 2 \\
\hline INTEGRATING & (migrants) & 16.43521 & 7.263161 & 2 \\
\hline
\end{tabular}




\begin{tabular}{|l|l|l|l|l|}
\hline \multicolumn{5}{|c|}{ 2008 (immigrant) } \\
\hline Collocate & Node & LL & MI & Freq \\
\hline BABAK & (immigrant) & 26.9343 & 10.49792 & 2 \\
\hline PROHIBITED & (immigrant) & 26.9343 & 10.49792 & 2 \\
\hline CENTENARIAN & (immigrant) & 25.20911 & 10.08288 & 2 \\
\hline MALEK & (immigrant) & 24.02509 & 9.76095 & 2 \\
\hline TEENAGE & (immigrant) & 71.24329 & 9.667841 & 6 \\
\hline EAMES & (immigrant) & 45.51356 & 9.382439 & 4 \\
\hline OLDEST & (immigrant) & 33.93602 & 9.345913 & 3 \\
\hline ADVOCATES & (immigrant) & 21.76057 & 9.082878 & 2 \\
\hline MALAYSIA & (immigrant) & 28.08102 & 8.082878 & 3 \\
\hline RUSSIAN & (immigrant) & 18.70858 & 8.082878 & 2 \\
\hline THAI & (immigrant) & 74.60406 & 8.038485 & 8 \\
\hline ARRIVING & (immigrant) & 18.20909 & 7.912953 & 2 \\
\hline DECLARED & (immigrant) & 18.20909 & 7.912953 & 2 \\
\hline DOCTORS & (immigrant) & 53.86972 & 7.80986 & 6 \\
\hline ILLEGAL & (immigrant) & 44.50482 & 7.760951 & 5 \\
\hline TEACHERS & (immigrant) & 35.37241 & 7.725327 & 4 \\
\hline SINGAPORE & (immigrant) & 34.9738 & 7.656614 & 4 \\
\hline BACKGROUND & (immigrant) & 17.3667 & 7.623447 & 2 \\
\hline PHILIPPINES & (immigrant) & 17.3667 & 7.623447 & 2 \\
\hline FILL & (immigrant) & 17.3667 & 7.623447 & 2 \\
\hline & & & & \\
\hline & & & \\
\hline
\end{tabular}




\begin{tabular}{|l|l|l|l|l|}
\hline \multicolumn{5}{|c|}{ 2008 (immigrants) } \\
\hline Collocate & Node & LL & MI & Freq \\
\hline ALGERIAN & (immigrants) & 24.33593 & 9.564616 & 2 \\
\hline EDUCATING & (immigrants) & 22.61159 & 9.149579 & 2 \\
\hline BLAMES & (immigrants) & 22.61159 & 9.149579 & 2 \\
\hline PROSPECTIVE & (immigrants) & 22.61159 & 9.149579 & 2 \\
\hline HITS & (immigrants) & 21.4284 & 8.827651 & 2 \\
\hline ILLEGAL & (immigrants) & 176.0759 & 8.593185 & 17 \\
\hline STRUGGLES & (immigrants) & 20.52209 & 8.564616 & 2 \\
\hline HAN & (immigrants) & 19.78624 & 8.342224 & 2 \\
\hline SCOTTISH & (immigrants) & 18.63081 & 7.979654 & 2 \\
\hline 66 & (immigrants) & 18.63081 & 7.979654 & 2 \\
\hline BLAMED & (immigrants) & 26.41987 & 7.647079 & 3 \\
\hline INDIAN & (immigrants) & 158.6191 & 7.619064 & 18 \\
\hline SRI & (immigrants) & 17.01012 & 7.449139 & 2 \\
\hline FLOOD & (immigrants) & 17.01012 & 7.449139 & 2 \\
\hline TOURISTS & (immigrants) & 24.19109 & 7.149579 & 3 \\
\hline COMPETE & (immigrants) & 16.12112 & 7.149579 & 2 \\
\hline ALLOWING & (immigrants) & 15.62332 & 6.979654 & 2 \\
\hline ATTRACTED & (immigrants) & 23.21505 & 6.927186 & 3 \\
\hline INTEGRATE & (immigrants) & 15.39618 & 6.901651 & 2 \\
\hline QUALIFIED & (immigrants) & 22.99432 & 6.87656 & 3 \\
\hline & & & & \\
\hline & & & \\
\hline
\end{tabular}




\begin{tabular}{|l|l|l|l|l|}
\hline \multicolumn{5}{|l}{$\mathbf{2 0 0 8}$ (Asians) } \\
\hline Collocate & Node & LL & MI & Freq \\
\hline 97 & (Asians) & 24.7733593 & 9.92653656 & 2 \\
\hline JOANNE & (Asians) & 24.7733593 & 9.92653656 & 2 \\
\hline REMARKS & (Asians) & 21.3252411 & 8.92653656 & 2 \\
\hline 38 & (Asians) & 41.6213989 & 8.75661182 & 4 \\
\hline INDIANS & (Asians) & 38.374073 & 8.22609711 & 4 \\
\hline BROWN'S & (Asians) & 18.8454475 & 8.11918163 & 2 \\
\hline TARGET & (Asians) & 17.1271477 & 7.53421879 & 2 \\
\hline V & (Asians) & 59.6463928 & 7.48596382 & 7 \\
\hline WINSTON & (Asians) & 59.2671051 & 7.44848919 & 7 \\
\hline MUSLIMS & (Asians) & 25.0478916 & 7.38221598 & 3 \\
\hline SMALLER & (Asians) & 16.0831108 & 7.17164898 & 2 \\
\hline TRIADS & (Asians) & 16.0831108 & 7.17164898 & 2 \\
\hline PROTECT & (Asians) & 22.9659367 & 6.89678907 & 3 \\
\hline 22 & (Asians) & 21.5272179 & 6.55730247 & 3 \\
\hline EAST & (Asians) & 20.8772717 & 6.40297461 & 3 \\
\hline OTHERS & (Asians) & 41.676796 & 6.38221598 & 6 \\
\hline PETERS & (Asians) & 54.5415878 & 6.28268003 & 8 \\
\hline 9 & (Asians) & 26.3443813 & 6.13212061 & 4 \\
\hline BORN & 31.6548119 & 5.94468355 & 5 \\
\hline LOT & 24.5433197 & 5.80759525 & 4 \\
\hline & & & & \\
\hline & Asians) & & \\
\hline
\end{tabular}




\section{Appendix C: Data set}

For access to the 2007, 2008 corpora and the full qualitative data set see the CD attached. 
